\title{
Microseismicity of the Central Alpine Fault Region, New Zealand
}

by

Bronwyn Cherie O'Keefe

\author{
A thesis \\ submitted to the Victoria University of Wellington \\ in fulfilment of the \\ requirements for the degree of \\ Master of Science \\ in Geophysics.
}

Victoria University of Wellington

2008 



\begin{abstract}
This study investigates the spatial and temporal patterns in microseismicity along the central section of the Alpine Fault, South Island, New Zealand. This section, between Harihari and Karangarua, has significantly lower seismicity than the regions to the northeast and southwest. Several hypotheses of mechanisms said to contribute to the anomaly have been proposed over the years including locked fault, slow slip, shallow creep and external fluids affecting the thermal regime and brittle-ductile transition.

Focussing on the shallow crust, the contrasting seismic character is compared to the northern and southern sections from seismicity behaviour, focal mechanisms and seismogenic depth. A temporal array of eight seismographs (including three broadband instruments) was augmented with three GeoNet stations bounding the array. This provided an average spacing of $14 \mathrm{~km}$ and a magnitude cut-off of $\mathrm{M}_{L} 1.6$ compared to the GeoNet national network cut-off of $\mathrm{M}_{L} 2.6$ and station spacing of $80-100 \mathrm{~km}$.

The Gutenberg-Richter distribution for the four month time frame analysed defined a b-value of $0.75 \pm 0.06$ which may indicate a locked, heterogeneous zone under high-stress from fluid pressure or a predominance of thrust mechanisms over the survey period.

Seismicity over the deployment was within the average range of the last 15 years. The "horseshoe" shaped seismicity pattern observed from long-term national catologue data is similar for smaller magnitudes. While the central portion of the Alpine Fault is quieter with unusually low b-value, the region is not aseismic. Neither does it experience the level of microseismicity seen in creeping faults.

The brittle-ductile transition varies laterally along the fault and is estimated at up to $15 \mathrm{~km}$ for most of the survey region but closer to $10 \mathrm{~km}$ for the region associated with the highest orogenic uplift rates which compares well with past studies.

A local magnitude scale was developed from direct linear inversion of the pseudo WoodAnderson amplitudes and event-station distances. A linear inversion of data from the standard New Zealand magnitude equation characterised an attenuation parameter of $0.0167 \mathrm{~km}^{-1}$; more than double the value used in national local magnitude calculations (of $0.0067 \mathrm{~km}^{-1}$ ).

Swarm clustering dominates the seismicity character of the time frame. Utilising the earthquake relocation program HypoDD, a selection of clusters both near the Alpine Fault and away from it resolve to point sources. Those close to the Alpine Fault are located in what may be the footwall of the Fault which may indicate that the velocity model has located the events too far to the northwest.
\end{abstract}




\section{Acknowledgements}

Thank you to Euan Smith and Martha Savage for such a complete project from inception and field work through to data analysis. Thank you also to Tim Stern for funding assistance. Euan, I appreciate the open-door policy and weekly meetings, even if I was rarely on time.

Thanks to all those who helped me through the turbulent data processing: to Mark, Sandra, Sonja, Adrian and Daniel for help with programming; to PASSCAL staff for their help diagnosing the strange timing error and thank you to SEISAN developers especially Lars Otemöller for trouble-shooting error messages.

To the GeoNet team for their freely available data, Kevin Fenaughty for specific data requests, and Bryan Field for the use of their facilities and friendly support for a long download at Avalon, thanks.

I would like to acknowledge the DoC staff and all the landowners who graciously allowed us to drive over and dig up their property; to helicopter pilot James Scott who was not only patient, but helped with station setup; to the keas who only nibbled around the edges and were there to see us off after an extended stay at Chancellor Hut; and to the field work volunteers Andreas, Anya, Euan, Mark, Martha, Michael, Nastasja, Raj and Sandra.

Finally, thanks to my friends and family: my office-mates Daniel and Nastasja; Settlers of Catan addicts; Anya, Ralph, Jonathan, Sarah, Lucy, Elizabeth, Deb and Debbie; my flatmates Julia and Thomas for being lenient on housework duties; and my family for their support and confidence in me. 


\section{Contents}

Acknowledgements

1 Introduction $\quad 1$

1.0.1 Thesis objectives . . . . . . . . . . . . . . . 2

1.0.2 Questions to investigate throughout thesis . . . . . . . . . . . 3

1.1 Past studies . . . . . . . . . . . . . . . . . . 3

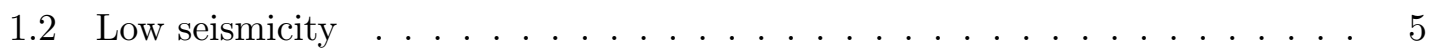

1.3 Swarms and clusters $\ldots \ldots \ldots \ldots \ldots \ldots$

2 The Central Alpine Fault $\quad 9$

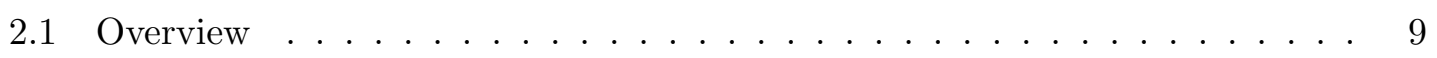

2.2 Kinematics . . . . . . . . . . . . . . . . . . 9

2.3 Along strike variation $\ldots \ldots \ldots \ldots \ldots$

2.4 How the fault evolved . . . . . . . . . . . . . . . 11

2.5 Seismicity characteristics . . . . . . . . . . . . . . . . 12

$\begin{array}{llr}3 & \text { Survey } & \mathbf{1 5}\end{array}$

3.1 Analysis of GeoNet catalogue . . . . . . . . . . . . . . . . 15

3.2 Station selection $\ldots \ldots \ldots \ldots \ldots \ldots$

3.3 Station description . . . . . . . . . . . . . . . . . . 18

3.4 Huddle tests . . . . . . . . . . . . . . . . . . . . 20

4 CAlF Network Catalogue $\quad 21$

4.1 Data processing overview . . . . . . . . . . . . . . . . 21

4.2 Initial HYPOCENTER parameters . . . . . . . . . . . . . . . . . . . . . . . . . . . . . 24

4.3 Station $\mathrm{CHH}$ timing error . . . . . . . . . . . . . . . 25

4.4 Location program parameters . . . . . . . . . . . . . . 25

4.5 Velocity model analysis . . . . . . . . . . . . . . . . . 29

4.5.1 Velocity model comparison . . . . . . . . . . . . 29

4.5 .2 Velocity model sensitivity . . . . . . . . . . . . . . . 29

4.5.3 Identifying velocity model $1 \mathrm{D}$ bias . . . . . . . . . . . . . . 31

4.6 Assessment of location error . . . . . . . . . . . . . . . . . 34

4.6.1 Assessment of phase pick precision . . . . . . . . . . . 34 
4.6.2 Wave front time delay analysis . . . . . . . . . . . . . 35

4.7 VELEST velocity model comparison . . . . . . . . . . . . . . 38

4.8 Depth resolution . . . . . . . . . . . . . . . . . . . . 44

5 Magnitude Determination $\quad 47$

5.1 Magnitude estimates . . . . . . . . . . . . . . . . . . 47

5.2 Magnitude formulae . . . . . . . . . . . . . . . . . . . 47

5.3 Attenuation and geometric spreading . . . . . . . . . . . . . . . 52

5.4 Station corrections . . . . . . . . . . . . . . . . . 53

5.5 Final magnitude model . . . . . . . . . . . . . . . . . . . . . 55

5.6 Gutenberg-Richter distribution parameters . . . . . . . . . . 56

6 Final Hypocenters $\quad 63$

6.1 Final locations . . . . . . . . . . . . . . . . 63

6.2 Catalogue uncertainties . . . . . . . . . . . . . . . . 64

6.3 Seismicity distribution . . . . . . . . . . . . . . . . . 64

7 Focal Mechanism Determination $\quad 69$

7.1 Cluster test . . . . . . . . . . . . . . . . . . . . . 69

7.2 Polarity analysis . . . . . . . . . . . . . . . . . . 69

8 Double-difference Relocation $\quad \mathbf{7 5}$

8.1 The HypoDD double-difference algorithm . . . . . . . . . . . . . . 75

8.2 Relocation procedure followed . . . . . . . . . . . . . . . 76

8.3 Relocation results . . . . . . . . . . . . . . . . . . . . . 77

8.3.1 Cluster 1: the "Fox Swarm" . . . . . . . . . . . . . . 77

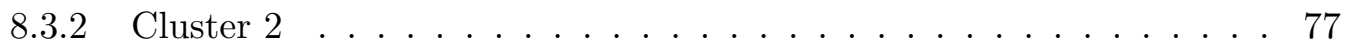

8.3.3 Cluster 3: the "Waitaha Swarm" . . . . . . . . . . . . . 78

8.3.4 Cluster 4: the "Clyde Swarm" . . . . . . . . . . . . . . . . . 79

8.3 .5 Cluster $5 \ldots \ldots \ldots \ldots \ldots \ldots$

9 Discussion and Conclusion $\quad 81$

9.1 Survey . . . . . . . . . . . . . . . . . . . . . . . 81

9.2 Catalogue processing . . . . . . . . . . . . . . . . 81

9.3 Magnitude calculation . . . . . . . . . . . . . . . . . . 82

9.4 b-value implications . . . . . . . . . . . . . . . . . . . . 84

9.5 Locations . . . . . . . . . . . . . . . . . . . . 86

9.6 Focal mechanisms . . . . . . . . . . . . . . . . . . . . . . 88

9.7 Swarms and clusters . . . . . . . . . . . . . . . . . 89

9.8 Review of thesis questions . . . . . . . . . . . . . . . . . . . . 89

9.9 Conclusion . . . . . . . . . . . . . . . . . . . . . . 91

$\begin{array}{ll}\text { Appendices } & 103\end{array}$ 
$\begin{array}{ll}\text { A Stations } & 103\end{array}$

B Magnitude Inversion Statistics 105

$\begin{array}{ll}\text { C CAlF Event Catalogue } & 107\end{array}$

$\begin{array}{ll}\text { D HypoDD relocation output } & 121\end{array}$ 


\section{List of Figures}

1.1 Seismicity of central South Island . . . . . . . . . . . . . . . 1

1.2 GeoNet catalogue plots of 1997 and 2006 swarms $\ldots \ldots \ldots$. . . . . 7

3.1 GeoNet catalogue seismicity for 1991-2006 . . . . . . . . . . . . 15

3.2 GeoNet catalogue seismicity contours for 1990-2006 . . . . . . . . . . . . 17

3.3 Broadband and short-period seismographs . . . . . . . . . . . 18

3.4 Seismograph example - a small event central to the array . . . . . . . . . . 19

4.1 Example of SEISAN location output . . . . . . . . . . . . . . . 22

4.2 Event locations for $\mathrm{CHH}$ phase corrected by 0,1 and 2 seconds . . . . . 26

4.3 Average time residual per event and phase for $\mathrm{CHH}$ corrected data . . . . 27

4.4 SEISAN Wadati plot example . . . . . . . . . . . . . . . 28

4.5 Event locations for the three velocity models tested . . . . . . . . . . . 30

4.6 Sensitivity of location parameters to velocity model . . . . . . . . . . . . . . 32

4.7 Removal of phase residual mean . . . . . . . . . . . . . . . . 33

4.8 Histogram of average $\mathrm{P}$ and $\mathrm{S}$ phase residuals $\ldots \ldots \ldots$. . . . . . . . 35

4.9 Residual times from wave front time analysis . . . . . . . . . . . . 38

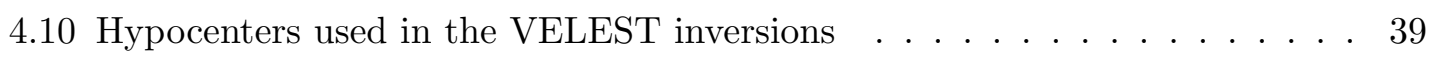

4.11 Hypocenter error distribution . . . . . . . . . . . . . . . . . . 43

4.12 Quality of epicenters: map, cross-section and velocity model for each model 45

4.13 Suspected ice fall events . . . . . . . . . . . . . . . . . . . 46

5.1 Final magnitude inversion residuals . . . . . . . . . . . . . . . . . . 50

5.2 Magnitude differences for the two models . . . . . . . . . . . . . . 51

5.3 Linear relationship between geometric spreading factor and inelastic atten-

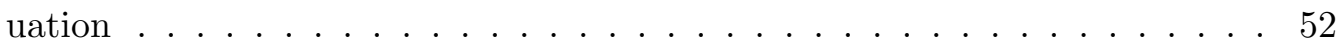

5.4 Distance component of magnitude calculation for each inversion procedure . 54

5.5 Evaluation of adjusted amplitude distance attenuation . . . . . . . . . . 55

5.6 Station magnitude corrections . . . . . . . . . . . . . . . . 56

5.7 Time series of magnitudes . . . . . . . . . . . . . . . . . 57

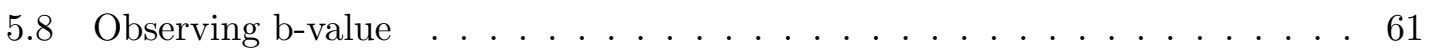

5.9 GeoNet magnitude cut-off and b-value . . . . . . . . . . . . . . . 62

6.1 Final locations for CAlF hypocenters . . . . . . . . . . . . . 63 
6.2 Epicenters and depth cross-sections showing magnitudes . . . . . . . . . . 65

6.3 Epicenters and depth cross-sections of final locations . . . . . . . . . . . 66

7.1 Map of selected Alpine Fault event focal mechanisms . . . . . . . . . . . . 70

7.2 Selected Alpine Fault event polarity plots ～. . . . . . . . . . . . . 71

8.1 Relocation of cluster 1: the "Fox Swarm" . . . . . . . . . . . . . 77

8.2 Relocation of cluster 2: sporadic events near the Main Divide . . . . . . . 78

8.3 Relocation of cluster 3: the "Waitaha" swarm . . . . . . . . . . . . 78

8.4 Relocation of cluster 4: the "Clyde" swarm - example of a swarm not associated with the Alpine Fault ～. . . . . . . . . . . . . 79

8.5 Relocation of cluster 5: sporadic events near Whataroa . . . . . . . . . . 79

9.1 Final map and cross-section locations compared to Little et al. (2005); Allis and Shi $(1995) \ldots \ldots \ldots \ldots$. . . . . . . . . . . . . . . . . . . . 


\section{List of Tables}

3.1 Seismograph polarities . . . . . . . . . . . . . . . . 20

4.1 Catalogue phase statistics . . . . . . . . . . . . . . . 23

4.2 Mean differences in location after $\mathrm{CHH} 1$ second correction . . . . . . . . 25

4.3 Velocity models trialled . . . . . . . . . . . . . . . . . . 31

4.4 Depth dependence on s10 second layer velocity . . . . . . . . . . . . . . 31

4.5 Station time corrections from mean time residual $\mathrm{rms}$ analysis . . . . . . . . 34

4.6 Average changes in locations from iterations of removing station-phase velocity model bias . . . . . . . . . . . . . . . . . . . . . . 34

4.7 Wave Front Time Delay Analysis . . . . . . . . . . . . . . . . . . 37

4.8 VELEST model comparison of depth ranges for two swarms . . . . . . . . . 40

4.9 VELEST best velocity model chosen as final velocity model . . . . . . . . . 40

4.10 Absolute and relative errors in location for the two best VELEST velocity models . . . . . . . . . . . . . . . . . . . 4 4 41

4.11 Location differences observed from cumulative variation in depth by $\pm 1 \mathrm{~km} 41$

4.12 VELEST velocity model station corrections . . . . . . . . . . . . . . . 42

4.13 Shallow depth reliance on station corrections . . . . . . . . . . . . . . 44

6.1 Summary of location quality . . . . . . . . . . . . . . 67

7.1 SEISAN focal mechanism solutions for selected events (in Fig 7.2) in order of decreasing latitude. . . . . . . . . . . . . . . . . . . . 74

A.1 Seismograph stations . . . . . . . . . . . . . . . . . . . . . 104

B.1 Magnitude inversion statistics . . . . . . . . . . . . . . 106

C.1 CAlF Event Catalogue . . . . . . . . . . . . . . . . . . . 108

D.1 HypoDD relocation output . . . . . . . . . . . . . . . . 122 


\section{Chapter 1}

\section{Introduction}

The purpose of this study is to investigate spatial and temporal patterns and characteristics of shallow crust microseismicity within the central section of the Alpine Fault and the surrounding region (CAlF). This section, between Harihari and Karangarua, has significantly lower seismicity than the regions to the northeast and southwest (as seen in Fig 1.1). The cause of the low seismicity anomaly of this section is that the fault may be weakly creeping at shallow depth or rigidly locked. Identifying which is key to understanding the risk of large earthquakes along this major New Zealand fault.

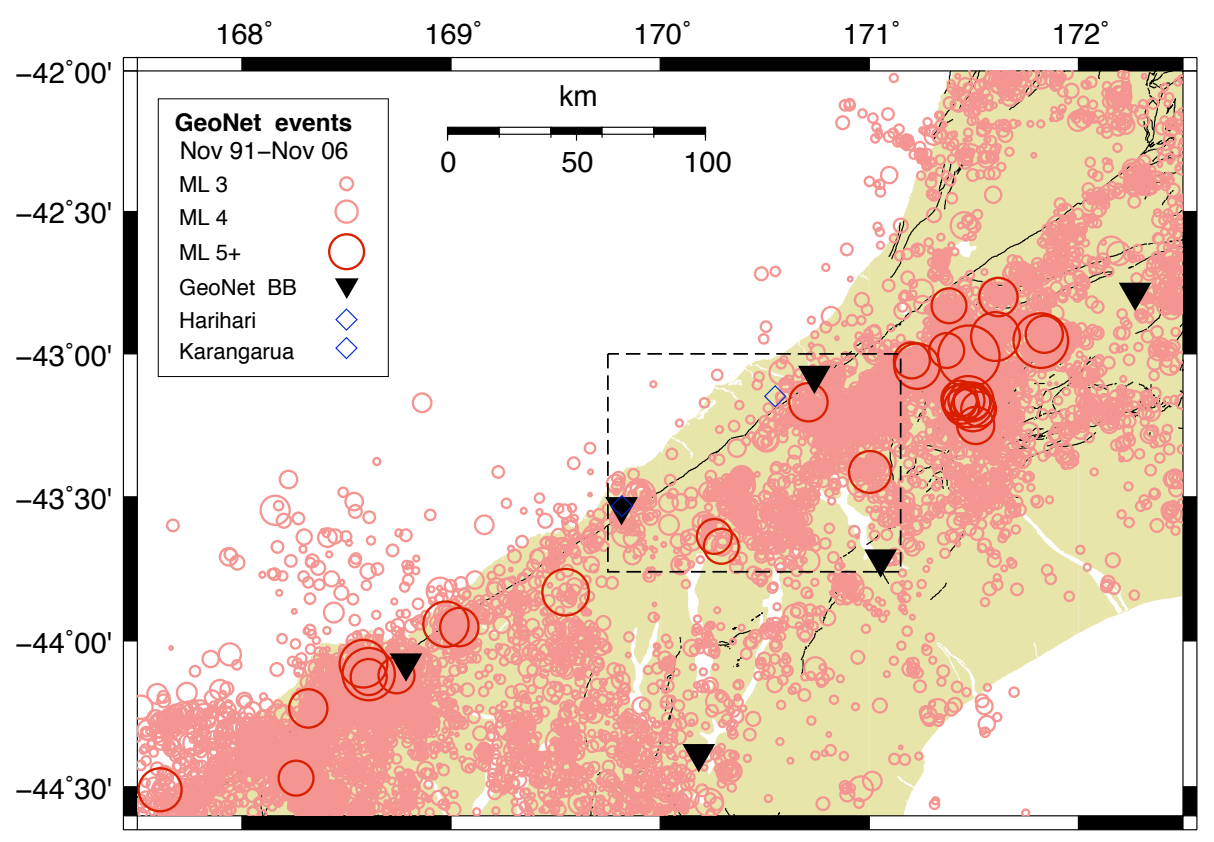

Figure 1.1: Last 15 years of shallow seismicity of central South Island. $\mathrm{Z}<20 \mathrm{~km}$, period November 1991- November 2006. For reference, subsequent figures are plotted within the dashed box limits unless otherwise stated. The seismicity is restricted to the last 15 years as the deployment of the GeoNet network was completed by this time, providing a relatively consistent network. 
Although several past seismicity studies (Eiby, 1959; Evison, 1971; Hatherton, 1980; Reyners, 1989; Anderson and Webb, 1994) and microseismicity studies (Scholz et al., 1973; Eberhart-Phillips, 1995) have included analysis of the central section of the Alpine Fault, earthquake location resolution has restricted conclusions. In order to survey smaller earthquakes, and therefore a greater range of magnitudes, data from a denser network than has been used previously is combined with data from previous studies and GeoNet national array data ${ }^{1}$. Seismicity in a 4 -month period is analysed.

The completeness of earthquake catalogues is characterised by the cut-off magnitude; i.e. the magnitude at which the catalogue has captured all events of this magnitude and greater. This cut-off magnitude is dependent on the signal-to-noise ratio that can be achieved in the region as well as the station spacing. The national seismic network has a cut-off magnitude of local magnitude $\left(\mathrm{M}_{L}\right) 2.6$ for an average station of $100 \mathrm{~km}$ (Eberhart-Phillips, 1995). This is too high to assess the microseismicity characteristics of the area.

Seismic cycle studies of long-range (geologic and geomorphic anomalies) medium-range (national seismic and geodetic networks) and short-range (microseismic temporary dense arrays) help to characterise the repeatability and variation of destructive, large earthquakes. They also may provide an indication about the strain build-up and likelihood of a large event in the near future.

Microseismicity studies in particular give a snapshot view in more detail of spatial and temporal patterns, the nature of earthquake clustering and fault dynamics through focal mechanisms and earthquake relocation studies.

\subsubsection{Thesis objectives}

1. Collate a microearthquake catalogue.

2. Evaluate the completeness of the catalogue and how representative the seismicity is compared to past years.

3. Evaluate the distinctive characteristics of the shallow crust seismicity along the central Alpine Fault compared to sections to the north and south.

\footnotetext{
${ }^{1}$ GeoNet data was obtained from the New Zealand National Earthquake Information Database at http://www.gns.cri.nz/store/databases/indexb.html\#Earthquake both by ftp and by direct assistance from GeoNet staff.
} 
4. Compare microseismicity observations to previous studies of the area.

\subsubsection{Questions to investigate throughout thesis}

1. What is the 4-monthly variation in seismicity recorded by GeoNet? How does the period of this study compare with this? (i.e. how typical is my survey period?)

2. What is the spatial and temporal seismicity distribution laterally and with depth?

3. Is the Alpine Fault well defined by seismicity with depth? Is there any curvature?

4. Are there any planar trends of seismicity that could be attributed to hidden faults?

5. What is the frequency-magnitude distribution? Is there anything distinctive about it?

6. What is the behaviour of earthquakes in the central Alpine Fault region? Are they independent, swarm-like or fore-main-after shock like?

7. What are the focal mechanisms? Are they coherent, vary smoothly with latitude or chaotic?

8. What is the depth of the brittle-ductile transition? Is it abrupt or gradual?

\subsection{Past microseismic studies}

A microseismic survey of the Alpine Fault and surrounding region in 1972 by Scholz et al. (1973) was unable to draw any conclusions beyond what was already known from national network analysis. The authors noted that the area has significantly lower seismicity than surrounding regions. Their conclusions were restricted by the poor dataset recovered from a survey impeded by technical difficulties in timing and needing to adjust the instrumental gain after increased noise from extreme weather.

Several studies of the national network have analysed the character of national seismicity patterns with limited success at attributing seismicitiy in the central Alpine Fault region to specific fault structures (Eiby, 1959; Evison, 1971; Hatherton, 1980; Reyners, 1989; Anderson and Webb, 1994). Evison (1971) was able to distinguish between three seismic regions of the South Island. He showed that from the limited accuracy of the 
national network at the time, the Alpine Fault could not be definitively ascribed to any seismicity and proposed that all southern seismicity could be related to the opposing subduction margins. Little activity and no evidence of creep suggested a locked or dormant fault structure.

The national seismicity study of Anderson and Webb (1994) which analysed data from the upgraded national network at that time gave brief mention to the "relatively aseismic" central Alpine Fault due to the lack of seismicity. The band of seismicity to the east was tentatively attributed to Alpine Fault activity at depth but insufficient accuracy of event depth determinations could not confirm this. Limited depth resolution could not clarify how closely earthquakes map to the Alpine Fault trace. Two earthquake swarms were identified within the central zone.

A simultaneous inversion of velocity and travel-time data by Eberhart-Phillips (1995) revealed no linear features of seismicity suggesting the Anderson and Webb (1994) observations may have been artifacts of poor velocity model. Limited clustering behaviour was observed with some regular clusters of activity noted and other time-limited swarms.

A recent survey (SAPSE discussed in Leitner et al. (2001)) was sparser than the Scholz et al. (1973) survey but was able to complement the national network to provide a combined network of 30-50 km spacing over 6 months. The aseismic band (10-20 km wide) just north of Franz Josef was identified with a few earthquakes $M_{L}<2$. The central portion seismicity was "low but comparable to locked sections of the San Andreas Fault, with large earthquakes expected" (Leitner et al., 2001).

Detailed discussion also suggested accommodation of some strain by the Marlborough Fault Zone which seems to be migrating southward in the form of a newly forming fault at Porters Pass. The lower limit of the low seismicity zone was identified as the likely extension of the Porters Pass fault zone. An alternative explanation of the lower seismicity depicted a thermally weakened central section "forming a barrier to southward propagating earthquakes" (Leitner et al., 2001) but was discounted as the maximum dip-slip rate occurs south of the low seismicity region. Simultaneous relocation and velocity inversion gave an average location error in depth of $1.5 \mathrm{~km}$, and $90 \%$ of data had a depth error of $\leq 3 \mathrm{~km}$. 


\subsection{The cause(s) of low seismicity}

The theories attempting to characterise low seismicity along the central Alpine Fault are diverse. The majority of opinions favour the overriding cause as a seismic gap building strain to a threshold point before rupturing in a large event in the arguably near future (Yetton, 1998; Wells et al., 1999; Rhoades and Van Dissen, 2003).

The Alpine Fault is often compared with the Californian San Andreas Fault (Hatherton, 1969; Scholz et al., 1973; Fuis et al., 2007). Both are long plate boundary faults with segments of low seismicity with a transfer from a singular main fault to a bend and splay zone of faults (Marlborough Fault Zone and Transverse Ranges). The central portion of the San Andreas, also relatively quiet, accommodates some plate motion through seismic creep in one section with sporadic large events elsewhere. This leads some to speculate that New Zealand's Alpine Fault is doing likewise.

Aseismic or slow slip (Wells et al., 1979, 1998, 1999; Stern et al., 2001) is a controversial theory not accepted by many. The aseismic and slow slip argument suggests that there are few, if any, examples of surface rupturing paleo-earthquakes and that the CAlF may be similar to lower magnitude regions of the San Andreas where levels of aseismic slip are observed. But recent geodetic measurements (Beavan et al., 1999) of the Whataroa fault monitoring pattern established in 1972 shows no evidence of aseismic slip on the Alpine Fault between 1972 and 1998. Also, the $80 \mathrm{ft}$ concrete wall built in May 1964 (Evison, 1971) to transect the surface trace of the fault $(6 \mathrm{~km}$ east of Springs Junction and around $120 \mathrm{~km} \mathrm{NE}$ of the CAlF survey region) shows no signs of deformation. Nor do any roads or other man-made infrastructure built across the fault (including within the CAlF survey region) show any displacement or deformation that could be associated with this phenomenon (Sutherland et al., 2007).

Little et al. (2005), suggested that a lateral curvature of a localised steeper footramp dip for the CAlF near Fox could fit structural data and higher uplift rates (Wellman, 1979) which may increase normal stress and shear resistance resulting in lower seismicity much like the lateral curvature in the San Andreas Fault appears to reduce seismicity in that particular section. However the proposed CAlF lateral curvature is located between Franz Josef and Fox glaciers which is at the southern limit of the aseismic CAlF where the seismicity is slightly higher. 
External influences of the surrounding area have also been suggested: Marlborough Fault Zone migrating south (Leitner et al., 2001), Main Divide Fault Zone and deforming schists (Little et al., 2005; Cox and Findlay, 1995), and the southern boundary of transition from strike-slip to subduction (Norris, 2004; Wallace et al., 2006) have all been proposed as accommodating a proportion of strain away from the Alpine Fault and thus reducing overall seismicity of the CAlF zone.

The Marlborough Fault Zone is said to transfer deformation from Hikurangi margin subduction zone to the Alpine Fault (Leitner et al., 2001) but also could accommodate stress away from parts of the Alpine Fault through the southern limits of the Marlborough tectonic regime.

The backshearing fault system east of the Main Divide may also be accommodating strain (Little et al., 2005; Cox and Findlay, 1995). Findlay (1997), suggests the Main Divide Fault Zone may be considerably older than the Alpine Fault and has undergone significant reactivisation. Cox and Findlay (1995) argue that the unbalanced partitioning of the relative plate motion across the Alpine Fault and Main Divide Fault Zone causes the fault zone to move westward, be uplifted and eroded while a new fault zone forms in its place. For instance, Findlay (1997), identifies the Paringa Domains in the Alpine schist as ductile imprints of an earlier Main Divide fault.

Fluid pressures are known to weaken rock strength (as seen in laboratory measurements) and would thus increase the likelihood of rupture and stress release through smaller earthquakes (Stern et al., 2001). A low velocity zone and conductivity and thermal anomalies observed during the multidisciplinary SIGHT study (as well as previously) suggested a region of high pressure fluid which may approach lithostatic pressure below $3 \mathrm{~km}$ within the depth range associated with rapid uplift and erosion. Higher fluid pressures could decrease the stress threshold for rupture and therefore more microearthquakes could be expected, which could dissipate some strain built up (Stern et al., 2001). Stern et al. (2001) also proposed the abnormally warm region may rupture in low frequency slow earthquakes.

High fluid pressures and temperature would also lift the brittle-ductile boundary. A numerical modelling of the thermal regime by Reyners (1987) indicated rapid uplift would thin the brittle part of crust that would limit the width of rupture in large events.

Leitner et al. (2001) proposed a thermally weakened zone would form a barrier to southward propagating earthquakes from the Marlborough Fault Zone but it was noted 
the anomaly is at the southern limit of the low seismicity zone rather than the north. Perhaps a thermally weakened zone may affect propagation from the southern section of the Alpine Fault and thus limit the length of rupture in large events.

However, the low seismicity is not unique to the Alpine Fault: "Many major faults in New Zealand seem to be essentially aseismic at the moment. For example, the major strike-slip faults near Wellington are not delineated by microseismicity even though a good local seismograph network has existed since 1978" (Robinson, 1986).

\subsection{Swarms and clusters}

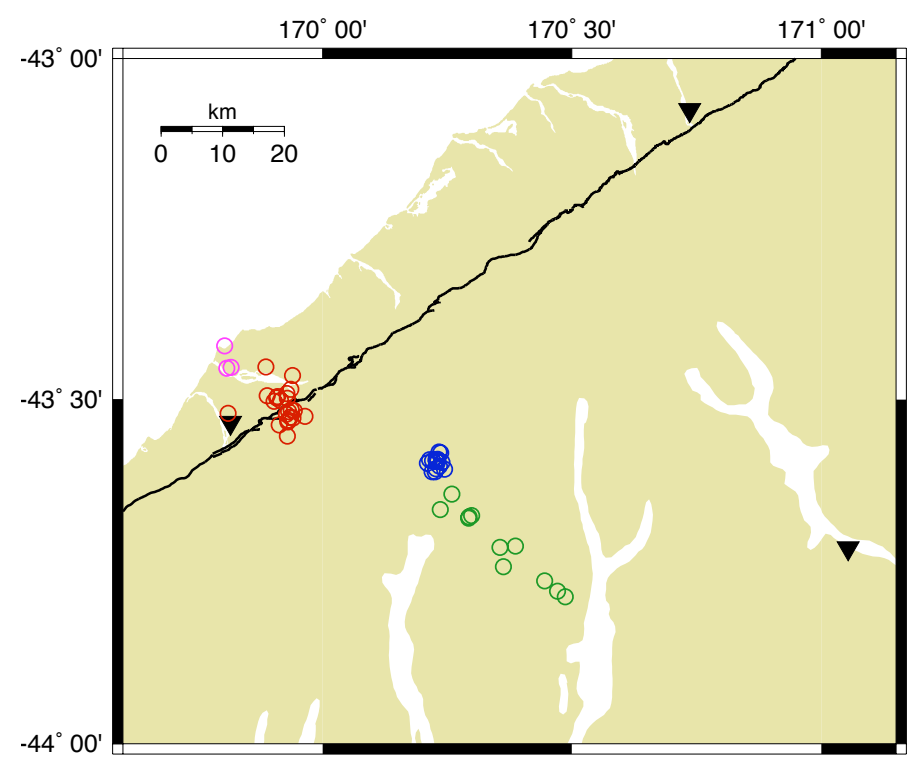

Figure 1.2: GeoNet catalogue locations of September 1997 "Mt Cook" swarm and the October 2006 Fox swarm. Mt Cook swarm is in green with nearby events within a month after in blue. The green apparent lineation occurred within a day and included two $M_{L} \approx 5$ and 11 events within the catalogue. The tight blue cluster of 16 events occurred over 26 days; around 1 every 1.5 days \pm 1 day. Fox swarm is in red with nearby events within a month before in pink. The pink events occurred within one day around 21 days before the red cluster. Around two thirds of the red cluster was also within 1 day then gradually slowed with the last event (located in the center of the cluster) 10 days after the first Fox swarm event. These data are GeoNet catalogue locations. The data and discussion of the locations found within the CAlF catalogue can be found throughout this thesis. For reference, the GeoNet catalogue contains 21 Fox swarm events; the CAlF catalogue contains 38 .

An additional point of interest of this region's seismicity is the occurrence of swarms.

The Mt Cook earthquake swarm of September 1997, which was briefly discussed in Leitner et al. (2001) (although it was described as an earthquake sequence - a double main shock with several aftershocks) and the "Fox Swarm" recorded by CAlF in October 2006 (see Fig 1.2) are the two main swarms discussed in this thesis. However, there were 
many other swarms observed over the CAlF survey and these are also briefly examined (See Chapter 8 for more detail). The national network catalogued 21 Fox swarm events during early October 2006 including three events $M_{L}>4\left(M_{L} 4.3,4.4\right.$, and 4.6) compared to the 38 located in the CAlF catalogue.

Many overseas studies have used double difference techniques to relocate clusters and provide relative locations for these clusters and swarms (spatio-temporal clusters) which can provide a better picture of the alignment of related events to identify a fault or faults and provide mechanisms for these events.

This method has been utilised to examine the distribution of several swarms and clusters. 


\section{Chapter 2}

\section{The Central Alpine Fault}

\section{$2.1 \quad$ Overview}

The Alpine Fault is a transpressional boundary (i.e. undergoing oblique collision causing stike-slip and thrust) between the Australian and Pacific Continental Plates (Wells et al., 1979; De Mets et al., 1994). It extends from Milford Sound in the southwest to the Wairau Fault in the northeast up to Nelson (Wellman and Willet, 1942; Norris and Cooper, 2001).

The total displacement of the Alpine Fault since inception is estimated at $850 \mathrm{~km}$ from plate model reconstructions (Stock and Molnar, 1982); (Sutherland, 1999) although $480 \mathrm{~km}$ of this is attributed to slip (Little et al., 2002; Sutherland et al., 2007) and can be seen by the displacement of the Matai, Murihiku and Caples terranes. The remainer is attributed to distributed (shortening) shear (Molnar et al., 1999) and transpressional (bending) shear (Little et al., 2002).

The central section of the Alpine Fault strikes at $55^{\circ}$ and is dipping between 30 to $60^{\circ}$ (Norris et al., 1990; Kleffman et al., 1998).

\subsection{Kinematics}

The Alpine Fault is currently a dextral slipping (north-west side sliding north-east) fault and is oblique with both strike-slip and convergence at a ratio of around 3.5:1 (Okaya et al., 2007) along the central section and is likely to have been sliding $>27 \pm 4 \mathrm{~mm} / \mathrm{yr}$ for the last 3 million years (Berryman et al., 2002; Norris and Cooper, 2001).

The difference between plate motion measurements and Alpine Fault paleoseismic slip 
measurements can also be inferred by modelling geodetic strain measurements. According to Beavan et al. (1999); Wallace et al. (2006) these measurements agree and suggest the Alpine Fault accommodates $50-80 \%$ of the fault-parallel plate motion of around $38 \mathrm{~mm} / \mathrm{yr}$.

The GPS vertical motion survey of Beavan et al. (2004) processed 3.5 years of continuous GPS data. Two stations immediately west of the fault were anomalously rising but this could indicate plate buckling from compression. East of the fault is rising with a maximum of vertical motion within the mountainous region.

\subsection{Along strike variation}

The Alpine Fault is generally described by three segments of distinct seismic character. The northern section includes the substantial bend of the Alpine Fault and splays into 4 major and many minor sub-parallel faults. The region has the highest seismicity of the three regions which is dispersed in space and time. In the central section, the plate motion is restricted largely to the Alpine fault with few additional minor faults. However, the seismicity is the lowest and is largely located to the southeast of the fault's extent. And the southern section has relatively medium seismicity that is more dispersed around the Alpine Fault. All sections have been known to rupture in large earthquakes with some expectation that large events will include more than one segment (Adams, 1980; Yetton, 1998; Sutherland et al., 2007).

The variation in footwall dip (of $15-20^{\circ}$ ) from North to South is inferred from structural data with an average of $40-50^{\circ}$ dip in the central region and $25-35^{\circ}$ in the south (Kleffman et al., 1998; Norris and Cooper, 2001). Little et al. (2005) suggest there is a localized curvature of $10-20 \mathrm{~km}$ width near Fox Glacier where the dip steepens by up to $20^{\circ}$.

Dip-slip rate varies from nearly zero in the SW to more thrust in the central South Island (Norris and Cooper, 2001).

The oblique nature of the fault can be seen in the variation of exhumation and uplift of the Southern Alps where the central Southern Alps extend to the highest elevations within $<15 \mathrm{~km}$ from the Alpine Fault, whereas to the north and south the Main Divide is some $20 \mathrm{~km}$ from the fault (Cox and Findlay, 1995). 


\subsection{How the fault evolved}

The Alpine Fault originated from a soley strike-slip fault which initiated c. 23-22 Ma (King, 2000; Sutherland, 1999; LeBrun et al., 2003) from a change in subduction kinematics in the northeast as the southward moving Hikurangi subduction zone met the Chatham Rise continental block. Sutherland (1999) noted that the Alpine Fault likely developed from a growth of many faults gradualy interconnecting to form one linear trace. At this time it is said to be a vertical fault, a common feature in strike-slip faults around the world.

At 12-10 Ma the southern subduction zone developed where previously the southern area was a spreading zone. The relative plate motion vector rotated at c. 6-5 Ma (King, 2000; LeBrun et al., 2003); causing collsion, orogeny and increasingly oblique strike-slip along the Alpine Fault and evolution to its present rate of $38 \mathrm{~mm} / \mathrm{yr}$ (Okaya et al., 2007). The oblique nature also causes dip. It is unknown whether the ancient fracture zone affects seismicity. It is possible the fault may be multi planar, accommodating the gradual change in dip.

Strike-slip motion on the Awatere Fault started around 7 Ma (Little and Jones, 1998). Lamb (1988) estimated that there has been c. $10^{\circ}$ tectonic rotation in the east Nelson area in the last 4 m.y. A GSNZ workshop publication (GNS., 1991) noted "There is evidence to support slip rates of Wairau Fault decelerated from 16 to $5 \mathrm{~mm} / \mathrm{yr}$ over last 200,000 yrs" supporting the change in strain accommodation.

The greater region continues to evolve with blockwise fault zones splaying from the north and south transferring deformation from the opposing subduction zones in the northeast and southwest.

The Hikurangi margin has drifted east and now south with time while the Marlborough Fault Zone (MFZ) has adapted to this shift in stress regime by propagating south with newer faults to the south that strike more easterly than northern counterparts. The newest fault to be included in the MFZ is the Porters Pass fault zone of discontinuous fault traces. The SAPSE study in 1995 identified an east-west seismicity band that intersected the Alpine Fault near Fox Glacier and speculated the band was part of the Porter's Pass Fault Zone (Leitner et al., 2001). 


\subsection{Seismicity characteristics}

The region is largely dominated by seismicity to the southeast of the fault trace. Activity to the northwest is low (Eiby, 1959; Evison, 1971). The contrast reflects the difference in geology of the two sides, with metasediments and granite to the northwest and relatively weak and highly fractured schist and mylonites to the southeast (Norris and Cooper, 2001, 2007).

Measurement accuracy of the frequency of large ruptures along the Alpine Fault is restricted by reliable paleoseismic record (difficult to find in a region with high erosion rate), and measurement of strain build-up (for which we have a limited timeframe of geodetic measurements). Likelihood of rupture is constrained by the maximum possible slip from the length and locking depth of the fault.

Geological and geochemical measurments imply past large ruptures along the Alpine Fault at AD 1717, 1620, 1425, 1220 (Bull and Brandon, 1998; Norris and Cooper, 2001; Yetton, 1998; Wells et al., 1999). Robinson (2004) modelled the recurrance interval from computer simulations of the Alpine-Marlborough-Buller fault network and suggested an average recurrence of 240 years but with broad variation from 89 to 718 years. Sutherland and Norris (1995) calculated a recurrence of $330 \pm 90$ years based on accommodating the plate relative displacement rate in 8-9 m earthquake slip. Adams (1980); Wells et al. (1999) interpret the last large rupture along the central Alpine Fault to be c. 550 years ago.

The seismic gap estimates for the central Alpine Fault vary. The magnitude of the next large event is generally expected to be larger than 7 with some suggesting as large as 8. Rupture length estimates include $>180 \mathrm{~km}$ with Sutherland and Norris (1995) stating at least $100 \mathrm{~km}$ will rupture, but there are no data constraining whether it will be limited to $100 \mathrm{~km}$ or that the whole length of the fault (at least $400 \mathrm{~km}$ visible) will rupture.

The brittle-ductile transition zone of a region is a significant characteristic for seismic hazard. It determines the maximum depth extent of fault rupture. It also governs under what conditions small events fracture. Estimates of the brittle-ductile transition zone can be made through heat-flow measurements and seismicity studies as this zone is related to the thermal structure and the seismogenic zone.

Shi et al. (1996) modelled geotherms from thermal well measurements, paleothermal 
indicators in outcrops, uplift and erosion rates. They interpret the brittle-ductile zone as an isotherm of $300^{\circ}$ at around $25 \mathrm{~km}$ under the Southern Alps, rising steeply up the Alpine Fault to less than $10 \mathrm{~km}$ although they acknowledge some seismicity below this level. An isotherm of $300 \pm 50^{\circ}$ is the established value of brittle-ductile transition for quartz lithologies (Bonner et al., 2003) which is the predominant rock type of the regional basement of granite and schist. Bonner et al. (2003) differentiated two zones of cutout depth in California (defined as the depth that covered $99 \%$ of seismicity) restricted to isotherms of $450 \pm 50^{\circ}$ and $260 \pm 40^{\circ}$. The differences in isotherm temperature between the two zones correlated to regional heat flow of above and below $60 \mathrm{~mW}$ m-2 respectively. The lower heat flow regions included both the deepest earthquakes of the San Andreas Transverse Ranges region as well as shallow events of the largely creeping Mojave block.

Measurements of the upper crust brittle-ductile transition depth based on seismicity surveys range from 8-14 km, mostly due to lateral variation with a $10-20 \mathrm{~km}$ wide band of shallow brittle-ductile zone observed by Eberhart-Phillips (1995) from inversion of NZNSN catalogue data and confirmed by Leitner et al. (2001) in the SAPSE microseismicity study. The brittle-ductile zone is probably a gradual rather than abrupt transition as no reflectors are observed (Kleffman et al., 1998) and velocity modelling showed no velocity discontinuities in this zone (Eberhart-Phillips, 1995). The depth estimates of the zone, however, are consistently less than transition depths to the north and south and are largely linked to the interrelated local features of higher near-surface heat flow, rapid uplift and erosion. A numerical modelling of the thermal regime by Allis and Shi (1995) indicated rapid uplift would thin the brittle part of crust, and that this would limit the width of rupture in large events.

High fluid pressures would also lift the brittle-ductile boundary. Fluids have been inferred from low $\mathrm{P}$-wave velocity of $10 \%$ coinciding with high electrical resistivity regions two orders of magnitude lower as this observation suggests the presence of interconnecting fluid (Stern et al., 2001; Jiracek et al., 2007). This is in contrast to petrochemical and structural evidence which suggests the Alpine Fault mylonite zone is relatively dry at about 5-10 km depth, where much of the seismogenic activity occurs. 


\section{Chapter 3}

\section{Survey}

\subsection{Analysis of GeoNet catalogue}

To address the objectives and assess the likely nature of the shallow crust microseismicity study, the seismicity pattern of the region was studied from the New Zealand National Seismograph Network (NZNSN or GeoNet) catalogue. Seismicity maps were plotted for all events as well as those after 1991 where the network upgrade to digital recorders was completed in the region. This was to ensure no seismicity anomalies were due to changes in network coverage or instrument type.

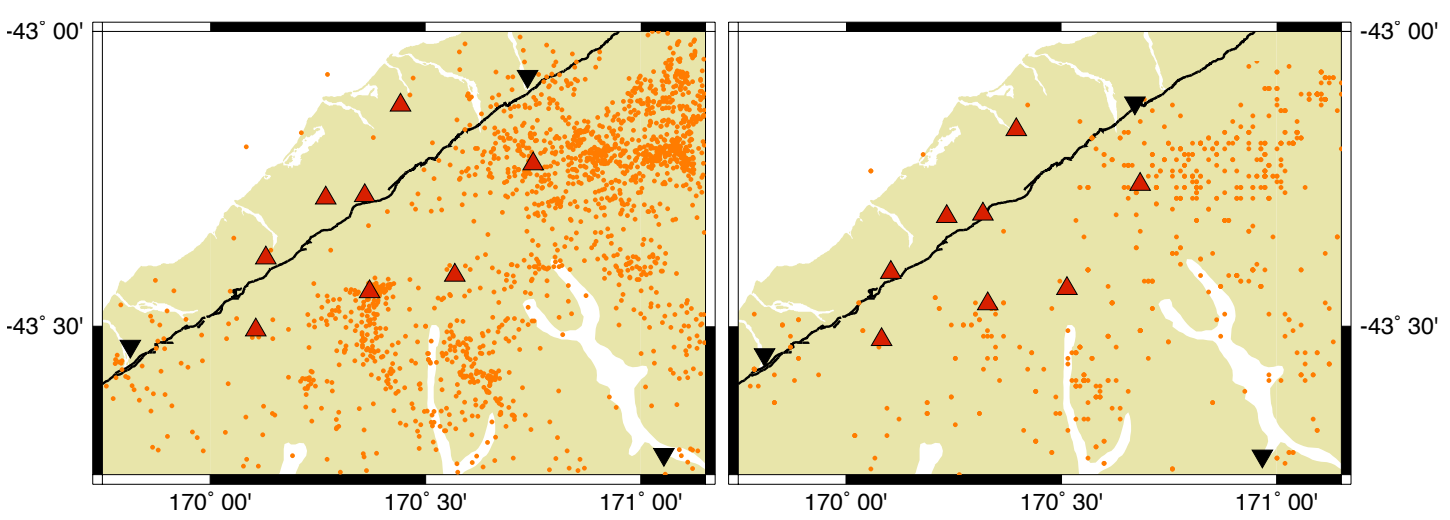

Figure 3.1: GeoNet catalogue seismicity for 1991-2006 Left: All 14388 events; Right: with aftershock activity removed including the Cass and Arthurs Pass sequences leaving $11 \%$ remaining. The events were filtered using a modified algorithm based on the method of Gardner and Knopoff (1974).

An aftershock filter algorithm adapted by Savage (pers. comm) using the Gardner and Knopoff (1974) method was also applied. The algorithm outputs events of magnitude equal or higher than previous events within a magnitude dependent space-time window 
(subject to catalogue errors). The space-time window can be calculated by the equation in Gardner and Knopoff (1974) but is interpolated from a table within the algorithm that is based on Table 1 within Gardner and Knopoff (1974) with distances modified to the New Zealand magnitude distribution (Savage and Rupp, 2000).

The low seismicity zone of the central region can be seen in Fig 3.1 where the zone is evident even with aftershock seismicity removed demonstrating that the seismicity pattern is not an artifact of a few large earthquake sequences.

A sharp break in seismicity is observed immediately south of Harihari with a more gradual return in seismicity south of Franz Josef (see Fig 3.3 for locality names). Thus the survey plan involved placing stations at the northern cusp of the sudden break, and dispersed between the two nearest NZNSN stations WVZ and FOZ (as seen in Fig 3.3).

Before deciding on any array geometry and survey timeframe, the seismicity of the area was examined using GeoNet phase and catalogue data. It was important to estimate what timeframe was necessary to capture locatable seismicity within the low-seismicity zone and determine the best array configuration based on likely magnitude distribution within the region.

It was judged that a time frame of 4 months was a minimum requirement to ensure some seismicity within the quiet zone would be recorded. Six months was recorded as a buffer period in case seismicity was lower than expected. As can be seen in Fig 3.2, the seismicity for the recording period was within the average expected (left Panel compared to CAlF recorded in right Panel). The middle Panel highlights the expectation of a "worstcase-senario" where a lower-than average seismicity might be encountered. In this case, it would have been possible that only 3 events would be detected within the centre of the "horseshoe".

\subsection{Station selection}

To create a catalogue of microearthquakes for the quieter segment of the central Alpine Fault, an array geometry was designed that was more closely spaced than previous studies. Three national network stations (WVZ, FOZ and RPZ as seen in Fig 3.3) bordered the area of interest. A temporary array of three broadband and five short-period instruments, all three-component, were deployed along both sides of the Alpine Fault between Harihari 


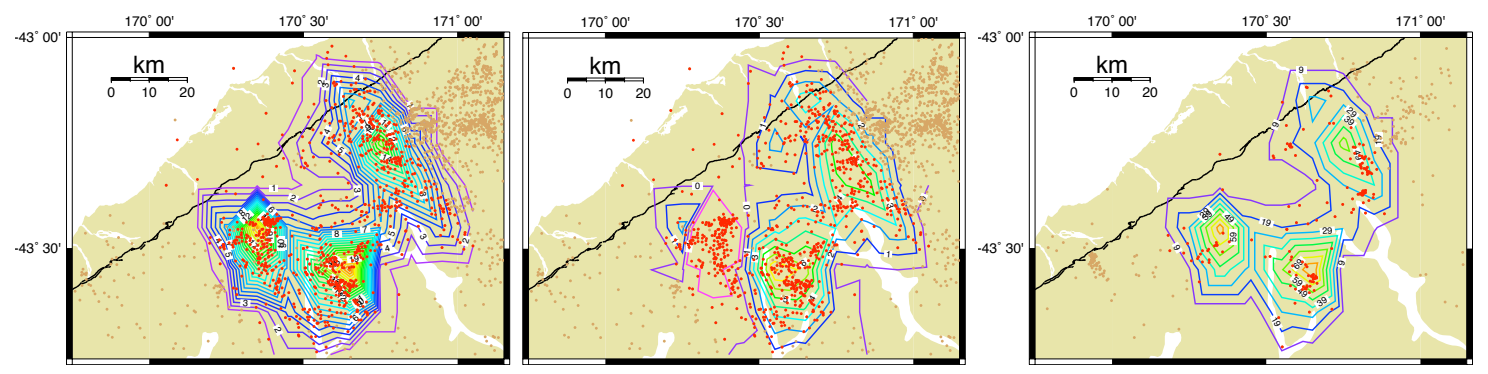

Figure 3.2: GeoNet catalogue seismicity contours for 1990-2006 compared to CAlF survey seismicity. Contours calculated from $0.1^{\circ} \times 0.1^{\circ}$ bins for events (in red) within $30 \mathrm{~km}$ of the center of the "aseismic" zone and $50 \mathrm{~km}$ from the Alpine Fault scarp. Events not included are displayed in brown. As the likely survey was to be within 4-6 months, but with a better magnitude cut-off, an estimate of survey seismicity was made by analysing 4 year intervals for the target zone (approximately equivalent to a 4 month interval with a magnitude cut-off an order of magnitude lower). Left: Four month mean of GeoNet catalogue event count per bin; Middle: Right: estimate of likely "worst-case-senario" of mean count minus standard deviation per bin. Right: Actual seismicity over the 4 month interval.

and Fox Glacier as pictured in Fig 3.3. This gave an average station spacing of $14 \mathrm{~km}$ (this average did not include RPZ whose nearest neighbour is $\mathrm{SCH}$ at $52 \mathrm{~km}$ ) compared to $30-50 \mathrm{~km}$ for SASPE (Anderson et al 1997) and $81 \mathrm{~km}$ for the three GeoNet stations.

The broadband instruments were spaced within the national permanent stations to give a geometric T array (Fig 3.3). The analysis of the wider range of frequencies recorded on the broadband array was not within the scope of this thesis, but the data recordings will be available for further studies.

Ideally, seismographs would have been evenly distributed and away from major seismic noise sources (trees, rivers, towns). However, the majority of the West Coast is dense forest and steep alpine topography with many creeks and rivers. Instead, sites were optimised by geography - avoiding Department of Conservation (DOC) sensitive areas, noise (towns, main roads, dense forest and rivers) and, to the extent possible, away from glacial till and close to basement.

This was not always feasible. SCH (Scone Hut) was positioned between a river and a DOC hut although dense bush made it difficult to find a better site nearby that met our resource permit. To keep a broad array width, two sites on glacial till were necessary (HTR and HSN) but every effort was made to ensure these two were the least noisy among a set of possible sites. Alpine sites were picked close to DOC approved helipads or landing areas to simplify the permit seeking process. To reduce the effect on the Alpine flora (key to environmental impact assessment of permit) the site access from helicopter landing was 


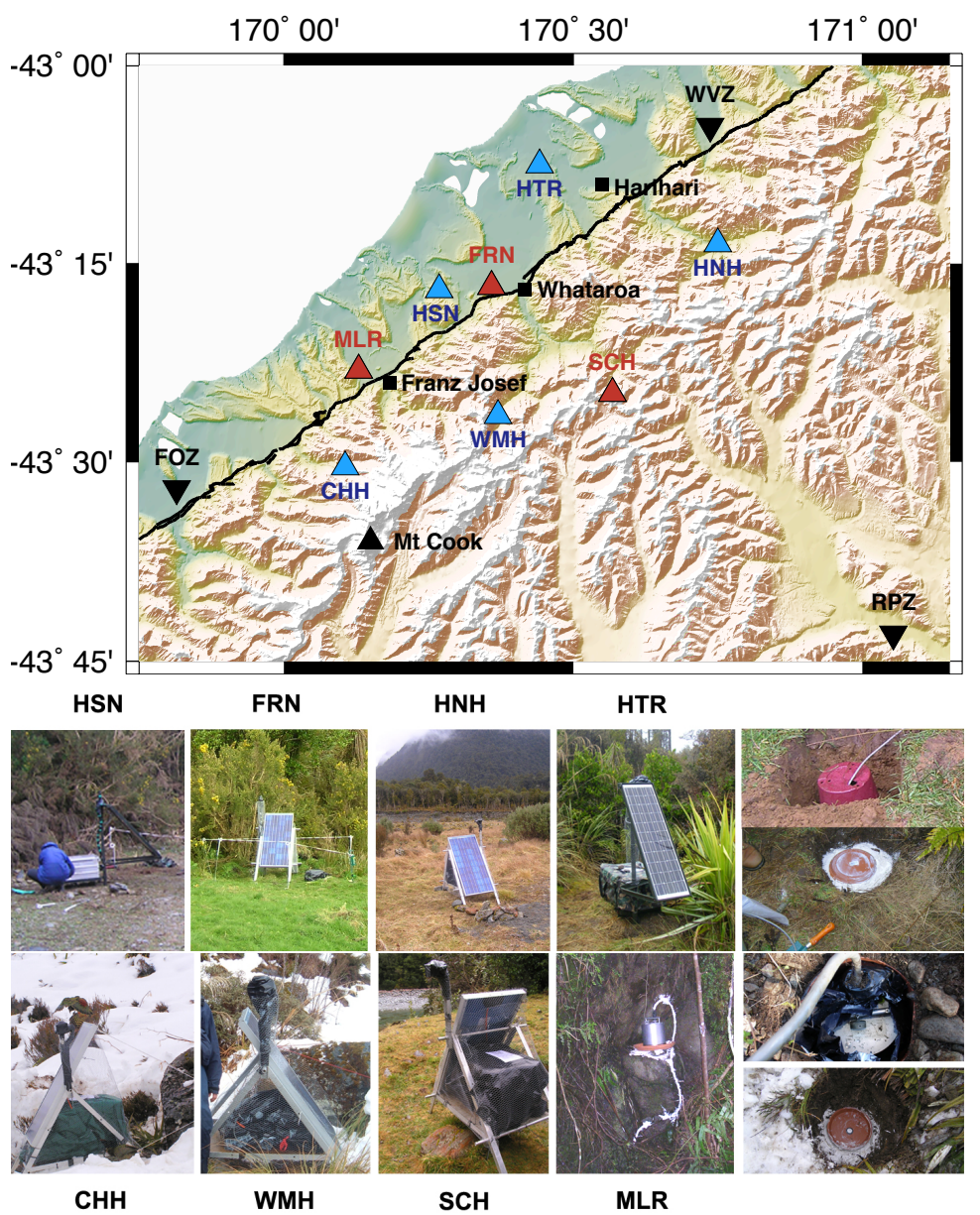

Figure 3.3: Broadband and short-period seismographs. Red triangles are the broadband stations, with short-period stations in blue. The GeoNet national broadband stations are the three inverted triangles bounding the array. Photographs of each station and examples of seismometer setup are also displayed.

minimized and sites were away from visibility of regular visitors.

\subsection{Station description}

Each temporary seismograph station consisted of a GPS unit for timing, power supply of solar panel and three or four 60 Amp-h batteries, seismometer and RefTek130 or ORION Data Acquisition System (DAS) with disk data storage. Seismometers taped into bags were generally buried to knee-height (for weather noise protection) with rock contact (schist fragments) and given plastic shelter (flowerpot and base) waterproofed with sealant. See Fig 3.3 for photographic examples. The two exceptions to this were the two Nanometrics ORION stations, MLR and FRN, which were plastered directly onto apparent basement. Recording units were either locked in aluminium boxes (in publicly accessible areas) or 
taped into bags and fenced by wire mesh under the solar panel to protect from local fauna (eg rats, calves, keas and other birds). At sites where livestock roamed, a temporary electric fence was installed as well.

The array recorded continuously from September 2006 to mid March 2007. Data sampled at $100 \mathrm{~Hz}$ were recorded onto 4 and $1 \mathrm{~GB}$ disks for the RefTeks, and at $80 \mathrm{~Hz}$ onto the 2 GB disks for the ORIONS. A maintenance visit in mid November was made to check each site was running correctly, swap memory disks and assess any damage by weather or fauna. Refer to appendix for station maintenance notes and plots of station operability.

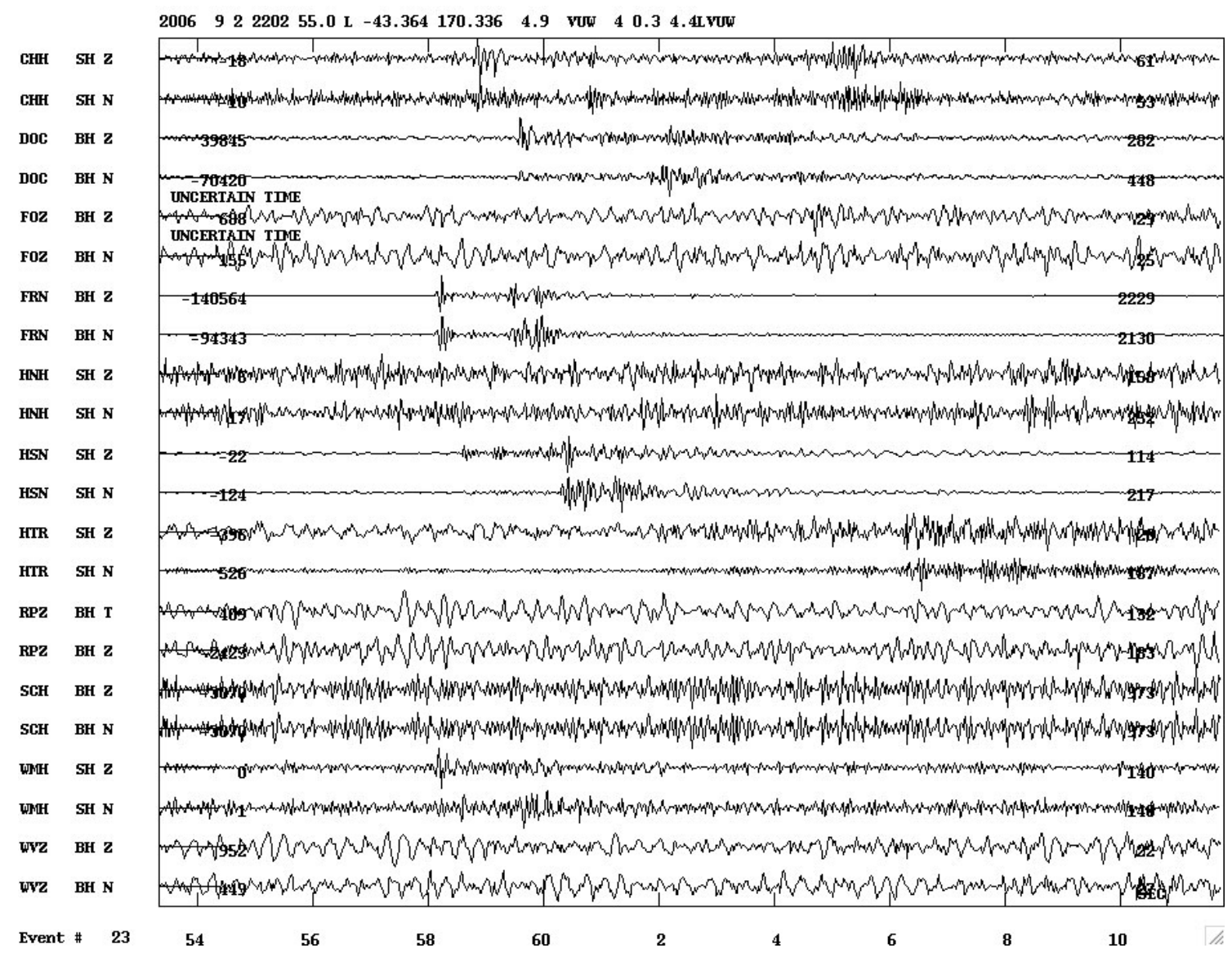

Figure 3.4: Seismograph example of a small event central to the array as seen in SEISAN (Havskov and Ottemöller, 2005) with a frequency filter of 3-10 Hz. This event occurred on 2 September 2006 at 22:02 located at $170.358,-43.361$, depth $6.4 \mathrm{~km}$ with $\mathrm{M}_{L} 0.64$. 


\subsection{Huddle tests}

One week huddle tests of the seismographs before and after the survey were made to identify any technical problems with the seismographs and to assess the polarity of each instrument for use in focal mechanism calculations. Few events were recorded during the huddle tests and these did not conclusively determine polarity. The event phases were too emergent or the amplitudes were too small to see clearly above the noise. A selection of event waveforms and large noise sources were cross-correlated across the postsurvey huddle after removing the instrument response. Unfortunately, the results were not consistent (Refer to Table 3.1).

I recommend that future huddle tests be conducted at a quiet site until consistent results are reached.

Table 3.1: Seismograph polarities determined by first-motion (fm) and cross-correlation (cc) of post-survey huddle test (HT) vertical waveforms and distant events (DE) during the survey with instrument response removed. Stations from the array were of the same seismometer and seismograph pairing within the huddle tests. The combined observations are summarized in the last column.

\begin{tabular}{|l|c|c|c|c|c||c|}
\hline Station & HD fm & HD cc & DE 318 & DE 346 & DE 252 & Inferred \\
\hline CHH & $\mathrm{D}$ & $\mathrm{D}$ & $\mathrm{D}$ & $\mathrm{D}$ & $\mathrm{D}$ & $\mathrm{D}$ \\
MLR & $?$ & $?$ & $\mathrm{U}$ & $\mathrm{U}$ & $\mathrm{U}$ & $\mathrm{U}$ \\
FOZ & - & - & $\mathrm{U}$ & $\mathrm{U}$ & $\mathrm{D}$ & $?$ \\
FRN & $?$ & $?$ & $\mathrm{U}$ & $\mathrm{U}$ & $\mathrm{U}$ & $\mathrm{U}$ \\
HNH & $\mathrm{U}$ & $\mathrm{U}$ & $\mathrm{U}$ & $\mathrm{D}$ & $\mathrm{U}$ & $\mathrm{U} ?$ \\
HSN & $\mathrm{U}$ & $\mathrm{U}$ & $\mathrm{D}$ & $\mathrm{D}$ & $\mathrm{U}$ & $?$ \\
HTR & $?$ & $\mathrm{U}$ & $\mathrm{D}$ & $\mathrm{D}$ & $\mathrm{D}$ & $\mathrm{D} ?$ \\
RPZ & - & - & $\mathrm{U}$ & $\mathrm{U}$ & $\mathrm{U}$ & $\mathrm{U}$ \\
SCH & $\mathrm{D}$ & $\mathrm{D}$ & $\mathrm{U}$ & $\mathrm{U}$ & $\mathrm{D}$ & $?$ \\
WMH & $\mathrm{U}$ & $\mathrm{U}$ & $\mathrm{U}$ & $\mathrm{U}$ & $\mathrm{U}$ & $\mathrm{U}$ \\
WVZ & - & - & $\mathrm{U}$ & $\mathrm{U}$ & $\mathrm{U}$ & $\mathrm{U}$ \\
\hline
\end{tabular}




\section{Chapter 4}

\section{CAlF Network Catalogue}

\subsection{Data processing overview}

The continuous waveform data recorded during the temporary deployment were augmented by waveform data from three permanent national network stations. Although the survey period exceeded six months, only four months were processed due to time constraints and the large volume of data. Stations' Z-component seismograms were manually examined simultaneously in SAC in four minute chunks. Possible local events were included if they exhibited recognisable $\mathrm{P}$ and $\mathrm{S}$ wave components recorded by 3 or more stations at a similar time and with S-P travel-times equivalent to local distances.

Uncertain events were also noted to be looked at within SEISAN (Havskov and Ottemöller, 2005) where filter and zoom features make it easier to examine seismographs.

Seismograms identified as possible or uncertain local events were processed to mseed local event files using ORION and PASSCAL program packages, then phase arrivals were picked and hypocenters calculated using the location program HYPOCENTER (Lienert et al., 1986) incorporated into the SEISAN seismic analysis system.

The location algorithm simultaneously uses P, S and S-P times and minimises the least squares misfit of location between calculated and modelled travel times until one of the user specified convergence criteria is met. The RMS (root mean square of phase time residuals) is therefore directly related to each residual, and the iterative nature of reducing the RMS value indirectly links each phase residual to the others and to the location solution. An example of the output can be seen in Fig 4.1.

An initial dataset of 2006 Julian days 275-279 was processed and analysed first (45 


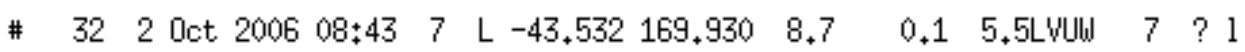

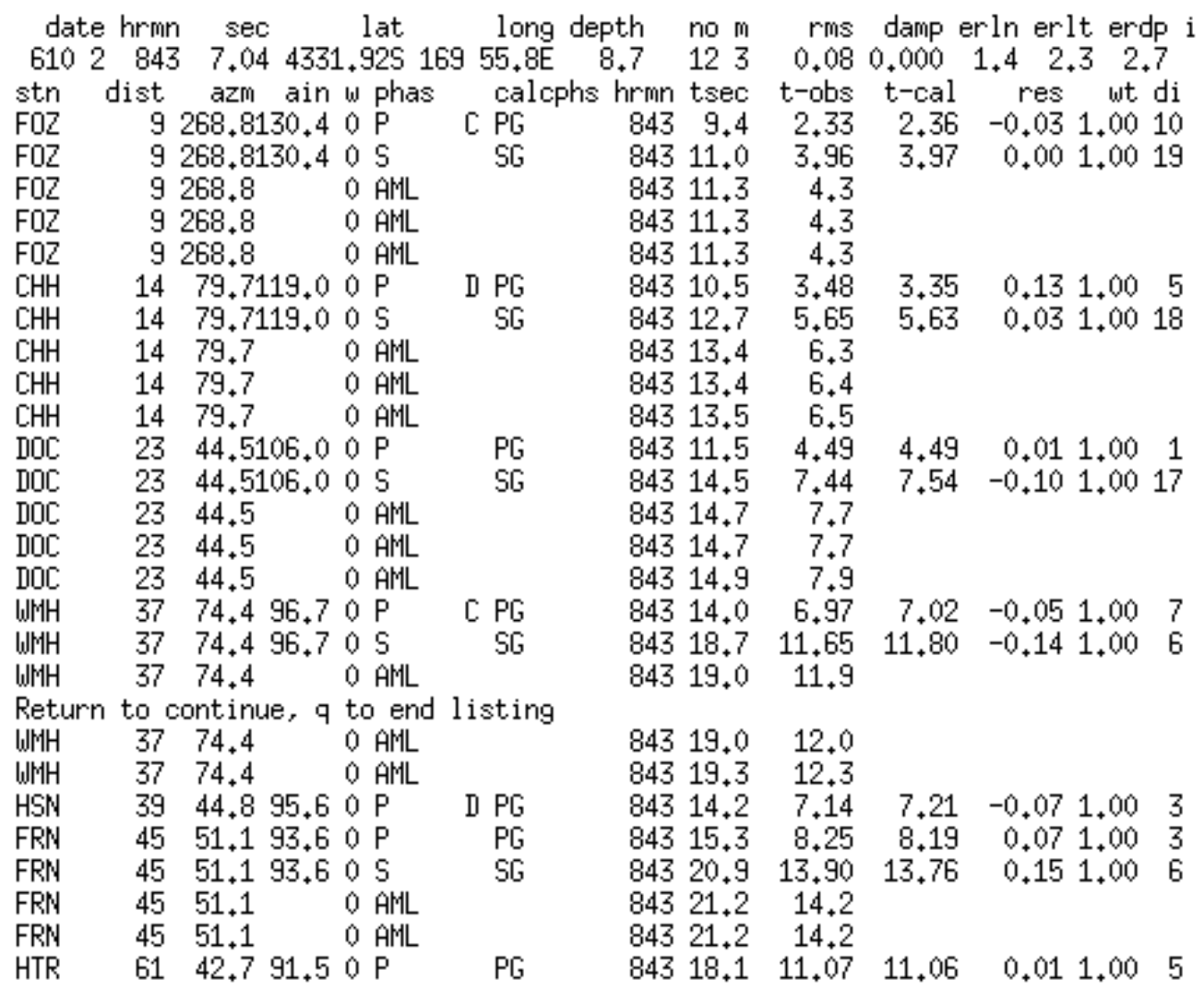

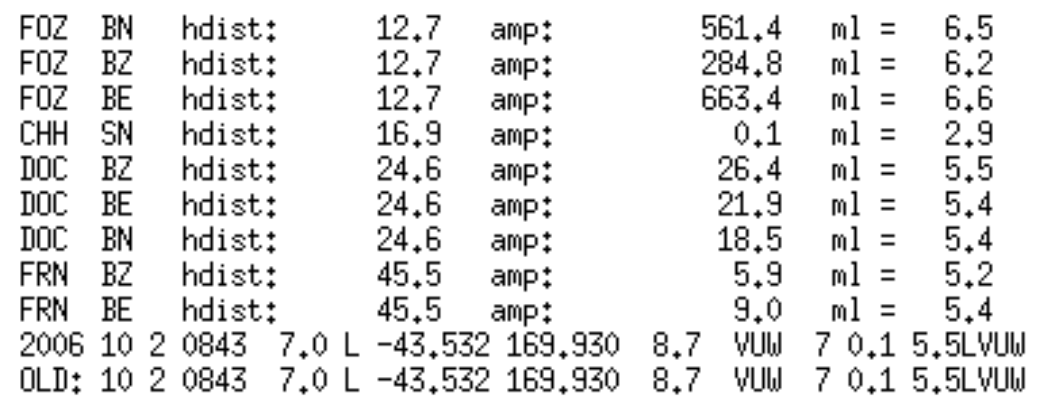

Figure 4.1: Example of SEISAN location output. The key statistics used in this thesis include rms (root-mean-square of time residual), erdp (depth error referred to as erz in $\mathrm{km}$ ) and erln, erlt (longitude and latitude error in degrees) which is also output as erh (horizontal error in $\mathrm{km}$ ). These error statistics were monitored during the iterative weighting of station phase picks to ensure the changes resulted in an improvement in hypocetner location. The station phase time residuals (in seconds) used in subsection 4.5.3 are denoted as "res". The hdist values (station to epicenter distance in $\mathrm{km}$ ) were used in the magnitude calibrations (see Chapter 5.

events or $>10 \%$ of final events) before the remainder of data were processed. Location parameters (starting depth, $\mathrm{V}_{p} / \mathrm{V}_{s}$ velocity ration (VPS) and velocity model) were varied one-by-one and resultant hypocenter locations and error statistics were compared to minimize error and stabilize locations (as discussed further throughout this chapter).

A time discrepency found in Chancellor Hut $(\mathrm{CHH})$ recordings was investigated (see 
Section 4.3). I concluded there was likely to be an error of one second but it was difficult to separate from an additional apparent time residual due to the variation from $1 \mathrm{D}$ velocity model. After removing the suspected 1 second error, the timing of all stations was analysed by looking at the variance and mean of the time residuals (see Section 4.5.3). A consistent time residual for each station phase was attributed to a bias in the $1 \mathrm{D}$ velocity model not fully describing the structure and the bias was reduced by removing the mean time residual of dominant stations CHH, HSN and HTR, as their mean time residuals were the largest and were apparently biasing the other residuals (as seen in Fig 4.7).

Table 4.1: Phase statistics for the final event catalogue describing the percentage of phases from each station weighted by half.

\begin{tabular}{|l|c|c|c|c|c|c|}
\hline Station & Total & P phases & S phases & \% Total weighted & \% P weighted & \% S weighted \\
\hline CHH & 208 & 101 & 107 & 28 & 37 & 21 \\
MLR & 613 & 308 & 305 & 11 & 9 & 14 \\
FOZ & 317 & 151 & 166 & 13 & 12 & 13 \\
FRN & 541 & 260 & 281 & 12 & 13 & 12 \\
HNH & 414 & 222 & 192 & 3 & 2 & 4 \\
HSN & 322 & 175 & 147 & 33 & 29 & 37 \\
HTR & 292 & 172 & 120 & 71 & 72 & 69 \\
RPZ & 212 & 121 & 91 & 9 & 7 & 13 \\
SCH & 339 & 166 & 173 & 8 & 4 & 4 \\
WMH & 275 & 145 & 130 & 11 & 7 & 15 \\
WVZ & 485 & 263 & 222 & 11 & & \\
\hline
\end{tabular}

Final phase weighting (in Table 4.1) were either 0 (full weighting of 100\%) 2 (50\%) or 4 (not used). Stations that had timing corrections applied to remove average timing errors from localised velocity model heterogeneity were given $50 \%$ weightings. The remainder of phases were iteratively weighted (coarsely according to time residuals but also subjectively from accumulated experience of the system) to minimise the depth, latitude and longitude errors as well as RMS time residuals.

The final phase data were used to obtain a $1 \mathrm{D}$ velocity model from the velocity inversion program VELEST (Kissling, E. and Kradolfer, U. and Maurer H., 1995). Magnitudes were calculated by inversion of a generalised magnitude equation (see Chapter 5).

At the completion of the earthquake locating, the consistency in picking phase arrivals over the duration of data processing was tested by randomly selecting several of the first set of events and re-picking the phases. No consistent or significant change in location accuracy was found. 
Out of a total of 1440 possible events, 619 were identified as probable events that were local and may be locatable and the final catalogue consists of 411 events with magnitudes from -0.2 to 4.63 and a cut-off magnitude of 1.6 (see Chapt 5. The remaining 208 were discarded as not having enough reliable arrival picks to triangulate a location.

\subsection{Initial HYPOCENTER parameters}

Events cut from days 275-279 (2-6 October 2006) were processed first for two reasons:

- They include an interesting swarm of events in the southern part of the area of the study, the "Fox Swarm".

- A focussed look at a segment of data allowed me to statistically analyse and determine preliminary problems in timing, velocity models and location program parameters.

The five day dataset consisted of 41 local events with 31-34 events attributed to the Fox Swarm.

The initial parameters used in the modified HYPOCENTER (Lienert et al 1986) location program included:

- crustal option which uses crustal travel time software (for local events)

- starting depth at $5 \mathrm{~km}(5,7,10,15$ tested)

- no weighting on stations or phases

- Only 1D P velocity model defined

- VPS initially 1.74 (NB: after Wadati analysis, this became 1.68).

Three velocity models were tested (outlined in Table 4.3). These were based on extracting a $1 \mathrm{D}$ velocity structure from model plots published from the following studies:

- Eberhart-Phillips (1995) 1D estimate from inverting microearthquake data

- Scherwath (2002) 2D slices from inversion of wide-angle active seismic recordings

- Smith et al. (1995) ray tracing model from active seismic recordings. 


\subsection{Station $\mathrm{CHH}$ timing error}

During the RefTek data processing, an unusual timing error was logged for Chancellor Hut station CHH indicating a possible internal clock error of $n$ seconds over and above the phase error detected ${ }^{1}$.

To diagnose by how many seconds the station was likely to have been delayed, station phase time residuals and event RMS values were compared for datasets with CHH phase picks corrected by 0,1 and 2 seconds. A few locations were made with a correction of 3 seconds enough to establish this delay was unlikely. Locations with no corrections had the highest residuals and RMS values. As can be seen in Fig 4.2, data corrected by 1 and 2 seconds were similar although the 2 second correction biased locations to implausibly shallow depths.

Mean, standard deviation of the sample and standard deviation of the mean of the phase time residuals for each set of locations showed there was not much difference between a time correction of 1 and 2 seconds (see Fig 4.3). A time correction of 1 second was chosen, although a further station correction was subsequently made on the basis of velocity model error (discussed later in subsection 4.5.3).

Table 4.2: Mean differences in location after CHH 1 second correction

\begin{tabular}{lrrl}
\hline Latitude: & $0.02^{\circ}$ & $\sim 2.2 \mathrm{~km}$ & $(\sigma 0.02)$ \\
Longitude: & $-0.02^{\circ}$ & $\sim 1.6 \mathrm{~km}$ & $(\sigma 0.02)$ \\
Depth: & & $2.5 \mathrm{~km}$ & $(\sigma 3.3)$ \\
RMS: & & 0.03 & $(\sigma 0.11)$ \\
\hline
\end{tabular}

\subsection{Location program parameters}

Location program parameters of VPS ( $\mathrm{P}$ to $\mathrm{S}$ velocity ratio) and hypocenter starting depth were examined. The VPS velocity ratio was determined using the Wadati analysis package in SEISAN. The starting depth was analysed by comparing the location statistics for different starting depth trials.

\footnotetext{
${ }^{1}$ The error was in the log file and said "INTERNAL CLOCK POSSIBLE DISCREPENCY OF -1 SECONDS". The software of the DAS was v2.7.5 which can determine phase errors of sub-second difference between the GPS timing and the internal clock and can suspect a more than one second problem but not how many seconds. This error was also encountered on a number of different seismographs in the end-ofsurvey huddle test. Software for the DAS units has been subsequently upgraded.
} 

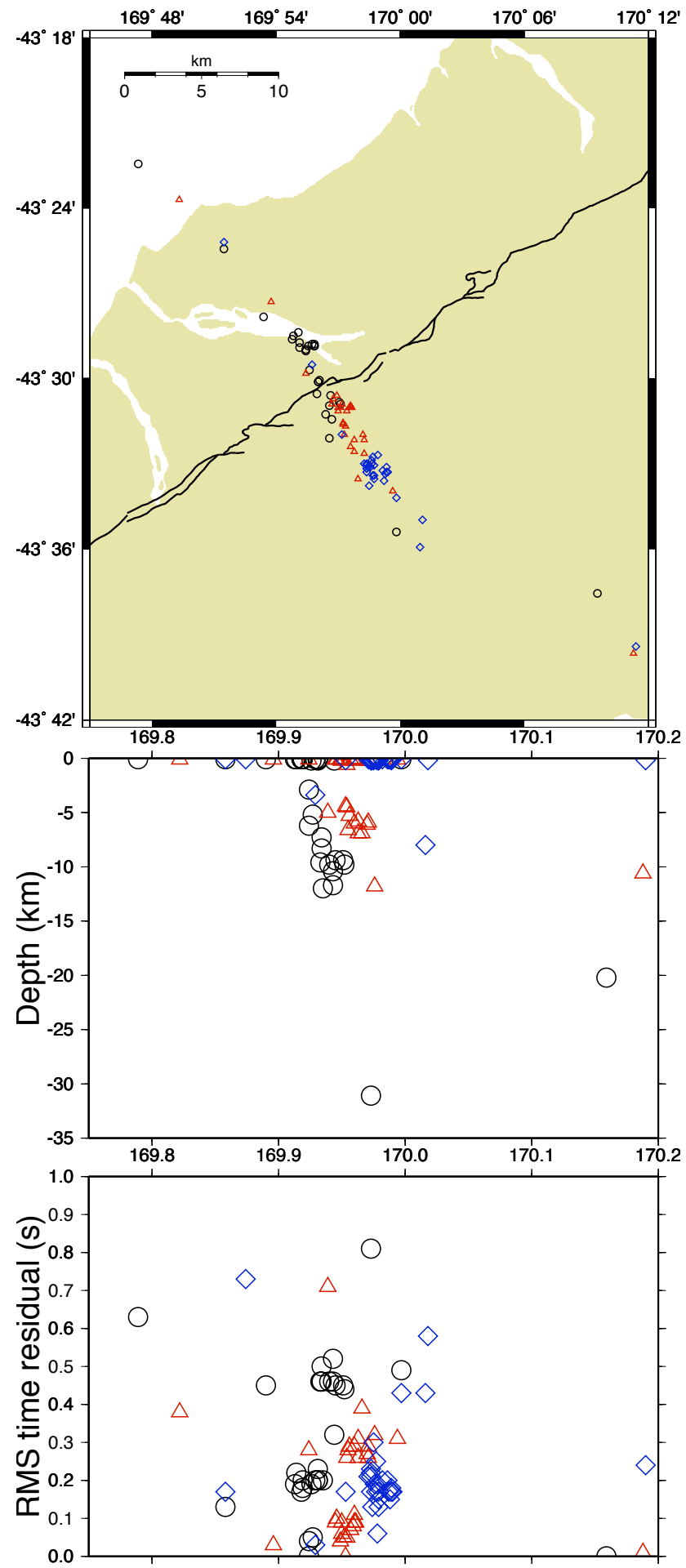

Figure 4.2: Event locations for CHH phase corrected by 0,1 and 2 seconds: latitude (top), depth (middle) and RMS (bottom) versus the longitude for events located with CHH phases corrected by 0 (black circles), 1 (red triangles) and 2 (blue diamonds) seconds. Note the 2 second correction has shallowed most of the locations to $0-0.2 \mathrm{~km}$. 


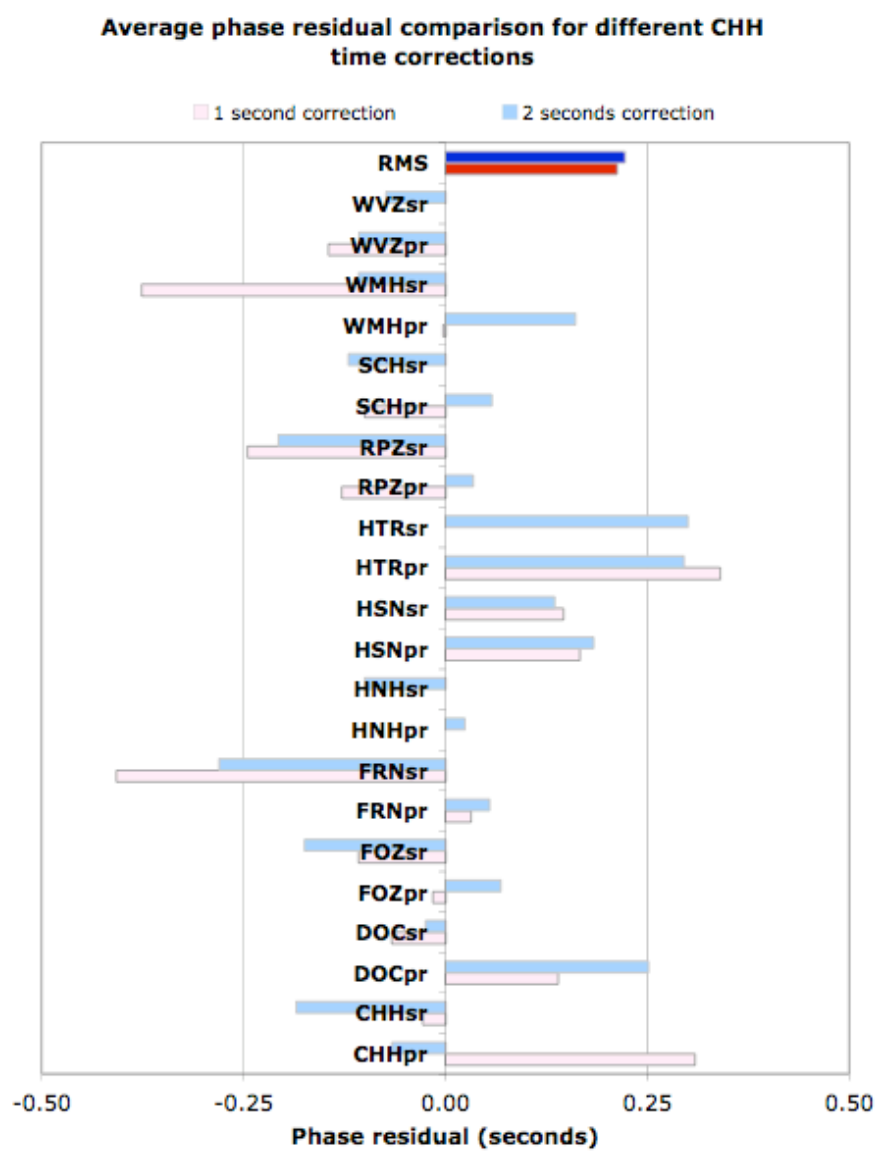

Figure 4.3: Average travel-time residual per event and per station for CHH corrected data: average RMS value for all events followed by average time residuals for each station phase.

A Wadati diagram is a plot of $t_{s}-t_{p}$ phase arrival difference against $\mathrm{P}$ phase arrival tp for an event recorded at many stations (Wadati, 1933). The slope of the plot is linear for local events and is ts/tp-1 thus a direct measurement of VPS as the distance travelled by the $\mathrm{P}$ and $\mathrm{S}$ waves from origin to station are the same.

The diagram also gives an idea of phase picking and velocity model accuracy (although there is a trade-off between these two variables). Bad picks (outliers compared to rest of stations) can be identified; and a more general assessment can be made of how well the measurements correlate to the assumed model.

A correlation coefficient (how well the data correlate to the linear ideal) of 1.0 indicates a perfect match. While the linear relationship is satisfactory in a local micro-event scenario, the slope of larger events including more distant and global stations becomes curved as VPS changes with depth, because with longer distances, raypaths travel deeper.

SEISAN can provide Wadati plots (eg Fig 4.4) and supporting statistics for individual 


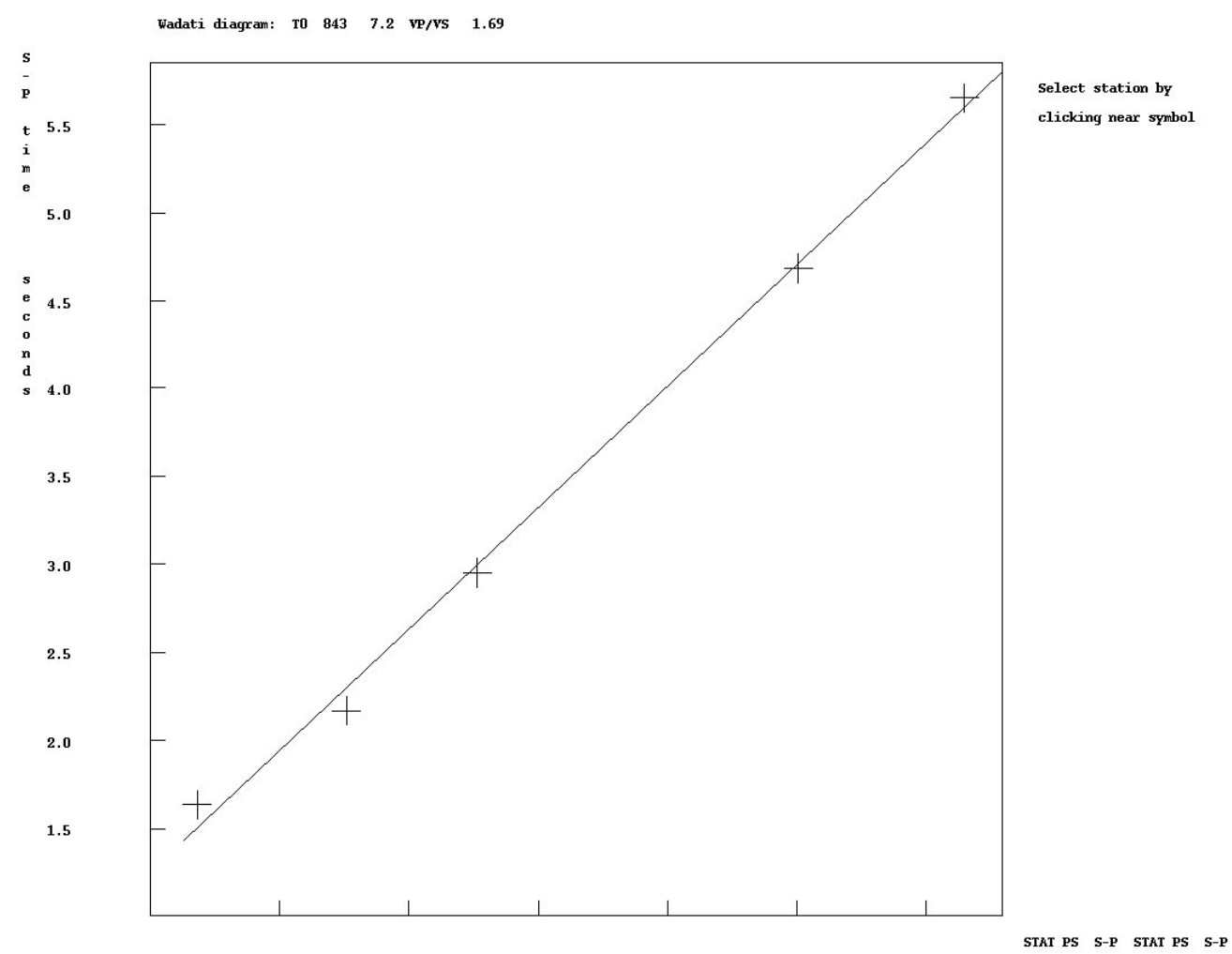

Figure 4.4: SEISAN Wadati plot example of $\mathrm{t}_{s}-\mathrm{t}_{p}$ phase arrival difference against $\mathrm{P}$ phase arrival tp for an event. The deviation from the linear trend can indicate bad phase picks or inadequacies in velocity model approximation.

events as well as calculating the parameters for each event automatically and outputting the averaged statistics over all events.

As another method of comparing the possible $\mathrm{CHH}$ station time corrections, Wadati plots were made for a sample of the larger earthquakes with various $\mathrm{CHH}$ time corrections $(0,1,2,3$ seconds). For events located with $\mathrm{CHH}$ phase times not corrected, or corrected by 3 seconds, the correlation coefficient (a measure of fit to the expected linear curve) was lower; and RMS (root mean square of the Wadati data points) were systematically larger and therefore these scenarios are not favoured. Correlation fits for events with 1 and 2 second corrections were similar to each other although the RMS residuals were usually smaller for the 1 second correction.

For the automated calculation of average Wadati VPS over an event dataset, the average VPS depended on which events were used, based on user defined choices of event location parameters (namely the number of stations used in the event location and RMS of the phase time residuals from that event).

While average VPS from the smaller sample of events gave different values dependent 
on the $\mathrm{CHH}$ correction, the larger event sample VPS was closer to 1.68 regardless of $\mathrm{CHH}$ correction of 1 or 2 seconds. Thus this more stable (and less model dependent) value was used for the remainder of the statistical analysis. Later, when all parameters and station corrections were finalized, an additional Wadati test confirmed the VPS choice.

For a 1 second correction to $\mathrm{CHH}$ station phase arrival times, changing VPS from 1.74 to 1.68 changed the mean RMS (the mean over all events of the root mean square of phase time residuals for each event) from 0.270 to 0.245 . Similarly, the data corrected by 2 seconds with VPS changing from 1.74 to 1.68 changed the mean RMS from 0.271 to 0.245 .

The starting depth of the locating program was then varied to see how sensitive the resultant locations were to this variable. Starting depths of 5, 7, 10 and $15 \mathrm{~km}$ demonstrated little variation. Locations remained reasonably stable with similar depths and RMS values for most events regardless of starting depth. A starting depth of $5 \mathrm{~km}$ was adopted.

\subsection{Velocity model analysis}

\subsubsection{Velocity model comparison}

Of the three velocity models tested (outlined in Table 4.3), model s10 (the modified Smith model) gave greater average depths and larger depth standard deviation (3.29 \pm 3.92 compared to $2.73 \pm 3.21$ for model $\mathrm{c}$ and $3.28 \pm 10.73$ for model a). However, there were more shallow depths using the s10 model (57\% under $2 \mathrm{~km}$ compared to 55 and $50 \%$ for c and a models respectively.)

Anisotropy was not considered, as although lab tests (Okaya et al., 1995) reported anisotropy as high as $17 \%$ close to the fault, Pulford et al. (2003) using active seismic data and found little apparent anisotropy.

\subsubsection{Velocity model sensitivity}

Still using the cluster database of 44 events and the modified Smith et al. velocity model s10, the dominant layer $(0.2-10 \mathrm{~km}$ at $5.35 \mathrm{~km} / \mathrm{s})$ was varied by $\pm 0.2 \mathrm{~km} / \mathrm{s}$ and 3 data sets with second layer P velocity set at 5.15, 5.35 and $5.55 \mathrm{~km} / \mathrm{s}$ were compared. From Figure 4.6 we can see that there is not much difference in the locations, although the velocity model with $5.15 \mathrm{~km} / \mathrm{s}$ for the second layer shallowed many of the depths to less than 0.2 


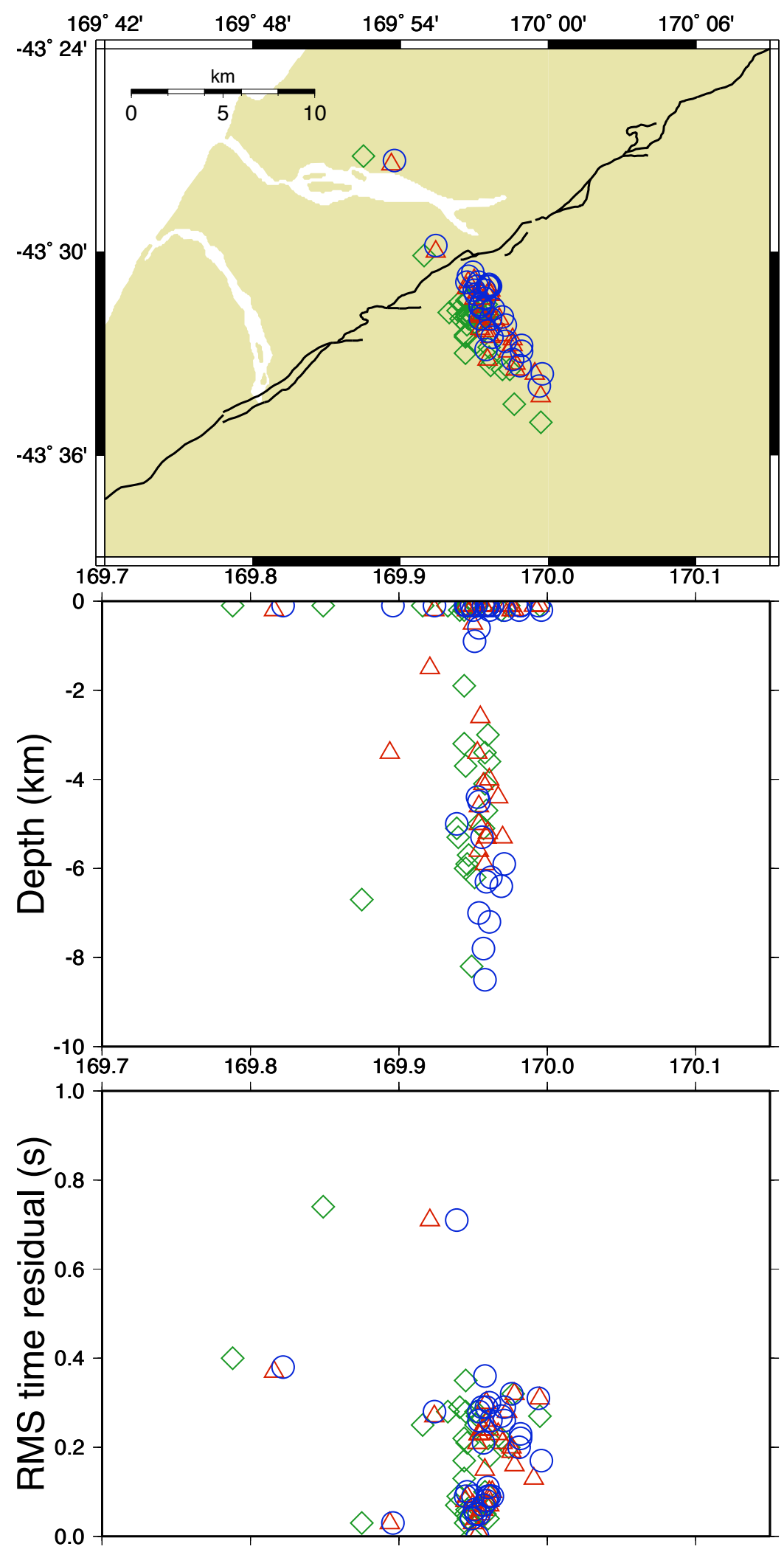

Figure 4.5: Event locations for the three velocity models tested. Panels as in Fig 4.2. Model a: green diamonds; model c: red triangles; model s10: blue circles. Note models c and s10 are similar in epicenter although model s10 deepens the events more while model c clusters the swarm tighter. 
Table 4.3: Model a: Eberhart-Phillips (1995): The published model was plotted in 1D and so there was no "flattening" interpretation necessary. Model c: Scherwath (2002) Fig 7.4 shallow structure from inversion of wide-angle data of Transect 2 (at the southern border of my array) Model s: from Smith et al. (1995) Model s10: An additional layer was added to the Smith et al. (1995) model and the 2nd layer velocity was varied to observe sensitivity.

\begin{tabular}{|l|l|l|l|l|l|l|l|l|}
\hline Model & a: Eberhart-Phillips & \multicolumn{2}{l|}{ c: Schwerwath } & \multicolumn{2}{|c|}{ s: Smith } & \multicolumn{2}{l|}{ s10: modified Smith et al. } \\
\hline & $\mathrm{Z}$ & $\mathrm{Vp}$ & $\mathrm{Z}$ & $\mathrm{Vp}$ & $\mathrm{Z}$ & $\mathrm{Vp}$ & $\mathrm{Z}$ & $\mathrm{Vp}$ \\
\hline & $0-0.1$ & 5 & $0-0.2$ & 3.5 & $0-0.2$ & 3.5 & $0-0.2$ & 3.5 \\
& $0.1-16$ & 6 & $0.2-15$ & 5.5 & $0.2-15$ & 5.35 & $0.2-10$ & $5.55(5.15,5.35)$ \\
& & & & & & $10-15$ & 5.6 \\
& $16-30$ & 6.6 & $15-25$ & 6 & $15-35$ & 6 & $15-35$ & 6 \\
& $30-40$ & 7.2 & $25-35$ & 7 & $35-40$ & 7.2 & $35-40$ & 7.2 \\
& $40+$ & 8.4 & $35+$ & 8 & $40+$ & 8 & $40+$ & 8 \\
\hline
\end{tabular}

$\mathrm{km}$ and increased the RMS of the event time residuals.

There were fewest shallow depths with the second layer velocity set at $5.55 \mathrm{~km} / \mathrm{s}(27 \%$ compared to 41 and $32 \%$ for the 5.15 and 5.35 variants) and clustered the FOZ cluster depths more than the other two models.

Table 4.4: Depth dependence on s10 second layer velocity

\begin{tabular}{lccc}
\hline Velocity of second layer $(\mathrm{km} / \mathrm{s})$ & 5.15 & 5.35 & 5.55 \\
\hline Mean depth between 2 and $10 \mathrm{~km}$ & 6.08 & 5.86 & 5.63 \\
Standard deviation from this mean & 2.52 & 2.25 & 1.83 \\
Depths between 2 and 10 km (\%) & 52 & 64 & 70 \\
\hline
\end{tabular}

Thus $5.55 \mathrm{~km} / \mathrm{s}$ was chosen as the velocity model for the subsequent analysis although a VELEST velocity model was also sought before a final velocity model was chosen.

\subsubsection{Identifying velocity model 1D bias}

Plotting time residuals for each station phase versus the event RMS indicated a linear relationship. This may indicate the 1D velocity model is biased for some stations more than others.

A box and whisker plot (Fig 4.7) of \pm 1 standard deviation of the mean within \pm 1 standard deviation of the sample for the time residuals for each station phase showed a few stations anomalously positive (delayed) and the other stations to be slightly negative.

The cause of the largest mean residuals was identified as a likely bias from using a 1D 

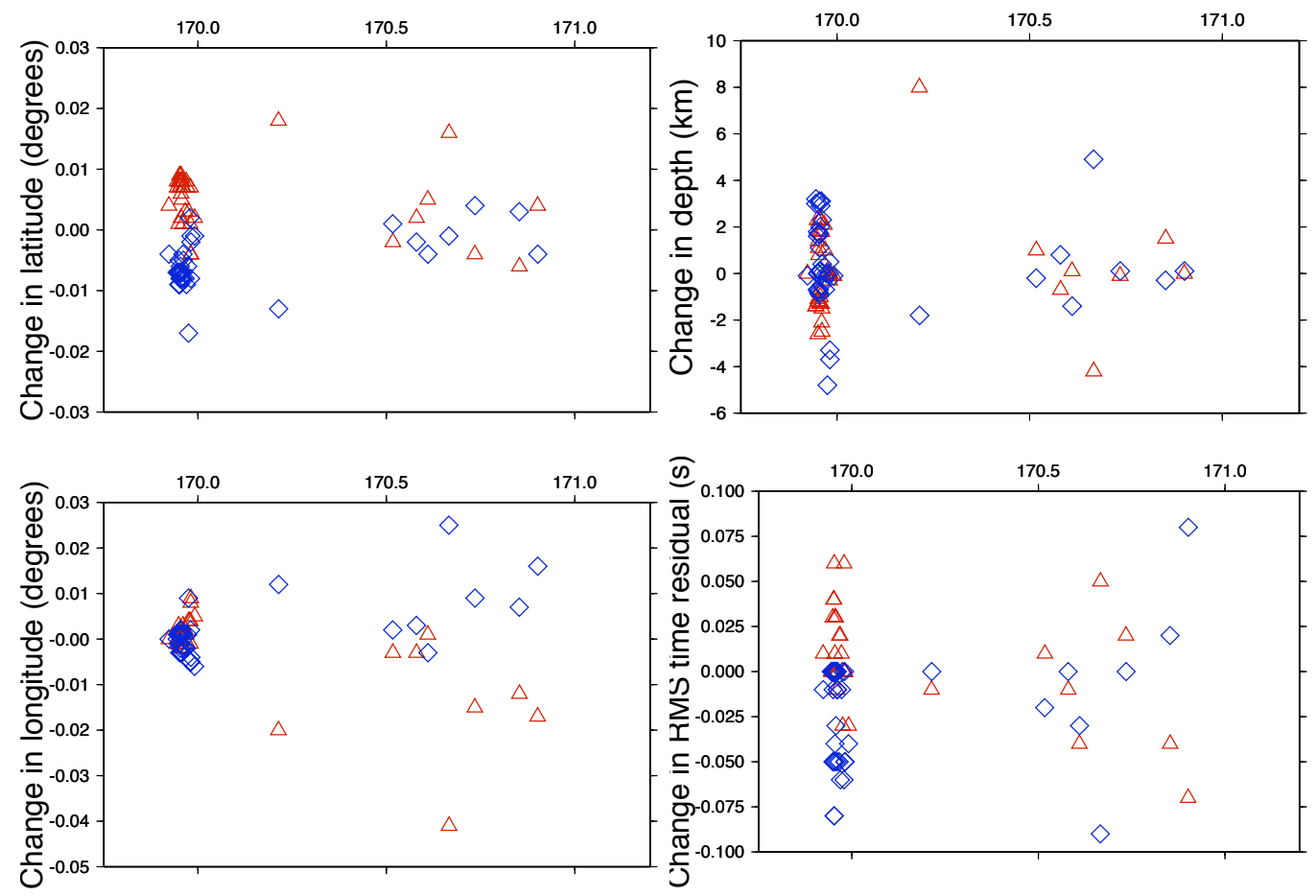

Figure 4.6: Sensitivity of location parameters to velocity model. Changes in latitude, longitude, depth and rms plots against longitude. Using the Smith et al. velocity model, the dominant layer $(0.2-10 \mathrm{~km}$ at $5.35 \mathrm{~km} / \mathrm{s})$ was varied by $\pm 0.2 \mathrm{~km} / \mathrm{s}(5.15 \mathrm{~km} / \mathrm{s}$ : blue diamonds; $5.55 \mathrm{~km} / \mathrm{s}$ : red triangles). The change in locations from the initial $5.35 \mathrm{~km} / \mathrm{s}$ velocity model were plotted against the longitude location from the initial dataset. From this analysis, it was decided that little difference exists and so the value of $5.55 \mathrm{~km} / \mathrm{s}$ was chosen with the expectation that the future VELEST analysis will be applied in any case.

velocity model in a region with complex $3 \mathrm{D}$ structure. The smaller mean residuals were probably biased to negative values by the interdependence between station residuals when locating earthquakes.

The largest mean was at station HTR, situated on glacial till (low velocity medium) and the next highest was HSN; also on glacial till, but not as thick. Then came CHH which was on basement but at high altitude $(1190 \mathrm{~m})$. The location program treats this by adding the altitude of the highest station to the thickness of the first velocity layer (in this case $0.2 \mathrm{~km}$ thickness; with $\mathrm{CHH}$ altitude of around $1.2 \mathrm{~km}$ added the layer becomes $1.4 \mathrm{~km}$ thick). Other stations were close to basement and had altitudes ranging from 54 $\mathrm{m}$ to $930 \mathrm{~m}$.

Removing the mean from the largest positive residuals (HSN S phases, HTR P and S phases) and relocating, produced lower overall phase residuals and event RMS values. A second pass removing the mean from the remaining larger residuals (this time CHH P and HTR S) further improved the location statistics to a level consistent with expected pick 
Station phase mean and standard deviation of sample and mean before corrections

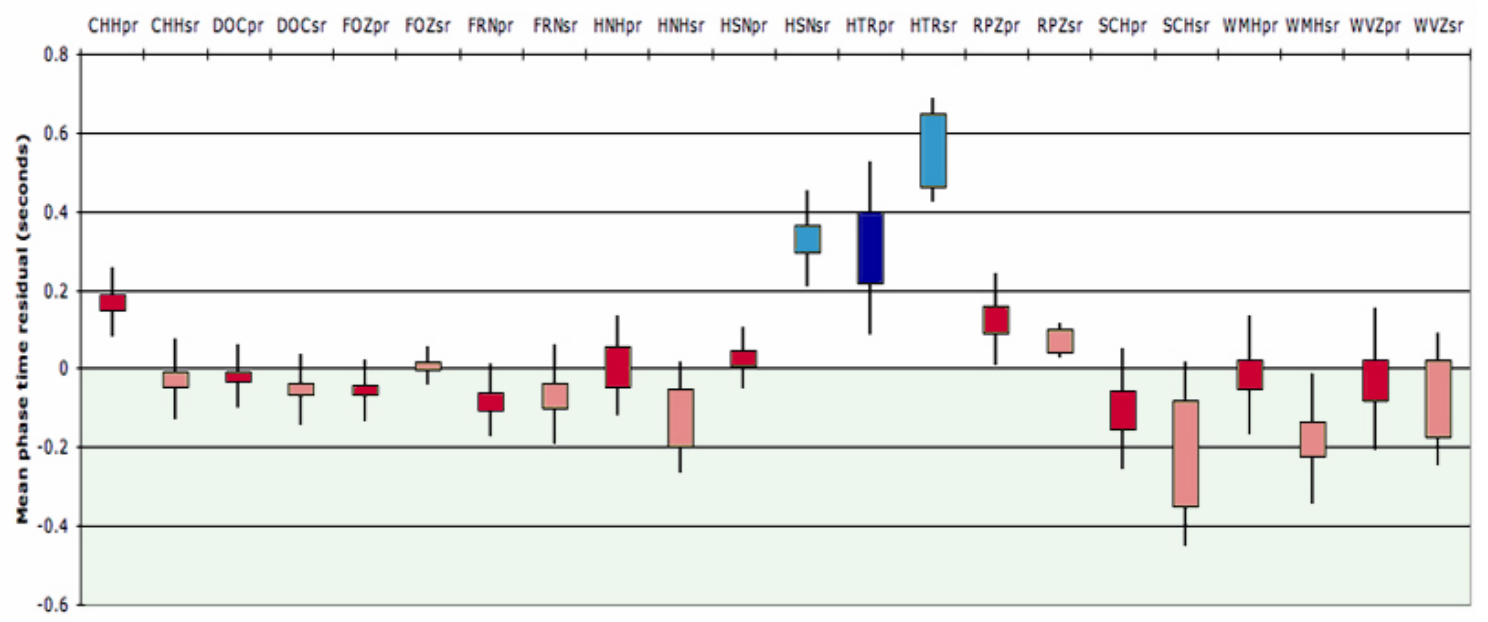

After removing mean of HSN S, HTR P and HTR S residuals from phase picks

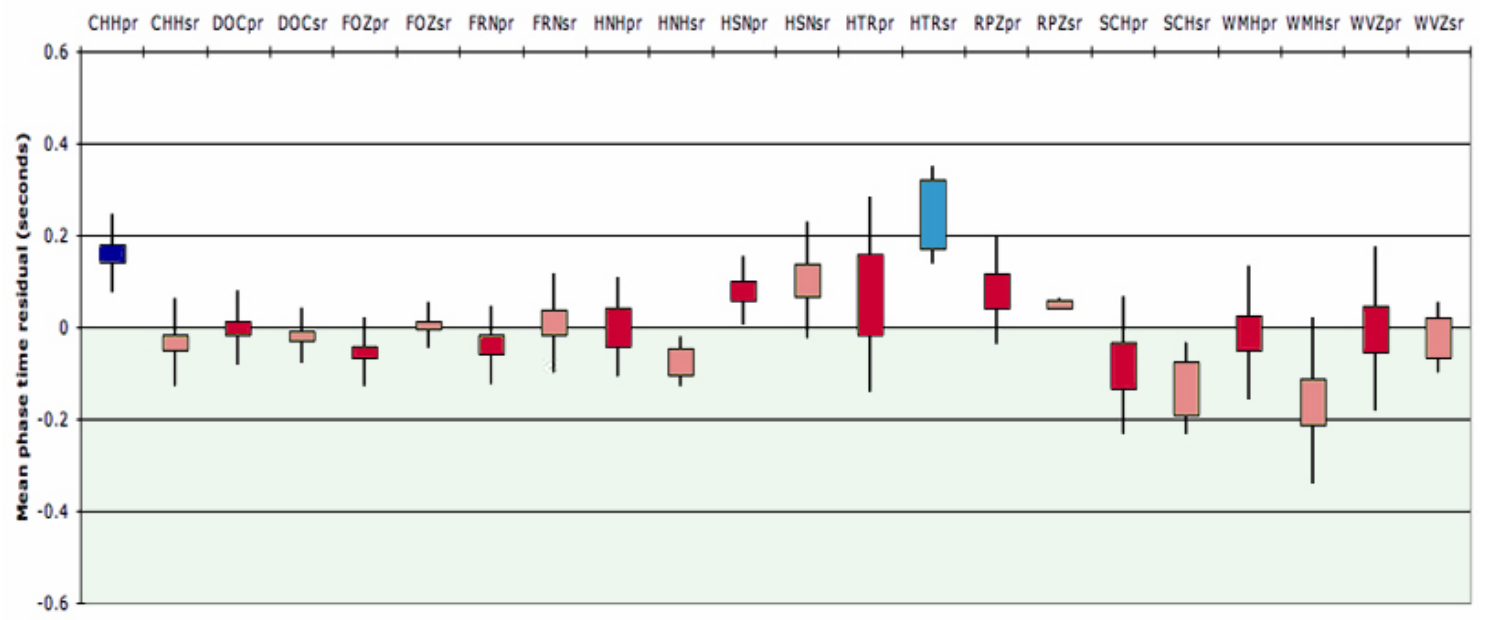

After second pass - removing mean from CHH P and HTR S residuals from phase picks

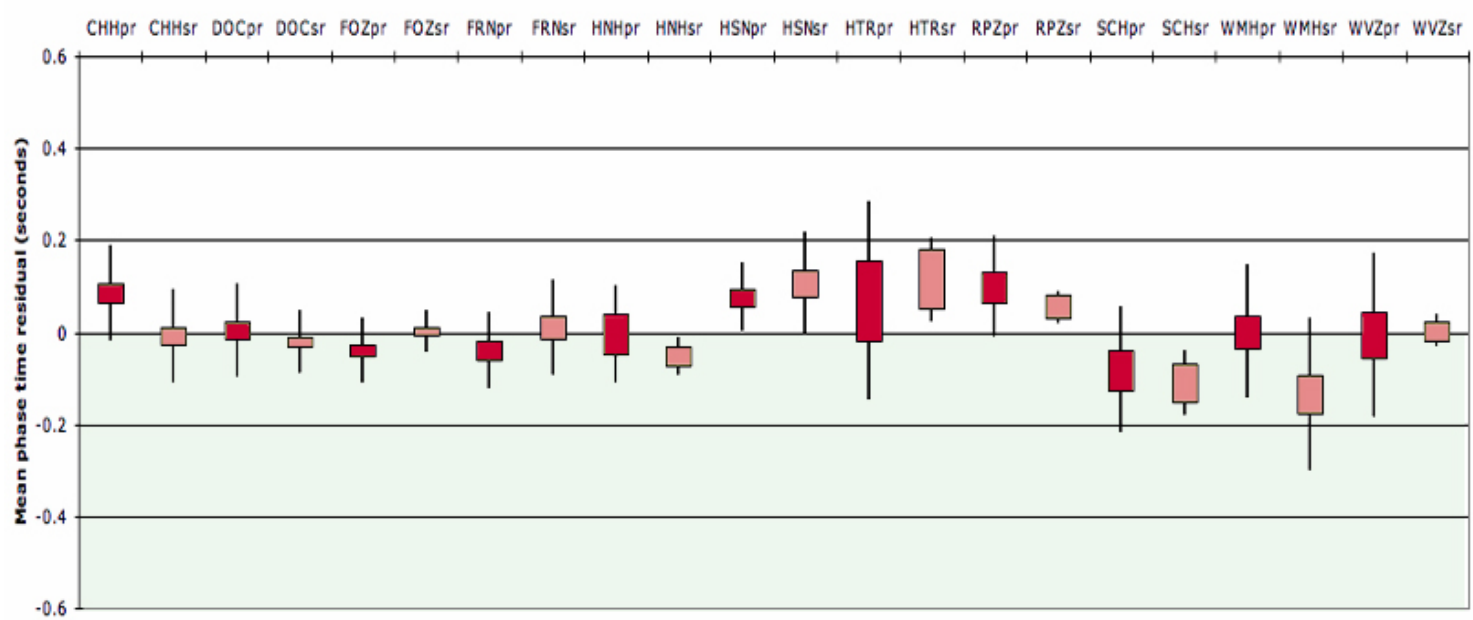

Figure 4.7: Removal of phase residual mean. The mean time residual was removed from arrival times of anomalously positive phases (blue boxes). Due to the interdependent nature of the time residuals, two iterations were applied. Initially, the HSN S phase and HTR P and S phases were identified in top Panel and the mean of these two were removed with locations recalculated and residuals reassessed as seen in middle Panel. A second pass was deemed necessary which removed the remainder mean time residual from HTR S phase and CHH P phase and resulted in the mean residuals shown in the lower Panel. 
Table 4.5: Station time corrections from mean time residual rms analysis

\begin{tabular}{|c|c|c|}
\hline Station & Phase & Correction (seconds) \\
\hline \multirow[t]{2}{*}{$\mathrm{CHH}$} & $\mathrm{P}$ & $\begin{array}{l}-1.00 \mathrm{~s} \text { instrumental } \\
-0.16 \mathrm{~s} \text { suspected } \mathrm{v} \text { model bias }\end{array}$ \\
\hline & $\mathrm{S}$ & $-1.00 \mathrm{~s}$ instrumental \\
\hline HSN & $\mathrm{S}$ & -0.33 $\mathrm{s}$ suspected $\mathrm{v}$ model bias \\
\hline \multirow[t]{2}{*}{ HTR } & $\mathrm{P}$ & - $0.31 \mathrm{~s}$ suspected v model bias \\
\hline & $\mathrm{S}$ & -0.81 s suspected $\mathrm{v}$ model bias \\
\hline
\end{tabular}

errors.

Average changes in locations from iterations of removing station-phase velocity model bias are shown in Table 4.6.

Table 4.6: Average changes in locations from iterations of removing station-phase velocity model bias

\begin{tabular}{lrl}
\hline Longitude & $-0.0004^{\circ}$ & $\sim 30 \mathrm{~m}$ east \\
Latitude & $0.003^{\circ}$ & $\sim 10 \mathrm{~m}$ south \\
Depth & & $390 \mathrm{~m}$ deeper \\
RMS & & from 0.12 down to 0.08 \\
\hline
\end{tabular}

\subsection{Assessment of location error}

\subsubsection{Assessment of phase pick precision}

To determine whether to follow standard practice of down-weighting the S phase picks, an F-test was performed on the five day data set. The F-Test is a measure of similarity of variances, comparing the variances of one set of measurements against another (Dixon and Massey, 1969). The arrival time picks of the $\mathrm{P}$ and $\mathrm{S}$ phases and residuals were considered as independent measurements (not quite true) and the variance ratio was calculated as an indication of precision comparison.

The distribution of time picks and residuals are approximately normal (Fig 4.8). Accordingly, the variances are the approximate of Chi squared, the sum of the square of the residuals divided by the degrees of freedom (df), so their ratio is approximately the Fdistribution. The larger variance is usually the numerator and in this dataset the variance of the S pick residuals were lower. 


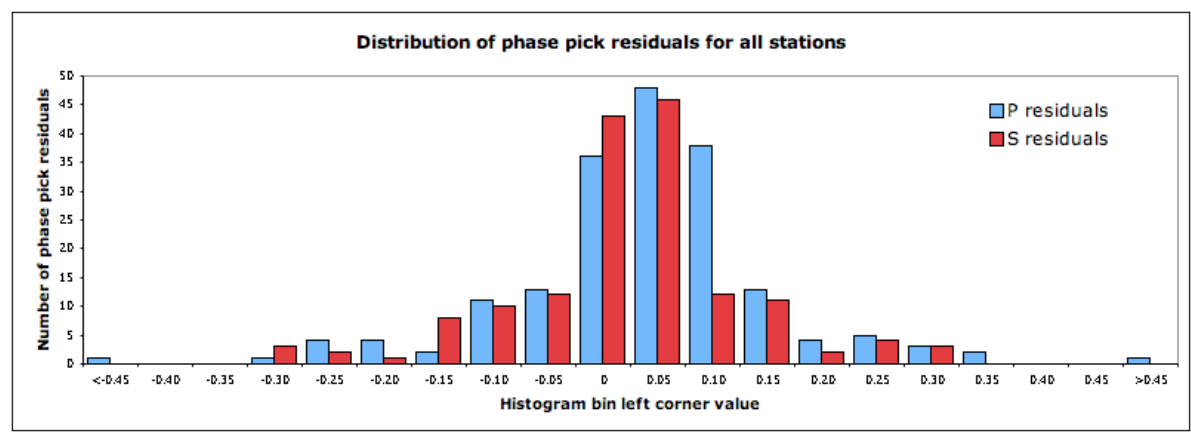

Figure 4.8: Histogram of average $\mathrm{P}$ and $\mathrm{S}$ phase residuals. The distributions are approximately normal justifying the use of an F-test which found the ratio of variances within acceptable limits. Note: in phase picking, it is generally observed that $\mathrm{S}$ phases have a higher pick error than $\mathrm{P}$ arrivals. The contrary example here may be indicative of the generally emergent $\mathrm{P}$ phases being harder to pick. However, this is not ideal when trying to determine first motion in focal mechanism analysis.

\begin{tabular}{ccc}
\hline variance of $\mathrm{P}_{\text {res }}=$ & 0.0135 & $186 \mathrm{df}$ \\
variance of $\mathrm{S}_{\text {res }}=$ & 0.0110 & $157 \mathrm{df}$ \\
Ratio $=1.23$ & & \\
\hline
\end{tabular}

With $186 \mathrm{P}$ phase arrivals (number of picks over 41 events) and $157 \mathrm{~S}$ phase arrivals measured, the ratio ${ }^{2}$ of 1.23 is acceptable to consider the $\mathrm{S}$ picks of a similar precision to the $\mathrm{P}$ picks, meaning there is no need to relatively weight them.

\subsubsection{Wave front time delay analysis}

In an attempt at confirming the time delay for each station, the time delay was compared for events far enough away to approximate planar wavefronts. $\mathrm{P}$ and $\mathrm{S}$ phases were picked for four well recorded regional events from Fiordland. While waves from events to the northeast of the array usually have to pass through the root of the alps, the Fiordland events to the southwest have a path clear of this.

\begin{tabular}{|c|c|c|c|c|c|c|c|c|}
\hline Year & Month & Day & Time & $M_{L}$ & Lat & Lon & Depth & Dist from array \\
\hline 2006 & 09 & 01 & $21: 54$ & 4.0 & -44.56262 & 167.97879 & 88.5832 & $240 \mathrm{~km}$ \\
2006 & 11 & 15 & $11: 27$ & 4.3 & -45.0953 & 167.32782 & 84.1734 & $315 \mathrm{~km}$ \\
2006 & 12 & 07 & $10: 31$ & 4.4 & -44.37453 & 168.20839 & 6.9509 & $210 \mathrm{~km}$ \\
2006 & 11 & 27 & $15: 48$ & 4.2 & -45.12504 & 166.86516 & 12 & $400 \mathrm{~km}$ \\
\hline
\end{tabular}

\footnotetext{
${ }^{2} \mathrm{~F}$ calculated using MSExcel function FINV: for $\alpha=0.05, \mathrm{~F}(186-1,157-1)=1.29$ compared to the measured $\mathrm{F}$ statistic of 1.23 for these data
} 
Assuming a distant event, the seismic wave front is approximately planar with slowness $\hat{s}=\mathbf{s} \cdot \hat{n}$. The time of arrival $t_{i}$ at station $i$ is given by:

$$
\begin{aligned}
\mathbf{t}_{\mathbf{i}}(x) & =\mathbf{t}_{\mathbf{o}}\left(x_{o}\right)+\mathbf{s}_{\mathbf{1}}\left(x_{i}-x_{o}\right) \\
\mathbf{t}_{\mathbf{i}}(y) & =\mathbf{t}_{\mathbf{o}}\left(y_{o}\right)+\mathbf{s}_{\mathbf{2}}\left(y_{i}-y_{o}\right)
\end{aligned}
$$

where $t_{0}$ is the time at the reference point $\left(x_{0}, y_{0}\right)$ and $\left(s_{1}, s_{2}\right)$ are the slowness components.

Station and event coordinates were converted to NZMG and then referenced from the centre of the array $(\hat{x}, \hat{y})$. So $x_{i}$ is the easting of the $i_{\text {th }}$ station from the array centre; similarly $y_{i}$ is the northing.

Put

$$
\begin{aligned}
& x_{o}=\bar{x} \\
& x_{i}^{\prime}=x_{i}-x_{o} \\
& y_{o}=\bar{y} \\
& y_{i}^{\prime}=y_{i}-y_{o}
\end{aligned}
$$

Then

$$
\tilde{t_{i}}=\left[\begin{array}{ccc}
1 & x_{1}^{\prime} & y_{1}^{\prime} \\
1 & x_{2}^{\prime} & y_{2}^{\prime} \\
\vdots & \vdots & \vdots \\
1 & x_{N}^{\prime} & y_{N}^{\prime}
\end{array}\right]\left[\begin{array}{l}
t_{o} \\
s_{1} \\
s_{2}
\end{array}\right]
$$

Solve by least squares:

$$
\begin{gathered}
\left(\begin{array}{c}
1_{i} \\
x_{i}^{\prime} \\
y_{i}^{\prime}
\end{array}\right) \tilde{t}_{i}=\left(\begin{array}{c}
1_{i} \\
x_{i}^{\prime} \\
y_{i}^{\prime}
\end{array}\right)\left(\begin{array}{lll}
1_{i} & x_{i}^{\prime} & y_{i}^{\prime}
\end{array}\right)\left(\begin{array}{l}
t_{o} \\
s_{1} \\
s_{2}
\end{array}\right) \\
{\left[\begin{array}{c}
\sum t_{i} \\
\sum x_{i}^{\prime} t_{i} \\
\sum y_{i}^{\prime} t_{i}
\end{array}\right]=\left[\begin{array}{ccc}
N & 0 & 0 \\
0 & \sum x_{i}^{\prime 2} & \sum x_{i}^{\prime} y_{i} \\
0 & \sum x_{i}^{\prime} y_{i}^{\prime} & \sum y_{i}^{\prime 2}
\end{array}\right]\left[\begin{array}{l}
t_{o} \\
s_{1} \\
s_{2}
\end{array}\right]}
\end{gathered}
$$

so

$$
\frac{\sum t_{i}}{N}=t_{o}
$$


Solving

$$
\left(\begin{array}{c}
\sum x_{i}^{\prime} t_{i} \\
\sum y_{i}^{\prime} t_{i}
\end{array}\right)=\left(\begin{array}{cc}
\sum x_{i}^{\prime 2} & \sum x_{i}^{\prime} y_{i} \\
\sum x_{i}^{\prime} y_{i}^{\prime} & \sum y_{i}^{\prime 2}
\end{array}\right)\left(\begin{array}{c}
t_{o} \\
s_{1} \\
s_{2}
\end{array}\right)
$$

gives

$$
\begin{gathered}
s_{1}=\frac{\sum x_{i}^{\prime} t_{i} \sum y_{i}^{\prime 2}-\sum y_{i}^{\prime} t_{i} \sum y_{i}^{\prime}}{\sum x_{i}^{\prime 2} * \sum y_{i}^{\prime 2}-\sum\left(x_{i}^{\prime} y_{i}^{\prime}\right)^{2}} \\
s_{2}=\frac{-\sum x_{i}^{\prime} t_{i} \sum x_{i} y_{i}^{\prime}-\sum y_{i}^{\prime} t_{i} \sum x_{i}^{\prime}}{\sum x_{i}^{\prime 2} * \sum y_{i}^{\prime 2}-\sum\left(x_{i}^{\prime} y_{i}^{\prime}\right)^{2}}
\end{gathered}
$$

and

$$
r e s_{i}=t_{i}-\bar{t}-s_{1} x_{i}+s_{2} y_{i}
$$

The bad picks of two events were removed: HNH and CHH for event 2006/12/07 and FRN for the 2006/09/01 event. This reduced the standard deviation of remaining picks to 0.44. The average slowness was calculated by $\sqrt{s_{1}^{2}+s_{2}^{2}}$ and the complementary incident angle $i_{c}$ was calculated at: $\arccos \left(s_{\text {ave }}\right)=\arccos \frac{8}{v_{\text {ave }}}$. See Table 4.7.

Table 4.7: Wave Front Time Delay Analysis

\begin{tabular}{|c|c|c|c|c|c|c|c|}
\hline Year & Julian Day & Month & Day & Time & $x_{\text {ave }}$ from array & $v_{\text {ave }} \mathrm{km} / \mathrm{s}$ & $i_{c}$ \\
\hline 2006 & 244 & 09 & 01 & $21: 54$ & $240 \mathrm{~km}$ & 9.2 & $29 \mathrm{deg}$ \\
2006 & 319 & 11 & 15 & $11: 27$ & $315 \mathrm{~km}$ & 8.5 & $20 \mathrm{deg}$ \\
2006 & 331 & 11 & 27 & $15: 48$ & $400 \mathrm{~km}$ & 4.8 & undefined \\
2006 & 341 & 12 & 07 & $10: 31$ & $210 \mathrm{~km}$ & 6.4 & undefined \\
\hline
\end{tabular}

While the method is robust, timing trends were not conclusive. A trial without station RPZ was made on the observation that it widened the array substantially and the linear assumption might be invalidated; but results were very similar to calculations which included the station.

Removing 1 second from the $\mathrm{CHH}$ station (as the earlier timing analysis suggested CHH DAS was consistently out by 1 second) made matters worse. Standard deviation of the residuals was slightly lower if the 06-341 data were ignored.

Although the results are interesting, no time delays from this analysis were used in the final model and they did not contribute to the understanding of the velocity model 1D bias. 


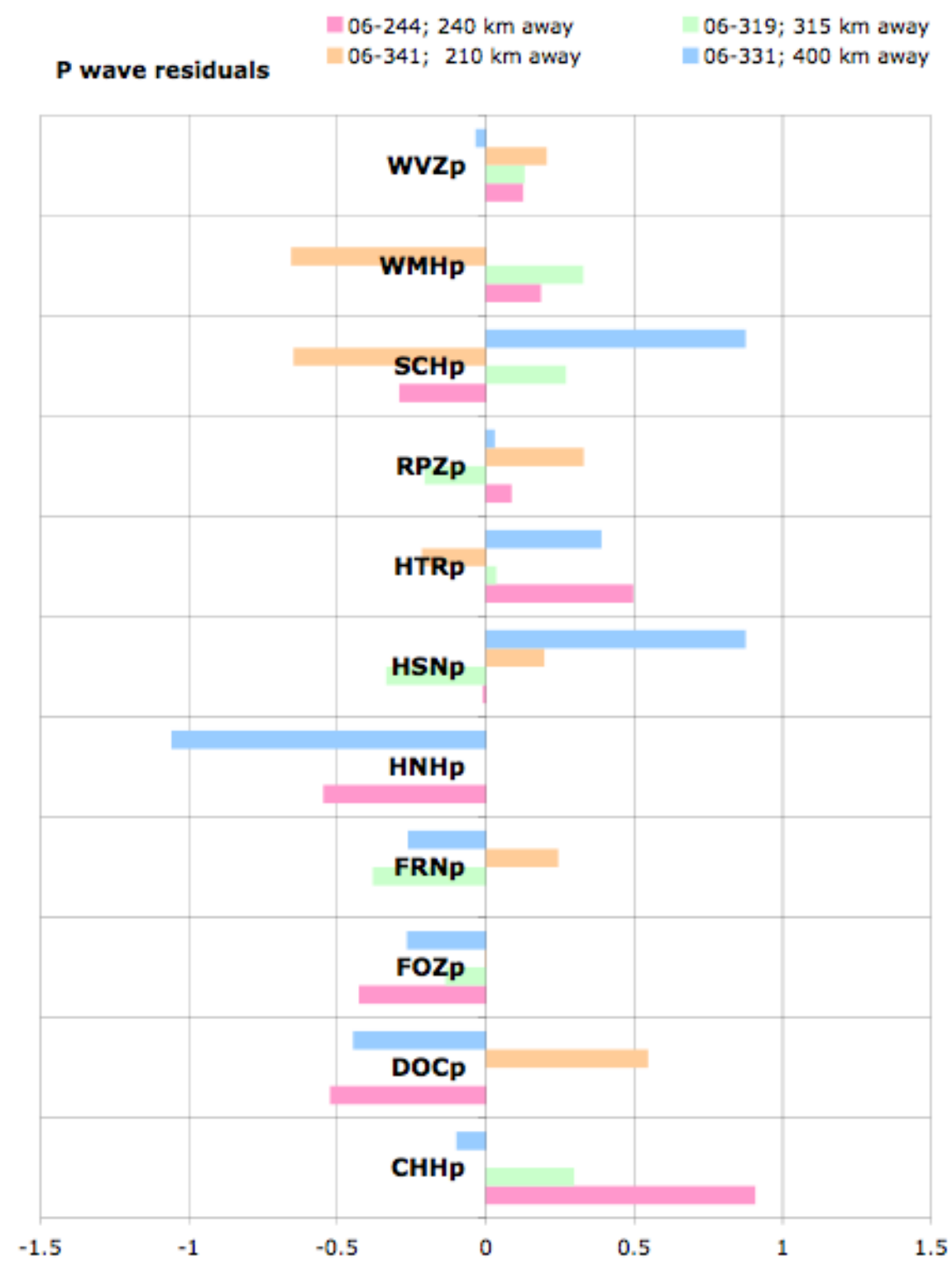

Figure 4.9: Residual times from wave front time analysis: Calculating the residual time from the measured absolute times, the residuals were plotted for each station phase.

\subsection{VELEST velocity model comparison}

The 1D velocity program VELEST (Kissling, E. and Kradolfer, U. and Maurer H., 1995) was used both on the clusters and on the entire catalogue to compare the resulting velocity model with the models initially used. Phases from stations HTR, HSN and CHH were given half weights representing Bayesian uncertainty of their DAS timing or local geology effects. Also, phases that had large time residuals or were affecting the depth, latitude or longitude error or RMS time residual were either removed or given half weights. Events that had an RMS of 0.3 or were outside the geographical limits of $[169.6,-42.8]-[171.2,-44.0]$ 
were excluded. Out of 411 events in the catalogue, 270 events were used in the VELEST inversion as seen in Fig 4.10. A total of 2404 phases (9\% weighted to 0.5, the remainder with full weighting) were used.

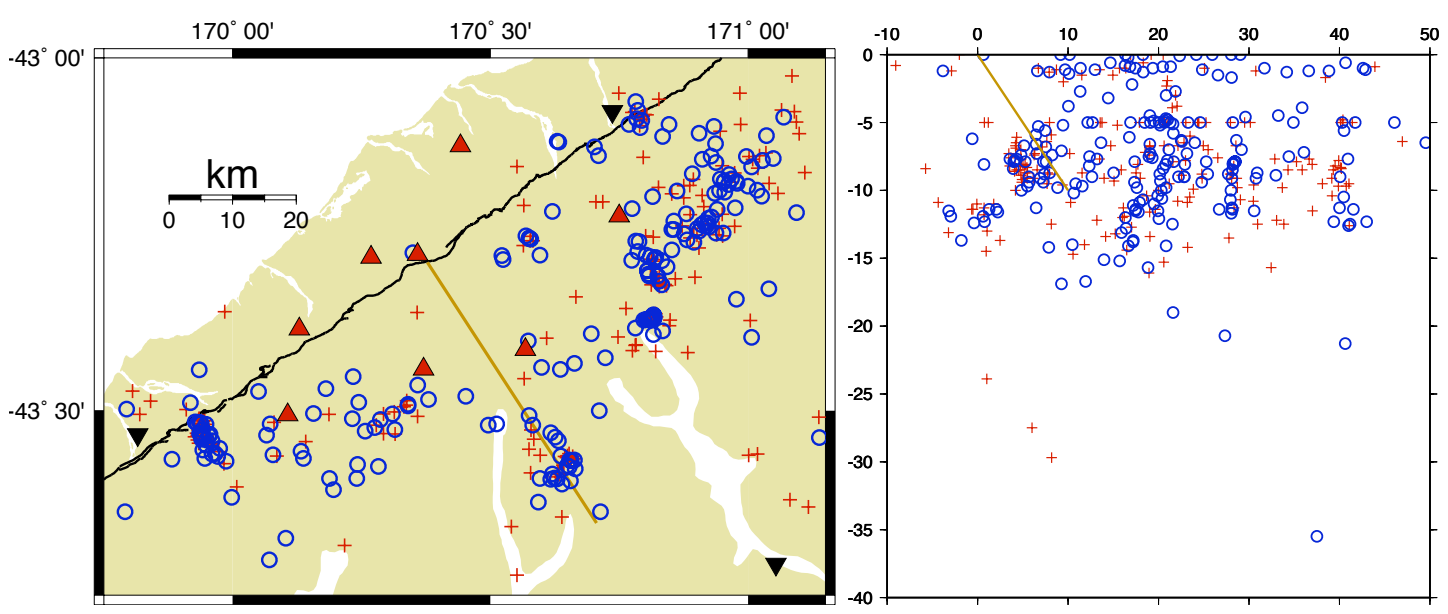

Figure 4.10: Hypocenters used in the VELEST inversions. Events were selected from a geographic area of [169.6 -44] to [171.2 -42.8] and an rms limit of under $0.3 \mathrm{~s}$. The events used are displayed as blue circles, while those discarded are red crosses. The location of the Alpine Fault is plotted in brown as dipping at $45^{\circ}$ although the actual dip is unknown.

Different input velocity models were trialled including the three velocity models s10, c and a described in 4.3. As c was a visual esimate of a tomographic slice, a range of velocity values was also examined. This maximum, minimum and mean approach was suggested in the VELEST user guide (Kissling, 1995) to get a feel for the range of solutions.

VELEST does not allow the depths of layer boundaries to vary during the inversion. To test the velocity structure in a less restrained way and see if the velocity layer depths are resolvable, a model of many $1 \mathrm{~km}$ layers was created with velocities estimated from s10. The output was simplified into a new input model by the amalgamation of similar velocity bands. This process was repeated until a stable solution was reached.

The dataset was also divided into half to see if any discrepancies were observable. The difference could have been attributed to an improvement in picking ability by the 2 nd half of the survey. However, this was discounted by randomly repicking a sample of events and finding little improvement in location. The likely cause of the apparent difference is the dominance of the FOZ cluster in the 1st half and the $\mathrm{HNH}$ cluster in the 2nd half.

Analysis of the average RMS per trial for the final locations revealed that the modified s10 trial produced RMS averages slightly less in the dataset using the final phase weights than the unadjusted set. The $1 \mathrm{~km}$ layered model of the $2 \mathrm{nd}$ half dataset produced the 
best average RMS overall (average RMS: 0.09; stdev: 0.04) while the best whole dataset model was from the c model with RMS average of 0.10 and stdev 0.06 . However there was little difference in RMS for each of the three velocity models used. As I preferred to use a velocity model based on a complete dataset, the depth range for the Fox and Hunter clusters were compared on the assumption that a well located cluster would have a smaller standard deviation of depth. For the VELEST velocity models from the 3 velocity models, the results are given in Table 4.8 .

Table 4.8: VELEST model comparison of depth ranges for two swarms

\begin{tabular}{|l|c|c|c|}
\hline & Trial 1 & Trial 1a & Trial c \\
\hline \multicolumn{4}{|c|}{ Fox cluster } \\
Average depth & 5.48 & 5.47 & 5.60 \\
Standard deviation & 3.27 & 3.26 & 3.20 \\
\hline \multicolumn{4}{|c|}{ Hunter cluster } \\
Average depth & 7.42 & 7.42 & 7.74 \\
Standard deviation & 2.74 & 2.74 & 2.58 \\
\hline
\end{tabular}

This suggests that the inversion of the $\mathrm{c}$ model resolved depths marginally better. The best output model with the layer above datum removed is most similar to the s10 (modified Smith et al. model) and within the ranges of c (Scherwath model).

Table 4.9: VELEST best velocity model chosen as final velocity model

\begin{tabular}{|c|c|}
\hline$V_{p}(\mathrm{~km} / \mathrm{s})$ & Top layer depth $(\mathrm{km})$ \\
\hline 3.85 & 0 \\
5.67 & 1 \\
5.79 & 8 \\
6.28 & 18 \\
7.35 & 35 \\
8 & 40 \\
\hline
\end{tabular}

The difference in statistics between the two best models $(1 \mathrm{~km}$ layer cake with the 2 nd half and the full dataset based on the c model); see Table 4.10 when used in the SEISAN relocation was very little in location but different in the error statistics, especially in the RMS.

The comparison of VELEST with other velocity models agrees with earlier analysis of the $\mathrm{c}$ and modified a (Eberhart Phillips) velocity models on the early October data.

To test the layer depths of the $1 \mathrm{~km}$ layered thickness trial model, the depths of the 
Table 4.10: Absolute and relative errors in location for the two best VELEST velocity models. latitude, longitude, depth of location; azimuthal gap of stations used; RMS in travel-time residual, horizontal error, depth error and error vector length (i.e. $\sqrt{\sum d x^{2}+d y^{2}+d z^{2}}$.

\begin{tabular}{|l|c|c|c|c|c|c|c|c|}
\hline & Lat & Lon & Depth & Gap & RMS & Erh & Erz & ErrVector \\
\hline \multicolumn{8}{|c|}{$1 \mathrm{~km}$ layered } \\
\hline Ave & -43.4 & 170.5 & 9 & 200 & 0.8 & 100 & 100 & 200 \\
Std & 0.3 & 0.5 & 8 & 50 & 0.4 & 300 & 300 & 400 \\
\hline \multicolumn{8}{|c|}{ Based on c } \\
\hline Ave & -43.4 & 170.6 & 7 & 220 & 0.4 & 70 & 200 & 200 \\
Std & 0.3 & 0.5 & 9 & 60 & 0.4 & 200 & 300 & 400 \\
\hline \multicolumn{8}{|c|}{ Difference } \\
\hline Ave & 0.0015 & -0.0262 & 1.59 & -20.63 & 0.39 & 51.37 & -8.15 & 36.68 \\
Std & 0.0707 & 0.0862 & 6.64 & 38.75 & 0.27 & 258.84 & 304.22 & 451.36 \\
\hline
\end{tabular}

layers were varied cumulatively by $1 \mathrm{~km}$ (i.e. first layer by $1 \mathrm{~km}$, second by $2 \mathrm{~km}$, third by $3 \mathrm{~km}$ etc). Location differences were within error limits (as seen in Table 4.11) and so the velocity model could not be improved in this way. Thus the inverted c model remained the best velocity model.

Table 4.11: Location differences observed from cumulative variation in depth by $\pm 1 \mathrm{~km}$

\begin{tabular}{|c|c|c|c|}
\hline & Original & Minus $1 \mathrm{~km}$ & Plus $1 \mathrm{~km}$ \\
\hline \multicolumn{4}{|c|}{ Depth } \\
\hline AVE & 8.49 & 8.13 & 8.47 \\
\hline STD & 7.94 & 7.96 & 7.88 \\
\hline \multicolumn{4}{|c|}{ RMS } \\
\hline AVE & 0.09 & 0.10 & 0.10 \\
\hline STD & 0.04 & 0.04 & 0.04 \\
\hline \multicolumn{4}{|c|}{$\operatorname{del} Z$} \\
\hline AVE & & 1.4 & 1.45 \\
\hline STD & & 0.4 & 0.03 \\
\hline \multicolumn{4}{|c|}{ del RMS } \\
\hline AVE & & 0.039 & 0.034 \\
\hline STD & & -0.007 & -0.007 \\
\hline
\end{tabular}

The VELEST inversion also created station correction files. Station corrections were similar across the two cluster datasets FOZ and HNH. These time corrections were higher that those resulting from the larger datasets. This is possibly because of the smaller dataset (56 and 59 events respectively).

Station corrections from the best VELEST velocity model (ref Table 4.12) were largely 
small for $\mathrm{P}$ phase times. The $\mathrm{S}$ phase time corrections were mostly larger despite the wadati analysis confirming the VPS ratio of 1.68 is appropriate. The phase correction for station RPZ was high and contrary to the mean removal analysis (ref subsection 4.5.3) based on a subset of events.

Table 4.12: Station corrections output from best VELEST velocity model relative to SCH $\mathrm{P}$ phase. The station corrections of Table 4.5 were already applied to the input data of VELEST. These additional corrections were applied with the best velocity model.

\begin{tabular}{|c|c|c|c|c|}
\hline Station & VELEST $P_{\text {cor }}$ & VELEST $S_{\text {cor }}$ & Total $P_{\text {cor }}$ & Total $S_{\text {cor }}$ \\
\hline CHH & -0.26 & -0.61 & -1.42 & -1.61 \\
HTR & 0.44 & 0.40 & -015 & -0.41 \\
HSN & 0.16 & 0.02 & 0.16 & -0.31 \\
HNH & -0.02 & -0.26 & -0.02 & -0.26 \\
WMH & -0.08 & -0.35 & -0.08 & -0.35 \\
WVZ & -0.02 & -0.31 & -0.02 & -0.31 \\
RPZ & 0.21 & 0.05 & 0.21 & 0.05 \\
FOZ & 0.01 & -0.08 & 0.01 & -0.08 \\
MLR & -0.02 & -0.18 & -0.02 & -0.18 \\
FRN & 0.01 & -0.18 & 0.01 & -0.18 \\
SCH & 0.00 & -0.23 & 0.00 & -0.23 \\
\hline
\end{tabular}

A comparison of locations using the best velocity model and all, larger and no station corrections (ref Figs 4.11 and 4.12) show the degree of reliance on the station corrections. The RMS travel-time residual, lateral and depth errors were improved significantly and the number of hypocenter parameters not definable were reduced as more station corrections were applied. 


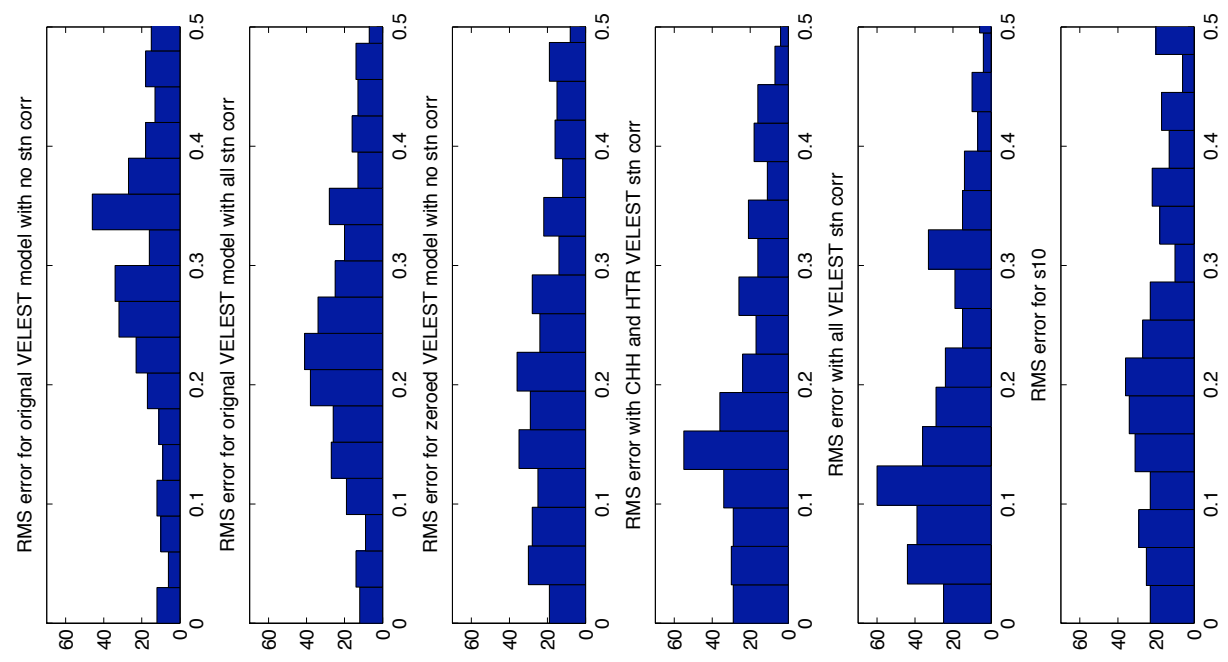

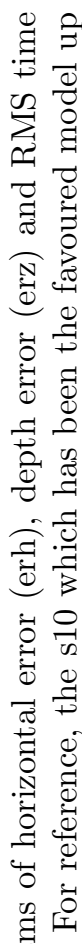

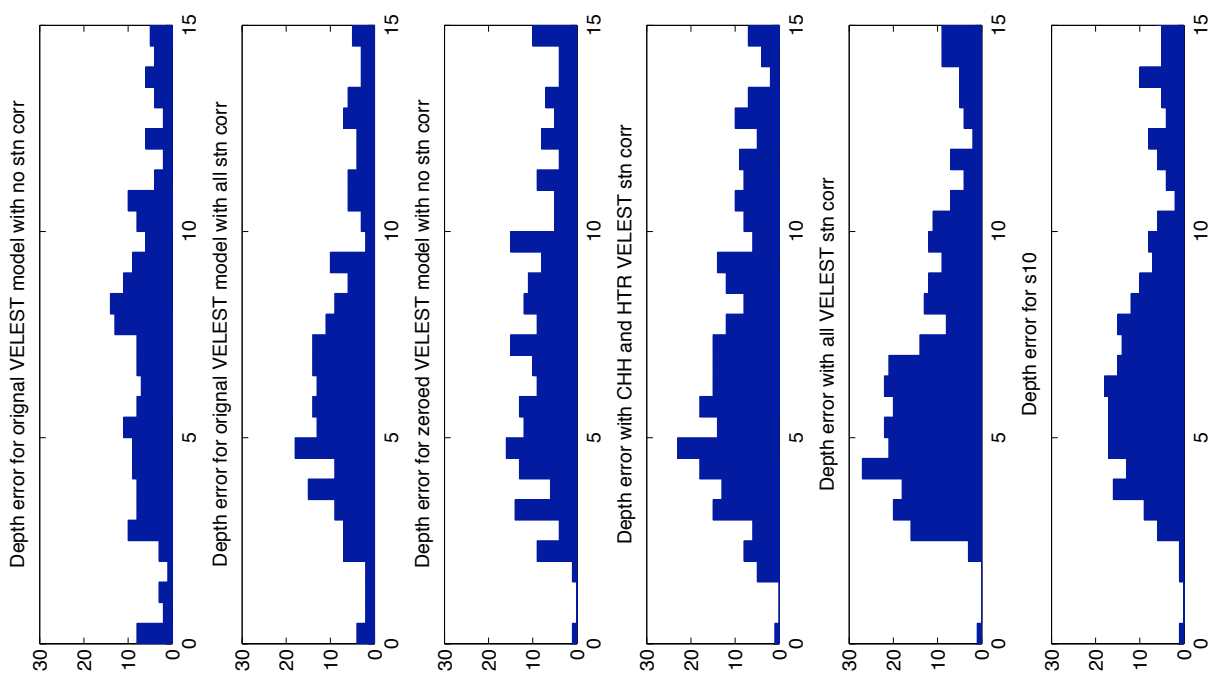

50

表

$\stackrel{9}{\dagger}$

.

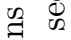

寻

8.9

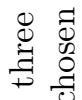

ज :

ن

웜

듕

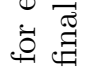
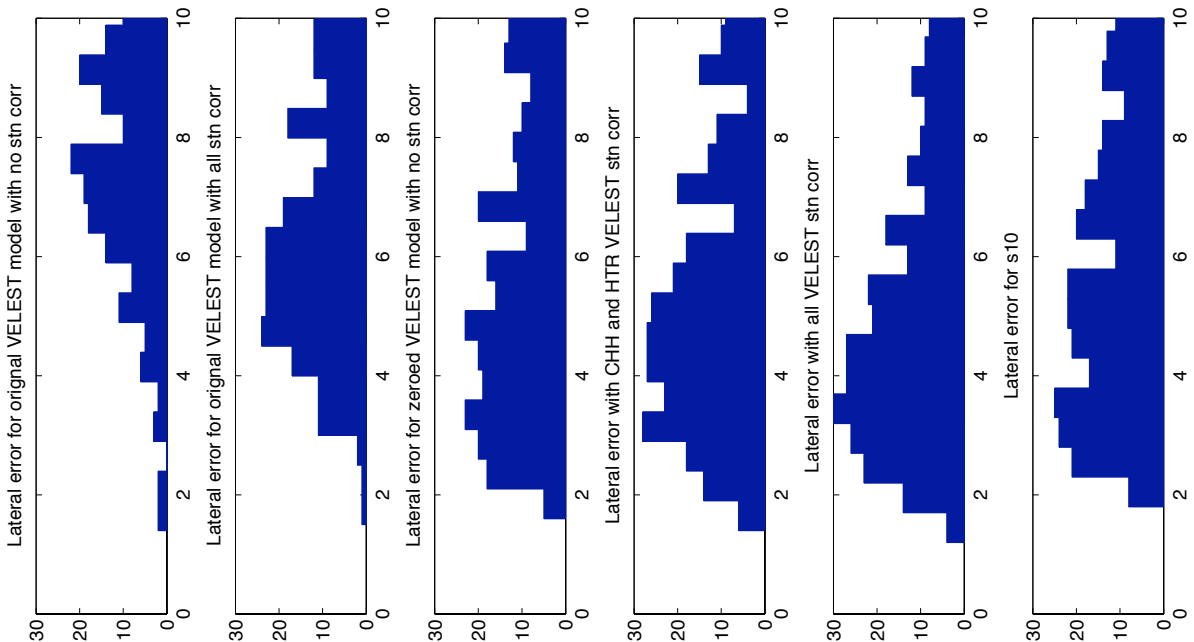

总

莺造

旁

氙兽

0.

过

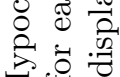

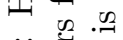

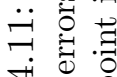

을

5 
The VELEST depths of some events around $20 \mathrm{~km}$ SE of the Alpine Fault (refer to Table 4.13 and Fig 4.13) were resolved to $<0.2 \mathrm{~km}$. The events appeared to form a horizontal layer. The HYPOCENTER depths of these anomalous events were generally not resolved and stated as $5 \mathrm{~km}$ (the model starting depth). Looking at the waveforms, these were generally small events. At first it was thought they may be earth movement due to ice falls.

After the VELEST velocity model had its station corrections applied, however, over half the suspected ice falls resolved to depths $>2 \mathrm{~km}$ suggesting that most were an artifact of the HYPOCENTER algorithm not being able to resolve location depths due to a poor velocity model.

Table 4.13: Shallow depth reliance on station corrections: many of the shallow locations suspected as icefall events resolved to deeper locations once VELEST station corrections were applied. * NB uncertainties of 999 are an algorithm stand-in for indeterminate locations.

\begin{tabular}{|c|c|c|c|c|}
\hline Date & Time & $\mathrm{z}(\mathrm{km})$ without corr & $\mathrm{z}(\mathrm{km})$ with corr & depth $\sigma(\mathrm{km})$ \\
\hline $06-09-06$ & $20: 57$ & 0.12 & 4.5 & 19 \\
$06-09-15$ & $12: 03$ & 4.42 & 4.9 & 6 \\
$06-10-06$ & $11: 19$ & 0.03 & 1 & 14.5 \\
$06-10-07$ & $01: 15$ & 0.03 & 0 & 5.1 \\
$06-10-17$ & $19: 06$ & 1.99 & 3.9 & 3.7 \\
$06-10-31$ & $09: 13$ & 1.85 & 1.1 & $999^{*}$ \\
$06-11-04$ & $13: 36$ & 0.09 & 0.9 & 172.1 \\
$06-11-11$ & $13: 40$ & 1.44 & 3 & 4.4 \\
$06-11-18$ & $14: 55$ & 0.13 & 5 & 14.1 \\
$06-12-01$ & $02: 54$ & 4.42 & 5 & 6.7 \\
$06-12-19$ & $05: 46$ & 0.04 & 1.3 & 5.8 \\
$06-12-19$ & $10: 42$ & 4.05 & 4.7 & 9.7 \\
$06-12-24$ & $00: 58$ & 0.2 & 0 & 16.8 \\
\hline
\end{tabular}

\subsection{Depth resolution}

The hypocenter depths are highly reliant on the velocity model used and station corrections applied. To justify the finalised hypocenters in the CAlF catalogue, the following statistical analyses were made.

Well constrained events were picked (lat, lon and depth error all $<5 \mathrm{~km}$ ) giving 41 events from a database of 631 local events. These events were relocated with the 2 nd closest phases removed to see how much the hypocenter moved. After phase removal, two 

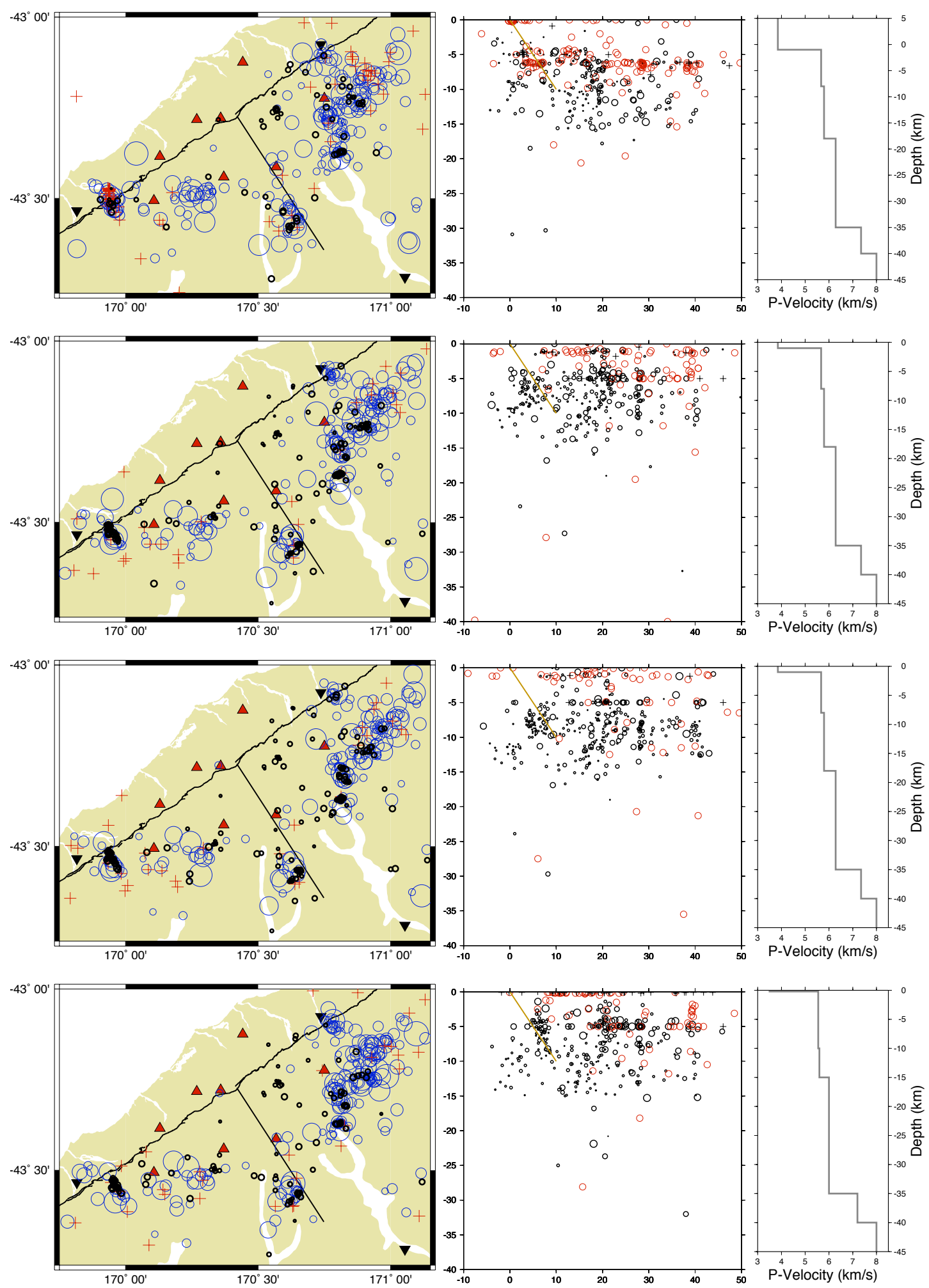

Figure 4.12: Quality of epicenters: map, cross-section and velocity model for each model. From top to bottom: best VELEST, best VELEST with 1st layer zeroed and CHH and HTR VELEST corrections, best VELEST with 1st layer zeroed and all VELEST corrections, bottom: s10 velocity model. Radius of bubble indicates lateral error. Thick circles are erh $<5 \mathrm{~km}$; other circles erh $<20$ $\mathrm{km}$; in red: erh between 20 and $900 \mathrm{~km}$; crosses erh>900 km and thus locations were "indeterminate". Note the artificial lineation of events at $5 \mathrm{~km}$ persists when the layer boundary changes from $5 \mathrm{~km}$ (in bottom panel) to $8 \mathrm{~km}$ (in other panels) indicating the artifact is not due to velocity model. 


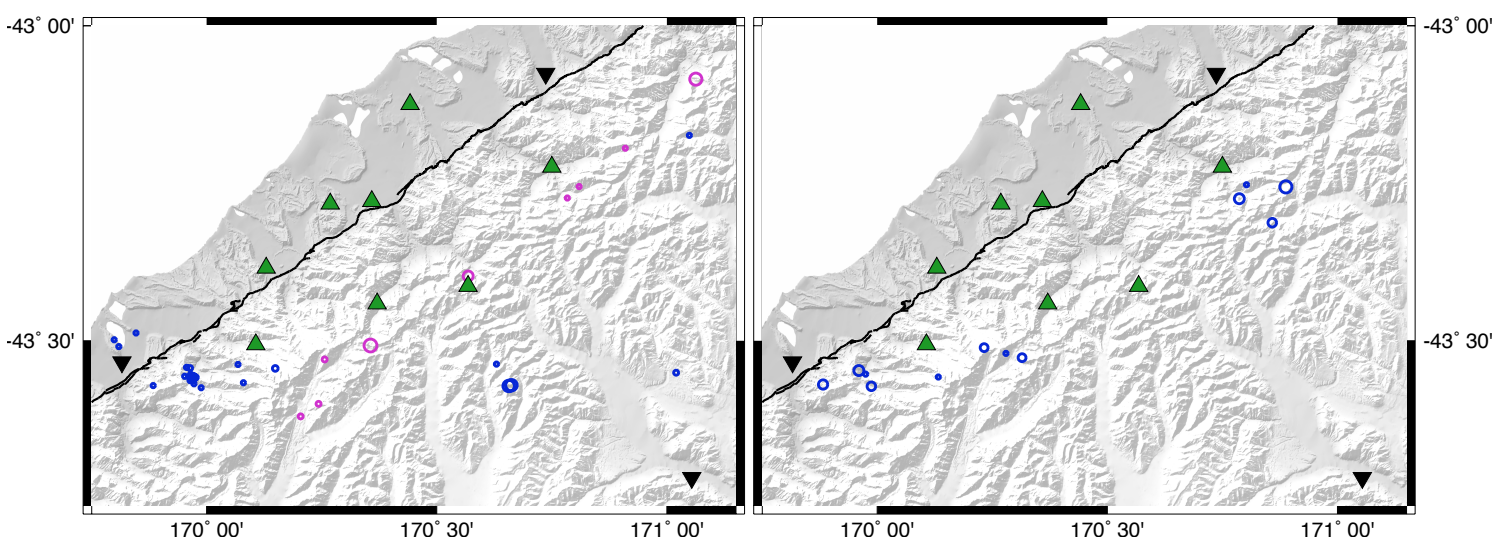

Figure 4.13: Suspected ice fall events. Circle radius indicates depth. Left Panel: locations derived from best VELEST model without station corrections. The magenta circles are events that were under $2 \mathrm{~km}$ depth and suspected ice falls. The blue circles are other events under $2 \mathrm{~km}$ depth. Right Panel: locations derived from VELEST model with station corrections. The blue circles are events under $2 \mathrm{~km}$ depth with depth error less than $10 \mathrm{~km}$. Note that over half of the suspected ice falls in the left Panel resolved to depths $>2 \mathrm{~km}$ once the station corrections were applied.

events could not be resolved as the locations moved $>20 \mathrm{~km}$. The average vector length (i.e. $\sqrt{\sum d x^{2}+d y^{2}+d z^{2}}$ ) of the rest was $2.5 \pm \sigma 2.8 \mathrm{~km}$.

The FOZ cluster events generally shallowed; the others generally deepened with the second closest phases removed.

In conclusion, the depth resolution appears to be stable with changes in data causing changes in hypocenters within error limits.

A summary of location parameters and resulting locations used in the finalized catalogue can be found in Chapter 6 after the following chapter on determining magnitudes. 


\section{Chapter 5}

\section{Magnitude Determination}

\subsection{Magnitude estimates}

Event magnitudes were calculated from amplitude measurements from pseudo-WoodAnderson seismograms; a tool within the SEISAN environment. Although the initial magnitude coefficients used were the same as GeoNet, the output magnitudes were very different from the GeoNet magnitudes.

The SEISAN algorithm only allowed for a universal "station correction" to be applied over the entire array. While this may be sufficient for arrays of similar seismographs (as most of the coefficient is the log of the instrument gain), it was not appropriate for the mix of CAlF short-period and broadband seismographs with GeoNet stations. The resultant magnitudes were highly dependent on the mix of seismographs from which amplitude measurements were taken. Also, the attenuation parameter was not within the expected range.

Rather than restricting the magnitude measurements to a few consistent stations, inversion methods for station corrections were investigated.

\subsection{Magnitude formulae}

The GeoNet magnitudes for events closer than $100 \mathrm{~km}$ are based on the magnitude equation of Robinson (1986) that was estimated from Wellington local earthquake data.

$$
A_{\max }=G * A_{o} D^{-n} * e^{-\alpha * D}
$$


where $G$ is the instrument gain, $D$ is the distance between station and hypocenter, $n$ is the geometric spreading factor and $\alpha$ is the inelastic attenuation coefficient. The spreading factor $n$ was 'insignificantly different from $1^{\text {' }}$ and once $n$ was set to 1 , the best fit of $\alpha$ was $0.0067 \mathrm{~km}^{-1}$ (Robinson, 1986).

So local magnitude

$$
M=\log _{10} A+n * \log _{10} D+\log _{10} e * \alpha * D+G
$$

or

$$
M=\log _{10} A+1.0 * \log _{10} D+0.0029 * D+G
$$

The default value $G=2.64$ was used to calculate initial magnitude estimates in SEISAN. As calculated magnitudes did not match GeoNet magnitudes and the differences were not just dependent on station correction terms G, two inversions were trialled. GeoNet catalogue magnitudes were used as calibrations.

A least-squares inversion can be described by the linear system

$$
Y=X m
$$

If the set of equations is overdetermined, the model $m$, may be solved for by least squares:

$$
m=\left(X^{T} X\right)^{-1} X^{T} * Y
$$

To apply this result, the observations $\mathrm{Y}$ must be independent and have common variances. If the variances are different, they can be weighted to give the resulting variables common variance.

The equations may then be solved in Matlab using LU decomposition:

$$
m=U \backslash\left(L \backslash X^{\prime} * Y\right)
$$

where the backslash is the Matlab function for left division which is a method of approximate inversion and $\mathrm{U}$ and $\mathrm{L}$ are the upper and lower triangular matrices of $X^{T} X$.

\section{Model 1}


We assume magnitude is related to $\log$ of $\mathrm{A}$ and $\log$ of $\mathrm{D}$ to some exponent + some constant related to station/seismograph/phase (power law) similar to the $>100 \mathrm{~km}$ equation GeoNet uses ${ }^{1}$

$$
M_{L}=\log _{10} A+\log _{10} D^{c}+K
$$

so from matrix equation above:

$$
\begin{aligned}
Y & =\left[\log _{10} \text { (amplitudes) }(5491 \text { equations); GeoNet magnitudes (88 equations) }]\right. \\
X & =\left[\text { event multipliers; } \log _{10}(\text { station-hypocenter distance); station-phase multipliers }]\right. \\
m & =[411 \text { magnitudes, c parameter, } 31 \text { station-phase corrections }]
\end{aligned}
$$

\section{Model 2 based on the Robinson equation}

From equation 5.3 we have:

$$
M_{L}=\log _{10} A+\log _{10} D+\alpha * \log _{10} e * D+G
$$

so from matrix equation above:

$Y=\left[\log _{10}(\right.$ amplitudes $)+\log _{10}($ station-hypocenter distance) (5491), GeoNet magnitudes (88) $]$ $X=[$ event multipliers; station-hypocenter distance; station-phase correction multipliers ] $m=\left[411\right.$ magnitudes, $\log _{10} e * \alpha, 31$ station-phase corrections ]

\section{From the first iteration:}

For both inversions, three amplitude measurements and five events (with magnitude residual above 0.4) were removed after the first solution was analysed. The amplitudes were from RPZ transverse components and the SEISAN conversion to Wood Anderson seismograph had not worked as it only recognises north and east horizontal components; not transverse and radial. The events were possibly badly located. Linear regression is

\footnotetext{
${ }^{1}$ GeoNet magnitudes for stations $>100: A=A_{0} D^{-n} e^{-\alpha D}$ where $\mathrm{n}$ is 2 and $\alpha$ is generally close to 0 .
} 
biased by outliers, so, if data are doubtful, they may be down-weighted, or, in extreme cases, removed.

\section{From the second iteration:}

GeoNet magnitude equations and log amplitudes were weighted by the ratio (about 1.73) of data: calibrated magnitude residuals from the first iteration. The data are of two types and the weighting is designed to give each type the same variance.

\section{From the final iteration:}

The final linear system consisted of a total of 444 parameters and 5491 data, the model produced 411 calibrated magnitudes, the pseudo spreading parameter c for Model 1 or the attenuation parameter $\log _{10} e * \alpha$ for Model 2 and 31 station corrections.
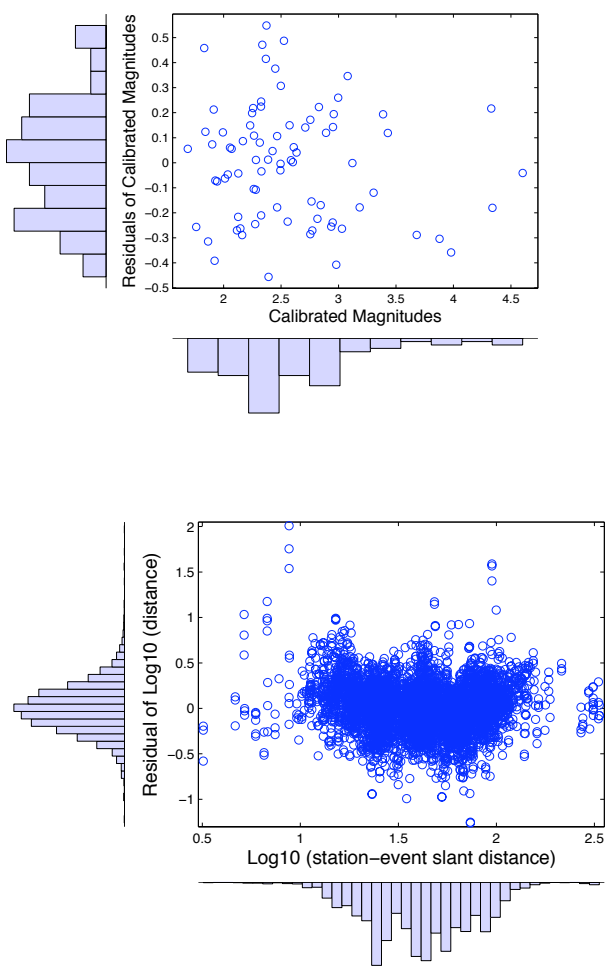
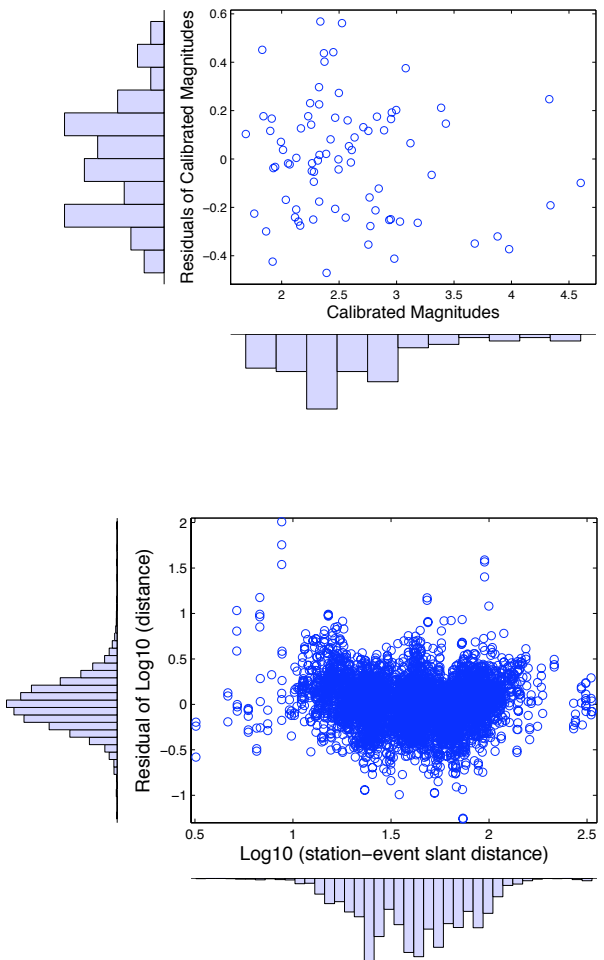

Figure 5.1: Final magnitude inversion residuals. Left: Model 1; right: Model 2. Top: the magnitude residuals are largely within 0.2 (standard deviation 0.25$)$ with a mean of zero $\left(2 * E^{-14}\right)$. Bottom: The log of slant distance residuals generally follows a normal distribution with a slightly longer right tail. There is no systematic variation with distance. Standard deviations were 0.26 and mean zero $\left(2 * E^{-14}\right.$ and $\left.8 * E^{-14}\right)$. See Appendix B for more detail. 

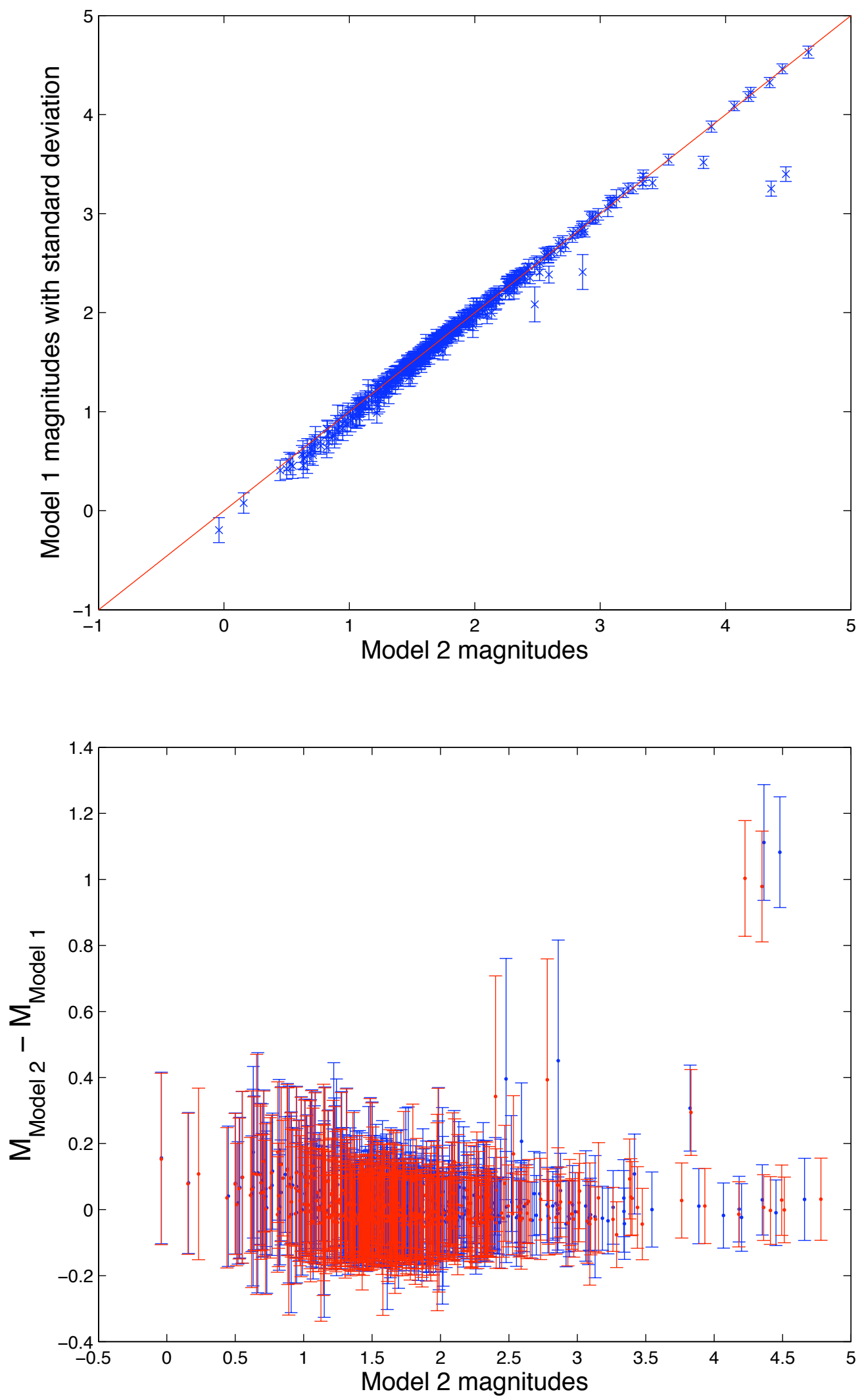

Figure 5.2: Magnitude differences for the two models. Top: Magnitudes determined from all data with trend of 0.998 shown in red. Bottom: Difference between magnitudes for all data in blue and with Mark Products L4 data removed in red. 


\subsection{Attenuation and geometric spreading}

The GeoNet magnitudes from stations less than $100 \mathrm{~km}$ away are calculated with attenuation parameter $\alpha=0.0067 \mathrm{~km}^{-1}$ and geometric spreading factor $n=1$ which are the terms Robinson (1986) calculated from local earthquakes of the Wellington region. In this study, the attenuation parameter was found to be $\alpha=0.0167 \mathrm{~km}^{-1}$ from inversion of Model 2, more than twice that of the Robinson (1986) value (refer to Appendix B for more detail).

The slant distance vs log of amplitudes slope for Model 2 (Fig 5.5 bottom left) is greater than that of Model 1, suggesting the spreading factor $n=1$ is not suitable for this region. Measurements around the world of spreading factor include 1 for Southern California (Hutton and Boore, 1987) South Australia 1.10 (Greenhalgh and Singh, 1986), and 1.2 for the Ethiopian Rift (Keir et al., 2006). To assess the possible spreading factor for the central Southern Alps, the values of $n=0.9,1,1.1$, and 1.2 were used in the inversion. The equivalent attenuation parameter showed a negative correlation decreasing from 0.0190 to 0.0125 for $n=0.9$ and $n=1.2$ respectively for world geometric spreading values, and a geometric spreading factor of 2 gave $\alpha=-0.0048 \mathrm{~km}^{-1}$ : a negative value as seen in Fig 5.3. A positive value for $\alpha$ equates to a geometric spreading factor $<1.77$.

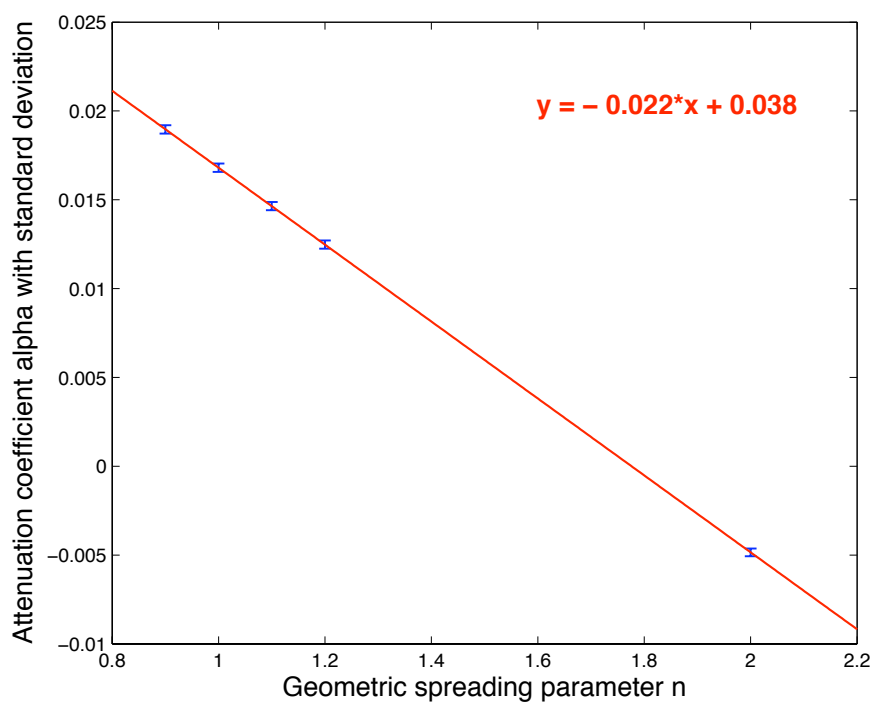

Figure 5.3: Linear relationship between geometric spreading factor and inelastic attenuation. A range of geometric spreading factors was used in the Model 2 inversion with 0.9-1.2 comparable to different values around the world. A positive value for $\alpha$ equates to a geometric spreading factor $<1.77$.

Model 1 did not separate out terms for $\alpha$ and $n$ but assuming the two magnitude 
equations 5.2 and 5.7 are equivalent, by equating the two magnitude equations and rearranging we have:

$$
\alpha=\frac{\log _{10} K-\log _{10} G+(n-c) * \log _{10} D}{D * \log _{10} e}
$$

The inelastic attenuation coefficient $\alpha$ was calculated using mean $K$ and $G$ and $n=$ $0.9,1,1.1$, and 1.2 . The comparison between these values and Model 2 are displayed in Fig 5.4.

The inversion models' treatment of attenuation can be assessed by plotting the log of hypocentral distance against the log of amplitude adjusted for attenuation (according to the model).

$$
\log _{10} A_{\text {adjusted }}=M_{L}-\log _{10} A-K \text { for Model } 1
$$

and $\log _{10} A_{\text {adjusted }}=M_{L}-\log _{10} A-G ;$ for Model 2 as $\log _{10} D<<\log _{10} e * \alpha * D$

If attenuation is fully modelled, the slope should be 0. From Fig 5.5 we can see Model 1 is well adjusted only when the short-period Mark Products L4 data are removed. The slope reduces from -0.95 to -0.09 although both datasets have a slope less than the Model 2 data of slope -1.90 with L4 data to -1.91 without.

\subsection{Station corrections}

Station corrections provide amplitude scaling due to instrument gain and site response due to geology. The station corrections of $K$ for Model 1 and $G$ for Model 2 are displayed in Fig 5.6.

According to Fig 5.6, the station corrections appear to be more dependent on instrument type than site. This would suggest that using the mean station corrections in calculating $\alpha$ is not appropriate. Changing the station correction component of Equation 5.9 to the mean of the difference applied to each measurement $i$ :

$$
\alpha=\frac{\log _{10}\left(\operatorname{mean}\left(K_{i}-G_{i}\right)\right)+(n-c) * \log _{10} D}{D * \log _{10} e}
$$

The plots of generalised $\alpha$ (Fig 5.4 bottom panel) are now less dependent on $n$ and are 

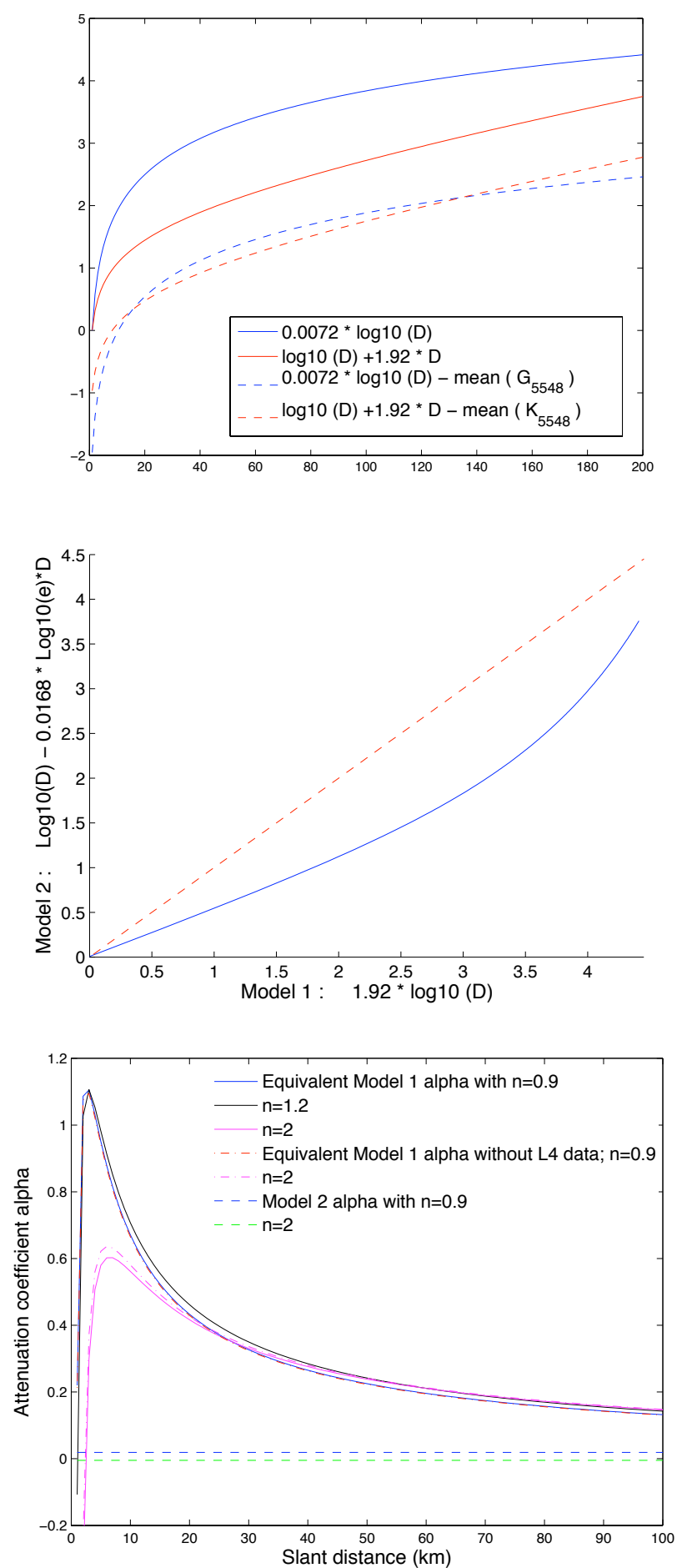

Figure 5.4: Distance component of magnitude calculation for each inversion procedure. Top: Both models are plotted over the distance range of the catalogue. Note how the models are similar once station corrections for each measurement are considered (dashed line). Middle: models plotted against each other with a dashed guideline of unity. The difference between them ranges from -0.01 to 1.20 compared to a maximum station correction difference of 1.18. This figure shows the Model 1 distance components of magnitudes are larger than Model 2 from stations at closer distances and may indicate the attenuation component of Model 2 is too low. The similarity in magnitudes as seen in Fig 5.2 shows the station correction largely accommodates this disparity. Bottom: Equivalent $\alpha$ calculations using mean station terms. Parameter $n$ is the geometric spreading factor used in the GeoNet equivalent inversion. Parameter $\alpha$ is the inelastic attenuation coefficient. 

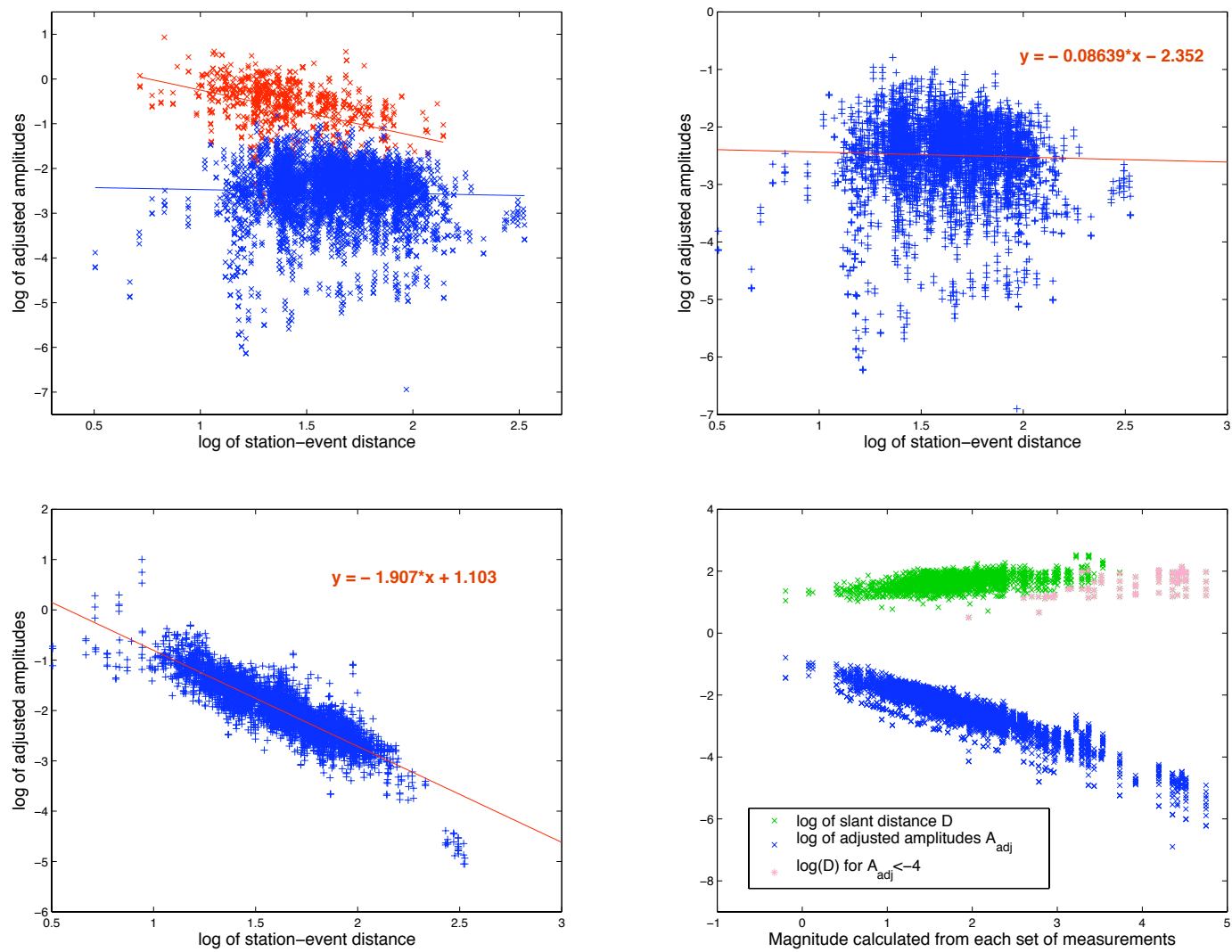

Figure 5.5: Evaluation of adjusted amplitude distance attenuation. Top left: log of adjusted amplitude vs $\log$ of distance shows some residual dependence with slope -0.95 but highly biased by the cluster of high amplitudes from short-period L4 data (red). Top right: the Model 1 data with the L4 data removed shows almost no residual attenuation coefficient remaining. Slope is now -0.09. Bottom left: the same plot for Model 2 shows a more definitive dependence. Removal of L4 data did not change the value by much. Bottom right: with log of distance and log of adjusted attenuation plotted against magnitudes calculated for each measurement. The lower scatter of Top-Right panel is identified as from amplitude measurements of larger magnitudes.

lower.

\subsection{Final magnitude model}

Regardless of whether L4 data are removed or not, the magnitudes from both inversion models are still similar. Plotting Model 2 vs Model 1 magnitudes (Fig 5.2) gives a slope of 0.9909 for all data and 0.9905 for without L4 data. Thus final magnitudes were calculated using Model 1 with no seismograph split.

The resultant catalogue of 411 events is an order of magnitude higher than the national network: GeoNet located 88 events in this time frame including 24 for the Fox swarm.

The cumulative event rate plot (refer to Fig 5.7) shows swarming to be the dominant seismicity behaviour with three major and three minor swarms visible in the cumulative 


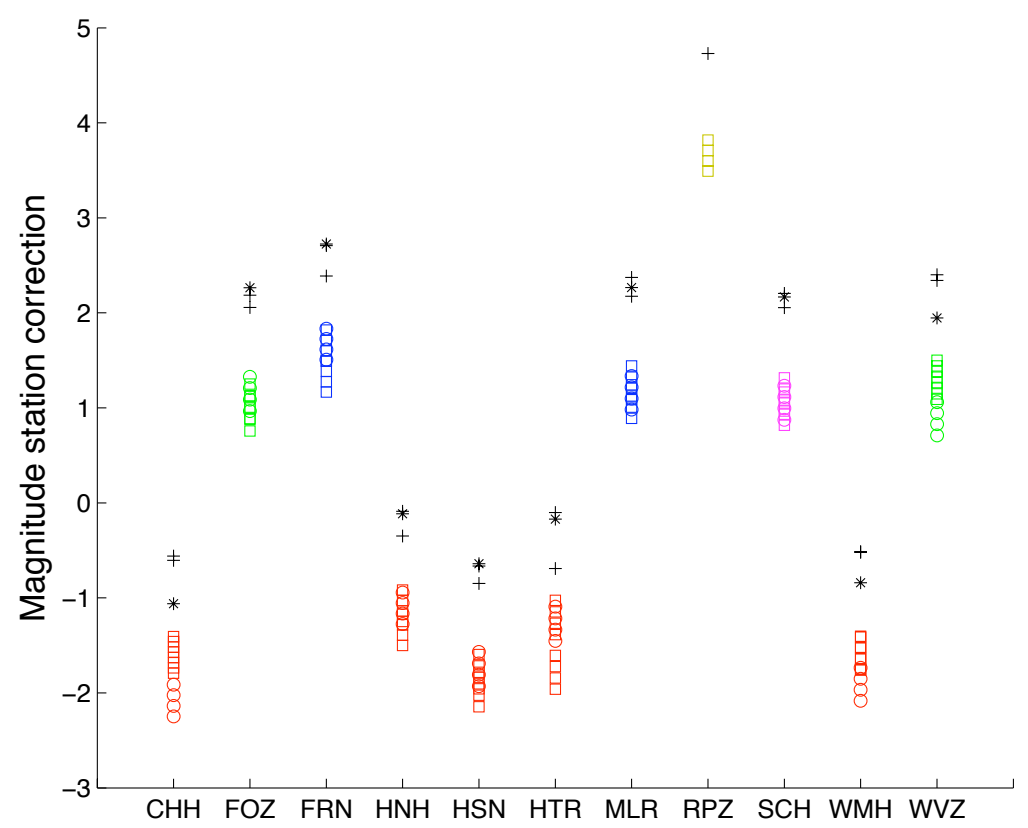

Figure 5.6: The station magnitude corrections for different inversion models and different $\mathrm{n}$. Black: Model 1 with $*$ as $\mathrm{P}$ phases and + as $\mathrm{S}$ phases. The remaining markers are from Model 2 inversions for $n=0.9,1,1.1$ and1.2. Circles: P phases, squares: S phases; Red: L4 data, blue: ORION data, green: GeoNet data and magenta Scone Hut. Magnitude correction values show more of a correspondence with instrument gain and Model 1 and Model 2 corrections are consistently different by a scalar value of $1.13 \pm 0.04$ for $n=1$ No correlation to topography or geography can be seen. Note the high value of RPZ (in gold) which is a borehole seismometer at depth $50 \mathrm{~m}$ below ground and so gain is higher to counter the low amplitudes found at this depth.

magnitude time series.

\subsection{Gutenberg-Richter distribution parameters}

The Gutenberg-Richter distribution (Gutenberg and Richter, 1986) describes the expected number of earthquakes for any magnitude. 


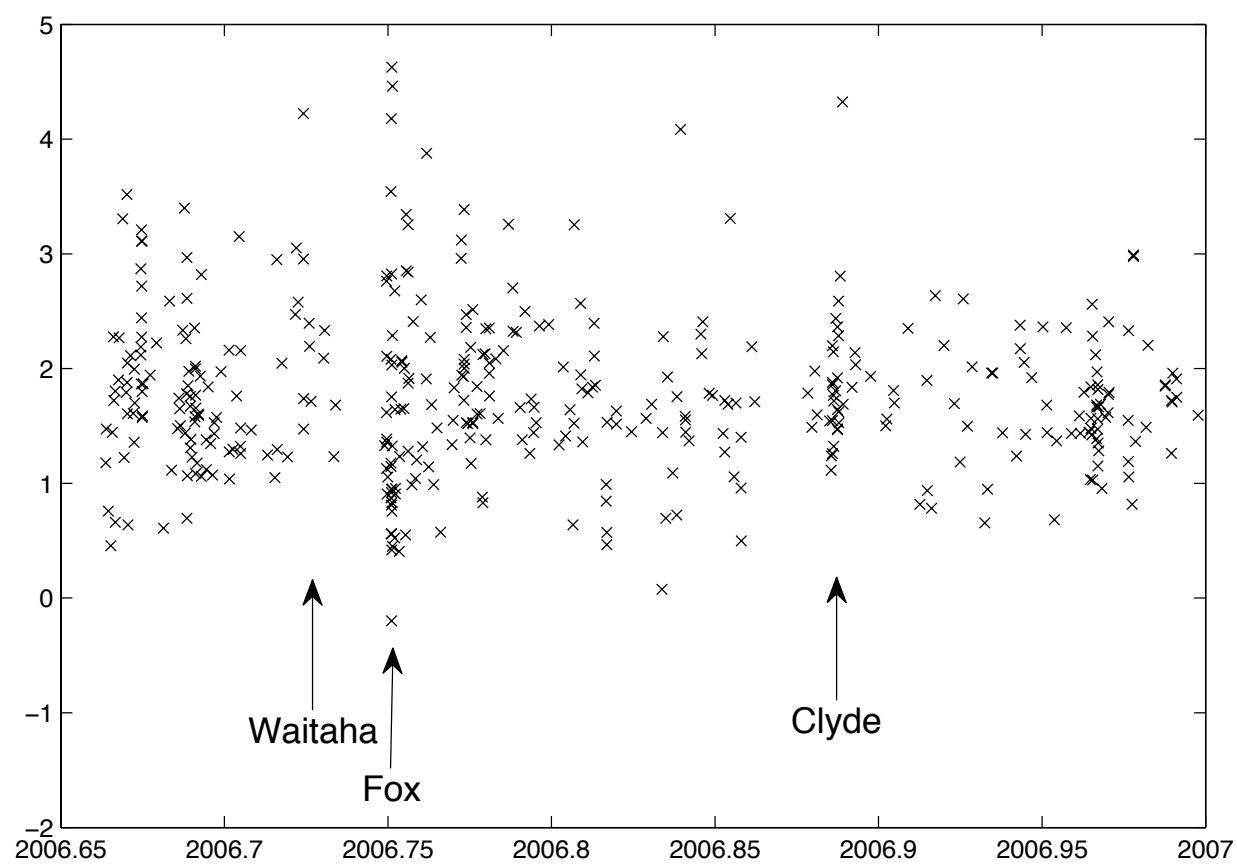

Cu rate $v$. Time

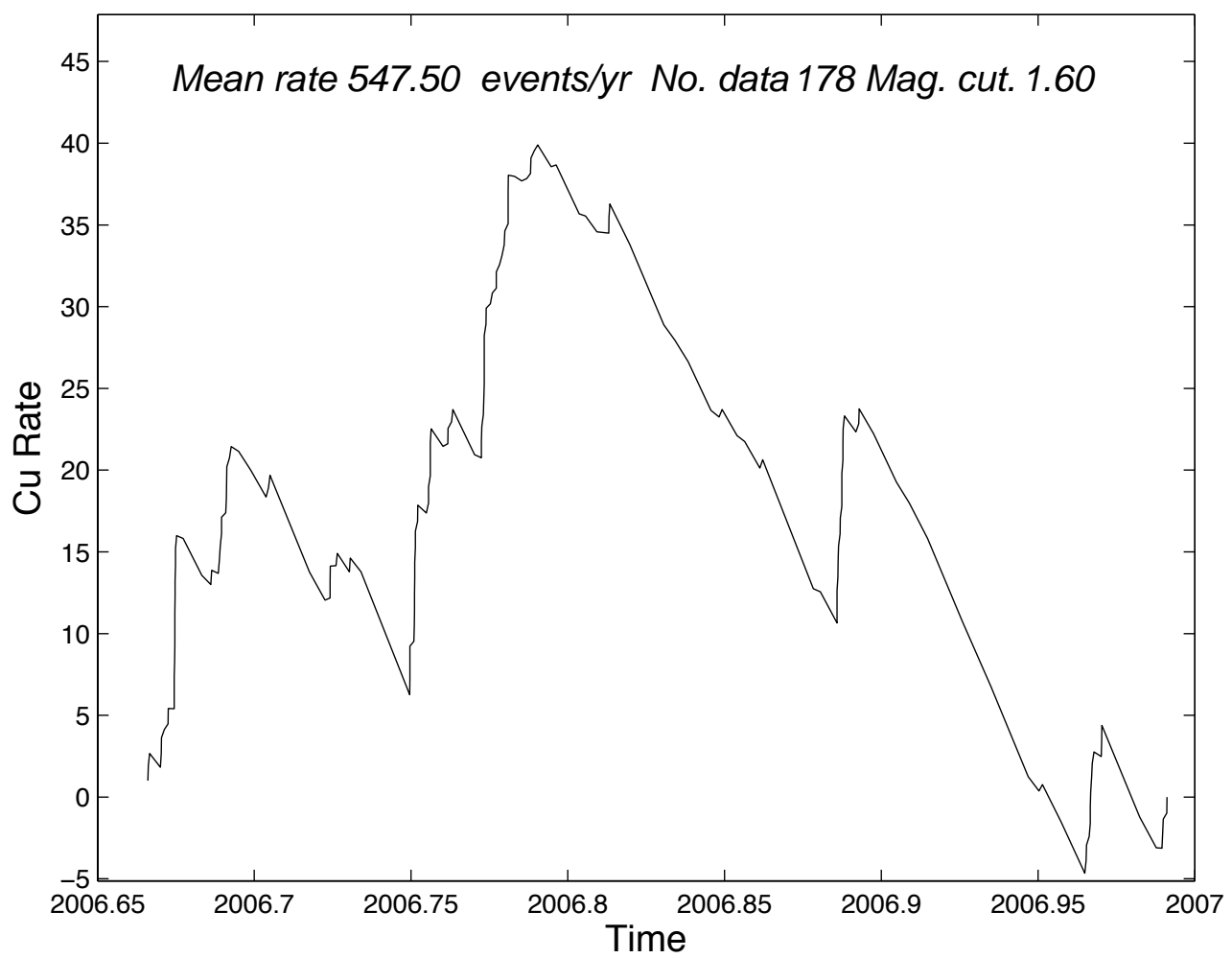

Figure 5.7: Time series of magnitudes. Top: the individual event magnitudes Bottom: the cumulative deviation from the mean rate of events from the mid-range polygon off events $M \geq 1.6$. See Fig 5.8 for explanation. Clusters can be seen as concentrations of magnitudes (top) and steep positive rate changes (bottom). The relocations of a selection of these with reasonable azimuthal coverage are discussed in Chapter 8. 


$$
\begin{gathered}
\begin{array}{c}
N(m)=N_{o} * e^{-\lambda\left(M-M_{c}\right)} \\
\log _{10} N=\log _{10} N_{o}-\lambda *\left(M-M_{c}\right) * \log _{10} e \\
\text { put } b=\lambda \log _{10} e \\
\log _{10} N=a-b * M-M_{c} \\
\text { where the maximum likelihood estimate of } b=\frac{\log _{10} e}{\bar{M}-M_{c}} \\
\text { and } a=\log _{10} N_{o}
\end{array}
\end{gathered}
$$

The parameter $b$ (or b-value) is a measure of the relative number of one magnitude to another while $a$ is an indicator of seismicity rate. $M_{c}$, or cut-off magnitude, is the lower magnitude limit where the array is certain to contain the complete population of event magnitudes greater or equal to it.

To determine the cut-off magnitude, the b-value maximum likelihood estimate was plotted against possible magnitude cut-off (similar to Cao and Gao (2002) who calculated maximum likelihood b-values with successively larger $\mathrm{M}_{c}$ guesses of 0.05 increments until a b-value change of $<0.03$ was reached).

This is more robust than the standard Gutenberg-Richter technique of estimating when the $\log (\mathrm{N})$ vs $M$ starts to curve away from linear. Events were selected from a polygon (Fig 5.8) that approximated consistent completeness (i.e. any subset of the polygon will have the same b-value and those outside are biased to larger events that were close enough to be captured). Different polygons were chosen to check the consistency of the outcome.

The Gutenberg-Richter relationship holds where the b-value is constant within a magnitude range. At higher magnitudes, the timeframe is too short to capture enough of these larger events to make the estimate accurate. At magnitudes lower than the cut-off, the catalogue is not complete. Not all the events of small magnitudes were captured by the array. The analysis revealed a b-value lower than 0.8 which is unusual. Most b-values around the world are closer to 1 and any significant deviation from this is controversial. Some suggest such departures indicate differences in seismic medium like stress, rheology and roughness (or presence of asperities) (Mori and Abercrombie, 1997; Wiemer and Wyss, 
1997; Öncel and Wyss, 2000; Schorlemmer et al., 2005; Öncel and Wilson, 2007).

However some argue that variation is caused by statistical artefacts from under-sampling or catalogue errors (in location, magnitude, irregular station distribution affecting detection) (Frohlich and Davis, 1993; Kagan, 1999), or inclusion of aftershock sequences. Aftershock sequences may skew distributions as they are caused by different mechanisms of triggering forces from nearby ruptures rather than continuous strain buildup of main shocks (Knopoff, 2000).

From the innermost polygon selection of Fig 5.8, the CAlF events numbered 179 compared to 28 GeoNet events. A plot of b-value maximum likelihood estimates versus possible lower magnitude cut-off gave a consistent b-value of $0.72 \pm 0.03$ for a local magnitude range 1.6-3.3 (Fig 5.8). The b-value is consistent with the visual inspection of the curvature point of the Gutenberg-Richter plot of magnitudes vs accumulative number of events at that magnitude or lower. The cut-off magnitude also agrees with the estimate from the GeoNet catalogue of the same time frame. An order of magnitude greater event count would decrease the cut-off magnitude by one. GeoNet publish their cut-off magnitude as 2.6 (Eberhart-Phillips, 1995) giving an estimate of around 1.6 for CAlF.

The same b-value search method was applied to the 28 GeoNet events within the same polygon to avoid regional affects (Fig 5.8). A sample of this small size is not statistically reliable on its own, however the magnitude cut-off of 2.7 is statistically the same as the national catalogue value of 2.6 and the b-value of $0.75 \pm 0.06$ coincides with the CAlF value within error limits.

The survey was only 4 months which is too short to determine a meaningful estimate of seismicity. The b-value temporal studies show high variability of $b$ for this time scale. And the clustering would contaminate any background seismicity measurement and characterisation of the Alpine Fault. The data would need to be declustered for this which would probably remove almost half the dataset. However, The consistency between CAlF and GeoNet b-values for the same geographic selection and four month sample suggests the b-value is not unique to the CAlF catalogue.

It is possible the low b-value estimate is due to sample size. To investigate this possiblilty, b-values for different time periods for the same area were calculated and plotted (Fig 5.9). Additionally, b-values for subsets of 200 sequential events were calculated and plotted to coincide with event subsets for the same region of the CAlF analysis. These are 
displayed in Fig 5.9 .

The unusual b-value curve for the 1994 period can be associated with the Arthurs Pass earthquake sequence which was outside of the geographical limits of the selection but seems to affect the seismicity observed. This is not surprising, as the Arthurs Pass aftershock sequence is known to extend to over $50 \mathrm{~km}$ from the mainshock affecting the stress regime over a wide region. It is widely recognized that large aftershock sequences have higher b-values than the background b-value. This is arguably due to changes in stress (Woessner et al., 2005), or the smaller events being obscured by larger events of the earthquake sequence (Kagan, 2004; Smith and Christophersen, 2007).

The b-value for CAlF is significantly below all the GeoNet 200 sample subset b-values and is likely associated with the dominant swarm behaviour of the CAlF survey period. This suggests the four month period includes anomalous swarming near or on the Alpine Fault. The fault may be locked, under high stress, with asperities or localised strong coupling sporadically rupturing in these swarms (Wiemer and Wyss, 1997). Alternatively, it could indicate that the anomolous swarms were thrust events compared to largely strikeslip events within the normal background seismicity (Schorlemmer et al., 2005). 

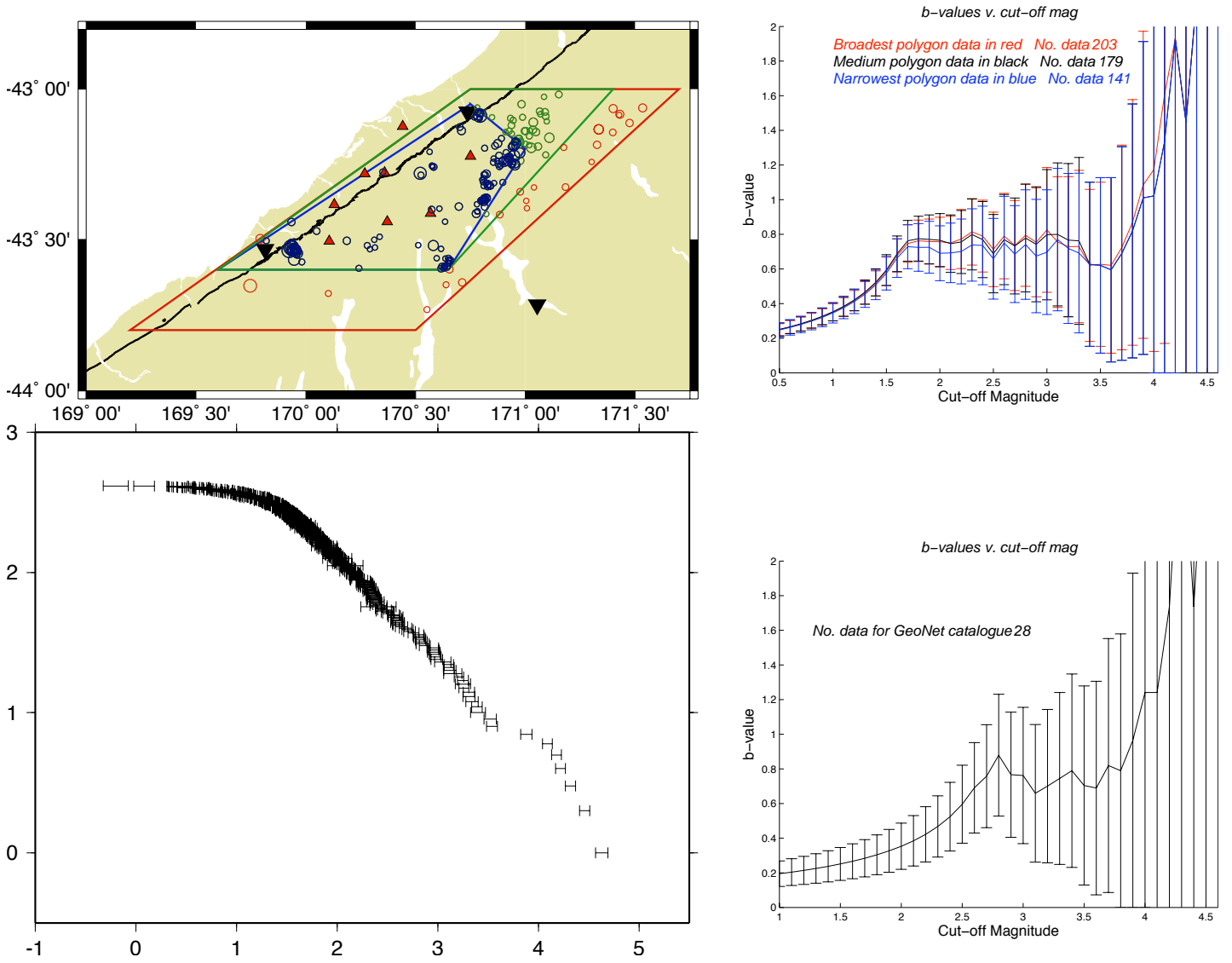

Figure 5.8: Observing b-value. Top left: The events within each polygon were used for the maximum-likelihood analysis of b. Bottom left: The visual cut-off magnitude is around 1.6 and the b-value (or slope of the linear portion) is around 0.72 for magnitude range of 1.7 to 2.2. Top right: The CAlF catalogue maximum likelihood estimates for different polygons and cut-off magnitudes. The mean b-value is 0.71 for $\mathrm{M}_{L}=1.6-3.3$ with a standard deviation of 0.03 although the narrowest polygon has a lower b-value overall. Note: data from the medium and narrow regions coincide from magnitude 3.4. Bottom Right: The GeoNet maximum likelihood estimates for the same polygons and time frame. The mean b-value is 0.75 for $\mathrm{M}_{L}=2.6-3.8$ with a standard deviation of 0.06 . The plot implies a magnitude cut-off of around 2.7 which is slightly higher than published values for the national catalogue, and the b-value is consistent within error to the CALF catalogue b-value. 

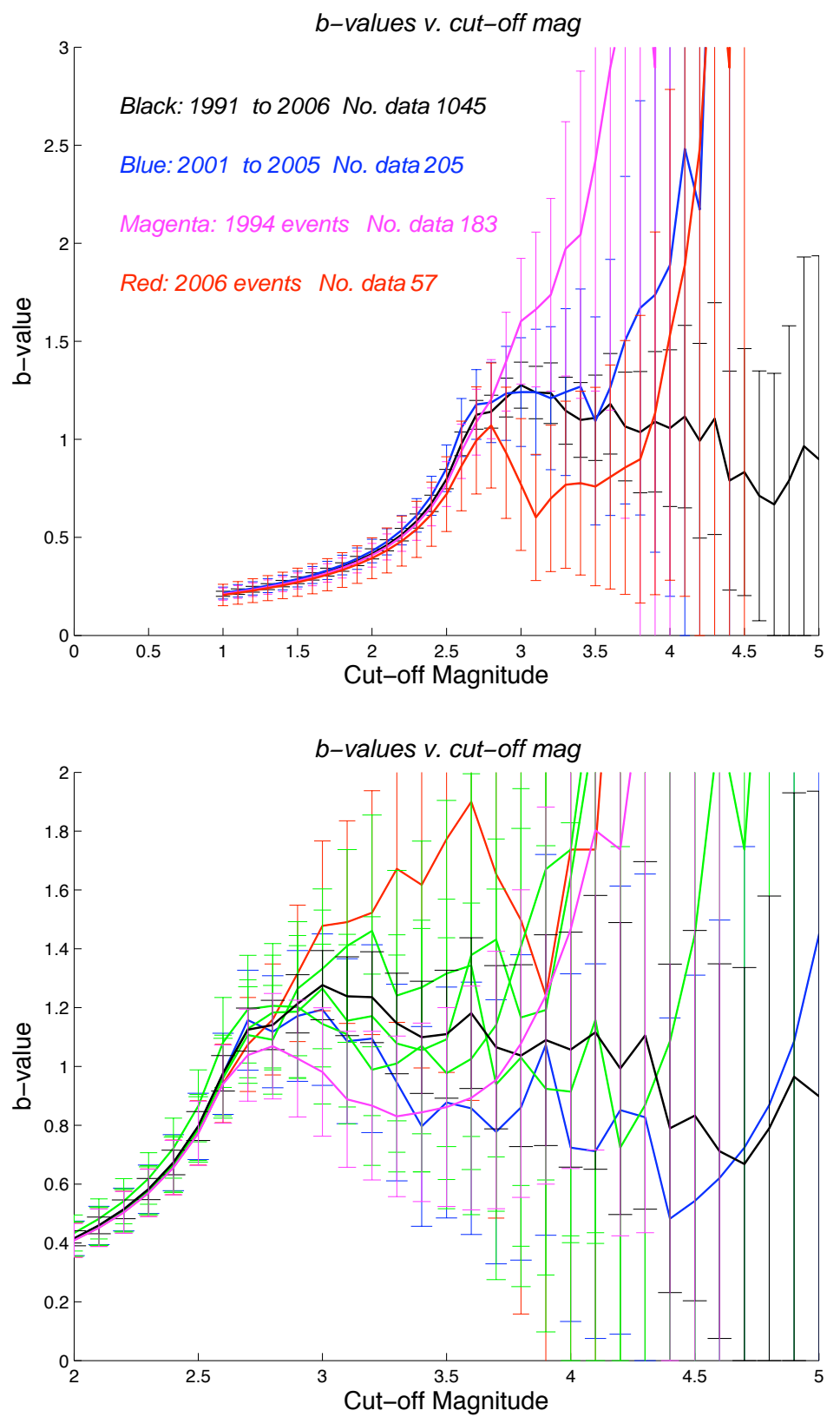

Figure 5.9: GeoNet magnitude cut-off and b-values. The GeoNet catalogue events within the middle polygon depicted in Fig 5.8 were used to determine an equivalent magnitude cut-off and b-value for different timeframes. Top: Various subsets of GeoNet catalogue data. The 1994 period was chosen as an anomalously high seismicity period (during the Arthurs Pass earthquake sequence). Bottom: Subsets of 200 sequential events to demonstrate constant sample size. Blue: 200 events before Arthurs Pass sequence; Red: Arthurs Pass earthquake sequence; Green: subsequent events; Magenta: last 200 events; Black: a reference of all events. The b-value for all subsets are consistently higher than the survey timeframe. The average b-value for all events (in black) is calculated for a magnitude range $2.7-3.7$ at $1.17 \pm 0.07$ standard deviation. Almost all the data points correspond within error. Only the (red) Arthurs Pass sequence timeframe partially lies outside these error limits for cut-off magnitude bins 3 and 3.1. This could be a catalogue incompleteness overshadowed in the seismic recordings by the Arthurs Pass sequence nearby. Note the cut-off magnitude is consistently 2.7 for all time frames and sample sizes. 


\section{Chapter 6}

\section{Final Hypocenters}

\subsection{Final locations}

Fig 6.1 presents the final epicenters and magnitudes. The "horseshoe" pattern of seismicity seen in Fig 3.1 surrounding the low seismicity zone persists into the lower magnitudes of the CAlF survey.

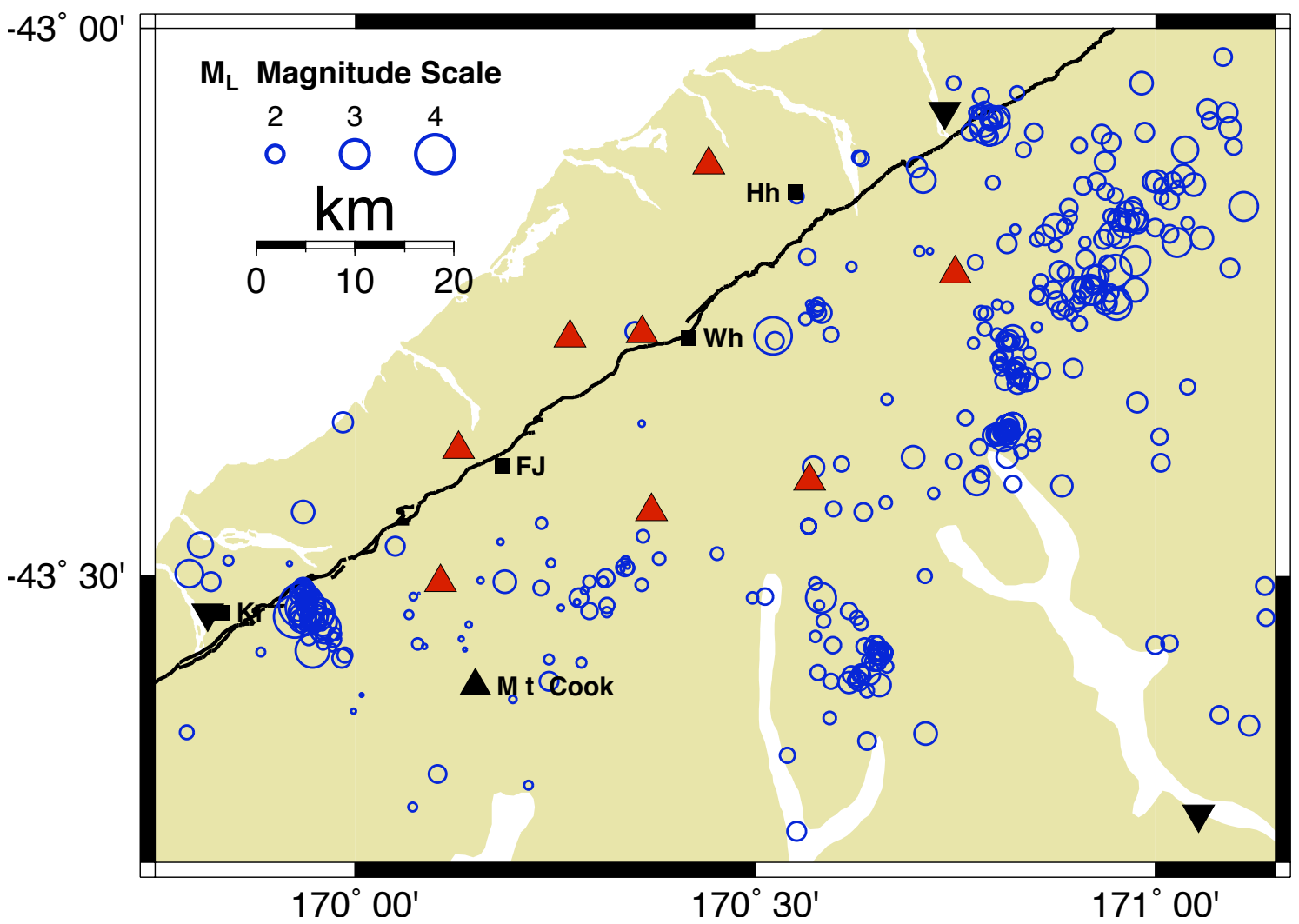

Figure 6.1: Final locations for CAlF hypocenters.

The final locations were output from HYPOCENTER using 
- Station corrections including $\mathrm{CHH}-1 \mathrm{~s}$ and station corrections of best VELEST velocity model (refer to table 4.12)

- Starting depth of $5 \mathrm{~km}$

- VPS from Wadati of 1.68

- Velocity model from VELEST:

$\begin{array}{cc}\text { velocity }(\mathrm{km} / \mathrm{s}) & \text { layer top depth }(\mathrm{km}) \\ 3.85 & 0 \\ 5.67 & 1.0 \\ 5.79 & 8.0 \\ 6.28 & 18 \\ 7.35 & 35 \\ 8.00 & 40+\end{array}$

At the completion of the earthquake locating, the consistency in picking over all the data was tested by randomly selecting several of the first events and re-picking the phases. No consistent or significant change in location accuracy was made.

Wadati analysis on final data confirms a VPS of 1.68.

\subsection{Catalogue uncertainties}

Of the 411 events, 235 events or $57 \%$ of locations have an azimuthal gap within the Califorina catalogue (NCSN) limits of $\leq 235^{\circ 1}$. More broadly, the quality of locations can be assessed by $\mathrm{Q}_{s}$ (Quality of solution) and $\mathrm{Q}_{d}$ (Quality of station distribution) rating either from A to D or 1 to 4. Refer to Appendix C for individual event quality.

From Fig 6.3 showing error distribution and Fig 6.2 showing magnitude distribution the location errors of the central zone within the array are comparatively low $(5 \pm 2 \mathrm{~km}$ laterally and $6 \pm 3 \mathrm{~km}$ in depth).

\subsection{Seismicity distribution}

Several swarms are visible within the map and cross-section plots and correspond to the patterns seen in the magnitude time series and cumulative magnitude plots in Fig 5.7.

\footnotetext{
${ }^{1}$ The NCSN catalogue limits can be found at http://www.ncedc.org/news/1995.08.01.ncsn.catalog.change.html
} 

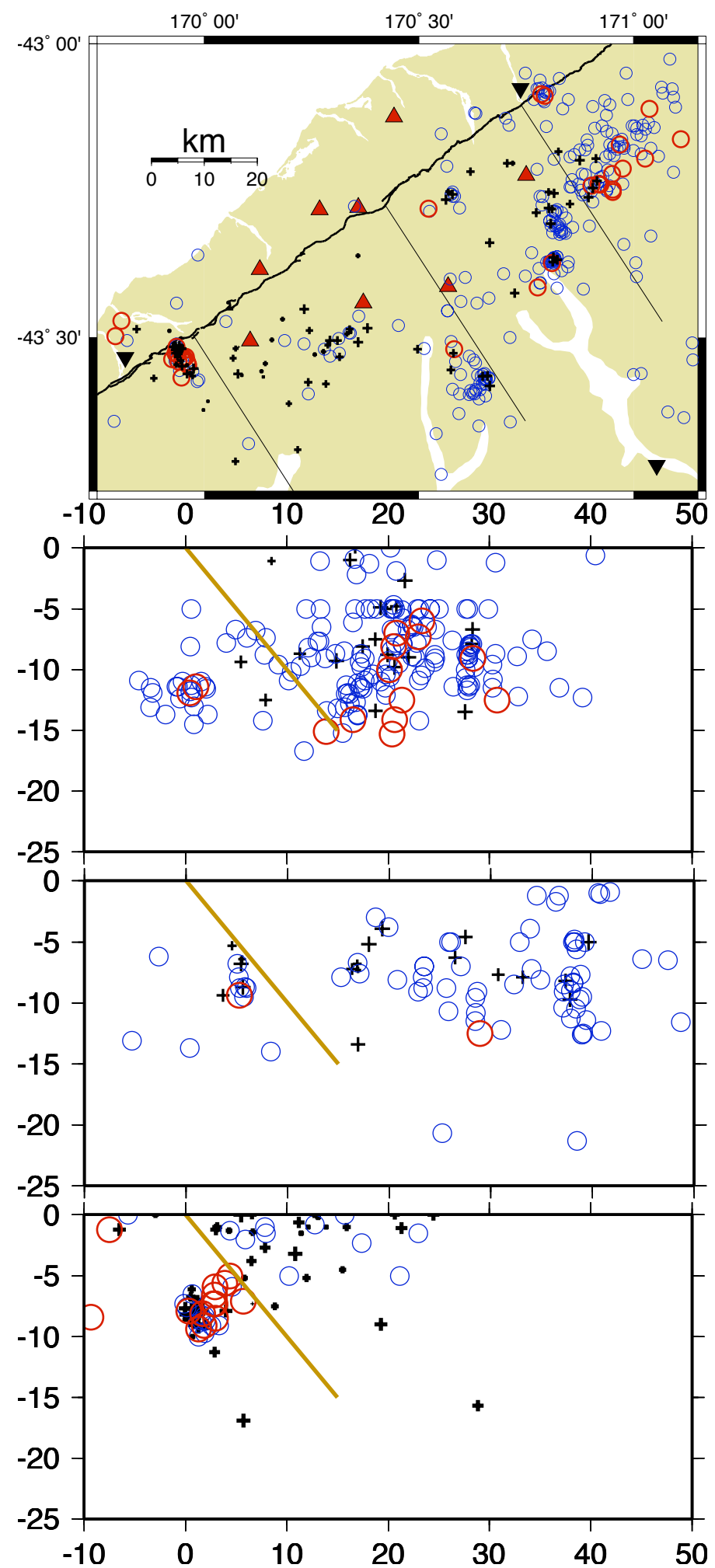

Figure 6.2: Epicenters and depth cross-sections showing magnitudes. From top to bottom: Map plot showing locations of profile lines and epicenters with magnitudes indicated. Bottom plots are ordered from north to south are projections within $20 \mathrm{~km}$ of each cross-section. Width of bubbles indicates magnitude range. Thick red circles are $M_{L}>2.6$ (i.e. above GeoNet $\mathrm{M}_{\text {cutoff }}$; blue circles: between 1.3 and 2.6 (some possibly seen by GeoNet) and crosses $M_{L}<1.3$ (unlikely to be seen by GeoNet). The location of the Alpine Fault is plotted in brown as dipping at $45^{\circ}$ although the actual dip is unknown. Notice the cluster in the "aseismic" zone at $[170.57,-43.25]$ and a cluster at each end of the low seismicity zone at $[170.79,-43.09]$ and $[169.94,-43.54]$. The higher magnitudes seem to be restricted to shallower depths to the south although this could be an artifact of the Fox cluster. 

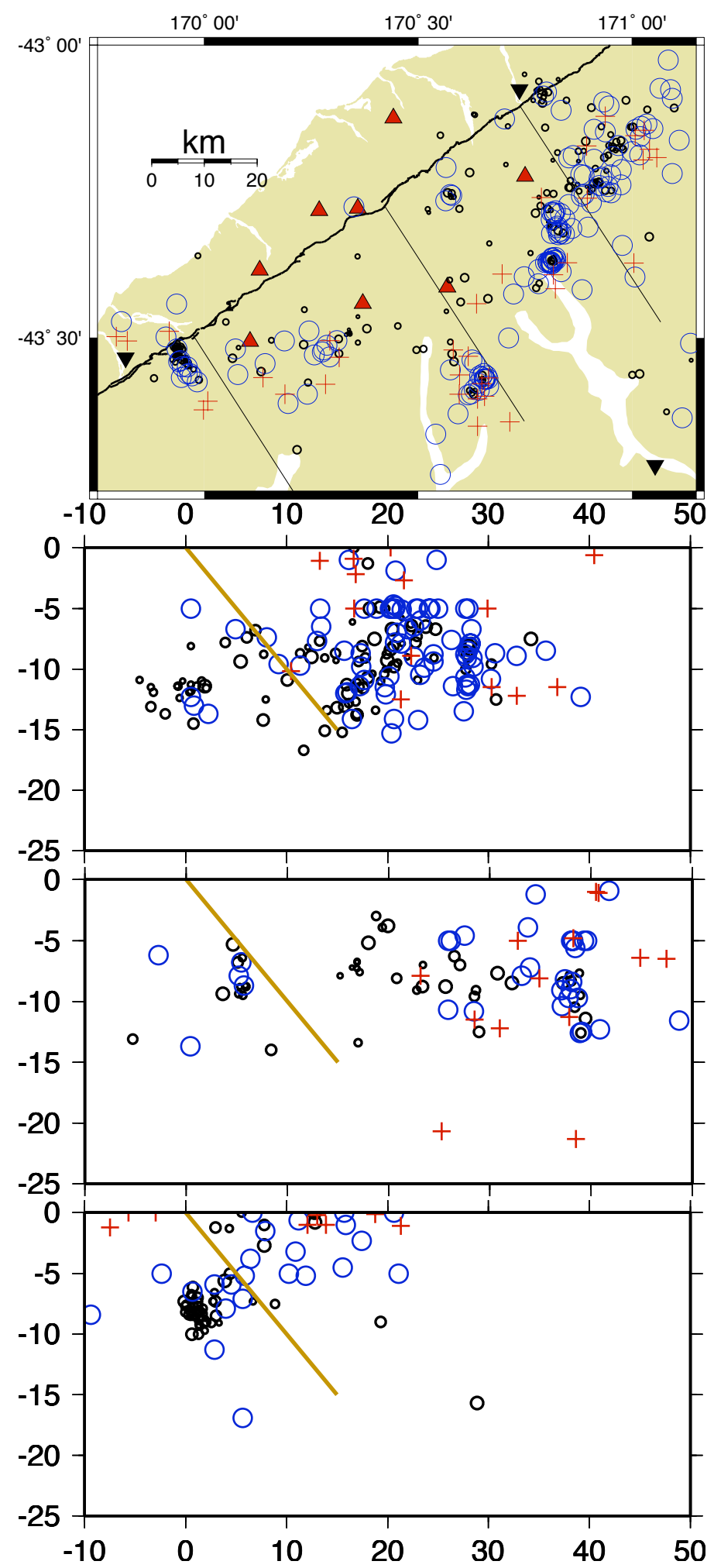

Figure 6.3: Epicenters and depth cross-sections of final hypocenter locations. From top to bottom: Map plot showing profile lines and lateral distribution of depth error. Bottom plots ordered from north to south are projections within $20 \mathrm{~km}$ of each cross-section. Radius of bubble indicates depth error. Thick circles are erz $<=7 \mathrm{~km}$; blue circles between 7 and $20 \mathrm{~km}$; red crosses: between 20 and $100 \mathrm{~km}$. The location of the Alpine Fault is plotted in brown as dipping at $45^{\circ}$ although the actual dip is unknown. 
Table 6.1: Summary of location quality

\begin{tabular}{|c|c|c|c|c|}
\hline \multicolumn{5}{|c|}{$\mathrm{Q}_{s}$ (Quality of solution) } \\
\hline & RMS (s) & ERH $(\mathrm{km})$ & ERZ $(\mathrm{km})$ & Total in catalogue \\
\hline 1 & $<0.15$ & $\leq 1.0$ & $\leq 2.0$ & 0 \\
\hline 2 & $<0.30$ & $\leq 2.5$ & $\leq 5.0$ & 23 \\
\hline 3 & $<0.50$ & $\leq 5.0$ & & 151 \\
\hline 4 & Other & & & 237 \\
\hline \multicolumn{5}{|c|}{$\mathrm{Q}_{d}$ (Quality of station distribution) } \\
\hline & $\mathrm{N}$ & Azimuthal Gap & $\mathrm{D}_{\min }$ & Total in catalogue \\
\hline 1 & $\geq 6$ & $\leq 90$ & $\leq$ Depth or $5 \mathrm{~km}$ & 0 \\
\hline 2 & $\geq 6$ & $\leq 135$ & $\leq 2^{*}$ Depth or $10 \mathrm{~km}$ & 10 \\
\hline 3 & $\geq 6$ & $\leq 180$ & $\leq 50 \mathrm{~km}$ & 104 \\
\hline 4 & Other & & & 297 \\
\hline
\end{tabular}

Three swarms near the Alpine Fault trace were of particular interest and were nominated for relocation analysis in Chapter 8. These are located within the "aseismic" zone at $[170.57,-43.25]$ and at each end of the low seismicity zone at $[170.79,-43.09]$ and $[169.94$, $-43.54]$.

The brittle-ductile transition zone seems to vary along the Alpine Fault as seen in the cross-sections of Figs 6.3 and 6.2 which agrees with Leitner et al. (2001) and EberhartPhillips (1995).

GeoNet catalogue locations compare well with CAlF hypocenters. Of the 88 GeoNet catalogue locations that correspond to the CAlF catalogue, only 8 have a latitude difference greater than $0.1^{\circ}$ and a longitude difference grater than $0.2^{\circ}$. The average location difference places GeoNet locations $0.04^{\circ} \pm 0.2^{\circ}$ more west and $0.03 \pm 0.1^{\circ}$ more north. But if only differences $\leq 0.1^{\circ}$ are analysed, around $70 \%$ are more northwest which is most pronounced with the Fox swarm locations. 


\section{Chapter 7}

\section{Focal Mechanism Determination}

\subsection{Cluster test}

As previously mentioned in Section 3.4, the polarities of the instruments were not unambiguously determined from the huddle test and evaluation of distant events. The results are tabulated in Table 3.1. Nevertheless, an attempt was made at determining a selection of focal mechanisms with the prospect of narrowing down the possible polarities to get consistent results.

The focal mechanism package within SEISAN was used to search for fitting mechanisms with search increments of 10 degrees. It is possible to refine the search increment, but within the uncertainty already mentioned, it would not add further detail. The program was written by Snoke et al. (1984) (described in Snoke (2003) and at http://www.geol.vt.edu/outreach/vtso/focmec) which searches for solutions within selection parameters. I used the "-1" option which minimises the number of polarity errors assigned.

\subsection{Polarity analysis}

The vertical component first motion polarity from each clear arrival was observed and corrected according to Table 3.1. From an iterative analysis of focal mechanism improvement, only the $\mathrm{CHH}$ and HTR polarities needed to be reversed. Few measurement sets gave a complete enough picture to resolve a unique solution. However, the solutions with the most clear first motions (d,e, f and $g$ in Fig 7.2) had solutions equivalent to a normal 
mechanism with strike parallel to the Alpine Fault. This is contrary to what is expected for an obliquely convergent margin where strike-slip to oblique thrust focal mechanisms should be prevalent. As the b-value for the central section over survey period was low $(<0.8)$ the mechanisms are likely thrust (Schorlemmer et al., 2005) and polarities are either all reverse or the first motion picked was actually half a wavelength later.

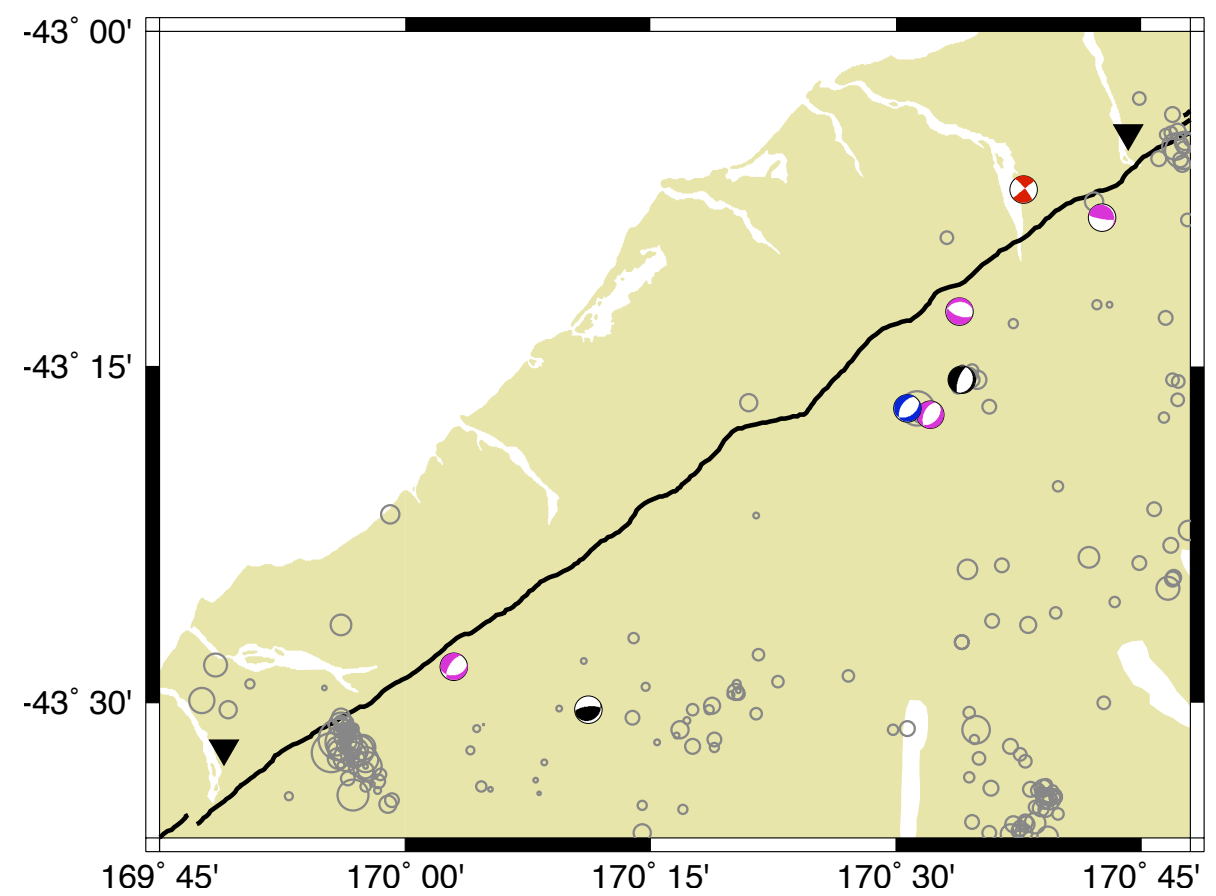

Figure 7.1: Map of selected Alpine Fault event focal mechanisms. All focal mechanism solutions are plotted using a lower hemisphere projection. Black mechanisms have 1 solution, blue have 3, magenta have 5 and the red mechanism has 9 . All catalogue event locations are plotted in grey for reference with circle size indicative of magnitude.

Polarity misidentification is likely a combination of uncertain seismograph polarity, emergent waveforms, and indistinct angles of incidence. The $\mathrm{P}$ wave first arrivals were generally emergent which can be expected (Stein and Wysession, 2003) from a region of high attenuation as the wavelet is dispersed. The high attenuation of the region was demonstrated in Chapter 5 where the inelastic attenuation coefficient from the magnitude inversions was $\alpha=0.0167 \mathrm{~km}^{-1}$ for dispersion factor $\mathrm{n}=1$ and 0.0190 to 0.0125 for $n=$ 0.9 to $n=1.2$. The majority of the observations were taken from near stations which would have angles of incidence $\left(i_{c}\right)$ near horizontal. Stations further than $30 \mathrm{~km}$ from the hypocenter are preferred in order to ensure $i_{c}>10^{\circ}$ from horizontal (Robinson, 1978). 


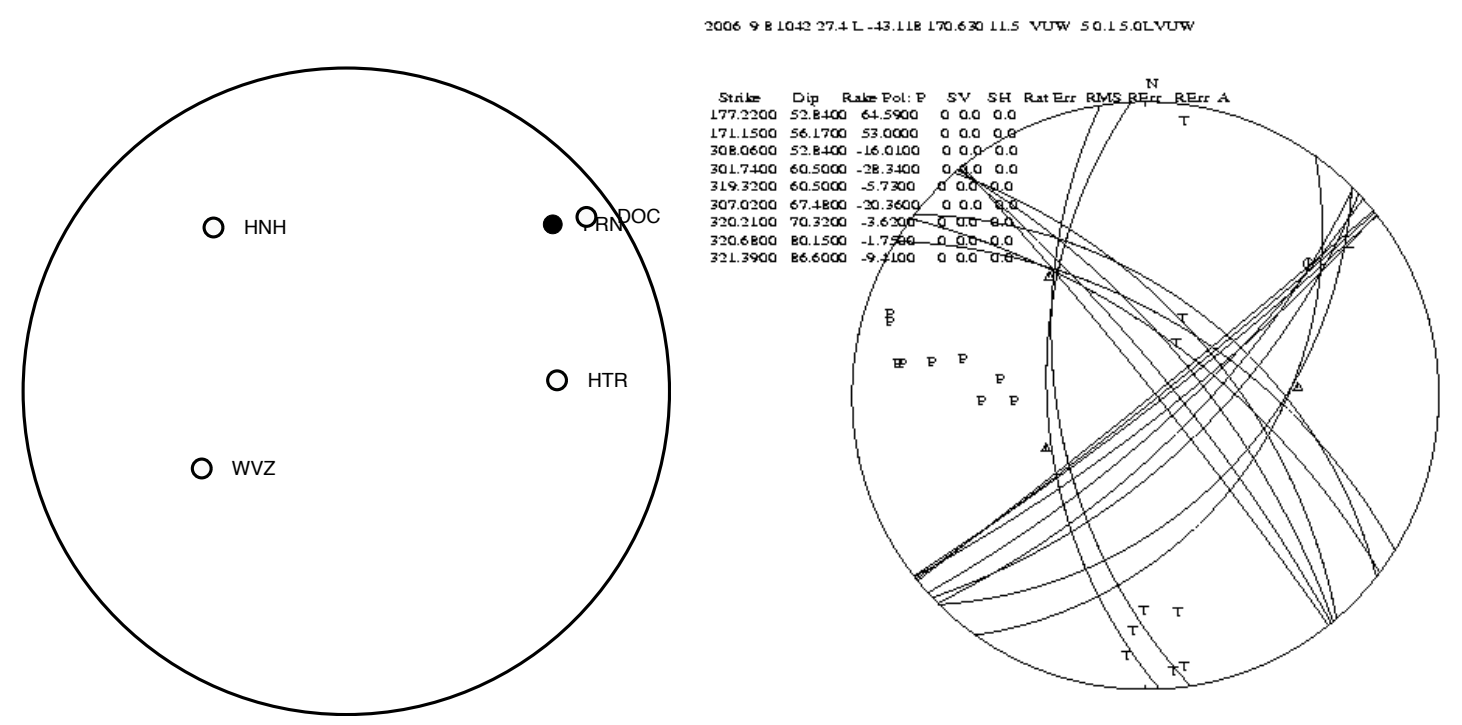

(a) Event 1 2006/09/08 10:42 (170.63 -43.118)

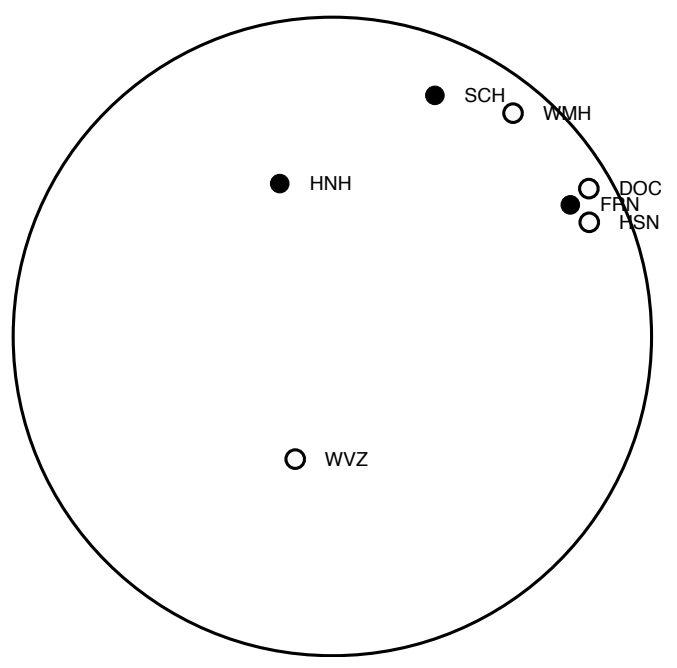

$2006971338+8.2$ L -13.139170 .71011 .6 vuw 100.1 5.8LVuw

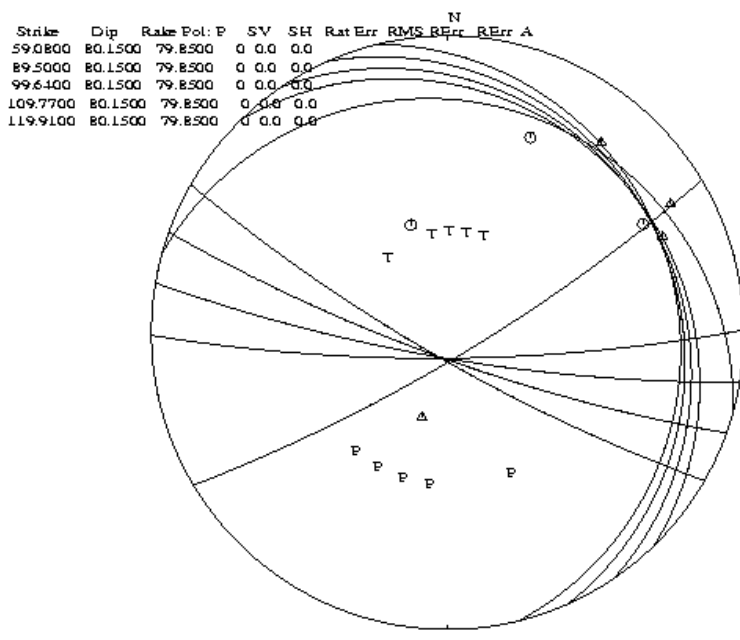

(b) Event 2 2006/09/07 13:38 (170.71 -43.139)

Figure 7.2: Selected Alpine Fault event polarity plots and SEISAN focal mechanism solutions in order of decreasing latitude on current and following two pages (see Table 7.1 for strike, dip and rake values for each solution). All focal mechanism solutions are plotted using a lower hemisphere projection. 


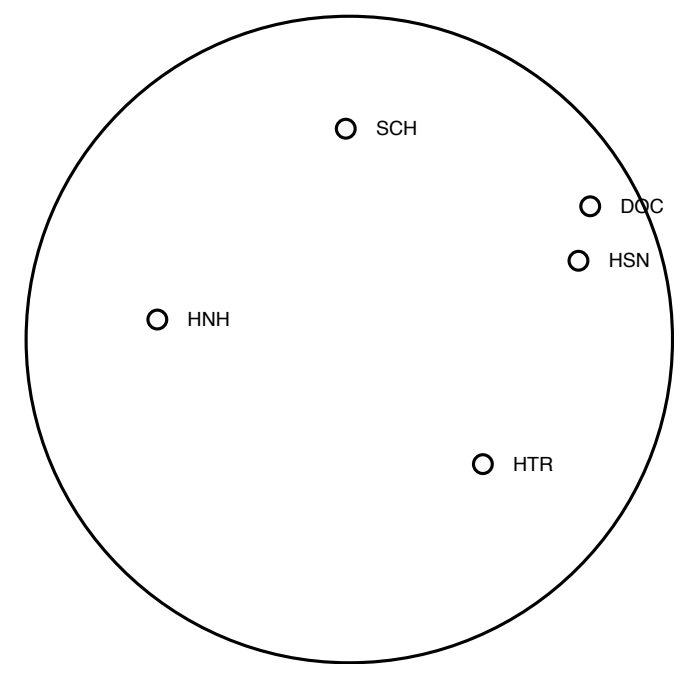

200691073955.6 L -43.209170 .56513 .6 Vuw 70.1 4.9 LVUW

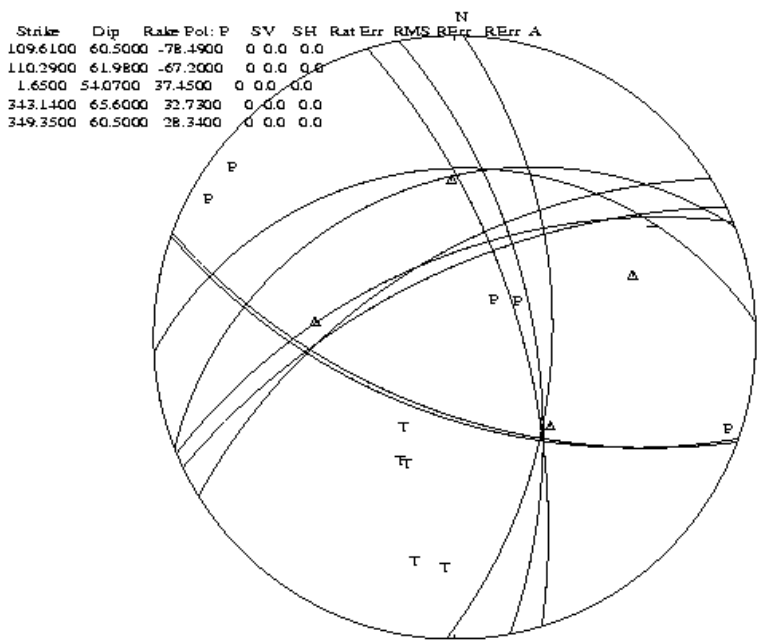

(c) Event 3 2006/09/01 07:39 (170.565-43.209)

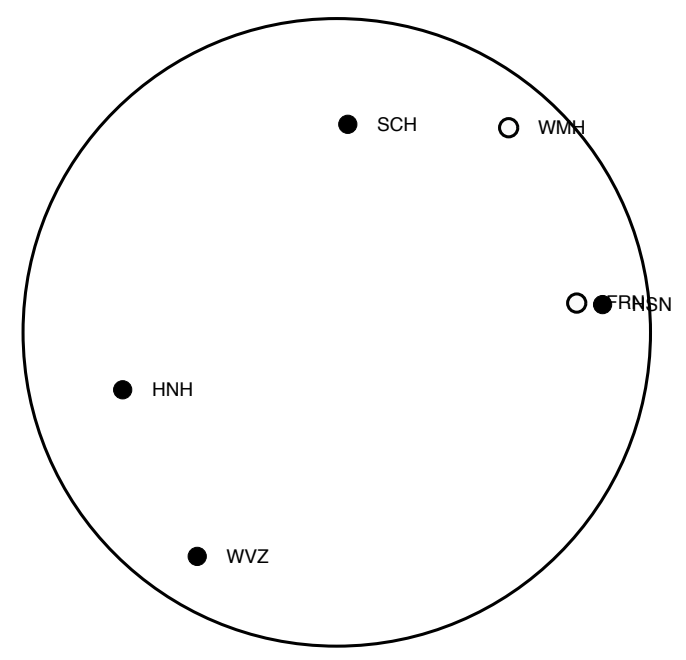

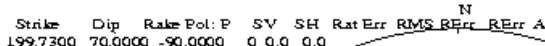

(d) Event 4 2006/10/06 19:38 (170.567 -43.26)

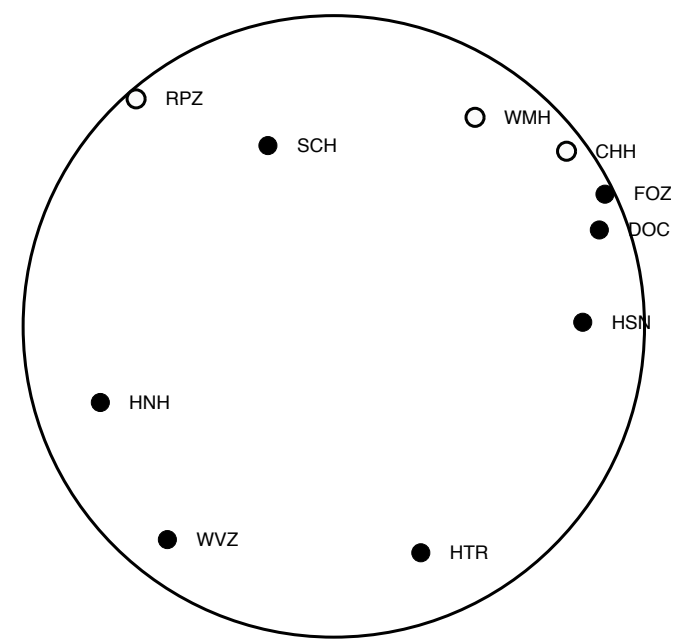

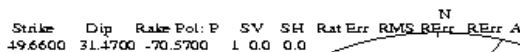

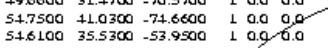

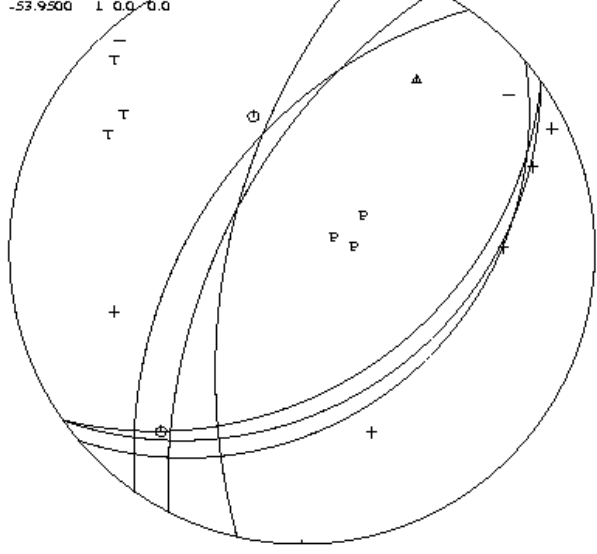

(e) Event 5 2006/10/06 06:13 (170.512 -43.281) 

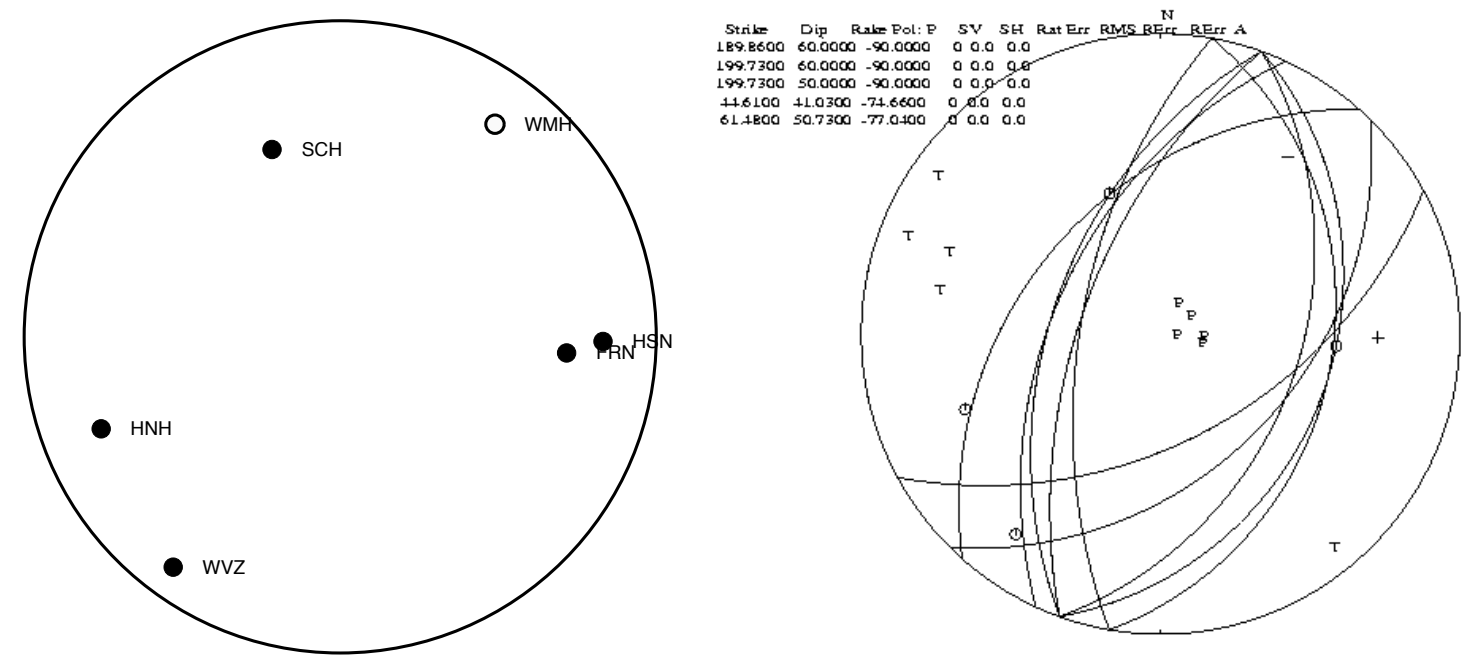

(f) Event 6 2006/10/09 07:55 (170.525 -43.286)

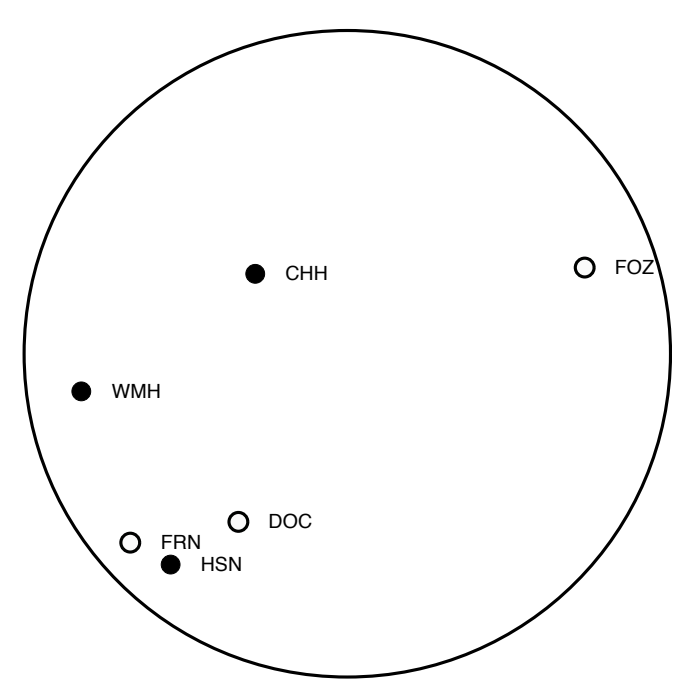

20061021 L221 12.5 L-43.173 170.050 10.0 VUW 60.25. 2LVUW

(g) Event 7 2006/10/21 12:21 (170.05 -43.473)
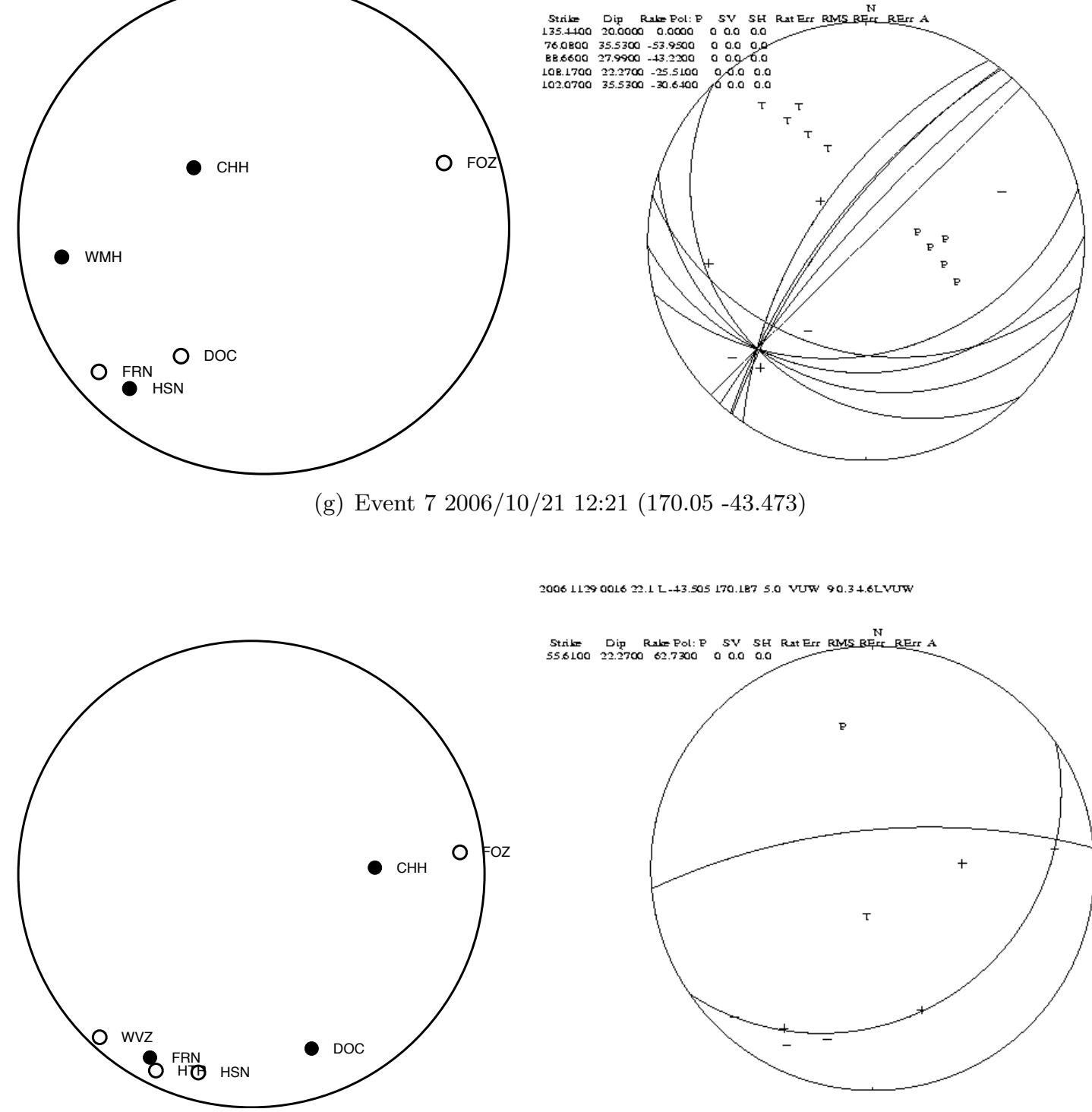

200611990016 2.1 L-13.505 170.187 5.0 VUW 90.3 1.6LVUW

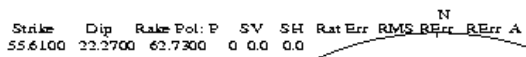

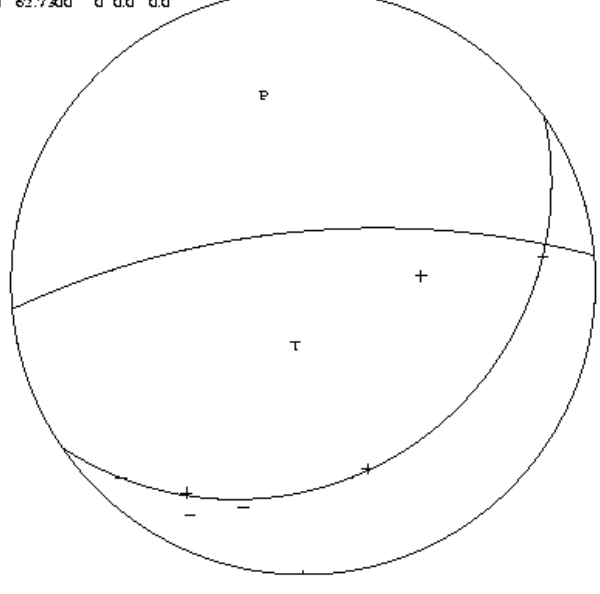

(h) Event 8 2006/11/29 00:16 (170.187 -43.505) 
Table 7.1: SEISAN focal mechanism solutions for selected events (in Fig 7.2) in order of decreasing latitude.

\begin{tabular}{|c|c|c|}
\hline Strike & Dip & Rake \\
\hline \multicolumn{3}{|c|}{060908 10:42 } \\
\hline 177.2200 & 52.8400 & 64.5900 \\
\hline 171.1500 & 56.1700 & 53.0000 \\
\hline 308.0600 & 52.8400 & -16.0100 \\
\hline 301.7400 & 60.5000 & -28.3400 \\
\hline 319.3200 & 60.5000 & -5.7300 \\
\hline 307.0200 & 67.4800 & -20.3600 \\
\hline 320.2100 & 70.3200 & -3.6200 \\
\hline 320.6800 & 80.1500 & -1.7500 \\
\hline 321.3900 & 86.6000 & -9.4100 \\
\hline \multicolumn{3}{|c|}{$060907 \quad 13: 38$} \\
\hline 59.0800 & 80.1500 & 79.8500 \\
\hline 89.5000 & 80.1500 & 79.8500 \\
\hline 99.6400 & 80.1500 & 79.8500 \\
\hline 109.7700 & 80.1500 & 79.8500 \\
\hline 119.9100 & 80.1500 & 79.8500 \\
\hline \multicolumn{3}{|c|}{$06090107: 39$} \\
\hline 109.6100 & 60.5000 & -78.4900 \\
\hline 110.2900 & 61.9800 & -67.2000 \\
\hline 1.6500 & 54.0700 & 37.4500 \\
\hline 343.1400 & 65.6000 & 32.7300 \\
\hline 349.3500 & 60.5000 & 28.3400 \\
\hline \multicolumn{3}{|c|}{$061006 \quad 19: 38$} \\
\hline 199.7300 & 70.0000 & -90.0000 \\
\hline \multicolumn{3}{|c|}{$06100606: 13$} \\
\hline 49.6600 & 31.4700 & -70.5700 \\
\hline 54.7500 & 41.0300 & -74.6600 \\
\hline 54.6100 & 35.5300 & -53.9500 \\
\hline \multicolumn{3}{|c|}{$06100907: 55$} \\
\hline 189.8600 & 60.0000 & -90.0000 \\
\hline 199.7300 & 60.0000 & -90.0000 \\
\hline 199.7300 & 50.0000 & -90.0000 \\
\hline 44.6100 & 41.0300 & -74.6600 \\
\hline 61.4800 & 50.7300 & -77.0400 \\
\hline \multicolumn{3}{|c|}{$061021 \quad 12: 21$} \\
\hline 135.4400 & 20.0000 & 0.0000 \\
\hline 76.0800 & 35.5300 & -53.9500 \\
\hline 88.6600 & 27.9900 & -43.2200 \\
\hline 108.1700 & 22.2700 & -25.5100 \\
\hline 102.0700 & 35.5300 & -30.6400 \\
\hline \multicolumn{3}{|c|}{$112900: 16$} \\
\hline 55.6100 & 22.2700 & 62.7300 \\
\hline
\end{tabular}




\section{Chapter 8}

\section{Double-difference Relocation}

\subsection{The HypoDD double-difference algorithm}

Waldhauser and Ellsworth (2000) developed a double-difference hypoDD location algorithm which minimises travel time difference residuals from closely spaced events. The algorithm assumes that pairs of events with similar travel times to a station have similar travel paths as long as the event pair distance is much smaller than the station distance from the events. Thus any travel time difference from the station to these two events arises from difference in event distance (Waldhauser and Ellsworth, 2000; Waldhauser, F., 2001). Phase picks and cross-correlation data can be used and data is weighted by quality and measurement accuracy. Ideally, both catalogue phase data and cross-corelation data are used as the former defines the large-scale structure while the latter refines the smaller-scale structure (Nakamura et al., 2005).

The relocation algorithm is a two-step process: the first step analyses phase and/or waveform data to derive travel-time residual differences between pairs of earthquakes using the hypoDD ph2dt routine; in the second step the differential travel times are used to determine double difference hypocenter location by iteratively adjusting the event pair differential travel times, solving the matrix of all hypocentral pairs by damped least squares.

HypoDD is a relative relocation algorithm and as such, conclusions on the resultant locations can only be analysed as relative locations. However, small location changes from well-located events (events with low location errors) could be considered as approximate ground truths, tying the data to actual locations. Although Newman et al. (2002) cite the method is not affected by velocity model inaccuracies between stations and clusters, and 
thus station corrections are not needed, Michelini and A. (2004) found the method was sensitive to the velocity model used as the partial derivitives of travel-times are directly related to calculated take-off angle for each event. From analysis of synthetic data, artifacts such as lineations were apparent, with flattening of depth distribution correlated to the width of the station array. To check the stability of results, use and comparison from results using different source-reciever distance ranges and velocity models are recommended.

Many international studies (Waldhauser and Ellsworth, 2000; Newman et al., 2002; Roumelioti et al., 2003; Nakamura et al., 2005; Nippress and Rietbrock, 2007) have used double difference techniques to relocate clusters and provide relative locations for these clusters and swarms and clarify alignment of inter-related events.

\subsection{Relocation procedure followed}

Swarms and nearby events were selected from the CAlF catalogue and relocated using HypoDD with phase arrival data. Phase data were converted into travel time double difference links using ph2dt with the routine output of event pairs linked by the same station and the travel time difference between the pair. Maximum parameter values were used to allow for all data within the geographical selection to be processed within the hypoDD algorithm.

The relocation algorithm was applied to each cluster data set to events with a minimum of 8 phase picks to account for the four degrees of freedom. Solutions were calculated under the conjugate gradients least squares option (LSQR). A weighting of 0.01 was applied to all phase data (P and $\mathrm{S}$ phases).

As suggested by Michelini and A. (2004), the distance range was changed to see if the locations were stable. A distance of $100 \mathrm{~km}$ (i.e. all stations) and $40 \mathrm{~km}$ (i.e. minimal distance that was not affected by the minimum of 8 observations) were compared. Locations did not vary beyond error limits (mean changes of latitude $0.0006^{\circ}$ and longitude $0.0003^{\circ}$ and a maximum of $-0.003^{\circ}$, depth mean change of $0.1 \mathrm{~km}$ and maximum $0.6 \mathrm{~km}$ ). The distance of $100 \mathrm{~km}$ was used for the final relocations. 


\subsection{Relocation results}

The relocations are shown in Subsections 8.3.1- 8.3.5 and detailed in appendix D. Many Fox swarm events were not relocated as I specified to only use events with 8 or more phase picks and the swarm included many small events with phase pick numbers under this threshold. The difference in relocations for most swarms and clusters was minimal although the Fox swarm significantly collapses down to point cluster. All swarms and clusters analysed show a predilection to cluster towards a point with any apparent vertical lineations likely to derive from errors in depth location.

\subsubsection{Cluster 1: the "Fox Swarm"}

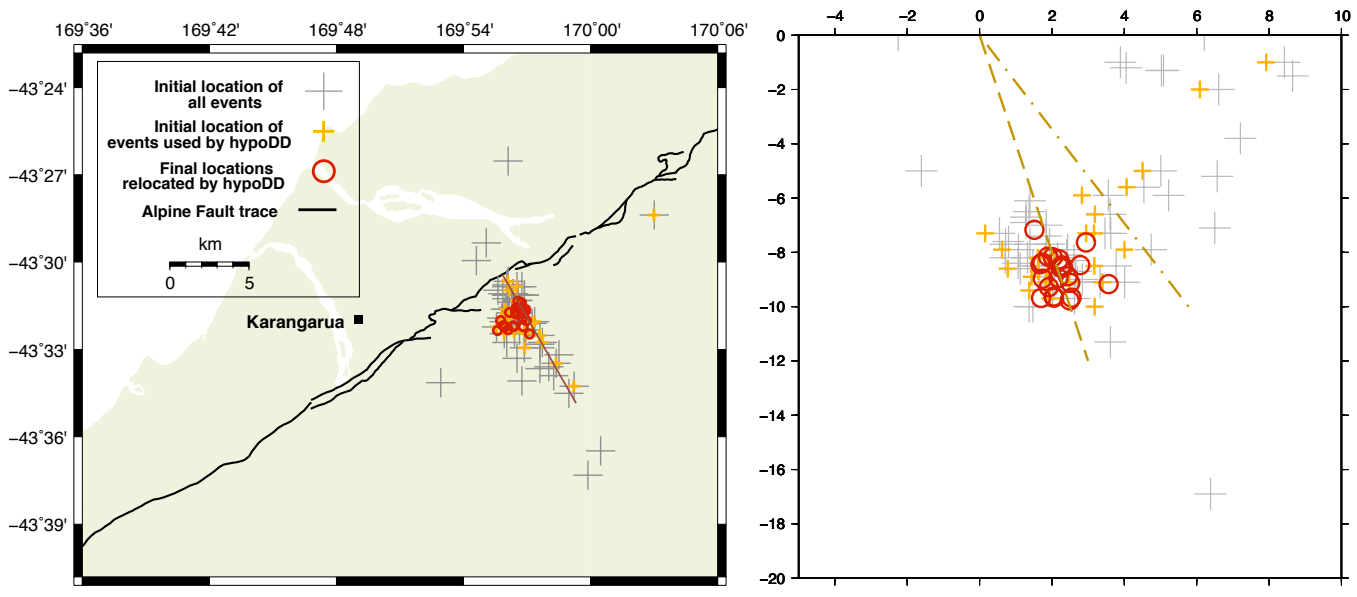

Figure 8.1: Relocation of cluster 1: the "Fox Swarm". Left: the profile line is shown in brown. Right: an indicative Alpine Fault is illustrated by the dot-dashed brown line dipping at $60^{\circ}$ and a dashed line dipping at $76^{\circ}$ through the majority of the swarm events. Events with the smallest HYPOCENTER depth error ( 6 events with depth error erz $<3$ $\mathrm{km}$ ) were located at an average depth $8.6 \pm 2.6 \mathrm{~km}$ and most events were relocated within this cluster.

Time frame: 1 Sept 18:41 to 23 Dec 1413 with swarm largely from 2-10 Sept ph2dt statistics: average travel-time: $7.00 \mathrm{~s}$; weakly linked: 11\%; average event offset: $2.53 \mathrm{~km}$; P used: 948; S used: 753

All events (grey crosses): 62; Events relocated (orange crosses moved to red circles): 22

\subsubsection{Cluster 2}

Time frame: Not a swarm but a cluster of sporadic events throughout survey period ph2dt statistics: average travel-time: $6.27 \mathrm{~s}$; weakly linked: $70 \%$; average event offset: 

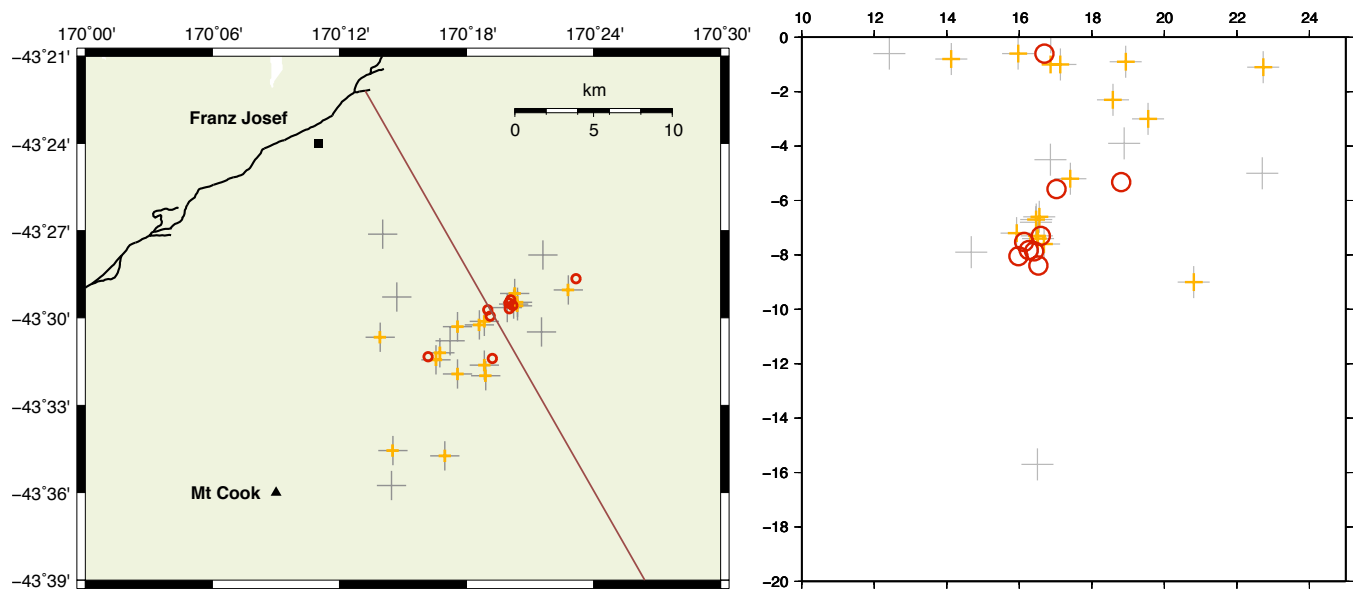

Figure 8.2: Relocation of cluster 2: sporadic events near the Main Divide. Left: the profile line is shown in brown. Right: note the Alpine Fault is not within the range of the plot. Refer to Fig 8.1 for symbol legend.

$5.52 \mathrm{~km}$; P used: 263 ; S used: 252

All events (grey crosses): 24; Events relocated (orange crosses moved to red circles): 9

\subsubsection{Cluster 3: the "Waitaha Swarm"}

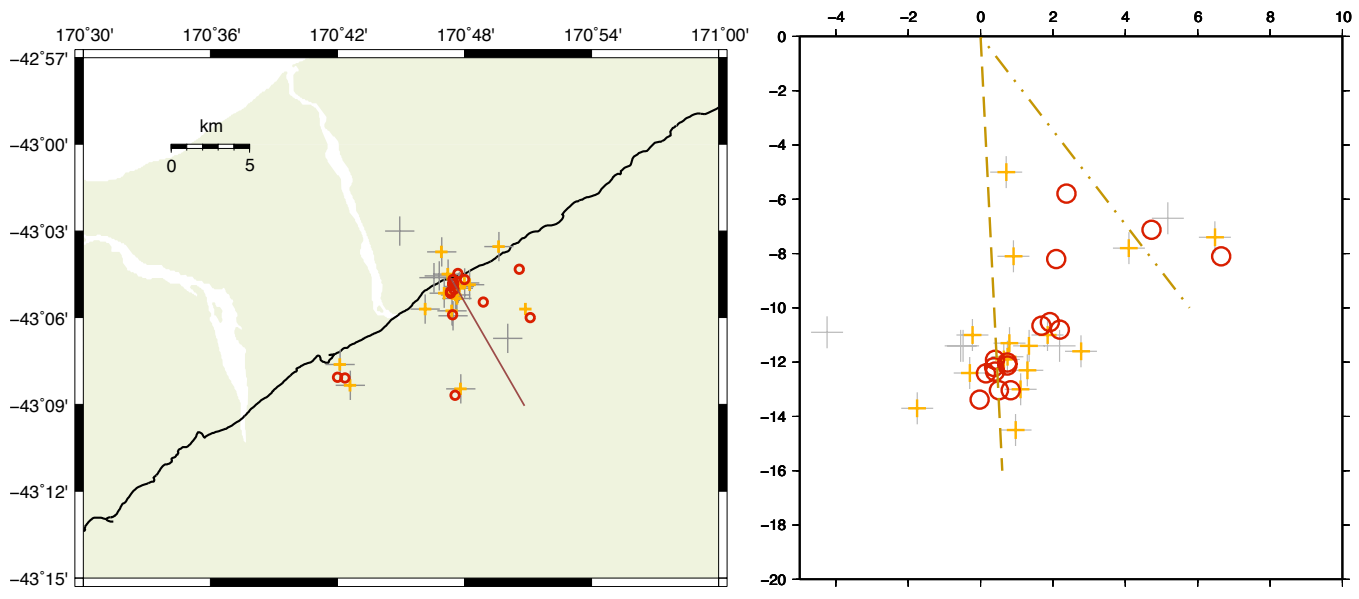

Figure 8.3: Relocation of cluster 3: the "Waitaha" swarm. Left: the profile line is shown in brown. Right: an indicative Alpine Fault is illustrated by the dashed brown line dipping at $60^{\circ}$ and a dashed line dipping at $88^{\circ}$ through the majority of the swarm events. Refer to Fig 8.1 for symbol legend.

Time frame: "Waitaha" swarm from 22-24 of September with a few neighbouring events

ph2dt statistics: average travel-time: $9.32 \mathrm{~s}$; weakly linked: 87\%; average event offset: $4.84 \mathrm{~km}$; P used: 232; S used: 190

All events (grey crosses): 21; Events relocated (orange crosses moved to red circles): 16 


\subsubsection{Cluster 4: the "Clyde Swarm"}

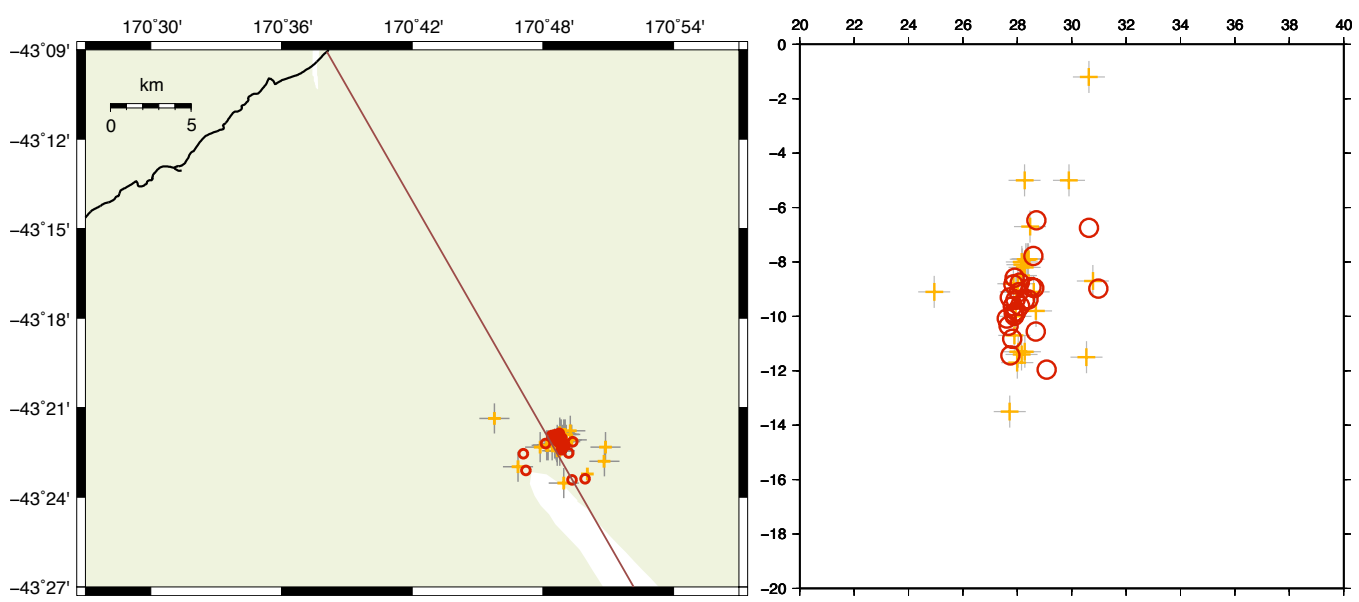

Figure 8.4: Relocation of cluster 4: the "Clyde" swarm - example of a swarm not associated with the Alpine Fault. Left: the profile line is shown in brown. Right: note the Alpine Fault is not within the range of the plot. Refer to Fig 8.1 for symbol legend.

Time frame: "Clyde" swarm from 20 Nov to 21 Nov with a few neighbouring events ph2dt statistics: average travel-time: $9.64 \mathrm{~s}$; weakly linked: $0 \%$; average event offset: 2.41 km; P used: 998; S used: 1010

All events (grey crosses): 27; Events relocated (orange crosses moved to red circles): 25

\subsubsection{Cluster 5}

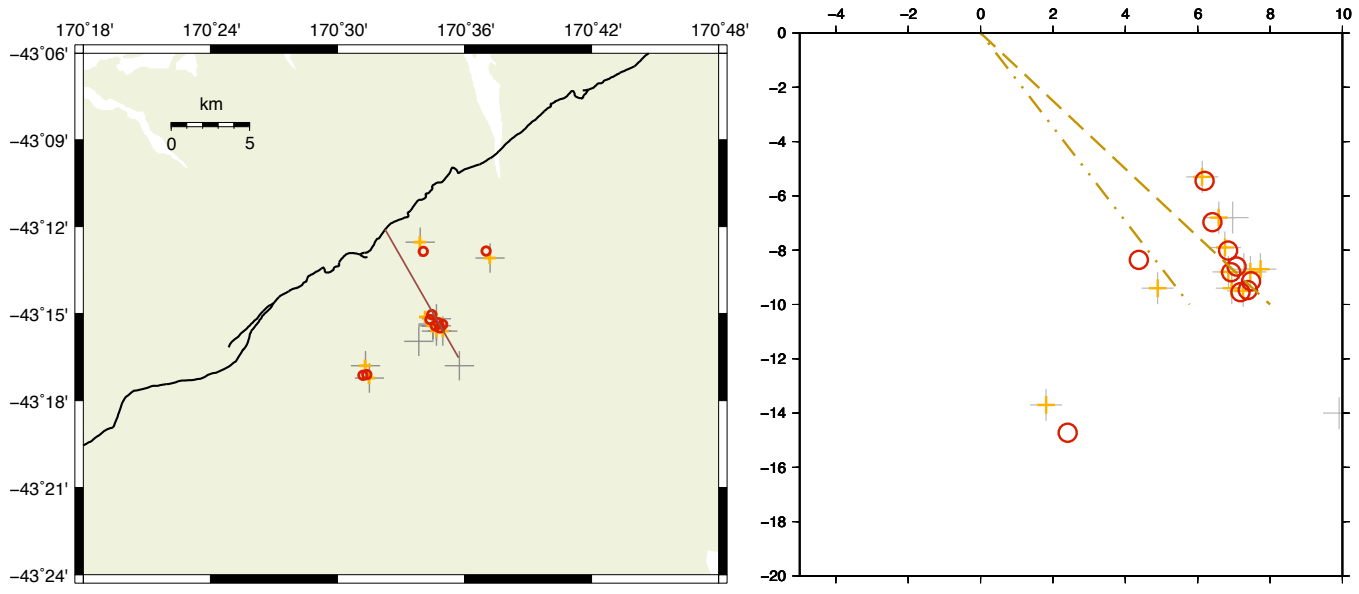

Figure 8.5: Relocation of cluster 5: sporadic events near Whataroa. Left: the profile line is shown in brown. Right: an indicative Alpine Fault is illustrated by the dot-dashed brown line dipping at $60^{\circ}$ and a dashed line dipping at $48^{\circ}$ through a subset of events. Refer to Fig 8.1 for symbol legend.

Time frame: Not a swarm but a cluster of sporadic events throughout survey period ph2dt statistics: average travel-time: 6.38 s; weakly linked: 100\%; average event offset: 
$3.57 \mathrm{~km}$; P used: 126; S used: 73

All events (grey crosses): 13; Events relocated (orange crosses moved to red circles): 10 


\section{Chapter 9}

\section{Discussion and Conclusion}

\subsection{Survey}

The four month time span, array geometry and spacing were suitable for detecting seismicity to a magnitude cut-off of 1.6 including several events within the "aseismic zone". The seismicity was within the average limis expected.

There are many limitations on array geometry including avoiding pervasive background noise, difficulty in widening the array due to access issues to the southeast and bad drainage and lack of access to bedrock to the northwest. This means that it would be difficult to improve array performance significantly without installing borehole seismometers.

\subsection{Catalogue processing}

A time discrepency found in Chancellor Hut (CHH) recordings was investigated. I concluded it was likely an error of one second but it was difficult to separate from an additional apparent time discrepency due to the variations from the $1 \mathrm{D}$ velocity model. The overall time corrections of -1.42 for $\mathrm{P}$ arrivals and -1.61 for $\mathrm{S}$ arrivals was a combination of the suspected one second timing error, the station correction calculated coarsely by removing mean rms and the additional station correction calculated by VELEST. The VELEST model also indicated an almost constant difference between $\mathrm{P}$ and $\mathrm{S}$ corrections of $0.2 \mathrm{~s}$ for each station despite the VPS ratio of 1.68 being confirmed by another Wadati analysis to check the ratio for the final velocity model.

The VELEST modelling favoured model $\mathrm{c}$ as a starting model but the output velocities 
were closer to s10 although within the range of values from the $2 \mathrm{D}$ slice of $\mathrm{c}$. This suggests that the s10 depths were not appropriate but the velocities of the s10 model may be a good approximation of the region studied. Eberhart-Phillips and Bannister (2002) published a $3 \mathrm{D}$ velocity model from inverting passive and active seismic data. Their $\mathrm{Y}=0,-30,-45,-$ $60 \mathrm{~km}$ cross-sections are similar to the final velocity model for the upper $15 \mathrm{~km}$. ( $\mathrm{Y}$ is the distance from the $2 \mathrm{~W}$ SIGHT transect and also approximately corresponds to the distance from the southern extent of my array. Thus $\mathrm{Y}=-60 \mathrm{~km}$ is approximately the northern limits of CAlF). Below these depths, my equivalent velocity changes are deeper. However, at these depths, my VELEST analysis would be indeterminate as only shallow, local events were relocated.

The VELEST depths of some events were resolved to $<0.2 \mathrm{~km}$ around $20 \mathrm{~km}$ southeast of the Alpine Fault. These appeared to form a linear trend. The HYPOCENTER depths of these anomalous events were generally not resolved and stated as $5 \mathrm{~km}$ (the model starting depth). Looking at the waveforms, these were generally small events. At first it was thought they may be earth movement due to ice falls. However, after the VELEST velocity model was used in HYPOCENTER with all VELEST model station corrections applied, over half the suspected ice falls resolved to depths $>2 \mathrm{~km}$ suggesting that most initial depths were an artifact of the HYPOCENTER algorithm not being able to resolve location depths due to a poor velocity model.

The CAlF catalogue includes 35 events at $5 \mathrm{~km}$ depth, an artifact caused by the starting depth bias of $5 \mathrm{~km}$. Although much of the analysis used variations of the s10 velocity model which included a layer boundary at $5 \mathrm{~km}$, the final model did not thus the artifact was not caused by the velocity model.

A number of depths were unusually shallow (14 at $0 \mathrm{~km}$ and $31 \leq 1 \mathrm{~km}$ with a nominal depth error of $116 \mathrm{~km}$ ). Their average azimuthal gap was $260^{\circ}$. As the azimuthal gap and depth errors of these shallow events were generally large, the likely cause is that the station distribution was not sufficient to resolve the depths.

\subsection{Magnitude calculation}

The magnitudes of -0.2 to 4.63 were calibrated to magnitudes of 88 GeoNet catalogue events with a magnitude range of 1.688 to 4.602 and mean of 2.59 . 
The GeoNet magnitudes would have been dependent on their hypocenter location. GeoNet hypocenter locations are generally more northwest than CAlF locations. However, an interim GeoNet catalogue was used initially with only 47 calibration events available (as the GeoNet catalogue is first analysed by the duty seismologist and later updated from further analysis of the GeoNet team). The 47 events ranged from $\mathrm{M}_{L} 1.996$ to 4.649 with mean of 3.03. The initial CAlF magnitudes for this smaller sample of calibration magnitudes ranged from -0.15 to 4.60 indicating a larger selection did not change the final calculated magnitudes significantly.

Model 2 modified the magnitude equation of Robinson (1986) which is used by GeoNet to calculate magnitudes from stations $\leq 100 \mathrm{~km}$ from an event. Initial values of attenuation parameter $\alpha$ using the same geometric spreading parameter $(n)$ of 1 as determined by Robinson (1986) gave a value of $\alpha=0.0167 \mathrm{~km}^{-1}$, more than twice that of Robinson (1986). Using different global values for $n$ still resulted in high attenuation values. Attenuation values from L4 instrument data were almost twice the size of broadband instrument data (0.0297 and $0.0156 \mathrm{~km}^{-1}$ respectively) and over 4 and 2 times that of the Robinson (1986) value of $0.0067 \mathrm{~km}^{-1}$ when using a geometric spreading factor of 1 . This may suggest the following.

- The attenuation is much greater than that at Wellington (the region of the Robinson (1986) study) and other regions of New Zealand also may be different. This may be confined to the uppermost few kilometers.

- The Wood Anderson conversion algorithm was not perfect and some frequency spectrum difference between short period and broadband data remains.

- The instrument response removed to create the synthetic Wood Anderson waveforms was an imperfect match. While the gain difference would be absorbed by the station correction terms, a difference in response slope from actual response would affect the frequency spectrum and hence the Wood Anderson seismogram.

- There is some frequency dependence of the attenuation parameter $\alpha$.

In future microseismicity studies where the shallow velocity structure and attenuation is important, the attenuation parameter may need to be recalculated. Also, for a network of seismographs with different frequency ranges, careful analysis is needed of the different 
instruments to ensure magnitude measurements across the network are consistent and not affected by any frequency dependence on $\alpha$.

Figs 5.2 and 5.4 show that the two models used in the magnitude inversion give similar magnitudes although they are dependent on the station correction to align them. Model 1 distance components of magnitudes are larger than Model 2 from stations at closer distances and may indicate the attenuation component of Model 2 is too low at closer distances. The similarity in magnitudes as seen in Fig 5.2 shows the station correction largely accommodates this disparity. The distance dependence on $\alpha$ at close distances makes intuitive sense as attenuation is greater at shallower depths and the further the station-hypocenter distance, the more the wave has travelled through the deeper crust.

The high attenuation may be due to elevated geotherms and/or the presence of fluids. However, the distance dependence on $\alpha$ indicates it is restricted to the upper layers and more likely associated with low density such as glacial till. The station correction has a larger influence at the shorter distances (seen in Fig 5.4) suggesting any azimuthal difference in velocity model may influence the magnitude calculation more than attenuation for close stations. From Fig 5.6 correction values show more of a correspondence with instrument gain than topography.

\section{4 b-value implications}

The b-value for the survey region (of $0.75 \pm 0.06$ for both my catalogue and the GeoNet catalogue) is anomalously low. It is consistent over a moderate magnitude range of 1.73.2 both in the traditional Gutenberg-Richter magnitude frequency plot as well as the maximum likelihood (ML) analysis and so can be considered a stable result. The GeoNet catalogue for the survey timeframe is still being processed and the final catalogue may include additional events. This will affect the GeoNet catalogue cut-off magnitude although should not affect the b-value significantly as it should be consistent over a wide range of magnitudes up to the cut-off magnitude. Initial CAlF b-values from a smaller range of calibration magnitudes ( 47 compared to 88 events) were similar: 0.73 from the Gutenberg-Richter plot and 0.72 \pm 0.03 from ML.

Factors that could influence the b-value include

- The number of events used. However, the b-value is stable over a wide magnitude 
range and the standard deviation shows the b-value of the survey period is less than the background value within error limits.

- The magnitudes used for calibration may be wrong. GeoNet use a national attenuation that seemed too high for this region compared to our analysis. This would increase the magnitude estimate with increased distance as smaller amplitudes would be over damped, so larger events observed further away would be overestimated giving a smaller b-value. However, this would not affect the comparative b-value result as the same attenuation model was used for the 1991-2006 time range compared.

- Swarms dominate my catalogue and so the b-value could be more a characteristic of swarms than of the region. The smaller b-value, equivalent to relatively more big magnitudes than usual, may indicate that a number of the swarms highlighted asperities along the fault (Wiemer and Wyss, 1997).

- The thrust focal mechanisms predominate the survey compared to usual largely strike-slip behaviour (Schorlemmer et al., 2005).

The survey was only 4 months which is too short to determine a meaningful seismicity estimate. The b-value temporal studies show high variability of $\mathrm{b}$ for this time scale and the clustering would contaminate any background seismicity measurement and characterisation of the Alpine Fault. The data would need to be declustered to remove this which would probably remove almost half the dataset. However, the consistency between CAlF and GeoNet b-values for the same geographic selection and four month sample suggests the b-value is not unique to the catalogue itself. From analysis of a longer period of the GeoNet catalogue (as seen in Fig 5.9) the characteristic b-value of the region is $1.17 \pm 0.07$ standard deviation.

Overall, the central Alpine Fault region is expected to be a weak, low stress, high thermal region based on heat-flow and magnetotelluric studies and so the expected long term seismic behaviour would be of high b-value with diffuse seismicity off the Alpine Fault. A low b-value could indicate the locked fault buckling with events rupturing asperities at either end of the locked section. Alternatively, it could indicate that the anomolous swarms were thrust events compared to largely strike-slip events within the background seismicity. 


\subsection{Locations}

The majority of hypocenters located were outside of the CAlF network, and the location errors reflect this. The survey was designed to capture microseismicity within the low seismicity zone. The magnitude cutoff was 1.6 within the network, and the error for the locations within the target zone were typically $5 \pm 2 \mathrm{~km}$ laterally and $6 \pm 3 \mathrm{~km}$ in depth.

The "horseshoe" pattern of seismicity surrounding the low seismicity zone persists into the lower magnitudes. This may rule out the possibility of shallow aseismic slip in the area as internationally regions of aseismic slip are coupled with microseismicity which is not seen here.

Swarms occur at two places near the trace of the Alpine Fault: at the location of a possible bend in the Alpine Fault (Little et al., 2005) and to the north at the transition zone from low seismicity to high seismicity conspicuously bounding the low seismicity region. The significance that these bound the "horseshoe" shape is another inference of a locked segment of the Alpine Fault.

Sutherland et al. (2007) have noted that the central Alpine Fault region has a shallow brittle-ductile transition zone due to the high exhumation rate and related heat flow. While this may be seen at the southern end, the majority of the seismogenic zone of the region appears to extend to moderate levels of $15-16 \mathrm{~km}$. Admittedly, the depth of the hypocenters was proven to be velocity model dependent, but some well constrained depths have been located at these lower depths (refer to Fig 6.3). The Fox swarm at [169.94, 43.54] is located within the uplift transition zone suggested by Little et al. (2005) and pictured in 9.1. The relocation of this cluster (refer to Subsection 8.3.1) suggests the swarm is a point cluster and events with the lowest depth error (6 events with depth error erz $<3 \mathrm{~km})$ are located at depth $8.6 \pm 2.6 \mathrm{~km}$.

Leitner et al. (2001) defined the brittle ductile transition zone at $12 \pm 2 \mathrm{~km}$ based on the range of lower depth values. This is closer to what I find. Eberhart-Phillips (1995) found the seismicity dipping from $10 \mathrm{~km}$ near the fault to $20 \mathrm{~km}$ to the SE. There were not enough events in the CAlF catalogue to distinguish any planar or dipping structure, but from Fig 9.1 the seismicity does appear to conform to the thermal model of Allis and Shi (1995).

Comparisons of GeoNet and CAlF locations reveal minor differences in locations. Of 

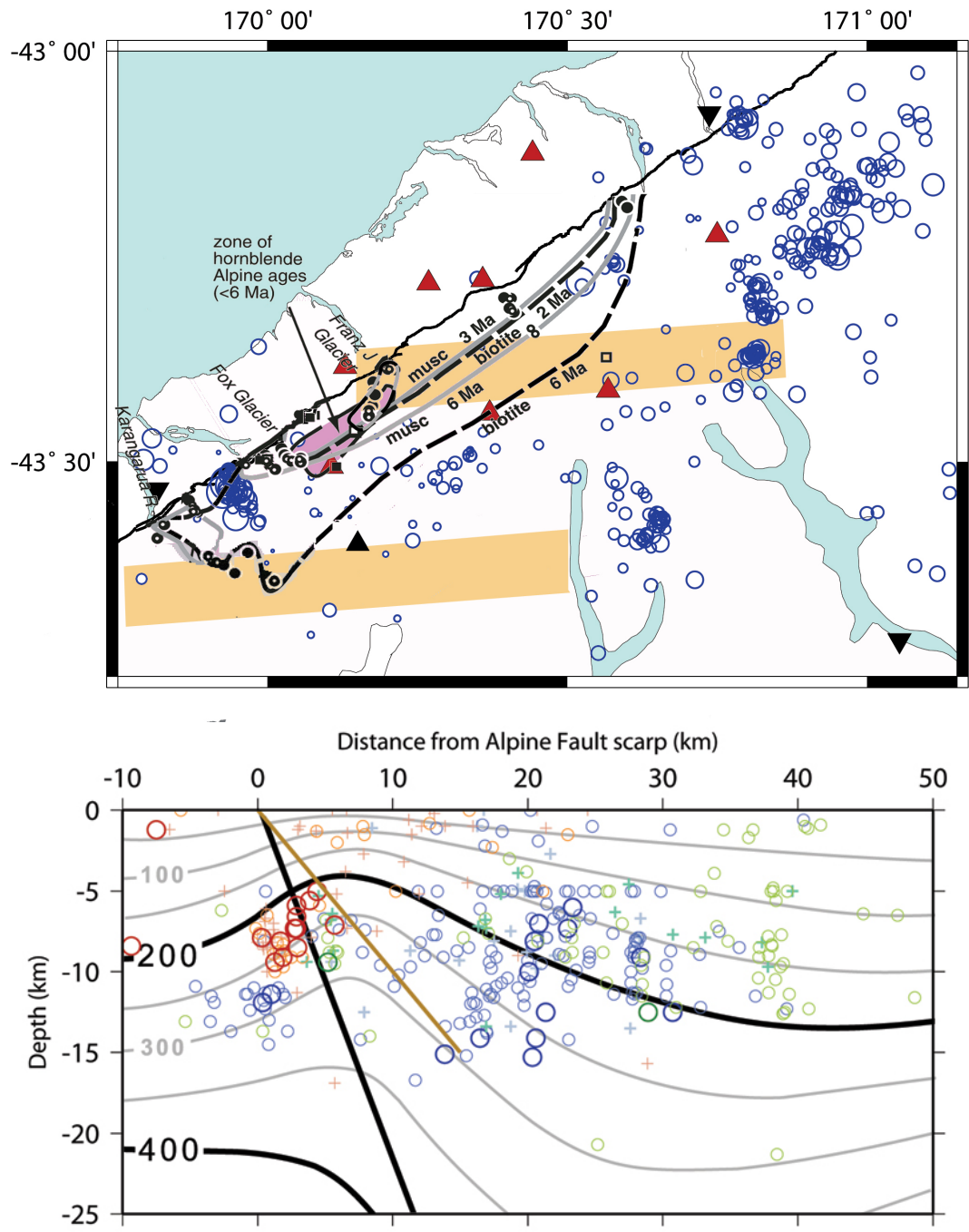

Figure 9.1: Final map and cross-section locations compared to Little et al. (2005); Allis and Shi (1995). Top figure: the map of seismicity from the CAlF catalogue is overlaid by the Little et al. (2005) figure with inferred transition zones of uplift rate in orange and observed zone of young hornblende in pink. These uplift anomalies are within the $20 \mathrm{~km}$ long section of fault where the fault is thought to steepen by $15-20^{\circ}$ compared to the south to a dip of around $40-50^{\circ}$ and extend deeper, with hotter rock from deeper sources being brought up rather than brought up from a localised hotter area (Little et al., 2005). Bottom panel: the cross-section events are differentiated into three colour sets of the three cross-sections seen previously in Fig 6.2: reds for the southern swath, greens for the centre and blues for the northern swath. Thick dark circles are $M_{L}>2.6$ (i.e. above GeoNet $\mathrm{M}_{\text {cutoff }}$; crosses $M_{L}<1.3$ (unlikely to be seen by GeoNet) small light circles: between 1.3 and 2.6 (some possibly seen by GeoNet). The plot is overlaid with the heat flow model of Allis and Shi (1995). The top thick line is the $200^{\circ}$ isotherm and bottom one $400^{\circ}$ with $50^{\circ}$ intervals between. Black dipping line is their inference of the Alpine Fault while the brown line dips at $45^{\circ}$. It is plausible to assign the brittle ductile transition at the $300^{\circ}$ isotherm and, in turn, observe the shallowing of the geotherm by around $5 \mathrm{~km}$ in the southern section (red circles) where the uplift rate is highest.

the 88 GeoNet catalogue locations that correspond to the CAlF catalogue, only 8 have a latitude difference greater than 0.1 and a longitude difference grater than 0.2 . The average location difference places GeoNet locations $0.04^{\circ} \pm 0.2^{\circ}$ more west and $0.03^{\circ} \pm 0.1$ more 
north. But if only differences $\leq 0.1$ are analysed, around $70 \%$ are more northwest which is most pronounced with the Fox swarm locations.

This bias suggests the differences in velocity model between the two catalogues may be the cause; or that anisotropy parallel and close to the Alpine Fault may influence the arrival times of the further GeoNet stations. Okaya et al. (1995) reported lab measurements of anisotropy as high as 17\% from samples close to the fault although Pulford et al. (2003) used active seismic data and revealed little apparent anisotropy suggesting the affect of any anisotropy may be overshadowed by the heterogeneous velocity structure.

There are several vertical lineations of seismicity between 20 and $40 \mathrm{~km}$ which could easily be misidentified as faults but which are more likely point clusters of seismcity that have spread over a range of depths due to low depth resolution. However, the distance from the Alpine Fault suggests that this activity is either from fractured regions affected by fluid flow or that it may coincide with Main Divide Fault Zone activity.

There were not enough events located within $15 \mathrm{~km}$ of the Alpine Fault trace to define a dip of the Alpine Fault or to identify which, if any are caused by the Alpine Fault. However, there were several events within the range of the scarp to qualify as candidates. In addition, Allis and Shi (1995) indicated a shallowing of the isotherm gradient which is reflected in the depth locations of CAlF seismicity (seen in Fig 9.1) which fall within the dip estimates of the Alpine Fault plane.

\subsection{Focal mechanisms}

Focal mechanisms for events with the best azimuthal gap were estimated, which, due to the seismograph array configuration were also those closest to the Alpine Fault trace. The focal mechanismis are inconclusive. This result is partially due to the uncertainty in seismograph polarity from poor huddle test results, but also because the events were largely shallow and small in magnitude making first motion readings difficult given the poor signal-to-noise characteristic of the region.

From an overview of polarities observed I could conclude, however, that focal mechanisms were not homogenous with at least two opposite subsets of focal mechanisms apparent. 


\subsection{Swarms and clusters}

Swarms usually occur in either highly fractured regions or regions dominated by fluid flow causing localised changes in pressure (Kurz et al., 2004).

Swarm activity dominated the seismicity of the survey period. Swarms occur near or on the Alpine Fault within the notably seismic region to the north of the array, at the edge of the proposed Alpine Fault lateral curvature of Little et al. (2005) and away from the Alpine Fault within the Main Divide Fault Zone region SE of the Main Divide.

Several swarms were seen away from the Alpine Fault also indicating that swarming is a common characteristic throughout the region. The cause is likely to be the changes in geographical characteristics of thermal and fluid regime rather than individual faulting behaviour.

The cummulative event rate plot (refer to Fig 5.7) shows three major and three minor swarm series.

Relocations of a selection of swarms and clusters (in Chapter 8) were of limited success although generally redefined the relative locations as approximately point sources. Those close to the Alpine Fault are located in what may be the footwall of the Fault which may indicate that the velocity model has located the events too far to the northwest.

The Alpine Fault evolved from a vertical strike-slip fault to a dipping oblique fault within the last c. 6-5 Ma (King, 2000; LeBrun et al., 2003). An alternative hypothesis might currently partition the Fault into multiple active fault planes at depth. If this is the case, then the three swarms relocated near the Alpine Fault may fall within the hanging wall of an earlier fault plane or on different fault planes.

\subsection{Review of thesis questions}

Questions to investigate throughout this thesis were:

1. What is the 4-monthly variation in seismicity recorded by GeoNet? How does the period of this study compare with this (i.e. how typical is my survey period)? The variation in seismicity is seen in Fig 3.2 with the CAlF catalogue seismicitiy falling within normal levels. Completeness determined from both classical Gutenberg-Richter magnitude frequency plots and maximum-likelihood b-value estimates showed compara- 
ble b-values for the same time range and geographic selection. However, the b-value analysis of the same region over different time periods and time scales confirmed the low b-value is unusual for the region.

2. What is the frequency-magnitude distribution? Is there substantially more microseismic activity in the central activity (from thermal effects on rupture onset)? What is the b-value distribution? The frequency magnitude distribution showed a good fit with slope and an unusually low b-value. This is in contrast to the background b-value of the longer time period. The anomaly is not an artifact of a low sample number, as similar sized subsets of the GeoNet catalogue prior to the survey showed b-values consistently larger and the same as the long-term b-value within error limits. It is possible that the dominance of the swarms over this period is the cause of the low b-value. These may be associated with high pressure rupturing asperities on or close to the Alpine Fault in contrast to diffuse, low pressure, high heat flow background seismicity off the fault or a predominance of thrust events within the swarms.

3. What is the spatial and temporal seismicity distribution laterally and with depth? The"horseshoe" shaped seismicity pattern observed from long-term national catologue data is similar for smaller magnitudes. While the central portion of the Alpine Fault is quieter with unusually low b-value, the region is not aseismic. Neither does it experience the level of microseismicity seen in creeping faults elsewhere.

4. What is the behaviour of earthquakes in the central Alpine Fault region? Are they independent, swarm-like or fore-main-after shock like? In some timeframes, the waveforms and locations looked very similar and it was not uncommon to find events within seconds and fractions of a second from each other. None of the earthquake sequences observed showed any definitive main-shocks indicating the prevalence of swarm behaviour.

5. What are the focal mechanisms? Are they coherent, vary smoothly with latitude or chaotic? Focal mechanisms were inconclusive due to largely emergent first motions and uncertainties in seismograph polarities. However, if, as suspected, first motion polarities were the reverse to those assumed, then the four focal mechanisms with 
the clear first motions are all approximately thrust mechanisms, agreeing with the deduction of Schorlemmer et al. (2005): that b-values of thrust mechanisms are low.

6. What is the depth of the brittle-ductile transition? Is it abrupt or gradual? Insufficient seismicity was recorded to distinguish between an abrupt or gradual transition. There were not enough events in the CAlF catalogue to distinguish any planar or dipping structure, but seismicity does appear to conform to the thermal model of Allis and Shi (1995) with most seismicity above the $300^{\circ}$ isotherm and seismicity shallowing near the Allis and Shi (1995) estimates of the Alpine Fault plane. Events near the isotherm are around $15 \mathrm{~km}$ depth. The SW limit of the seismicity is dominated by the Fox swarm at a depth of $8.6 \pm 2.6 \mathrm{~km}$ for well located events expressing either the dominance of the Fox cluster in the catalogue or a shallowing of the brittle-ductile zone by the high, localised exhumation rate and high heat flow.

\subsection{Conclusion}

Further study is needed to establish a 2 or $3 \mathrm{D}$ velocity structure and locate a longer timeframe of seismicity with this improved velocity model. A borehole array is recommended to improve signal-to-noise obscurity and assess attenuation effects. 


\section{Bibliography}

Adams, J. (1980). Paleoseismicity of the Alpine fault seismic gap, New Zealand. Geology, $8: 72-76$.

Allis, R. G. and Shi, Y. (1995). New insights to temperature and pressure beneath the central Southern Alps, New Zealand. New Zealand Journal of Geology and Geophysics, $38: 585-592$.

Anderson, H. and Webb, W. (1994). New Zealand seismicity: patterns revealed by the upgraded National Seismograph Network. New Zealand Journal of Geology and Geophysics, 37:477-493.

Beavan, J., Matherson, D., Denys, P., Denham, M., Herring, T., Hager, B., Molnar, P., and Walcott, D. (2004). A vertical deformation profile across the Southern Alps, New Zealand, from 3.5 years of continuous GPS data. In: Proceedings of Workshop, The State of GPS Vertical Positioning Precision: Separation of Earth Processes by Space Geodesy, Cahiers du Centre Europen de Godynamique et de Sismologie, 23:111-123.

Beavan, J., Moore, M., Pearson, C., Henderson, M., Parsons, B., Bourne, S., England, P., Walcott, D., Blick, G., Darby, D., and Hodgkinson, K. (1999). Crustal deformation during 1994-1998 due to oblique continental collision in the central Southern Alps, New Zealand, and implications for seismic potential of the Alpine fault. Journal of Geophysical Research, 104:25233-25256.

Berryman, K., Stirling, M., Webb, T., Beavan, J., and Darby, D. (2002). Kinematics and strain at the Australia-Pacific Plate Boundary, South Island, New Zealand: integration of seismicity, earthquake geology, geodesy and plate motions. EGS XXVII General Assembly, Nice, 21-26 April 2002, abstract \#6874, 27:6874. 
Bonner, J. L., Blackwell, D. D., and Herrin, E. T. (2003). Thermal Constraints on Earthquake Depths in California. Bulletin of the Seismological Society of America, 93(6):23332354.

Bull, W. B. and Brandon, M. T. (1998). Lichen dating of earthquake-generated regional rockfall events, Southern Alps, New Zealand. Geological Society of America Bulletin, 110:60-84.

Cao, A. and Gao, S. S. (2002). Temporal variation of seismic b-values beneath northeastern Japan island arc. Geophysics Research Letters, 29:1-3.

Cox, S. C. and Findlay, R. H. (1995). The Main Divide Fault Zone and its role in the formation of the Southern Alps. New Zealand Journal of Geology and Geophysics, 38:489-499.

De Mets, C., Gordon, R. G., Argus, D. F., and Stein, S. (1994). Effect of recent revisions to the geomagnetic reversal timescale on estimates of current plate motions. Geophysical Research Letters, 21:2191-2194.

Eberhart-Phillips, D. (1995). Examination of seismicity in the Central Alpine Fault region, South Island, New Zealand. New Zealand Journal of Geology and Geophysics, 38:571578.

Eberhart-Phillips, D. and Bannister, S. (2002). Three-dimensional crustal structure in the Southern Alps region of New Zealand from inversion of local earthquakes and active source data. Journal of Geophysical Research, 107:2262-2275.

Eiby, G. A. (1959). The structure of New Zealand from seismic evidence. Geologische Rundschau, 47:647-662.

Evison, F. F. (1971). Seismicity of the Alpine Fault, New Zealand. In: Collins, B. W.; Fraser, R. ed. Recent crustal movements. Royal Society of New Zealand Bulletin, 9:161-165.

Findlay, R. H. (1997). The so-called Main Divide Fault Zone from the Tasman and Murchison to Godley Glaciers - Repy. New Zealand Journal of Geology and Geophysics, 40:120. 
Frohlich, C. and Davis, S. D. (1993). Teleseismic b values; or, much ado about 1.0. Journal of Geophysical Research, 148:631-644.

Fuis, G. S., Kohler, M. D., Scherwath, M., ten Brink, U., van Avendonk, H. J. A., and Murphy, J. M. (2007). A comparison between the transpressional plate boundaries of South Island, New Zealand, and Southern California, USA: the Alpine and San Andreas fault systems. Geophysical Monograph, 175:307-327.

Gardner, J. and Knopoff, L. (1974). Is the sequence of earthquakes in Southern California, with aftershocks removed, Poissonian? Bulletin of the Seismological Society of America, 64:1433-1466.

GNS. (1991). Workshop: Structural transition from Alpine Fault to Hikurangi Margin in space and time. Programme and abstracts. Geological Society of New Zealand Miscellaneous Publication 56.

Greenhalgh, S. A. and Singh, R. A. (1986). A revised magnitude scale for South Australian earthquakes. Bulletin of the Seismological Society of America, 75:757-770.

Gutenberg, B. and Richter, C. F. (1986). Frequency of earthquakes in California. Bulletin of the Seismological Society of America, 34:185-188.

Hatherton, T. (1969). Geophysical anomalies over the eu- and miogeosynclinal systems of California and New Zealand. Bulletin of the Geological Society of America, 80:213-230.

Hatherton, T. (1980). Shallow seismicity in New Zealand 1956-75. Journal of the Royal Society of New Zealand, 10:19-25.

Havskov, J. and Ottemöller, L. e. (2005). SEISAN: The earthquake analysis software for Windows, SOLARIS, LINUX and MACKINTOSH Version 8.1. Manual. Department of Earth Science, University of Bergen, Norway.

Hutton, L. K. and Boore, D. M. (1987). The ML scale in Southern California. Bulletin of the Seismological Society of America, 77(6):2074-2094.

Jiracek, G. R., Victor, M., Gonzalez, T., Caldwell, G., Wannamaker, P. E., and Kilb, D. (2007). Seismogenic, electrically conductive, and fluid zones at continental plate 
boundaries in New Zealand, Himalaya, and California, USA. Geophysical Monograph, $175: 347-369$.

Kagan, Y. Y. (1999). Universality of the seismic momentfrequency relation. Pure and Applied Geophysics, 148:537-573.

Kagan, Y. Y. (2004). Short-term properties of earthquake catalogs and models of earthquake source. Bulletin of the Seismological Society of America, 94(4):1207-1228.

Keir, D., Stuart, G. W., Jackson, A., and Ayele, A. (2006). Local earthquake magnitude scale and seismicity rate for the Ethiopian Rift. Bulletin of the Seismological Society of America, 96(6):2221-2230.

King, P. R. (2000). Tectonic reconstructions of New Zealand 40 Ma to the present. New Zealand Journal of Geology and Geophysics, 43(4):611-638.

Kissling, E. and Kradolfer, U. and Maurer H. (1995). VELEST user's guide-short introduction, technical report. Inst. of Geophys. and Swiss Seismol. Serv., Eidg. Tech., Hochsch., Zurich.

Kleffman, S., Davey, F., Melhuish, A., Okaya, D., Stern, T., and SIGHT Team (1998). Crustal structure in the central South Island, New Zealand, from the Lake Pukaki seismic experiment. New Zealand Journal of Geology and Geophysics, 41:39-49.

Knopoff, L. (2000). The magnitude distribution of declustered earthquakes in Southern California. Proceedings of the National Academy of Science, 97:11880-11884.

Kurz, J. H., Jahr, T., and Jentzsch, G. (2004). Earthquake swarm examples and a look at the generation mechanism of the Vogtland/Western Bohemia earthquake swarms. Physics of The Earth and Planetary Interiors, 142:75-88.

Lamb, S. H. (1988). Tectonic rotations about vertical axes during the last $4 \mathrm{Ma}$ in part of the New Zealand plate-boundary zone. Journal of Structural Geology, 10:875-893.

LeBrun, J. F., Lamarche, G., and Collot, J. Y. (2003). Subduction initiation at a strikeslip plate boundary: The Cenozoic Pacific-Australian plate boundary, south of New Zealand. Journal of Geophysical Research, 108:2453. 
Leitner, B., Eberhart-Phillips, D., Anderson, H., and Nabelek, J. L. (2001). A focused look at the Alpine fault, New Zealand: Seismicity, focal mechanisms, and stress observations. Journal of Geophysical Research, 106:2193-2220.

Lienert, B. R. E., Berg, E., and Frazer, L. N. (1986). Hypocenter: An earthquake location method using centered, caled, and adaptively least squares. BSSA, 76:771-783.

Little, T. A., Cox, S. C., Vry, J. K., and Batt, G. (2005). Variations in exhumation level and uplift rate along the oblique-slip Alpine Fault, central Southern Alps, New Zealand. Geological Society of America Bulletin, 117(5/6):707-723.

Little, T. A. and Jones, A. (1998). Seven million years of strike-slip and related offfault deformation, northeastern Marlborough fault system, South Island, New Zealand. Tectonics, 17:285-302.

Little, T. A., Savage, M. K., and Tikoff, B. (2002). Relationship between crustal finite strain and seismic anisotropy in the mantle, Pacific-Australia plate boundary zone, South Island, New Zealand. Geophysical Journal International, 151:106-116.

Michelini, A. and A., L. (2004). The effect of velocity structure errors on double-difference earthquake location. Geophysical Research Letters, 31:9602.

Molnar, P., Anderson, H. J., Audoine, E., Eberhart-Phillips, D., Gledhill, K. R., Klosko, E. R., McEvilly, T. V., Okaya, D., Savage, M. K., Stern, T., and Wu, F. T. (1999). Continuous deformation versus faulting through the continental lithosphere of New Zealand. Science, 286(5439):516-519.

Mori, J. and Abercrombie, R. E. (1997). Depth dependence of earthquake frequencymagnitude distributions in California: Implications for rupture initiation. Journal of Geophysical Research, 102:15081-15090.

Nakamura, T., Suzuki, S., Sadeghi, H., Aghda, S. M. F., Gandomi, A. J., and M., M. (2005). Source fault structure of the 2003 Bam earthquake, southeastern Iran, inferred from the aftershock distribution and its relation to the heavily damaged area: Existence of the Arg-e-Bam fault proposed. Geophysical Research Letters, 32:09308. 
Newman, A. V., Schwartz, S. Y., Gonzalez, V., DeShon, H. R., Protti, J. M., and M., D. L. (2002). Along-strike variability in the seismogenic zone below Nicoya Peninsula, Costa Rica. Geophysical Research Letters, 29:1977.

Nippress, S. E. J. and Rietbrock, A. (2007). Seismogenic zone high permeability in the Central Andes inferred from relocations of micro-earthquakes. Earth and Planetary Science Letter, 263:235 - 245.

Norris, R. J. (2004). Strain localization within ductile shear zones beneath active faults: the Alpine Fault contrasted with the adjacent Otago fault system, New Zealand. Earth Planets Space, 56(12):1095-1101.

Norris, R. J. and Cooper, A. F. (2001). Late Quaternary slip rates and slip partitioning on the Alpine Fault, New Zealand. Journal of Structural Geology, 23:507-520.

Norris, R. J. and Cooper, A. F. (2007). The Alpine Fault, New Zealand: surface geology and field relationships. Geophysical Monograph, 175:157-175.

Norris, R. J., Koons, P. O., and Cooper, A. F. (1990). The obliquely convergent plate boundary in the South Island of New Zealand: Implications for ancient collision zones. Journal of Structural Geology, 12:715-726.

Okaya, D., Christensen, N., Stanley, D., and Stern, T. A. (1995). Crustal anisotropy in the vicinity of the Alpine Fault Zone, South Island New Zealand. New Zealand Journal of Geology and Geophysics, 175:579-583.

Okaya, D., Stern, T., Davey, F., Henrys, S., and Cox, S. (2007). Continent-continent collision at the Pacific/Indo-Australian plate boundary: background, motivation and principal results. Geophysical Monograph, 175:1-18.

Öncel, A. O. and Wilson, T. (2007). Anomalous seismicity preceding the 1999 Izmit event, NW Turkey. Geophysical Journal International, 169(1):259-270.

Öncel, A. O. and Wyss, M. (2000). The major asperities of the $1999 \mathrm{M}_{w}=7.4$ Izmit earthquake defined by the microseismicity of the two decades before it. Geophysical Journal International, 143:501-506. 
Pulford, A., Savage, M., and Stern, T. (2003). Absent anisotropy: the paradox of the Southern Alps orogen. Geophysical Research Letters, 30(20).

Reyners, M. (1987). Subcrustal earthquakes in the central South Island, New Zealand, and the root of the Southern Alps. Geology, 15:1168-1171.

Reyners, M. (1989). New Zealand seismicity 1964-87: an interpretation. New Zealand Journal of Geology and Geophysics, 32:307-315.

Rhoades, D. A. and Van Dissen, R. J. (2003). Estimates of the time-varying hazard of rupture of the Alpine Fault, New Zealand, allowing for uncertainties. New Zealand Journal of Geology and Geophysics, 46:479-488.

Robinson, R. (1978). Seismicity within a zone of plate convergence - the Wellington region, New Zealand. Geophysical Journal of the Royal Astronomical Society, 55:693-702.

Robinson, R. (1986). Seismicity, structure and tectonics of the Wellington region, New Zealand. Geophysical Journal International, 87:379-409.

Robinson, R. (2004). Potential earthquake triggering in a complex fault network: the northern South Island, New Zealand. Geophysical Journal International, 159:734-748.

Roumelioti, Z., Kiratzi, A., and Melis, N. (2003). Relocation of the 26 July 2001 Skyros Island (Greece) earthquake sequence using the double-difference technique. Physics of the Earth and Planetary Interiors, 138:231-239.

Savage, M. and Rupp, S. (2000). Foreshock Probabilities in New Zealand. New Zealand Journal of Geology and Geophysics, 43:461-469.

Scherwath, M. (2002). Lithospheric structure $\mathcal{G}$ deformation in an oblique continental collision zone, South Island, New Zealand. PhD thesis, Victoria University of Wellington, New Zealand.

Scholz, C. H., Rynn, J. M. W., Weed, R. W., and Frohlich, C. (1973). Detailed seismicity of the Alpine Fault zone and Fiordland region, New Zealand. Geological Society of America Bulletin, 84(10):3297-3316.

Schorlemmer, D., Wiemer, S., and Wyss, M. (2005). Variations in earthquake-size distribution across different stress regimes. Nature, 437:3297-3316. 
Shi, Y., Allis, R., and Davey, F. (1996). Thermal modeling of the Southern Alps, New Zealand. Pure and Applied Geophysics, 146:469-501.

Smith, E. G. C. and Christophersen, A. (2007). The Initiation of Aftershock Sequences: a New Formulation for the Omori Aftershock Law. Eos Trans. AGU, 88(52).

Smith, E. G. C., Stern, T., and O`Brien, B. (1995). A seismic velocity profile across the central South Island, New Zealand, from explosion data. New Zealand Journal of Geology and Geophysics, 38:565-570.

Snoke, J. A. (2003). FOCMEC: FOcal MEChanism determinations, International Handbook of Earthquake and Engineering Seismology, section 85.12. International Handbook of Earthquake and Engineering Seismology. Academic Press, San Diego.

Snoke, J. A., Munsey, J. W., Teague, A. G., and Bollinger, G. A. (1984). A program for focal mechanism determination by combined use of polarity and SV-P amplitude ratio data. Earthquake Notes, 55(3):15.

Stein, S. and Wysession, M. (2003). Physical dispersion due to anelasticity, section 3.7.8. An introduction to seismology, earthquakes and earth structure. Blackwell Publishing, Oxford.

Stern, T., Kleffman, S., Okaya, D., Scherwath, M., and Bannister, S. (2001). Low seismicwave speeds and enhanced fluid pressure beneath the Southern Alps of New Zealand. Geology, 29(8):679-682.

Stock, J. M. and Molnar, P. (1982). Uncertainties in the relative positions of the Australia, Antarctica, Lord Howe, and Pacific plates since the Late Cretaceous. Journal of Geophysical Research, 87:4697-4714.

Sutherland, R. (1999). Cenozoic bending of New Zealand basement terranes and Alpine Fault displacement: a brief review. New Zealand Journal of Geology and Geophysics, 42:295-301.

Sutherland, R., Eberhart-Phillips, D., Harris, R. A., Stern, T., Beaven, J., Ellis, S., Henrys, S., Cox, S., Norris, R. J., Berryman, K. R., Townend, J., Bannister, S., Pettinga, J., Leitner, B., Wallace, L., Little, T. A., Cooper, A. K., Yetton, M., and Stirling, M. 
(2007). Do great earthquakes occur on the Alpine fault in central South Island, New Zealand? Geophysical Monograph, 175:235-251.

Sutherland, R. and Norris, R. J. (1995). Late Quaternary displacement rate, paleoseismicity, and geomorphic evolution of the Alpine Fault: evidence from Hokuri Creek, South Westland, New Zealand. New Zealand Journal of Geology and Geophysics, 38:419-430.

Waldhauser, F. and Ellsworth, W. L. (2000). A Double-Difference Earthquake Location Algorithm: Method and Application to the Northern Hayward Fault, California. Bulletin of the Seismological Society of America, 90:1353-1368.

Waldhauser, F. (2001). hypoDD - A Program to Compute Double-Difference Hypocenter Locations (hypoDD version 1.0 - 03/2001). US Geological Survey Open File Rep., Menlo Park, CA, USA.

Wallace, L. M., Beavan, J., McCaffrey, R., Berryman, K., and Denys, P. (2006). Balancing the plate motion budget in the South Island, New Zealand using GPS, geological and seismological datas. Geophysical Journal International, 168:332-352.

Wellman, H. W. (1979). An uplift map for the South Island of New Zealand, and a model for the uplift of the Southern Alps. Origin of the Southern Alps, Royal Society of New Zealand Bulletin, 18:13-20.

Wellman, H. W. and Willet, R. W. (1942). The geology of the West Coast from Abut Head to Milford Sound. Part 1. Royal Society of New Zealand Bulletin, 71(4):282-306.

Wells, A., Yetton, M. D., Duncan, R. P., and Stewart, G. H. (1979). Prehistoric dates of the most recent Alpine Fault earthquakes, New Zealand. Origin of the Southern Alps, Royal Society of New Zealand Bulletin, 18:5-12.

Wells, A., Yetton, M. D., Duncan, R. P., and Stewart, G. H. (1998). Modes of oblique compression: Late Cenozoic tectonics of the South Island of New Zealand. Reviews of Geophysics, 36:1-26.

Wells, A., Yetton, M. D., Duncan, R. P., and Stewart, G. H. (1999). Prehistoric dates of the most recent Alpine Fault earthquakes, New Zealand. Geology, 27(11):995-998. 
Wiemer, S. and Wyss, M. (1997). Mapping the frequency-magnitude distribution in asperities: an improved technique to calculate recurrence times? Journal of Geophysical Research, 102:15115-15128.

Woessner, J., Wiemer, S., and Toda, S. (2005). Physical Mechanisms Causing high b-value Regions in Aftershock Zones. Geophysical Research Abstracts, 7:04452.

Yetton, M. (1998). Progress in understanding the paleoseismicity of the central Alpine Fault, Westland, New Zealand. New Zealand Journal of Geology and Geophysics, 41:307315. 
Appendix A

\section{Stations}




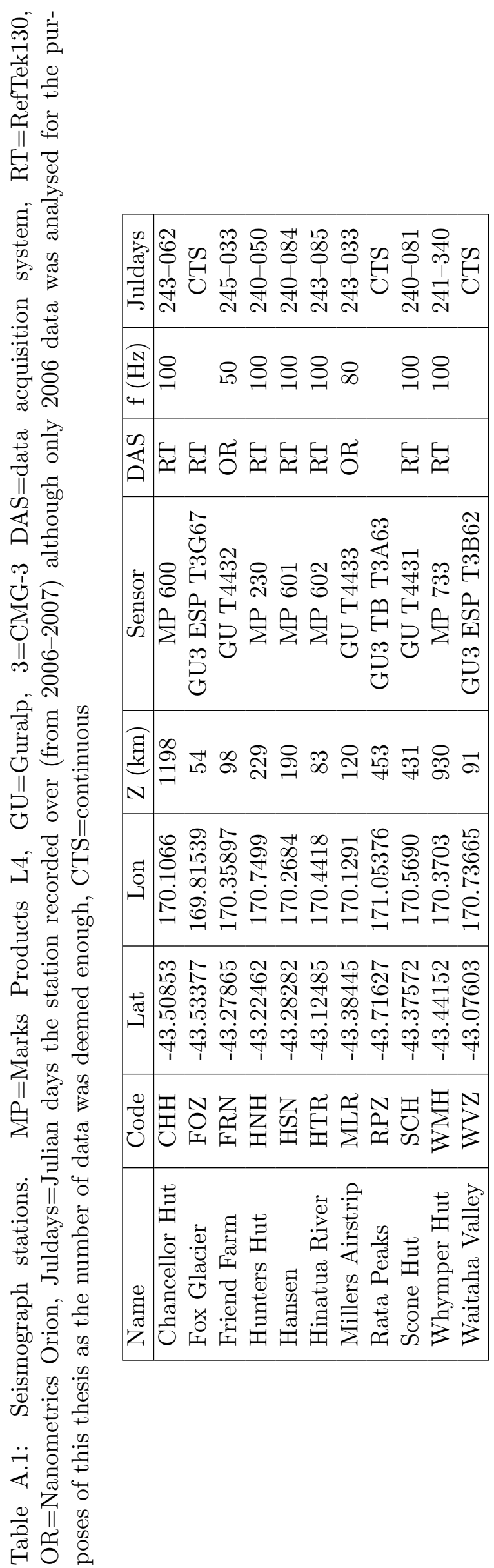


Appendix B

Magnitude Inversion Statistics 


\begin{tabular}{|c|c|c|c|}
\hline$\infty$ & 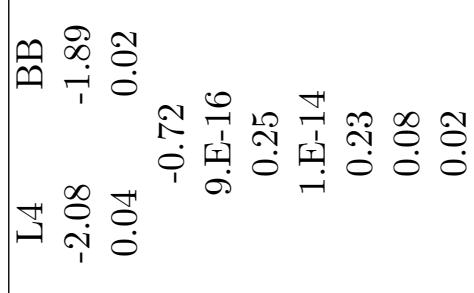 & $\infty$ & 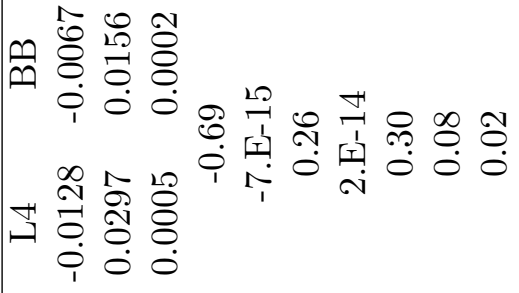 \\
\hline & 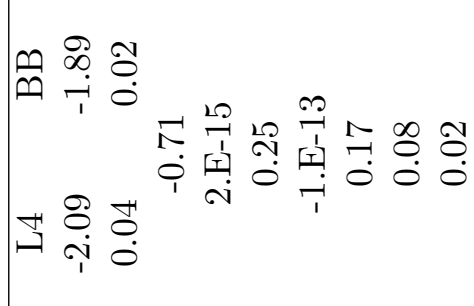 & 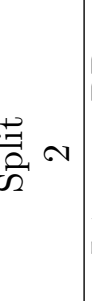 & 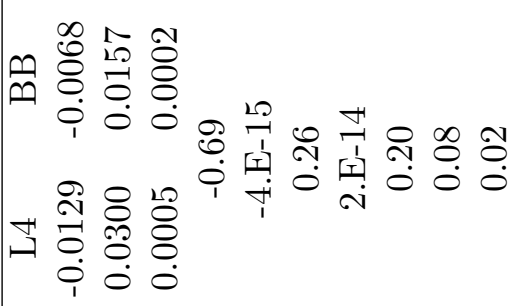 \\
\hline-1 & 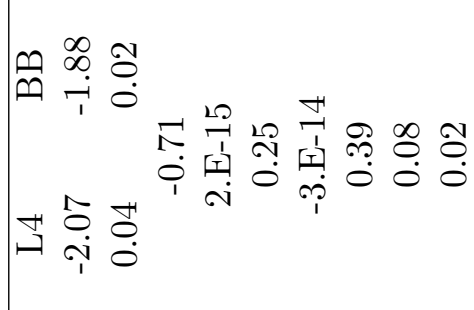 & - & 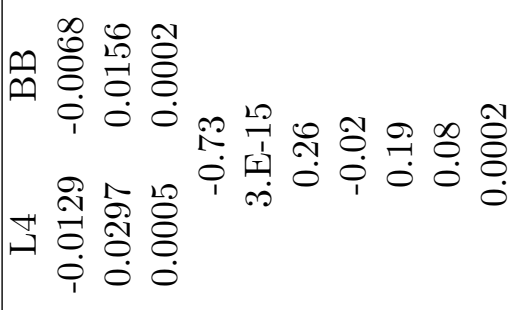 \\
\hline$\infty$ & 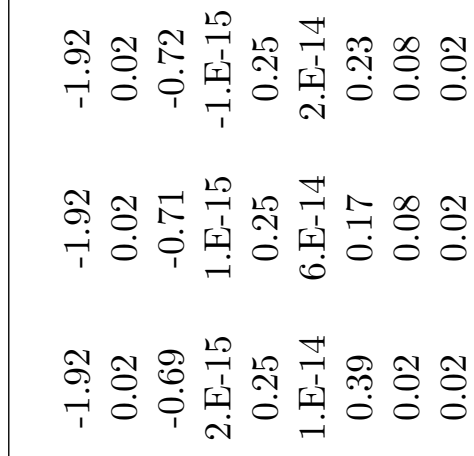 & 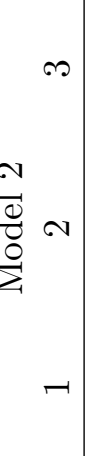 & 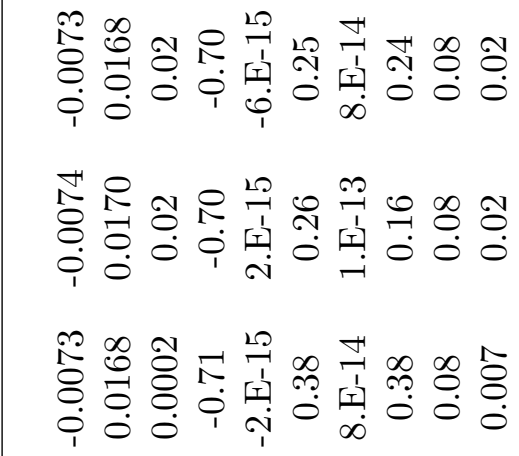 \\
\hline 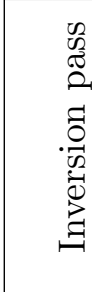 & 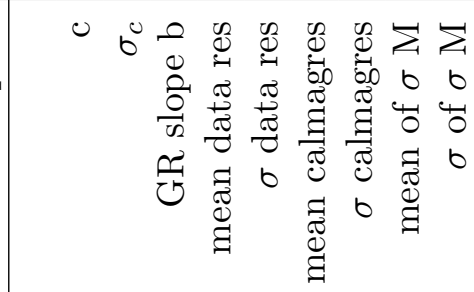 & 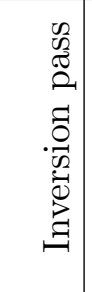 & 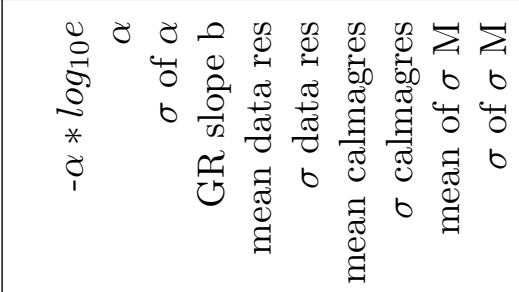 \\
\hline
\end{tabular}


Appendix C

CAlF Event Catalogue 


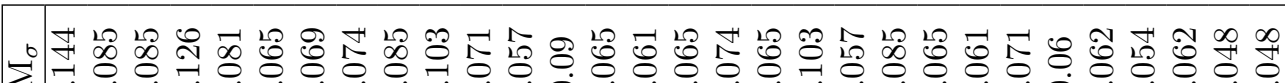

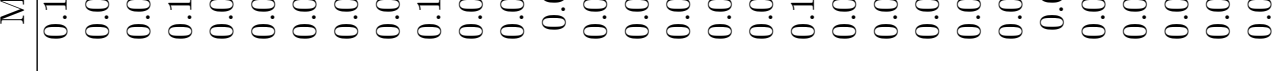

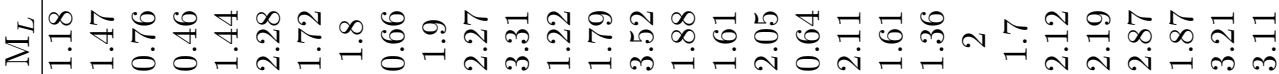
హ)

송

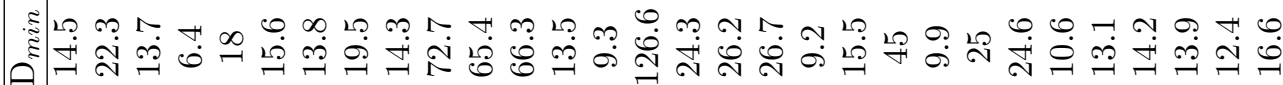
Zำ 0 ○以

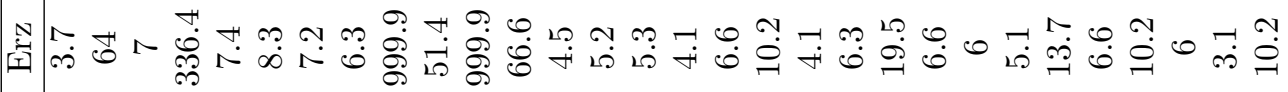
包| 島

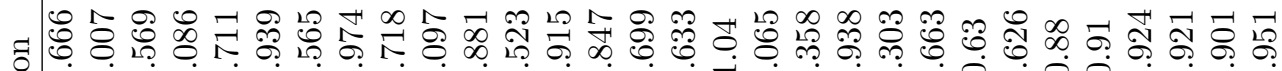

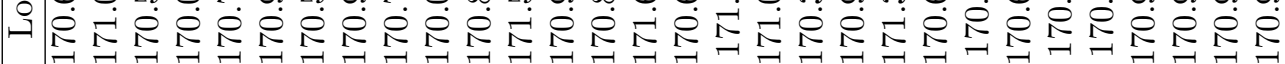

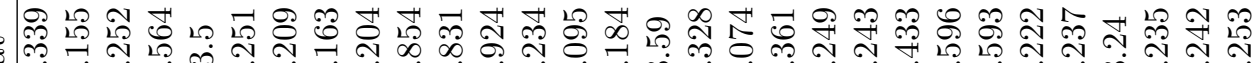
च न 两

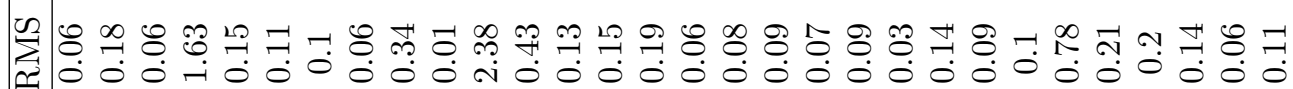
央 以 费 0 밥 켜으긍 예 勾的 


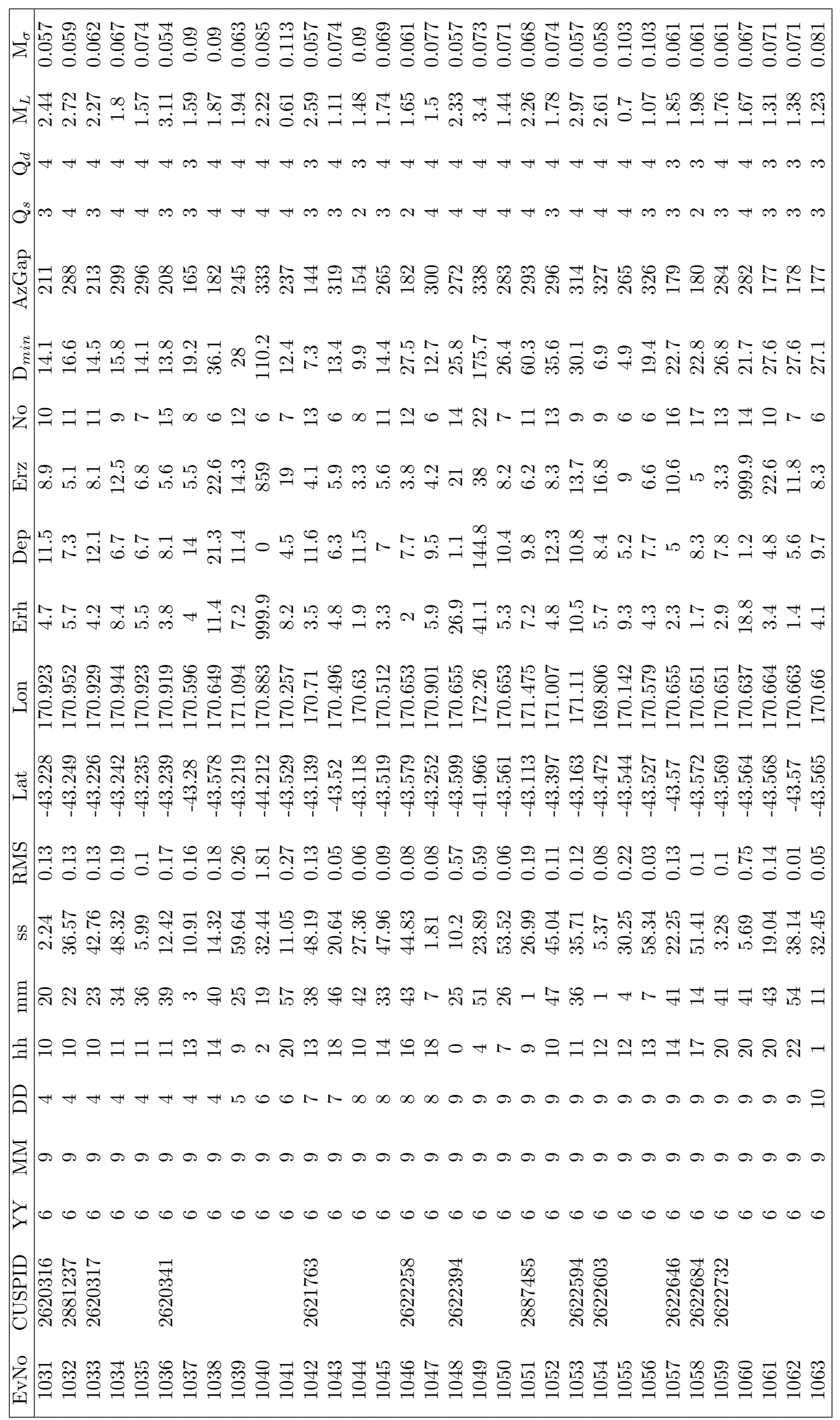




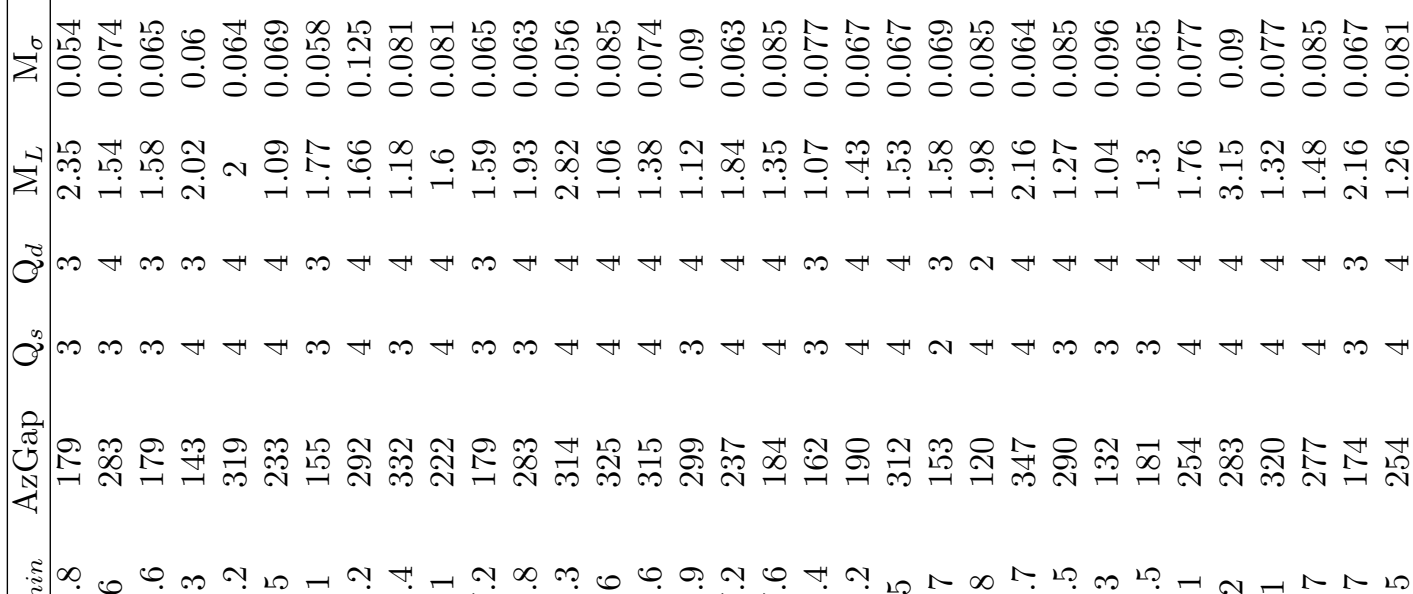

氞

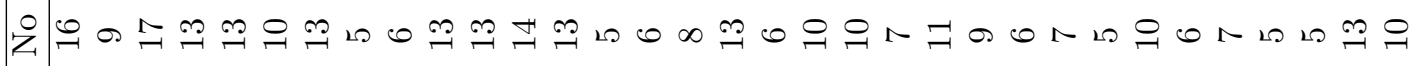
竎

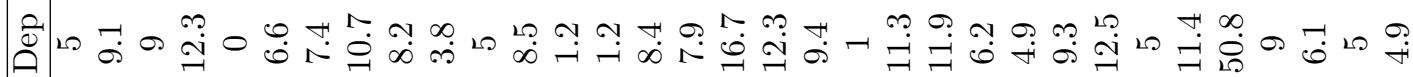
島

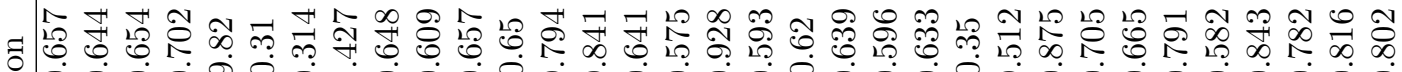
-

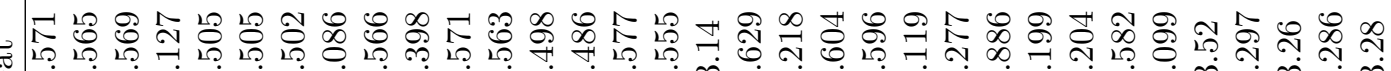

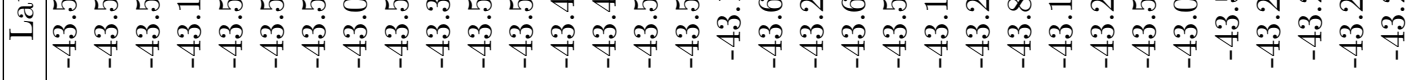

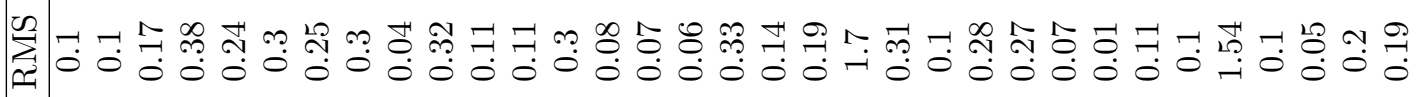

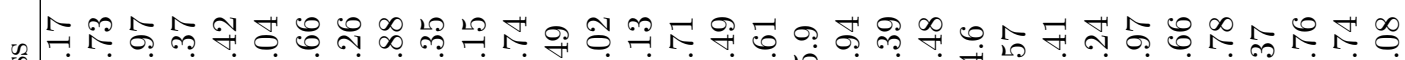
๙ 弱

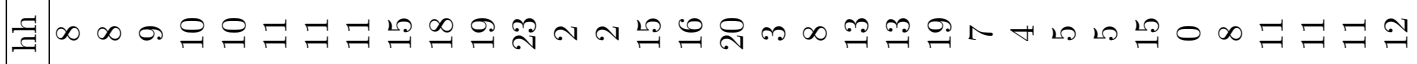

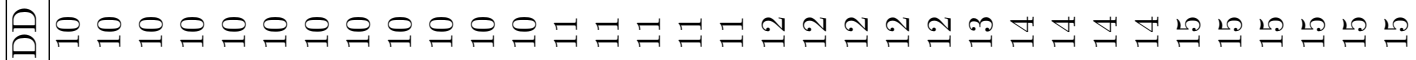

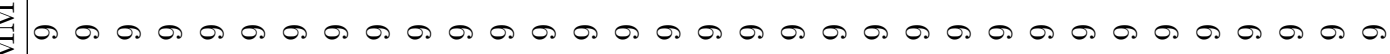
I 1000000000000000000000000000000000

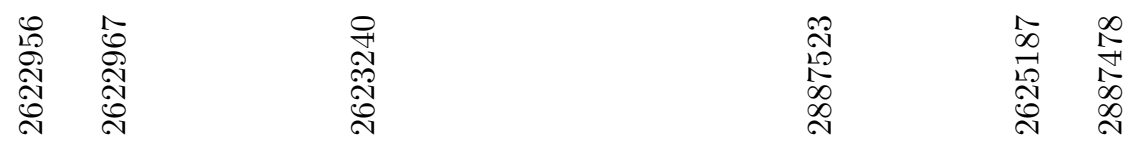

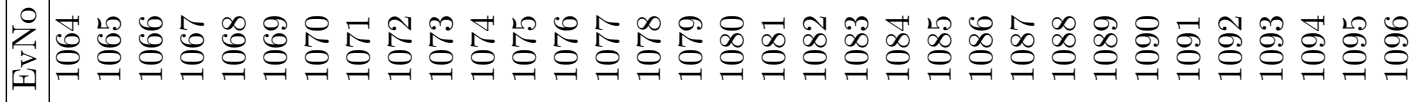




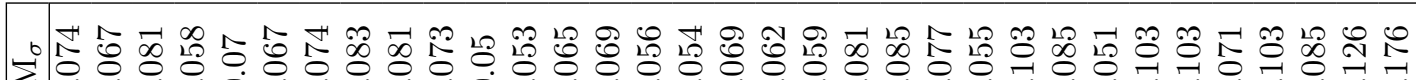

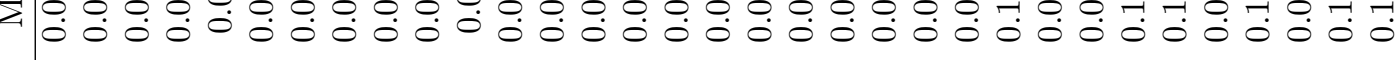

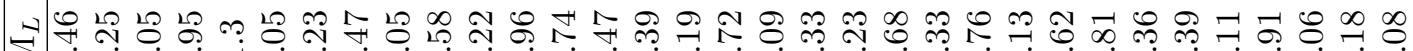

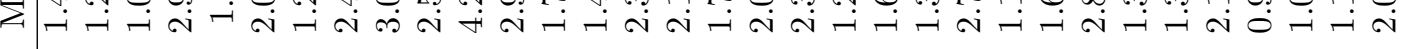
今

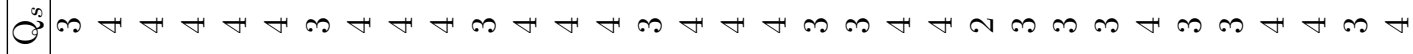

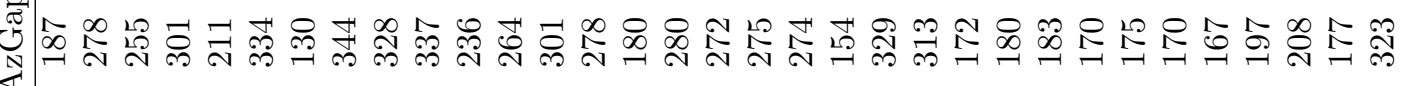

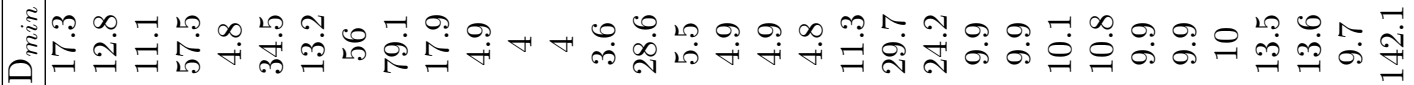

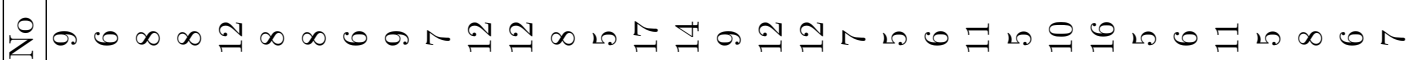

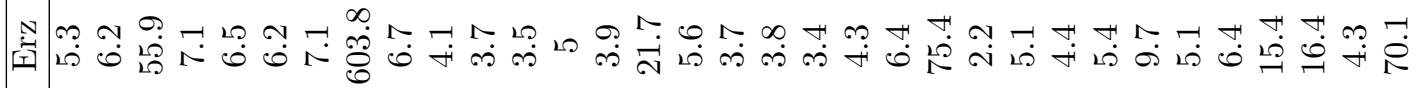

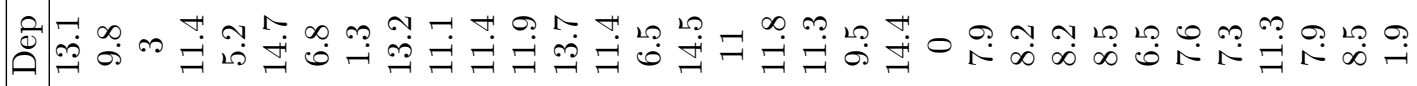

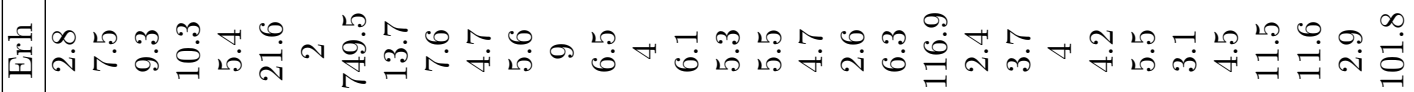
च

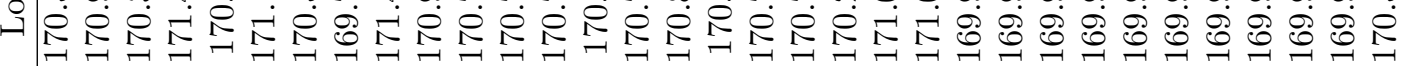

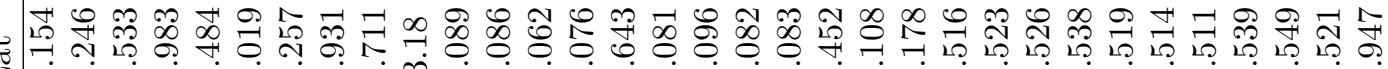
沓算

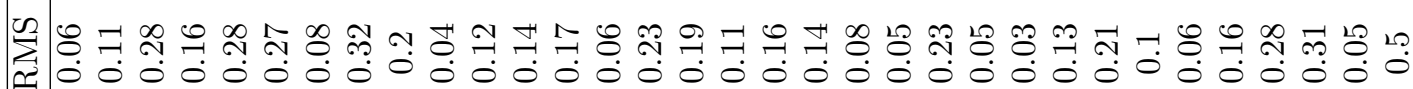

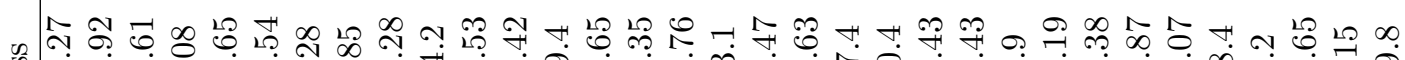
م 乎の○

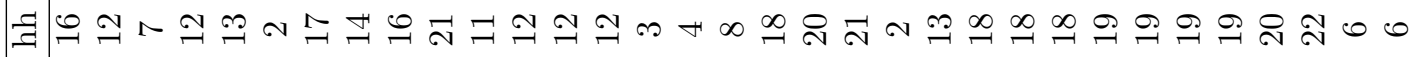

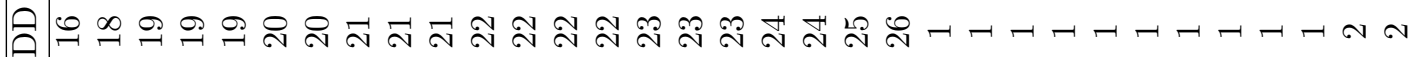

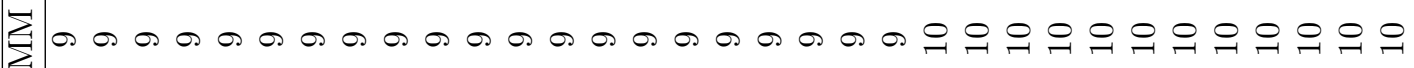
7000000000000000000000000000000000

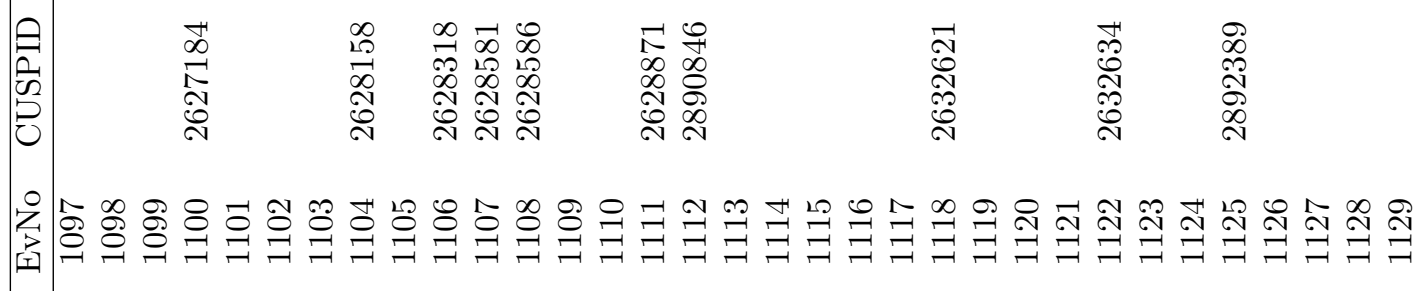




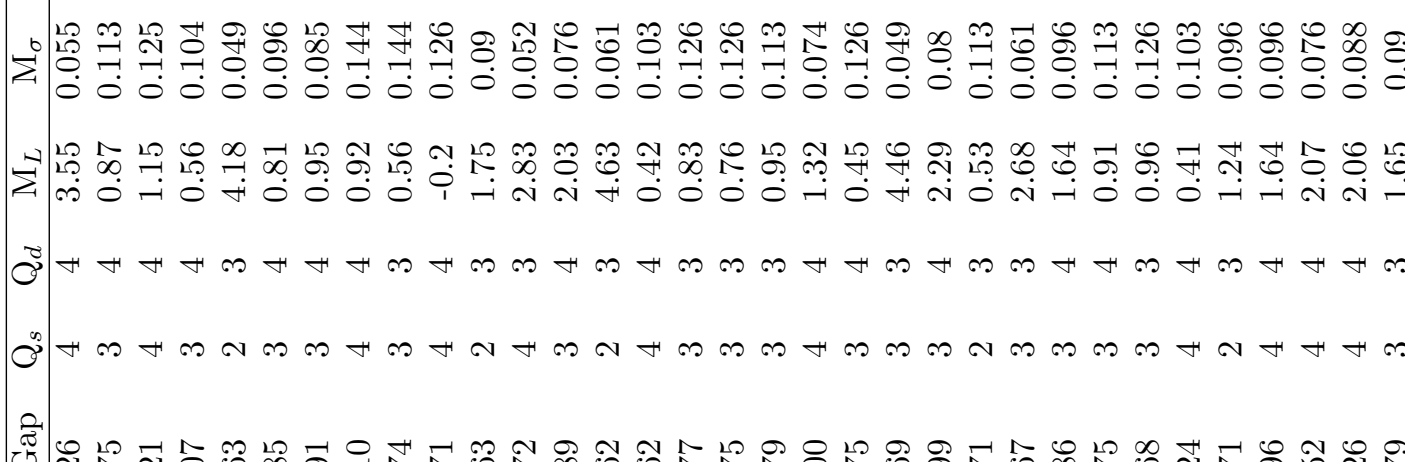

过 氙

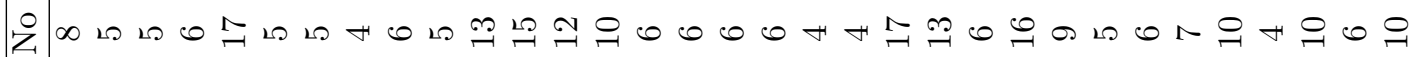

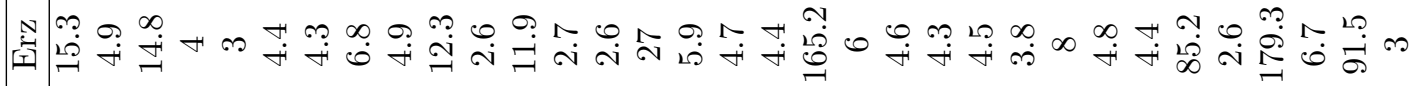

|ᄆ

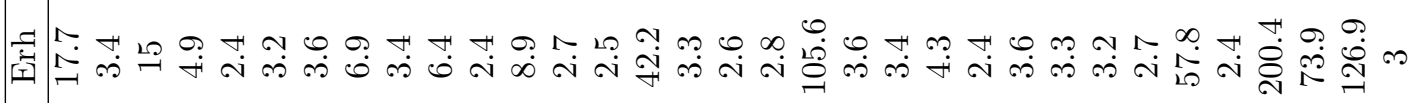

శี

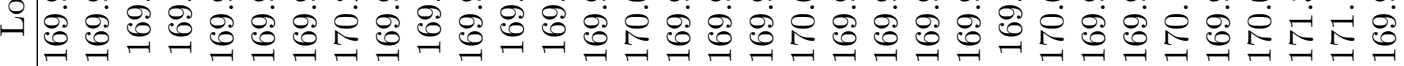

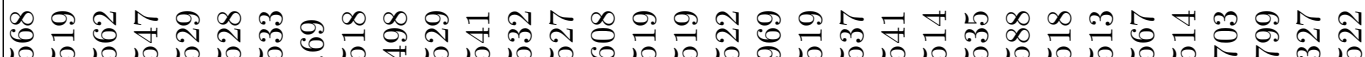

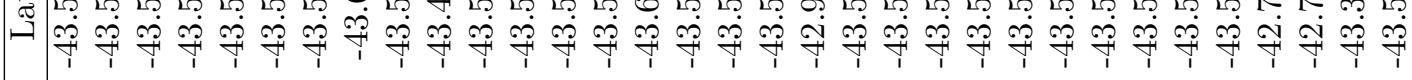

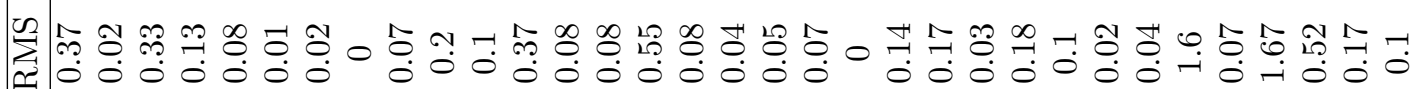

๘ ॠ 弱

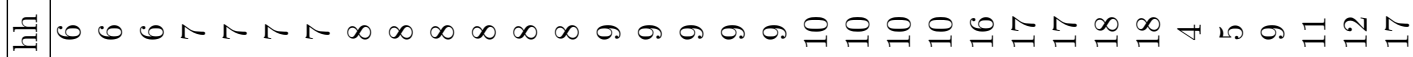

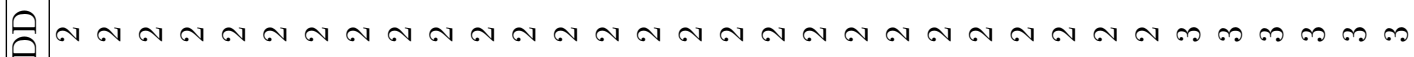

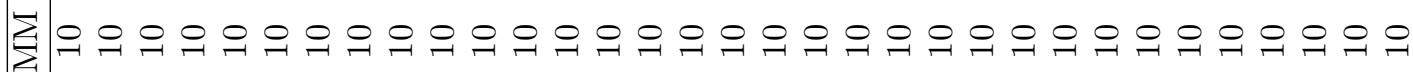
I 1000000000000000000000000000000000

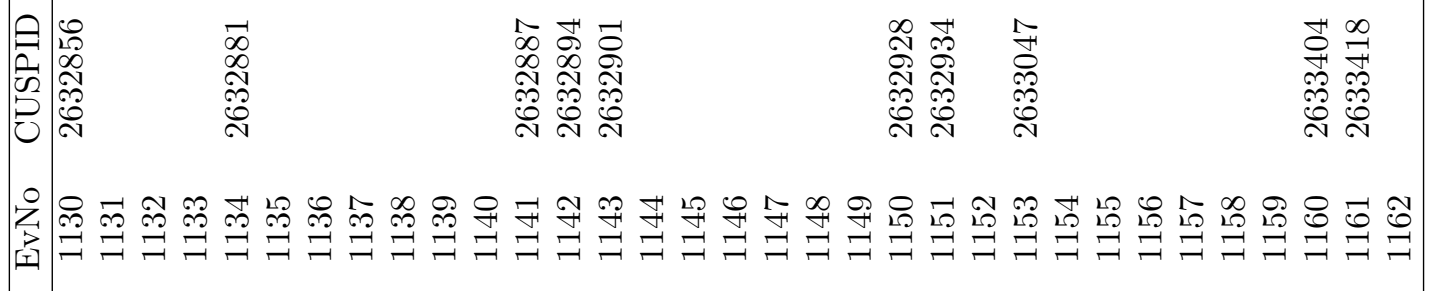




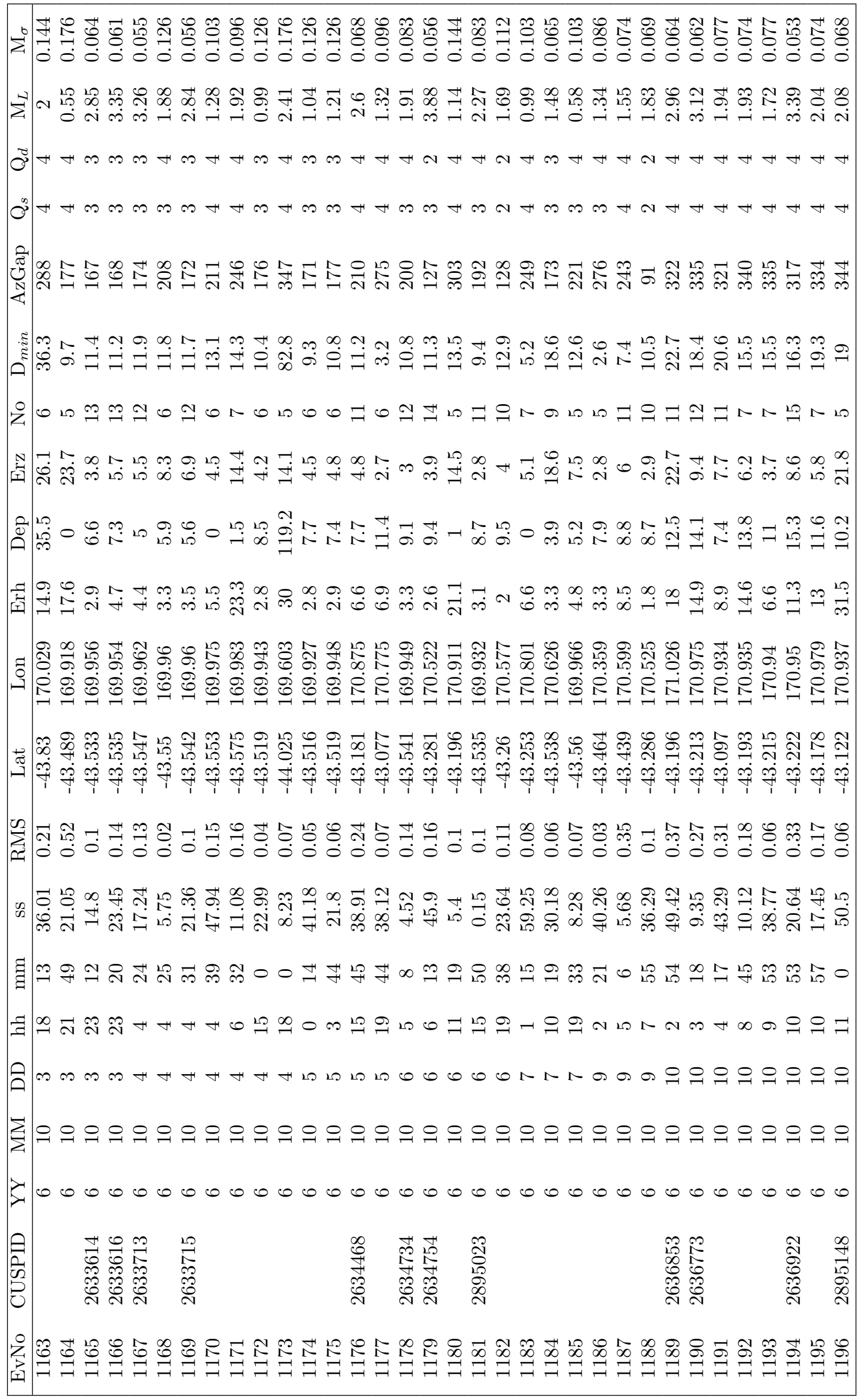




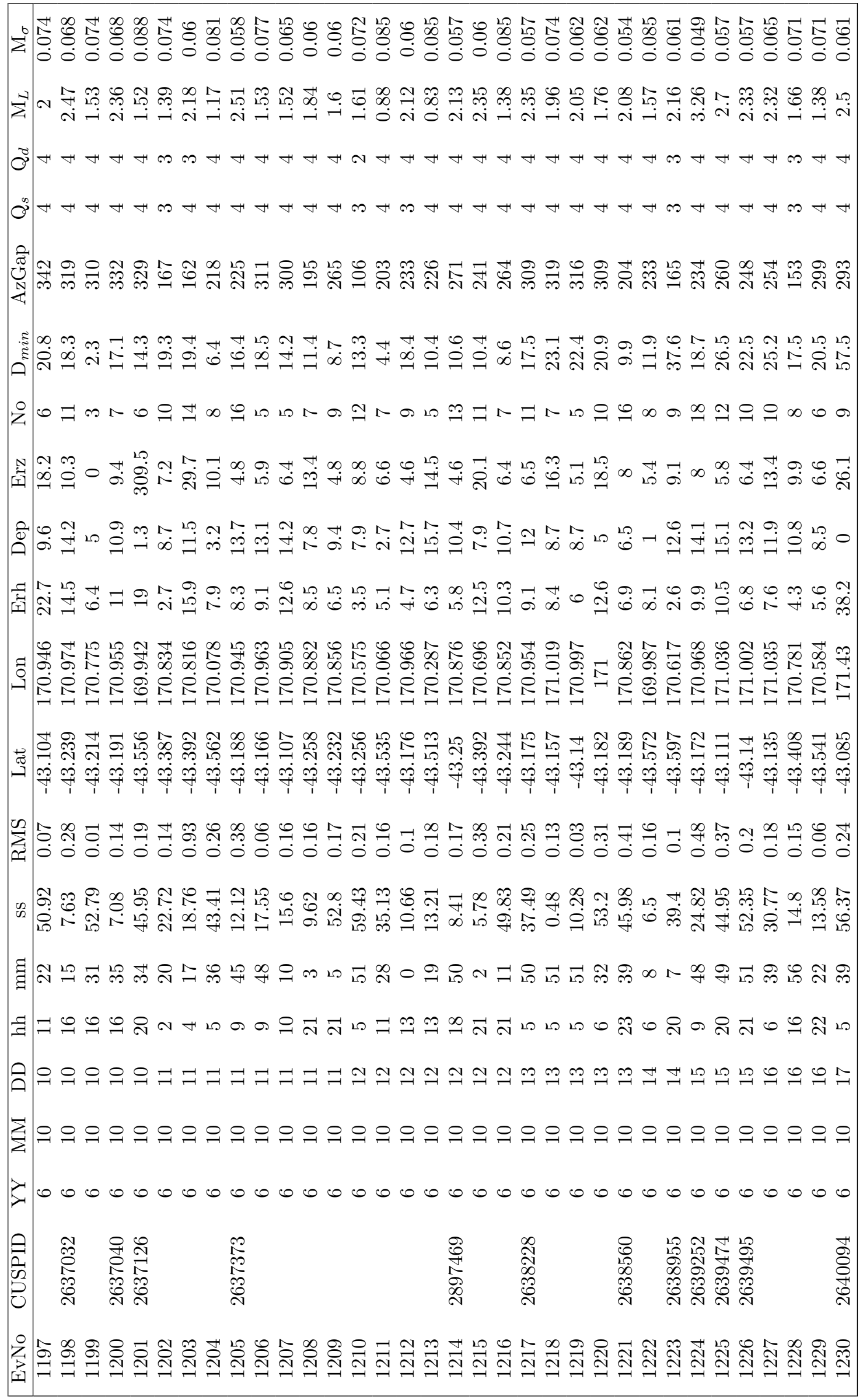




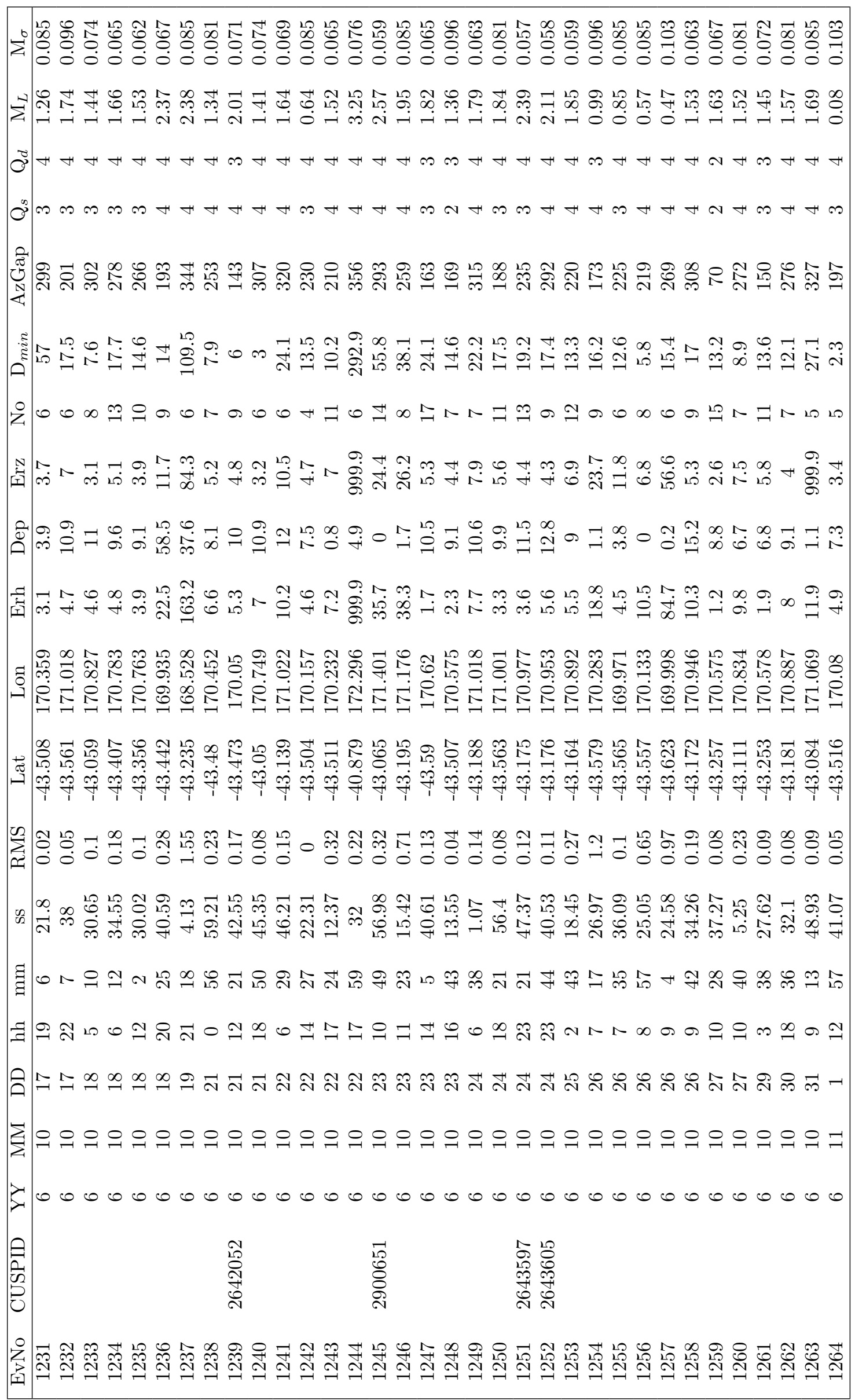




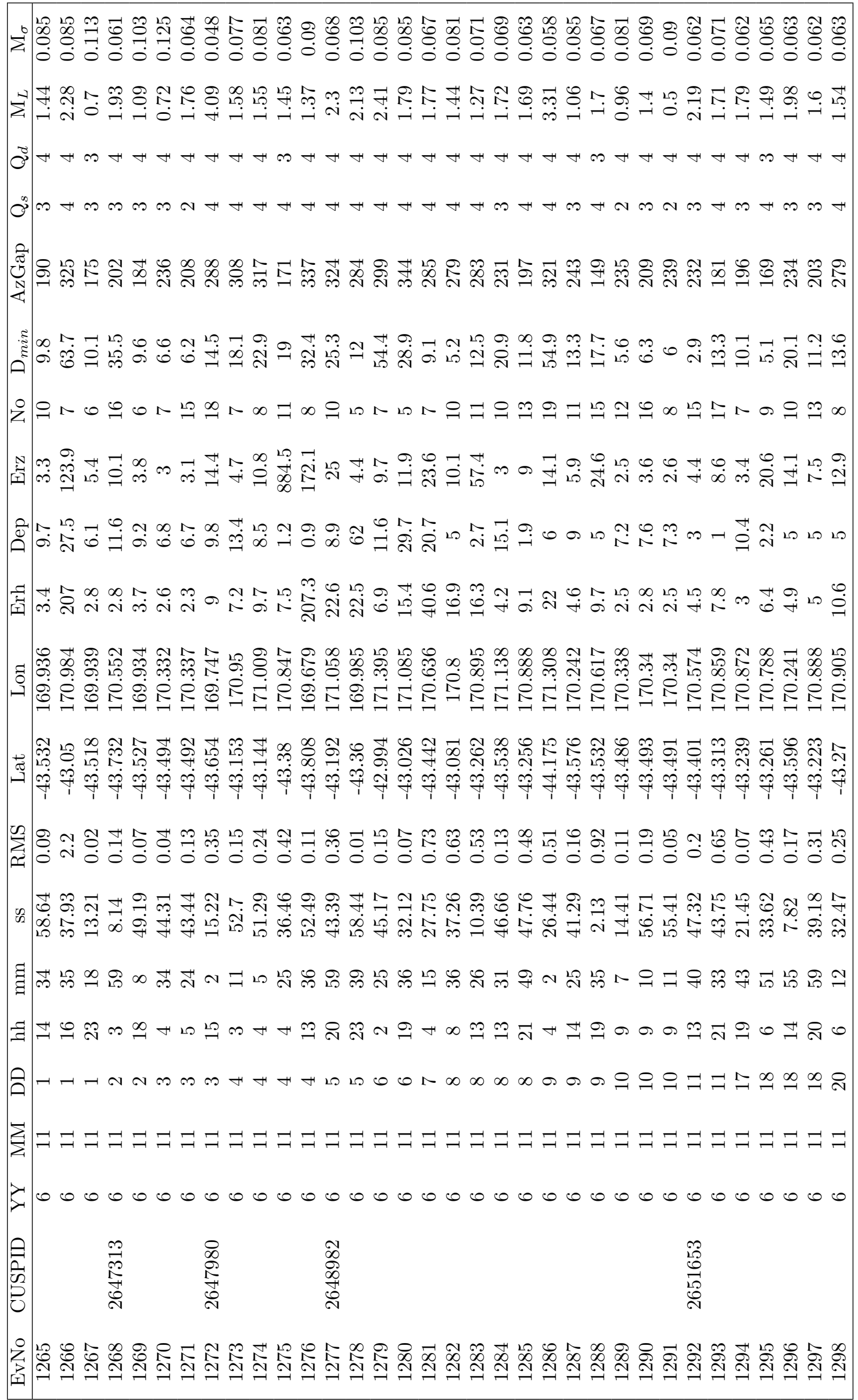


ᄂ

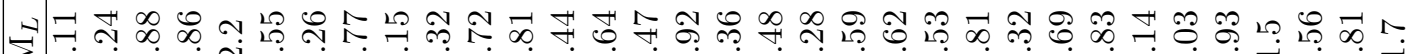
- - 的

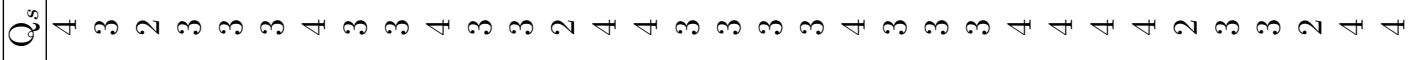

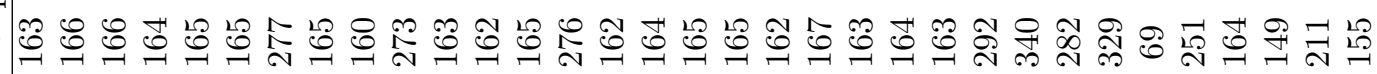

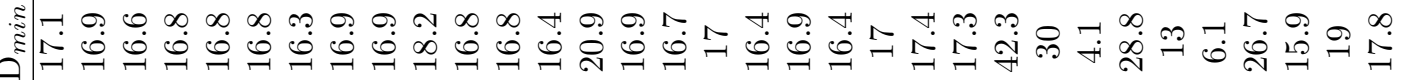


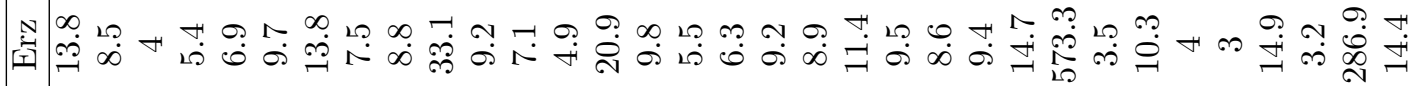
岗

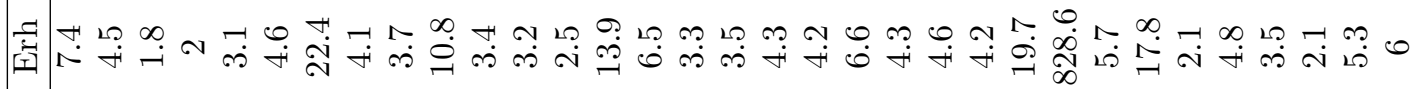

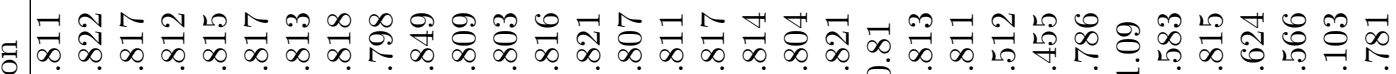
-

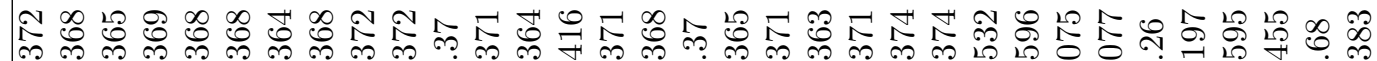

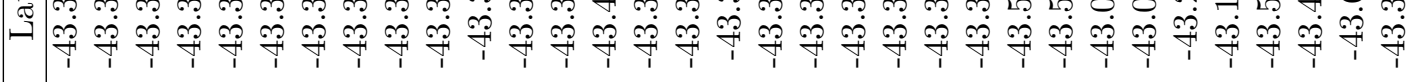
กิ in ๘ ळ

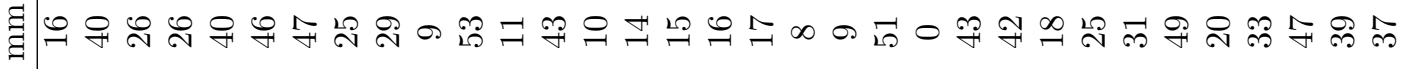

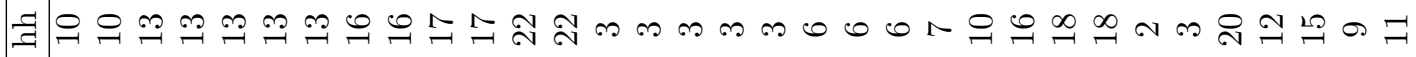

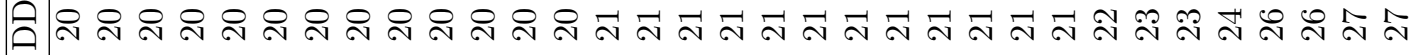

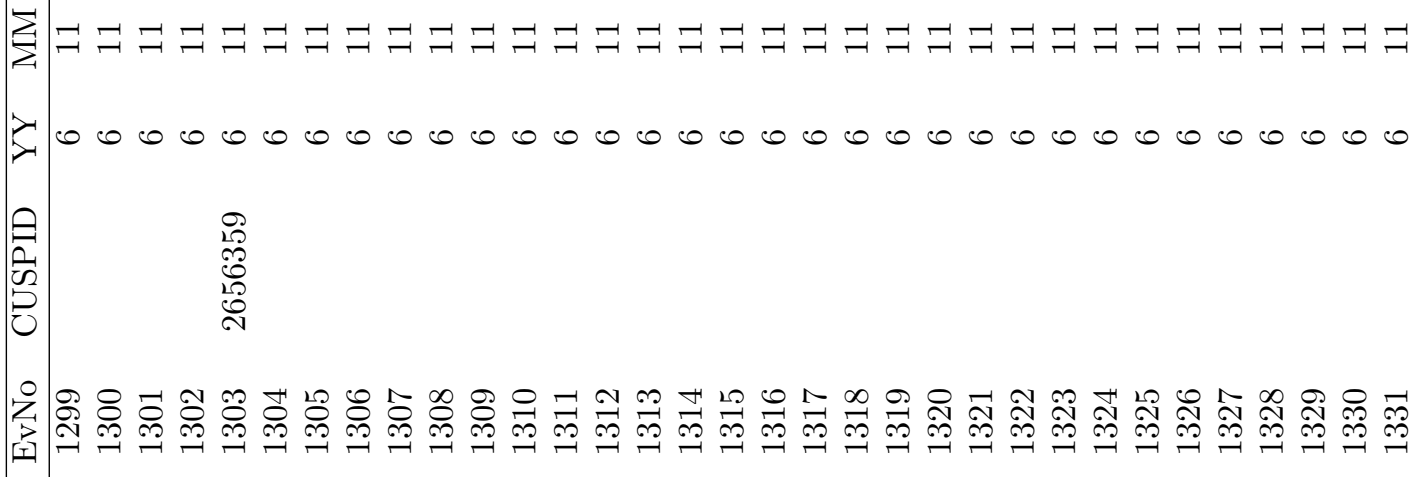




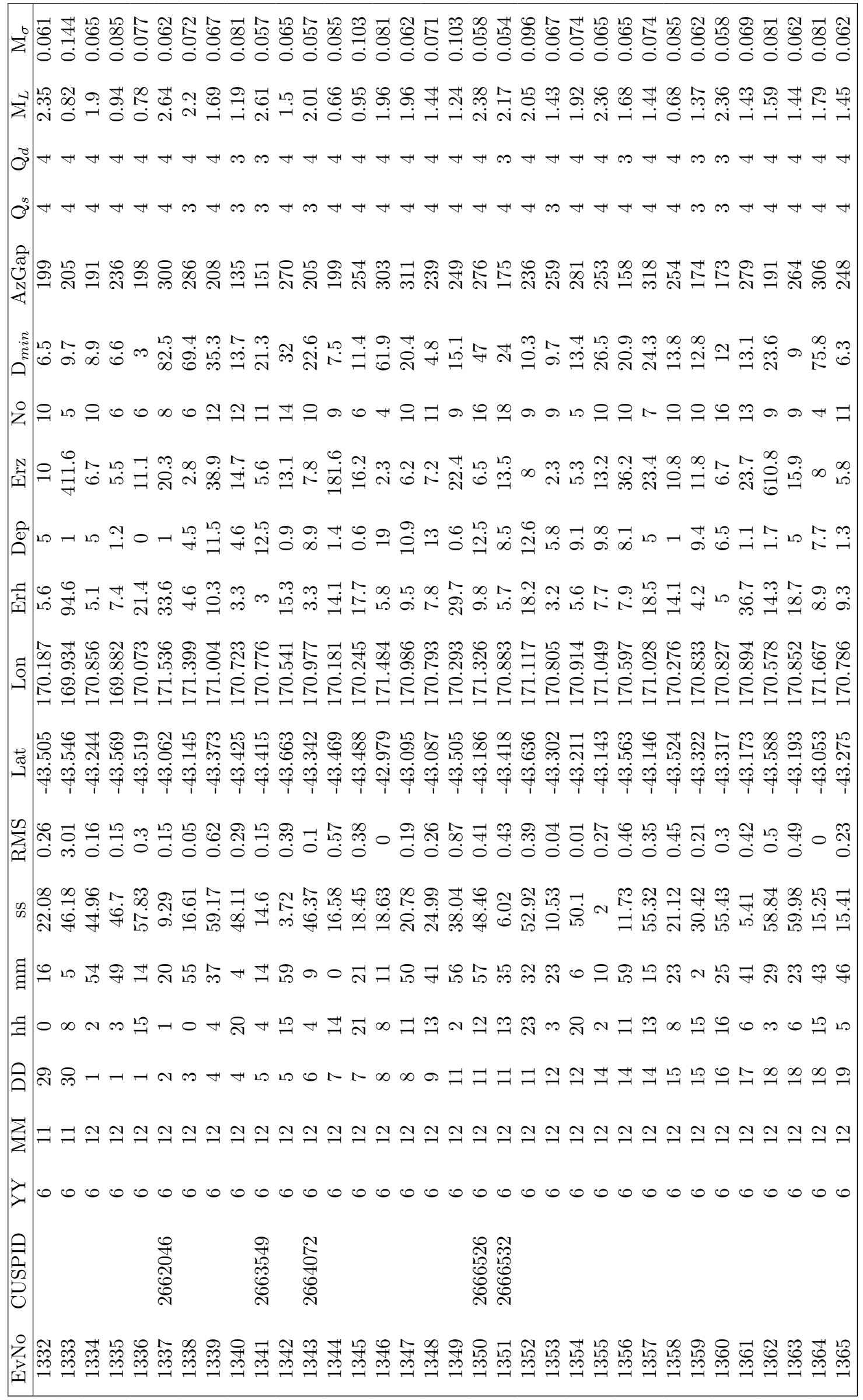




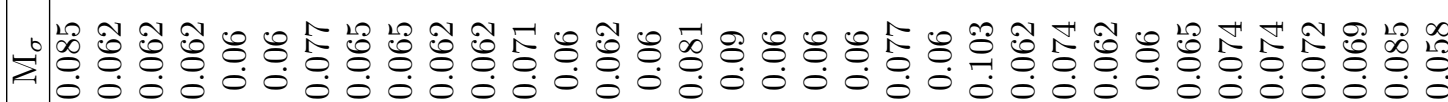

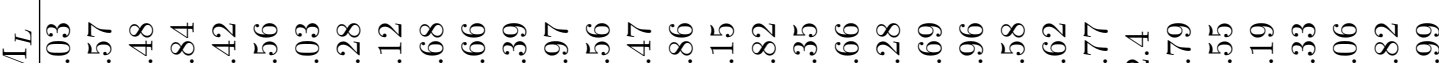

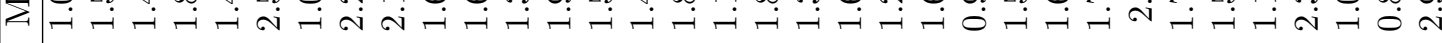

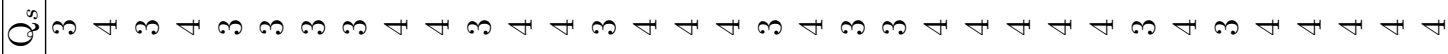

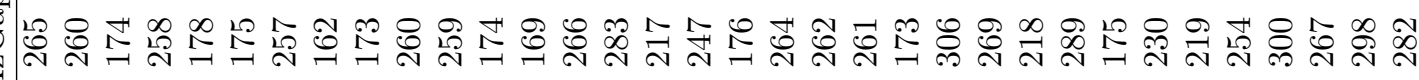

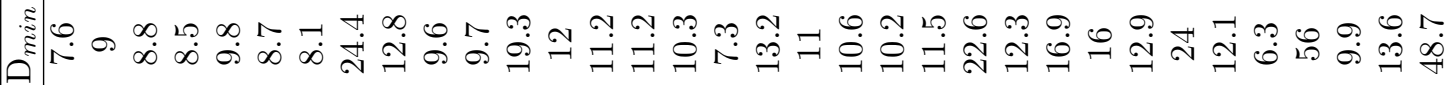

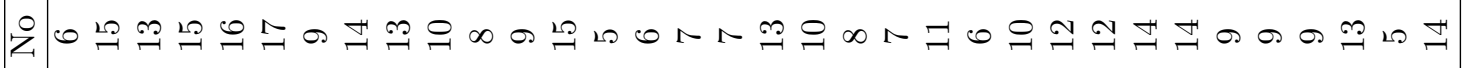

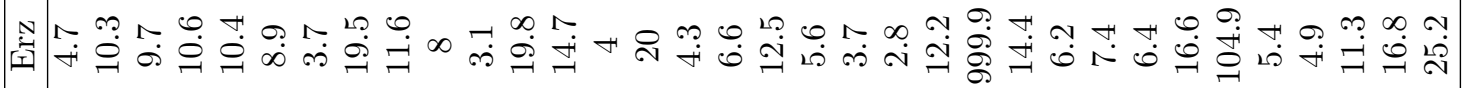

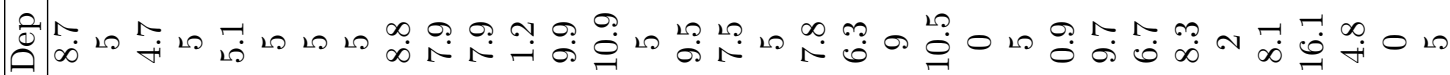

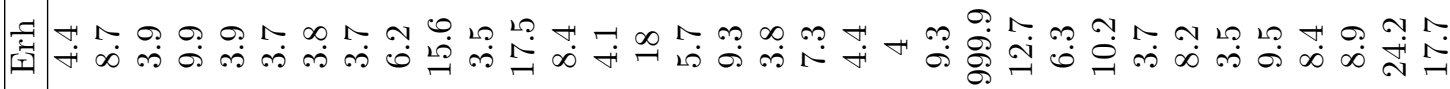

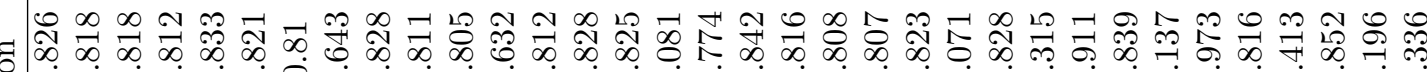

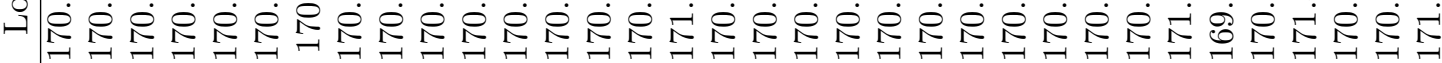

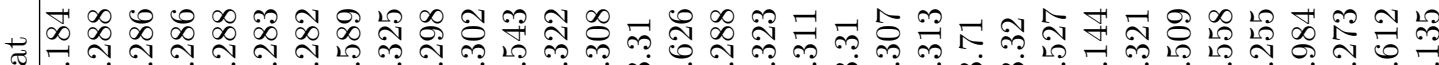

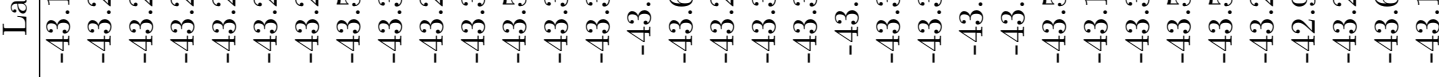

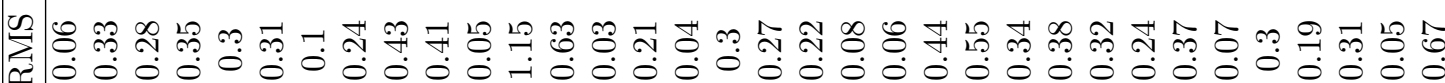

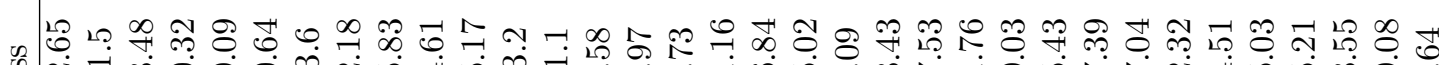
约

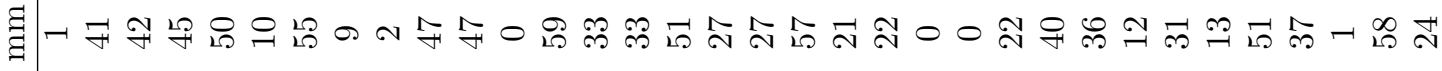

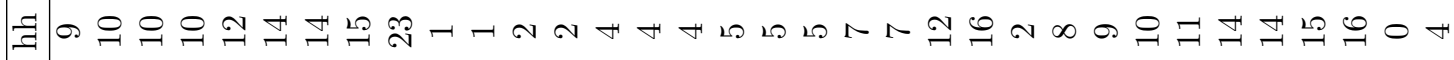

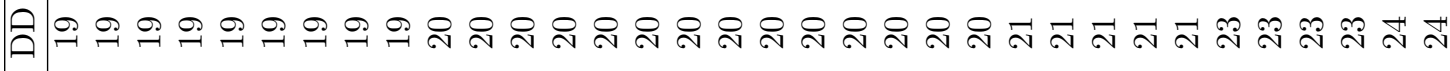

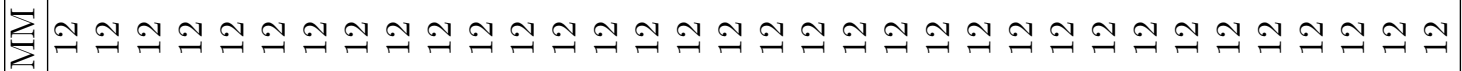
خلर000000000000000000000000000000000<smiles>CC1(O)CCCCC1</smiles>

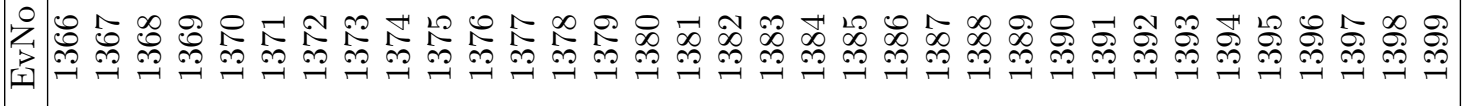




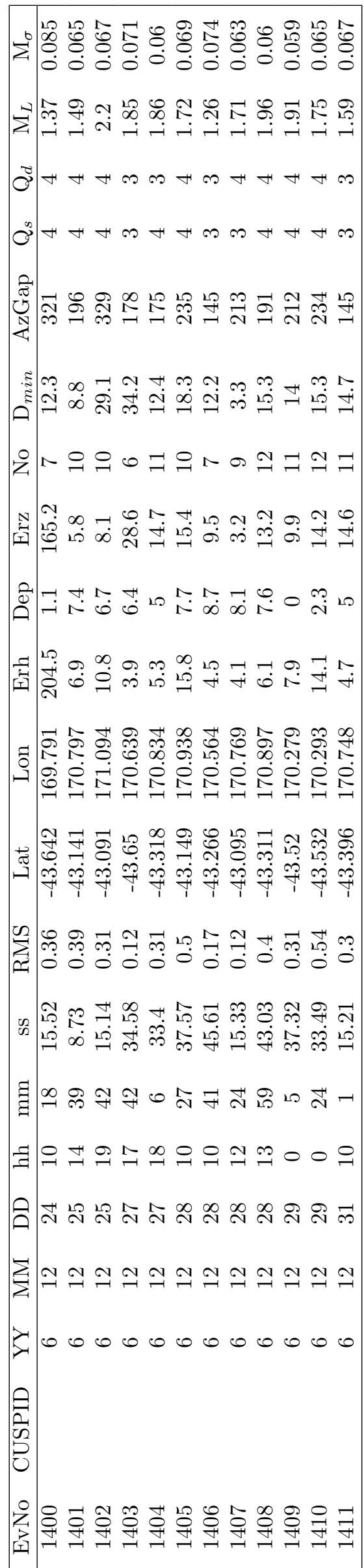


Appendix D

HypoDD relocation output 


\begin{tabular}{|c|c|c|}
\hline & 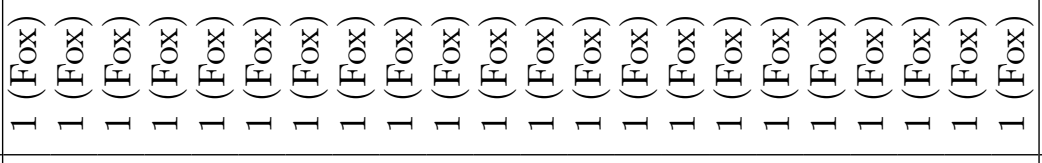 & $\sin \alpha \propto \sin \alpha \propto$ \\
\hline$\sum_{\infty}^{20}$ & 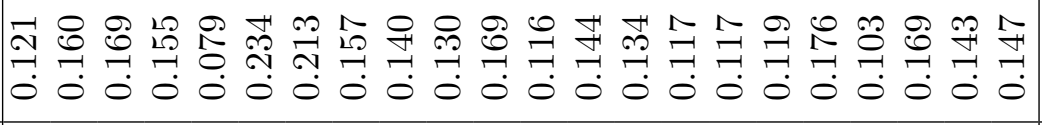 & 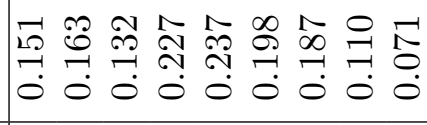 \\
\hline 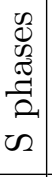 & 유 & 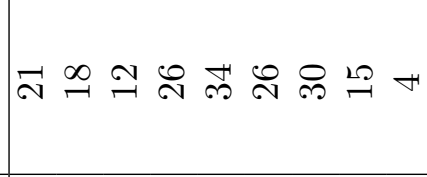 \\
\hline 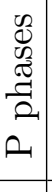 & 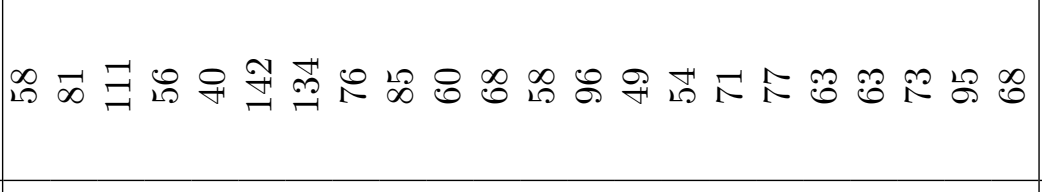 & 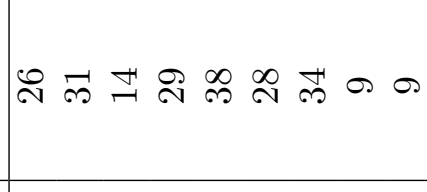 \\
\hline 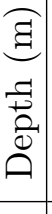 & 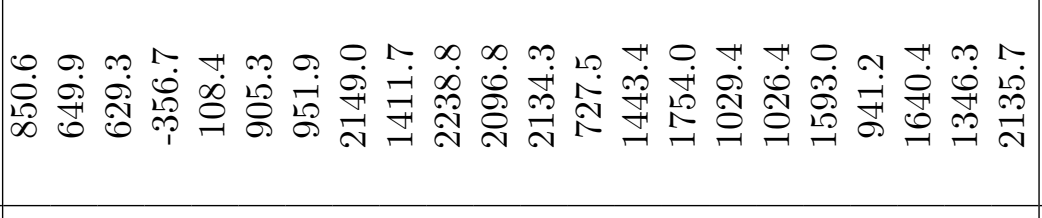 & 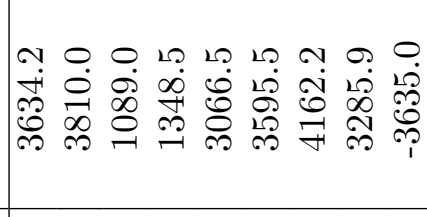 \\
\hline 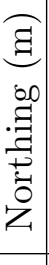 & 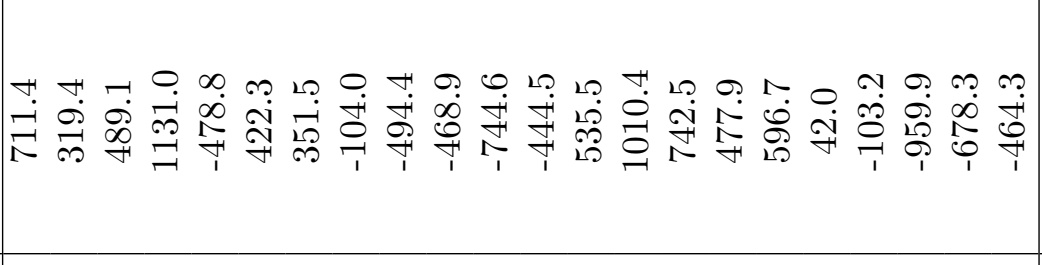 & 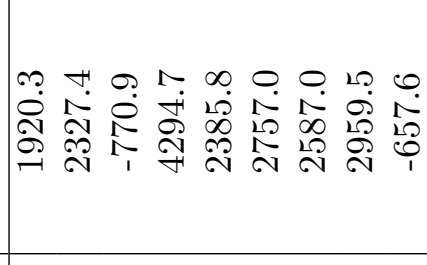 \\
\hline 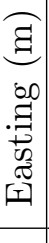 & 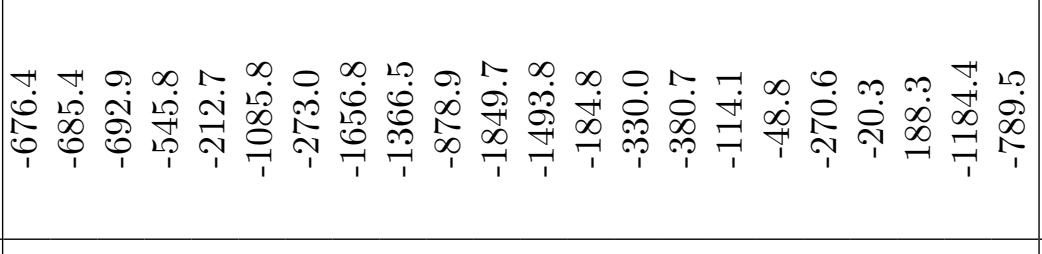 & 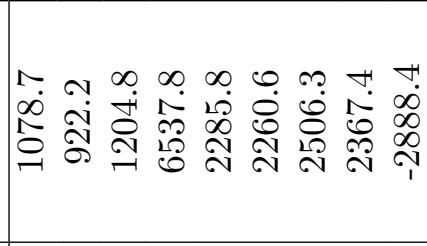 \\
\hline 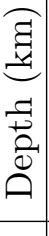 & 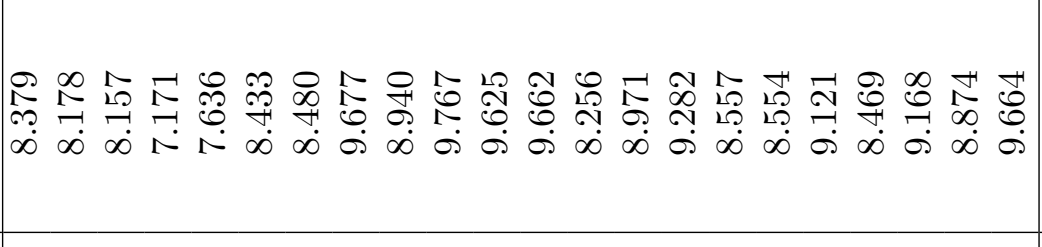 & 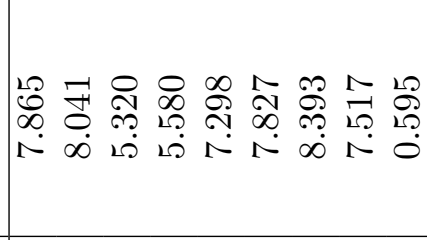 \\
\hline בี & 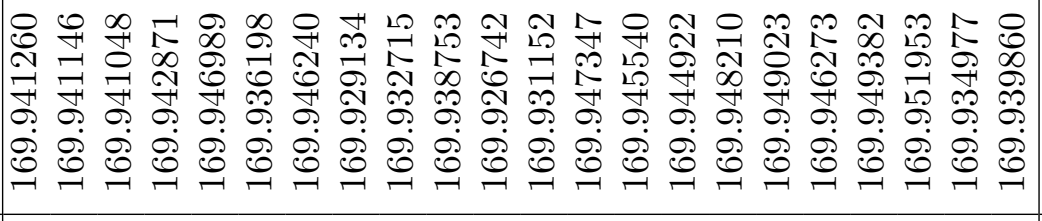 & 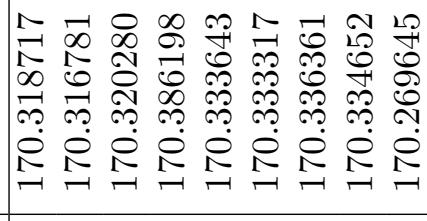 \\
\hline & 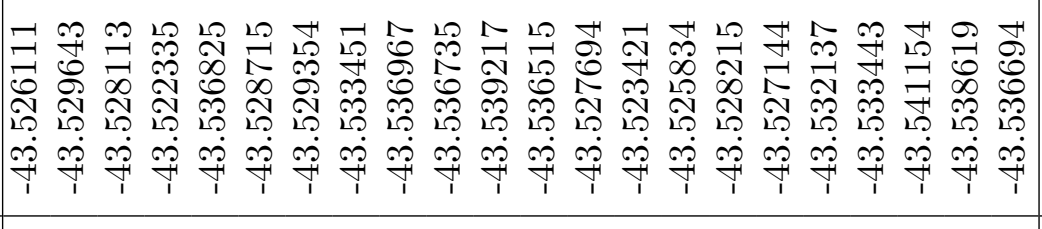 & 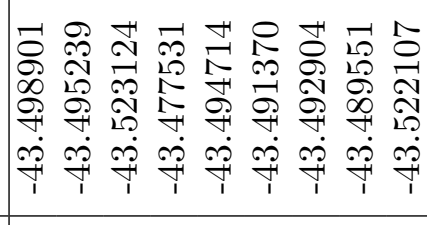 \\
\hline$\underset{己}{\stackrel{\Theta}{\Theta}}$ & 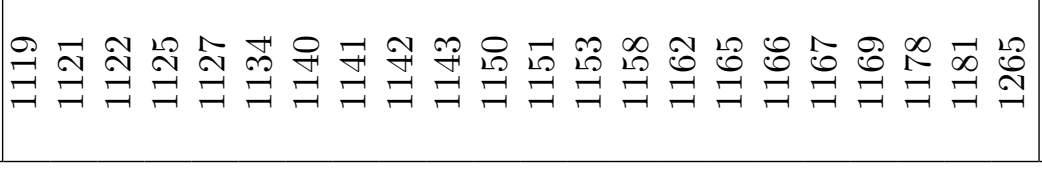 & 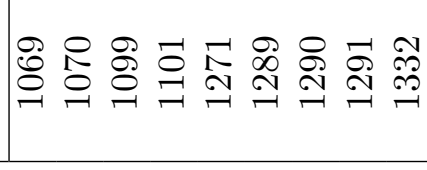 \\
\hline
\end{tabular}




\begin{tabular}{|c|c|c|}
\hline & 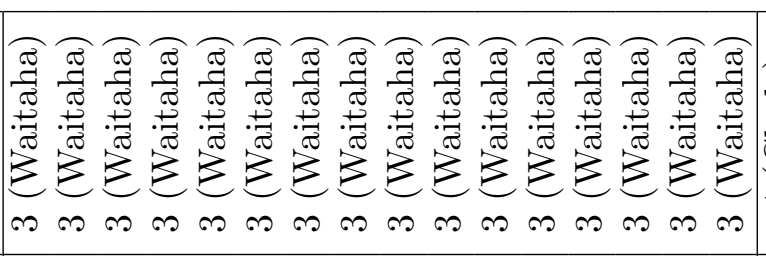 & 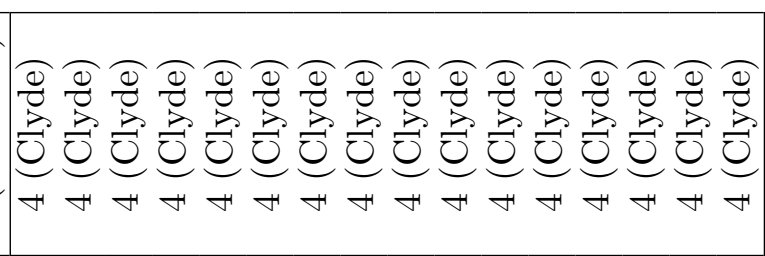 \\
\hline & 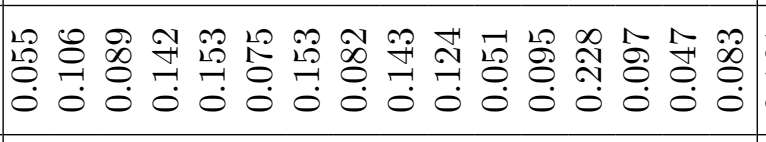 & 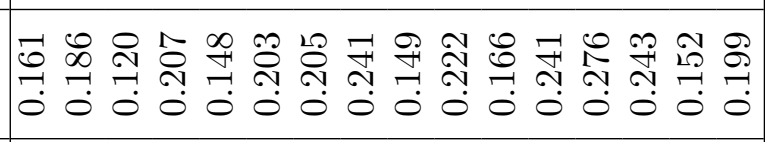 \\
\hline 焉 & 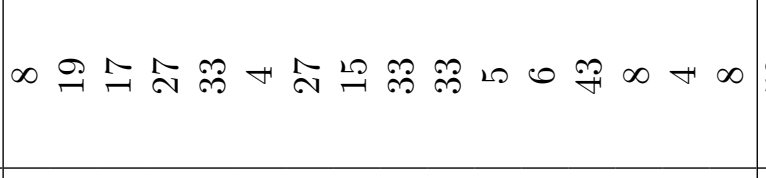 & 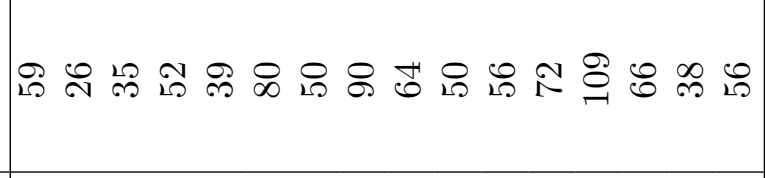 \\
\hline . & 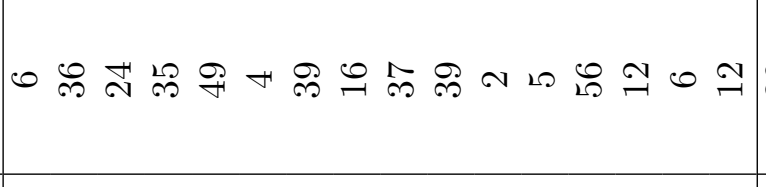 & 舟 \\
\hline & 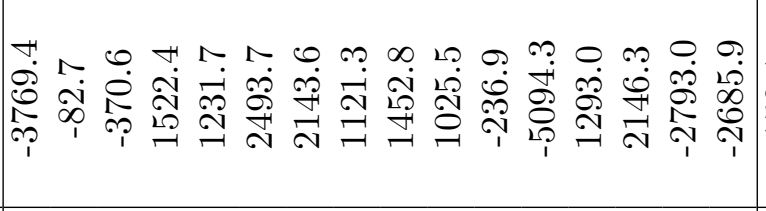 & 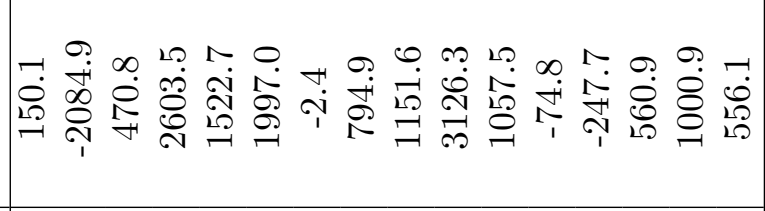 \\
\hline (g) & 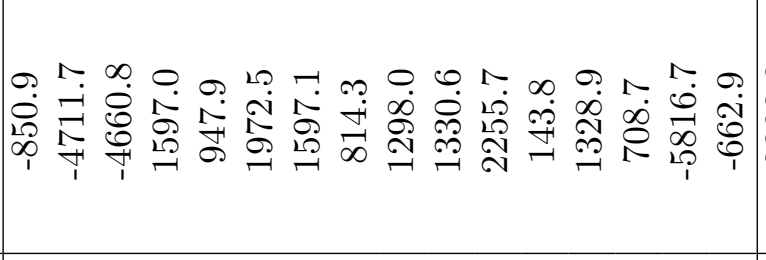 & 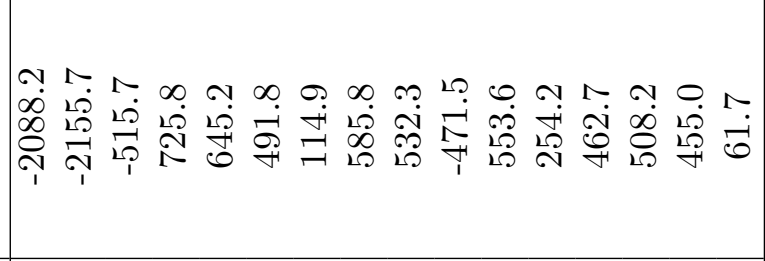 \\
\hline 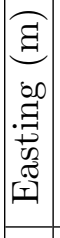 & 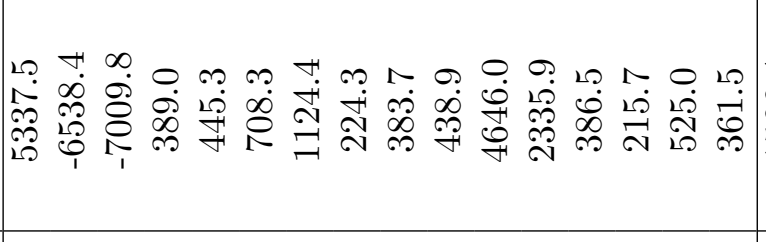 & 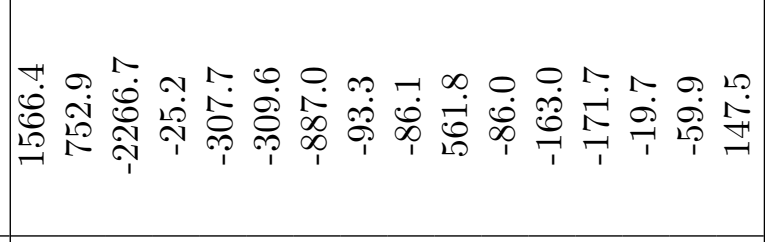 \\
\hline & 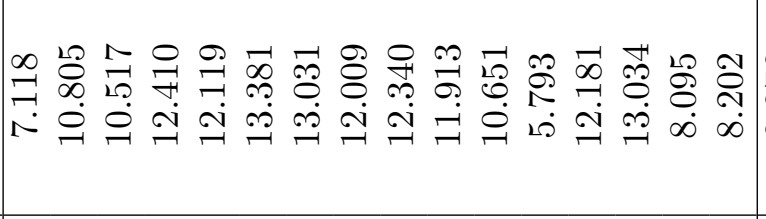 & 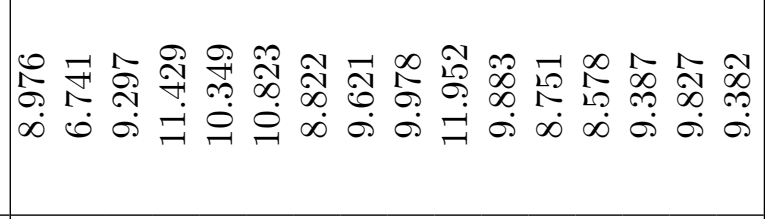 \\
\hline & 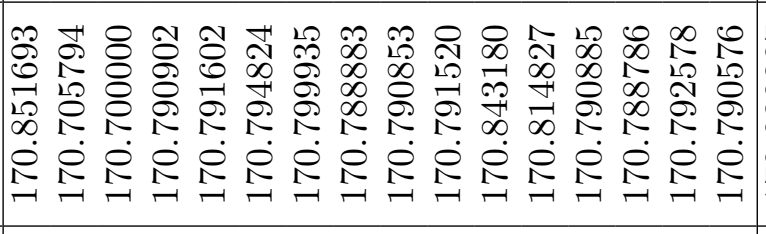 & 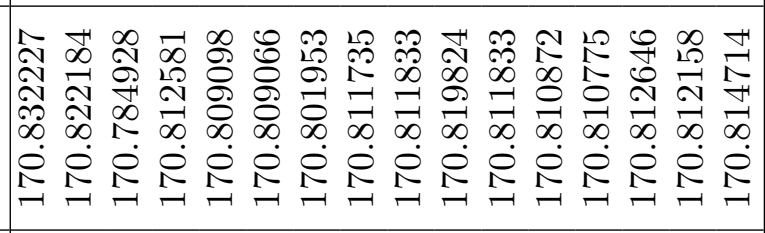 \\
\hline & 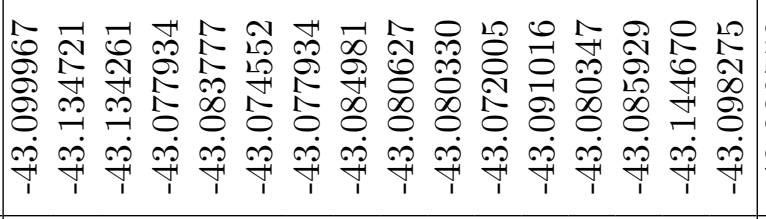 & 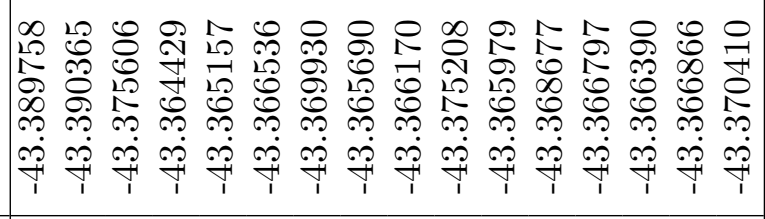 \\
\hline & 定 & 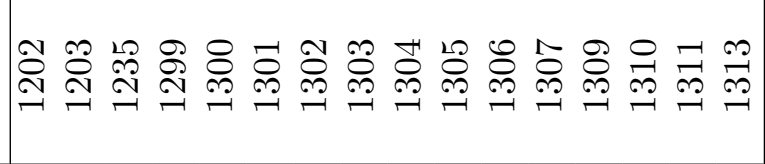 \\
\hline
\end{tabular}




\begin{tabular}{|c|c|c|}
\hline & 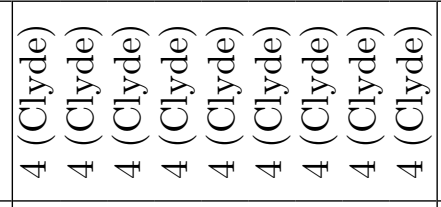 & S20 \\
\hline$\sum_{x}^{\Omega}$ & 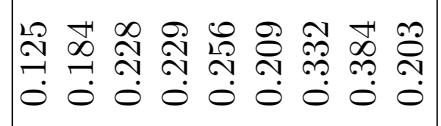 & 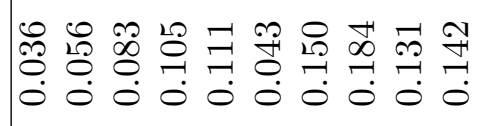 \\
\hline 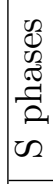 & ำ & 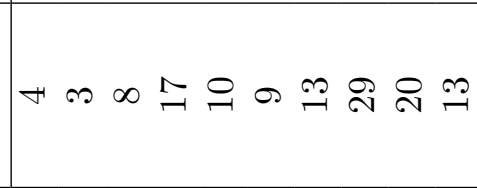 \\
\hline 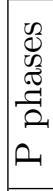 & ํํㅇ & 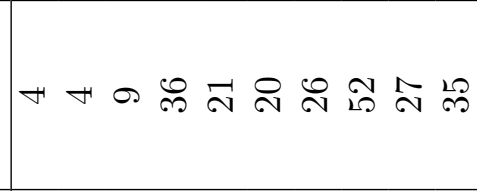 \\
\hline 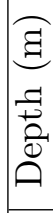 & 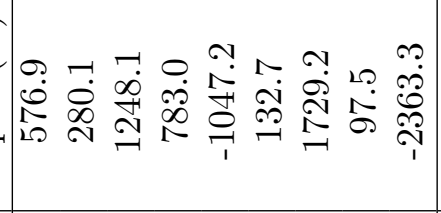 & 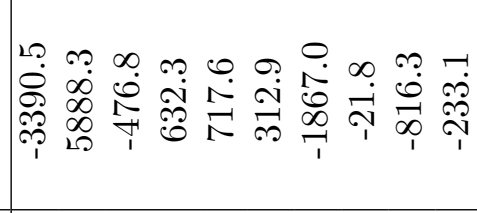 \\
\hline 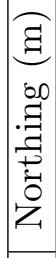 & 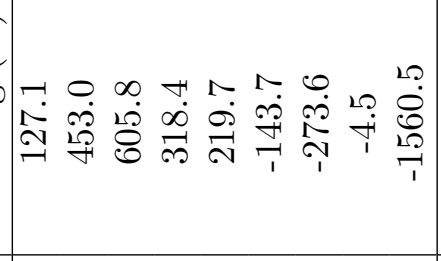 & 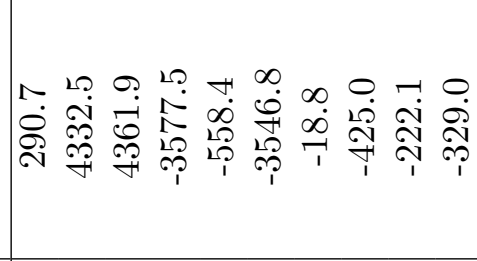 \\
\hline 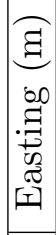 & 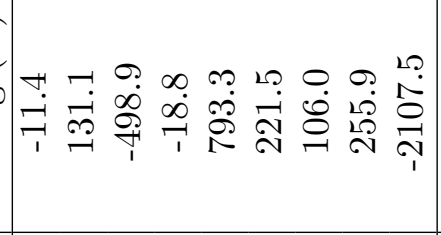 & 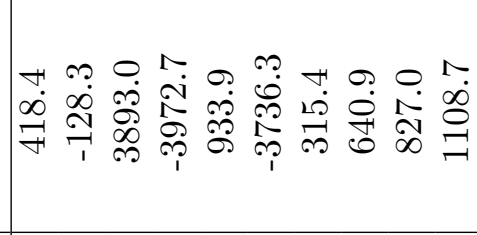 \\
\hline 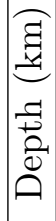 & 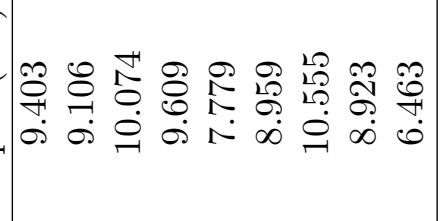 & 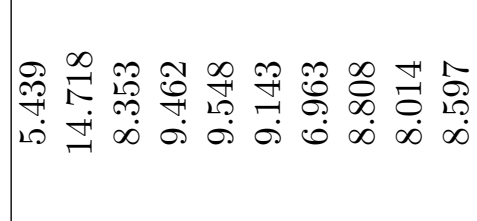 \\
\hline & 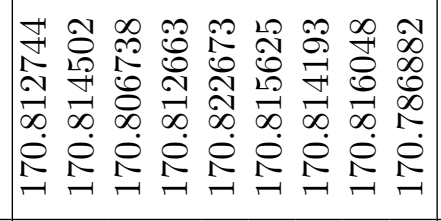 & 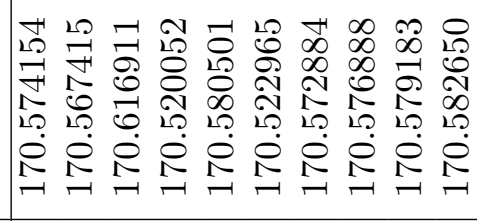 \\
\hline & 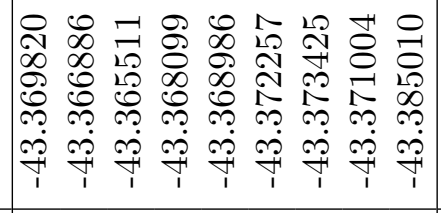 & 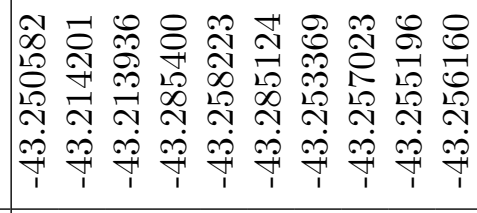 \\
\hline 层 & 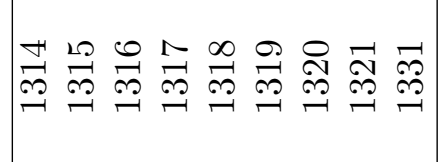 & 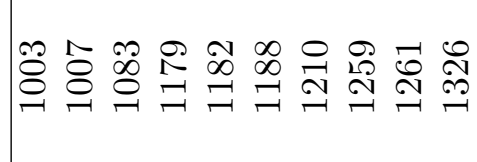 \\
\hline
\end{tabular}

